\title{
Analysis of Consumer Attitudes, Preferences, and Demand for Poultry Meat in Ghana
}

\author{
Dissertation \\ to obtain the doctoral degree \\ at the Faculty of Agricultural Sciences, \\ Georg-August-University Goettingen, Germany

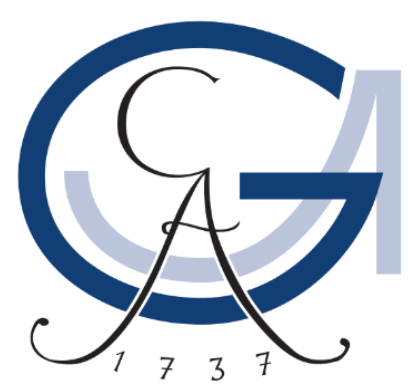

in the International Ph.D. Program for Agricultural Sciences in Goettingen (IPAG)

presented by

Collins Asante-Addo

born in Nkoranza, Ghana

Goettingen, March 2020 
1st Supervisor: PD Dr. Martin Banse

2nd Supervisor: Prof. Dr. Bernhard Brümmer

3rd Supervisor: Prof. Dr. Claudia Neu

Date of dissertation: $18^{\text {th }}$ May 2020 


\section{Summary}

Over the past decade, changing consumer preferences for variety, convenience, safer, and healthier attributes have been shaping meat demand patterns in sub-Saharan Africa (SSA), especially in Ghana. Some of these changes have led to the increasing consumption of poultry meat. This trend has further been spurred by the availability of cheap imports, mainly from the U.S., Europe, and Brazil. Consequently, poultry imports (mainly chicken) have been on the rise, while the supply and demand for domestic poultry meat have been low. Against the background of rising poultry meat imports into Ghana, there have been numerous concerns and criticisms of imports and a call for action to protect the domestic poultry industry and ensure its survival. One way of ensuring the survival of the domestic poultry industry is to address existing gaps in the demand profiles of consumers by identifying important product attributes and related factors that drive their choices and consumption behavior. Accordingly, the main objective of this thesis is to identify the relevant factors that contribute to the patterns of behavior change toward the consumption of poultry meat products. In doing so, the study accounts for the different origins of poultry meat supply (i.e., domestic and imported). Such analysis may allow supply chain actors and policymakers to anticipate trends and future changes in demand, develop effective marketing strategies, and provide products that meet consumers' needs and expectations.

The first article uses a qualitative approach (focus groups) to explore the drivers of demand for domestic and imported chicken meat, including motives, perceptions, and attitudes. Overall, seven focus group discussions involving 44 participants were conducted in Accra. The findings show that consumers hold positive perceptions of domestic chicken regarding freshness, taste, and healthiness compared to imported chicken. In contrast, most of the participants perceive domestic chicken meat as expensive and inconvenient. Interestingly, consumers generally believe that growth hormones are used in poultry production, although, in reality, they are not used. This suggests a general lack of knowledge about the actual use of growth hormones in production. In particular, concerns about growth hormones and the (over) use of antibiotics resulted in low-quality perceptions of imported chicken meat. Nevertheless, consumers positively value imported chicken in terms of price, availability, and convenience. In addition, the findings show differences in opinions about the use of protectionist measures in poultry trade. While some participants are in favor of banning or restricting imports to protect local poultry industries, others argue that such policies would be detrimental to consumers, especially when supply from domestic sources are inadequate to meet domestic demand. 
Article (2) takes the results of the focus groups further by quantifying the effects of personal factors (i.e., psychological and socioeconomic variables) on the frequency of chicken meat consumption. Based on the results from the focus groups, a face-face interview involving 500 respondents was conducted in two major cities (i.e., Accra and Kumasi) in Ghana. The empirical findings from the bivariate ordered probit model indicate that the consumption of domestic and imported chicken meat are not independent of each other. In other words, consumers of one type of chicken meat are less likely to consume the other type. Overall, the findings show that perceptions, attitudes and some socioeconomic characteristics of consumers are the main drivers of imported and domestic chicken consumption. For instance, income, perceived quality, and ethnocentrism are significant drivers of domestic chicken meat consumption, while price consciousness, food safety concerns, and perceived convenience negatively influence consumption. On the other hand, the presence of chicken in the household, formal employment, price consciousness, and availability and convenience orientation positively influence the frequency of imported chicken consumption. However, perceived quality and ethnocentrism are major barriers to imported chicken consumption.

The third article uses a choice experiment approach to understand how future demand for chicken meat will be shaped when value-added products are introduced into the market. The choice profiles consisted of five attributes: country-of-origin (Ghana and foreign), product form (whole-dressed and cuts), storage form (frozen and fresh), production claim (no claim and antibiotic/hormone-free claim), and price (four levels). Under a random utility framework, three models namely the multinomial logit (MNL), random parameter logit (RPL), and latent class (LC) logit are estimated. The results from both the MNL and RPL show that respondents derive positive utility from choosing fresh, cut, and antibiotic-free claimed chicken meat, but negative utility from choosing foreign chicken. The negative utility for foreign chicken compared to domestic chicken indicates a general preference for domestically produced chicken meat. The RPL results suggest that preferences for these attributes are heterogeneous.

Subsequently, the LC model was used to account for the source of heterogeneity among the sample population. The results reveal four consumer segments: domestic chicken advocates (27\% of the respondents), foreign chicken lovers (17\%), claim conscious (35\%), and random choosers $(21 \%)$ who attach different value to each of the attributes. The domestic chicken advocates assign high economic value to the domestic origin and are willing to pay more than twice [i.e., GH $\not 65.7 / \mathrm{kg}$ (US\$14.9)] the average for the overall sample [GH $₫ 30 / \mathrm{kg}$ (US\$6.8) for the RPL model], suggesting a great potential for domestically produced chicken meat. 
Altogether, the results indicate that attitudes largely explain the choice for the attributes compared to sociodemographic factors.

Article (4) identifies possible consumer groups (market segments) based on both use of and trust in information sources using the same survey data described in article (2). The results show that personal (family and friends and sellers) and electronic media sources (radio and television) are the most used information channels about chicken meat. Using a cluster analysis approach, three consumer groups are identified and profiled. The three clusters are defined as cautious consumers (18\%), enthusiasts (53\%), and optimists (29\%). To describe the segments, chi-square tests and one-way analysis of variance (ANOVA) with post-hoc Tukey comparison of mean scores were conducted. The clusters present significant differences in motivation levels, use of information cues, frequency of chicken consumption, and sociodemographic characteristics, offering prospects for targeted information provision efforts. The enthusiasts represent the largest group, are characterized by high use and trust in most of the information sources and display a significantly higher level of chicken consumption. In terms of targeting, this group is the easiest to reach because they are the most involved consumers who are open to receiving and using more information about chicken and also have high trust for the channels of information seeking.

To conclude, this thesis provides detailed insights into consumer behavior regarding domestic and imported chicken meat products in Ghana and contributes to the debate on the role of poultry imports in SSA. Specifically, the knowledge obtained through the analysis of consumer behavior provides a basis to identify opportunities for developing new chicken meat products or improving existing products to meet the needs of consumers. The findings of this study generally indicate that there is a high potential for domestic chicken meat with a group of consumers willing to pay a high positive price premium. Therefore, campaigns to promote the consumption of domestic chicken should aim at targeting potential consumer segments with appropriate messages that align with their needs and characteristics and communicating through relevant information channels. 


\section{Zusammenfassung}

In den letzten zehn Jahren haben sich die Verbraucherpräferenzen hinsichtlich Produktvielfalt, "Convenience" (Verbraucherfreundlichkeit im Zusammenhang mit dem Verarbeitungsgrad bzw. dem Zubereitungsaufwand), Lebensmittelsicherheit und Gesundheit geändert, was sich auf die Fleischnachfrage in Subsahara-Afrika (SSA), insbesondere in Ghana, auswirkt. Einige dieser Veränderungen haben $\mathrm{zu}$ einem steigenden Verbrauch von Geflügelfleisch geführt. Dieser Trend wurde durch die Verfügbarkeit von kostengünstigen Importen, hauptsächlich aus den USA, Europa und Brasilien, weiter gefördert. Folglich haben die Geflügelimporte (hauptsächlich Hähnchenfleisch) zugenommen, während Angebot und Nachfrage nach einheimischem Geflügelfleisch gering waren. Vor dem Hintergrund steigender Geflügelfleischimporte nach Ghana wurden zahlreiche Bedenken und Kritik an den Importen geäußert sowie Handlungsbedarf zum Schutz der heimischen Geflügelindustrie abgeleitet. Eine Möglichkeit, um das Überleben der heimischen Geflügelindustrie zu sichern, besteht darin, entsprechende Lücken im Nachfrageprofil der Verbraucher zu schließen. Dafür müssen wichtige Produkteigenschaften und andere Faktoren, die Verbraucherentscheidungen und Konsumverhalten beeinflussen, identifiziert werden. Dementsprechend ist das Hauptziel dieser Arbeit, die relevanten Faktoren herauszustellen, die $\mathrm{zu}$ den Verhaltensänderungen im Geflügelfleischkonsum beitragen. Dabei berücksichtigt die Studie sowohl inländisch produziertes als auch ausländisches Geflügelfleisch. Eine solche Analyse ermöglicht den Akteuren der Wertschöpfungskette und den politischen Entscheidungsträgern eine Antizipation von Trends und zukünftigen Veränderungen der Nachfrage. Darüber hinaus können effektive Marketingstrategien entwickelt und Produkte angeboten werden, die den Bedürfnissen und Erwartungen der Verbraucher entsprechen.

Der erste Artikel verwendet einen qualitativen Ansatz (Fokusgruppendiskussionen), um die Treiber der Nachfrage nach einheimischem und importiertem Hähnchenfleisch zu untersuchen, einschließlich der Motive, Wahrnehmungen und Einstellungen. Insgesamt wurden in Ghanas Hauptstadt Accra sieben Fokusgruppendiskussionen mit 44 Teilnehmern durchgeführt. Die Ergebnisse zeigen, dass die Verbraucher die Frische, den Geschmack und die Gesundheit von heimischem Geflügel im Vergleich zu importiertem Hähnchenfleisch positiv wahrnehmen. Im Gegensatz dazu empfinden die meisten Teilnehmer einheimisches Hähnchenfleisch als teuer und umständlich in der Zubereitung. Interessanterweise glauben die Verbraucher generell, dass Wachstumshormone in der Geflügelproduktion verwendet werden, obwohl dies nicht zutrifft. Dies deutet auf ein Informationsdefizit hinsichtlich des tatsächlichen 
Einsatzes von Wachstumshormonen in der Produktion hin. Insbesondere die Bedenken zu Wachstumshormonen und einer (übermäßigen) Verwendung von Antibiotika führen zu einer negativen Wahrnehmung von importiertem Hähnchenfleisch. In Bezug auf Preis, Verfügbarkeit und bequeme Zubereitung schätzen die Verbraucher importiertes Hähnchenfleisch positiv ein. Darüber hinaus zeigen die Ergebnisse unterschiedliche Meinungen über den Einsatz protektionistischer Maßnahmen im Geflügelhandel. Während einige Teilnehmer für ein Verbot oder eine Beschränkung von Importen zum Schutz der lokalen Geflügelindustrie sind, argumentieren andere, dass eine solche Politik den Verbrauchern schadet, insbesondere wenn das heimische Angebot nicht ausreicht, um die inländische Nachfrage zu decken.

Der zweite Artikel greift die Ergebnisse der Fokusgruppendiskussionen auf, indem die Auswirkungen von persönlichen Faktoren (d.h. psychologischen und sozioökonomischen Variablen) auf die Häufigkeit des Hähnchenfleischkonsums quantifiziert werden. Auf der Grundlage der Ergebnisse der Fokusgruppen wurde eine Befragung von 500 Personen in zwei großen Städten (Accra und Kumasi) in Ghana durchgeführt. Die empirischen Ergebnisse des bivariaten geordneten Probit-Modells zeigen, dass der Verzehr von einheimischem und importiertem Hähnchenfleisch abhängig voneinander ist. Mit anderen Worten: Die Konsumenten, die einheimische Hähnchenfleischsorten bevorzugen, konsumieren weniger importiertes Hähnchenfleisch (und umgekehrt). Insgesamt zeigen die Ergebnisse, dass die Wahrnehmungen, Einstellungen und einige sozioökonomische Merkmale der Verbraucher die Haupttreiber sowohl für den Konsum von importiertem als auch inländischem Hähnchenfleisch sind. So sind beispielsweise Einkommen, wahrgenommene Qualität und Ethnozentrismus wichtige Faktoren für den inländischen Hähnchenfleischkonsum, während Preisbewusstsein, Bedenken hinsichtlich der Lebensmittelsicherheit und die wahrgenommene Bequemlichkeit hinsichtlich der Zubereitung (Convenience) den Konsum negativ beeinflussen. Auf der anderen Seite beeinflussen das Vorhandensein von Hühnern im Haushalt, reguläre Beschäftigung, das Preisbewusstsein sowie die Verfügbarkeit und die Convenience-Orientierung die Häufigkeit des Verzehrs von importiertem Hähnchen positiv. Die wahrgenommene Qualität und der Ethnozentrismus sind jedoch wesentliche Hindernisse für den Verzehr von importiertem Hähnchenfleisch.

Der dritte Artikel verwendet einen „Choice Experiment“-Ansatz, um zu verstehen wie die zukünftige Nachfrage nach Hähnchenfleisch gestaltet wird, wenn aufgewertete Produkte auf den Markt gebracht werden. Die Auswahlprofile bestanden aus fünf Attributen: Herkunftsland (Ghana oder Ausland), Produktform (ganz oder zerlegt), Lagerform (gefroren oder frisch), Kennzeichnung (ohne Kennzeichnung oder gekennzeichnet als hormonfrei/frei 
von Antibiotika) und Preis (vier Stufen). Ausgehend von der Zufallsnutzentheorie werden drei Modelle geschätzt: Multinomial Logit (MNL), Random Parameter Logit (RPL) und Latent Class (LC). Die Ergebnisse des MNL-Modells sowie des RPL-Modells zeigen, dass die Befragten einen positiven Nutzen aus der Wahl von frischem, zerlegtem und als antibiotikafrei deklariertem Hähnchenfleisch ziehen, allerdings einen negativen Nutzen aus der Wahl von importiertem Hähnchenfleisch. Der negative Nutzen für importierte Hähnchen im Vergleich zu einheimischen Hähnchen deutet auf eine allgemeine Präferenz für im Inland produziertes Hähnchenfleisch hin. Die RPL-Ergebnisse weisen darauf hin, dass die Präferenzen für diese Attribute heterogen sind.

Anschließend wurde das LC-Modell verwendet, um die Heterogenität in der Stichprobenpopulation zu berücksichtigen. Das Modell liefert vier Verbrauchersegmente: „Fürsprecher von einheimischen Hähnchen“ (27\% der Befragten), „Liebhaber von importierten Hähnchen “ (17\%), „,Kennzeichnungsbewusste“ (35\%) und ,zufällig Wählende“ (21\%), die jedem der Attribute einen unterschiedlichen Wert beimessen. Die Fürsprecher von einheimischen Hähnchen weisen der heimischen Herkunft einen hohen wirtschaftlichen Wert zu und sind bereit mehr als das Doppelte zu zahlen [d.h. GH $\not 65,7 / \mathrm{kg}$ (14,9 US\$)] verglichen mit der durchschnittlichen Zahlungsbereitschaft der Gesamtstichprobe [GH $₫ 30 / \mathrm{kg}$ (6,8 US\$) für das RPL-Modell], was auf ein großes Potenzial für im Inland produziertes Hühnerfleisch hindeutet. Insgesamt konnte gezeigt werden, dass Konsumenteneinstellungen einen höheren Einfluss auf die Produktwahl haben als soziodemographische Faktoren.

Artikel (4) identifiziert basierend auf der Nutzung von Informationsquellen und dem Vertrauen in diese sowie auf den in Artikel (2) beschriebenen Umfragedaten mögliche Verbrauchergruppen (Marktsegmente). Die Ergebnisse zeigen, dass persönliche Kontakte (Familie und Freunde und Verkäufer) und elektronische Medienquellen (Radio und Fernsehen) die am meisten genutzten Kanäle hinsichtlich der Information zu Hähnchenfleisch sind. Mit Hilfe einer Clusteranalyse wurden drei Verbrauchergruppen identifiziert und charakterisiert. Die drei Cluster werden als vorsichtige Verbraucher (18\%), Enthusiasten (53\%) und Optimisten (29\%) definiert. Zur Beschreibung der Segmente wurden Chi-Quadrat-Tests und eine einseitige Varianzanalyse (ANOVA) mit einem Post-hoc-Tukey-Vergleich der Durchschnittswerte durchgeführt. Die Cluster weisen signifikante Unterschiede im Motivationsniveau, in der Verwendung von Informationshinweisen, in der Häufigkeit des Hähnchenfleischkonsums und in den soziodemographischen Merkmalen auf und deuten damit auf ein Potential für gezielte Maßnahmen zur Informationsbereitstellung hin. Die größte Gruppe der Enthusiasten zeichnet sich durch hohe Nutzung und großes Vertrauen in die meisten 
Informationsquellen aus und weist einen deutlich höheren Hähnchenfleischkonsum auf. In Bezug auf die Zielgruppen ist diese Gruppe am leichtesten zu erreichen, da sie die am stärksten involvierten Verbraucher beinhaltet, die offen gegenüber weiteren Informationen zu Hähnchenfleisch sind und auch ein hohes Vertrauen in die Informationskanäle aufweisen.

Die vorgelegte Arbeit ermöglicht detaillierte Einblicke in das Verbraucherverhalten bezüglich inländisch produziertem sowie importiertem Hähnchenfleisch in Ghana und trägt damit zu einer Debatte über die Rolle von Geflügelfleischimporten in SSA bei. Insbesondere bieten die durch die Analyse des Verbraucherverhaltens gewonnenen Erkenntnisse die Möglichkeit, neue Hähnchenfleischprodukte zu entwickeln, oder sie können zur Verbesserung bestehender Produkte beitragen, um die Bedürfnisse der Verbraucher zu erfüllen. Die Ergebnisse dieser Arbeit weisen darüber hinaus darauf hin, dass ein großes Absatzpotenzial für einheimisches Hähnchenfleisch besteht, da eine Gruppe von Verbrauchern bereit ist, einen hohen Preisaufschlag zu zahlen. Daher sollten Kampagnen zur Förderung des Verzehrs von lokal produziertem Geflügelfleisch darauf abzielen, über relevante Informationskanäle insbesondere potenzielle Verbrauchergruppen mit geeigneten Botschaften zu erreichen. 


\section{Acknowledgements}

This major academic accomplishment would not have been possible without the dedicated support of many people. First of all, I would like to express my sincere gratitude to my supervisor PD Dr. Martin Banse for his insightful guidance, useful suggestions, and unreserved support throughout my doctoral studies. He was always available and made sure I had everything I needed to complete my Ph.D. I am grateful to Prof. Dr. Bernhard Brümmer and Prof. Dr. Claudia Neu for serving on my thesis committee.

Special thanks to Dr. Daniela Weible and Dr. Janine Pelikan for their tremendous support, valuable comments, and suggestions that aided and encouraged me to complete this dissertation. I thank them also for opening their doors to me and always inviting my wife and me over for dinner whenever she is in Germany. I will forever be grateful for all their support and great hospitality. Dr. Isaac Ankamah-Yeboah and Dr. Jonathan Mockshell have been of great support and a source of encouragement. I thank all my colleagues at the Thünen Institute of Market Analysis for making my life at the Institute and in Braunschweig a wonderful and enjoyable experience. I would also like to thank Annika, Rebecca, and Cordula for assisting in reviewing the German version of my summary. I thank the GlobalFood Research Training Group (RTG 1666) for allowing me to participate in doctoral seminars and other programs it organized. My thanks go to my colleagues at the GlobalFood research group, Dela, Ayobami, and Makaiko for their friendship and assistance, and for making life in Goettingen easier.

I appreciate the fieldwork support provided by the team of enumerators. This research was supported by funds of the Federal Ministry of Food and Agriculture (BMEL) based on a decision of the parliament of the Federal Republic of Germany via the Federal Office for Agriculture and Food (BLE). This financial support is gratefully acknowledged. I also acknowledge the Johann Heinrich von Thünen Institute and the Society of the Friends of the Thünen Institute (Gesellschaft der Freunde des Thünen-Instituts, GdF) for providing additional financial support for my doctoral studies.

To my dear wife and best friend, Comfort Asante-Addo, a heartfelt thank you for taking this journey with me. I could not thank you enough for your unconditional love, prayers, support, motivation, and countless sacrifices you made in helping me achieve this goal. You gave me strength whenever I felt tired and reminded me of the reasons I chose this path. I also like to thank my parents and siblings for the love, support, and constant encouragement given to me over the years. Special gratitude goes to my mother-in-law, brothers-in-law, and sisterin-law. I undoubtedly could not have done this without their support. 
Above all, I thank the Almighty God for giving me strength and good health, guiding and helping me through all the difficulties, and making all things possible. To Him (God) who is able to do exceeding abundantly above all that we ask, or imagine, be the Glory! 


\section{Table of Contents}

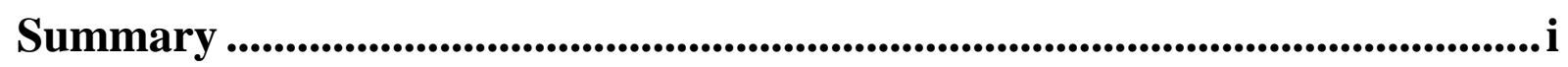

Zusammenfassung ............................................................................................

Acknowledgements......................................................................................................viii

List of Tables..........................................................................................................................xiii

List of Figures ......................................................................................... xiv

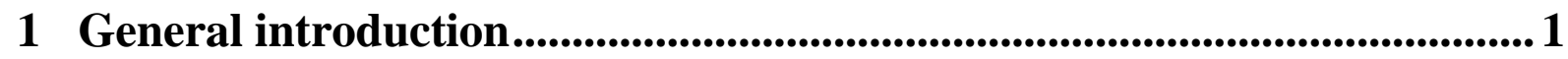

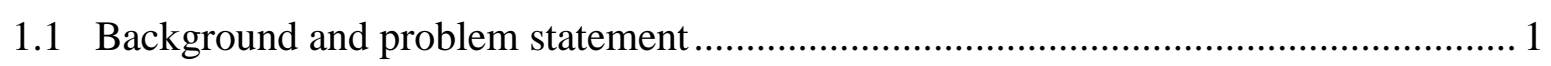

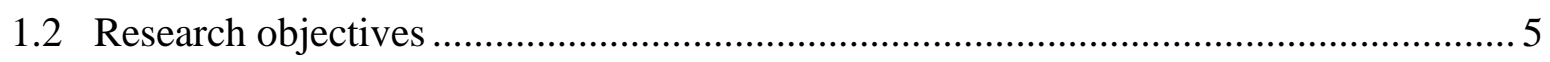

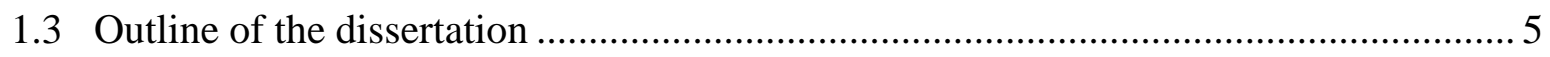

2 Theoretical framework ..................................................................................

2.1 Microeconomic theory of consumer behavior............................................................. 7

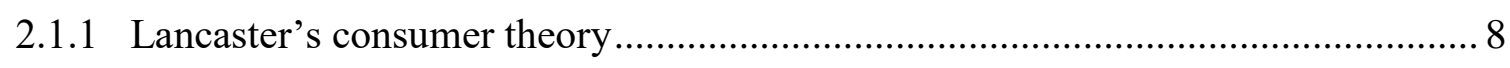

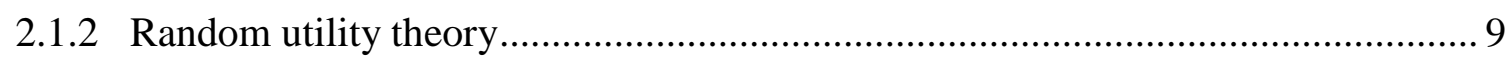

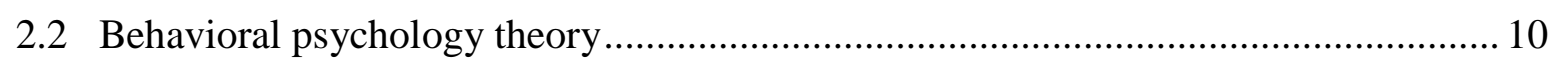

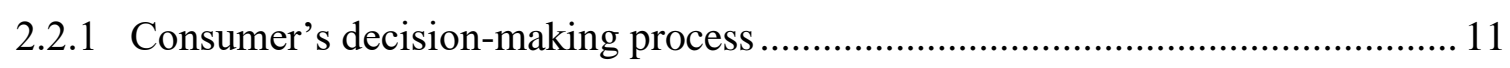

2.2.2 Neo-behavioristic theory — stimulus-organism-response .................................. 12

3 Methodology ............................................................................................ 14

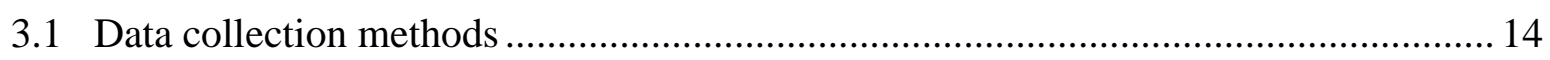

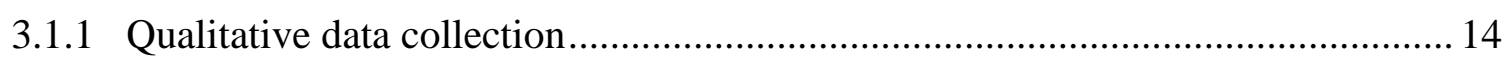

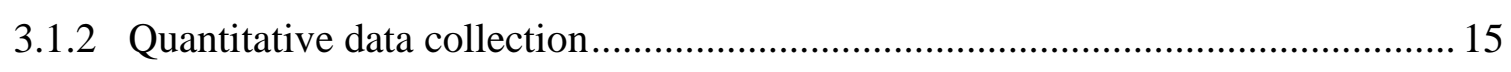

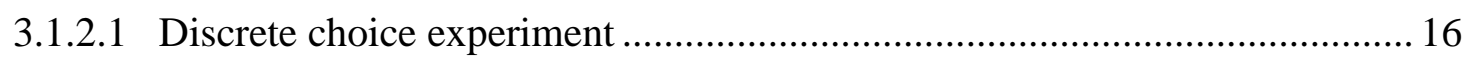

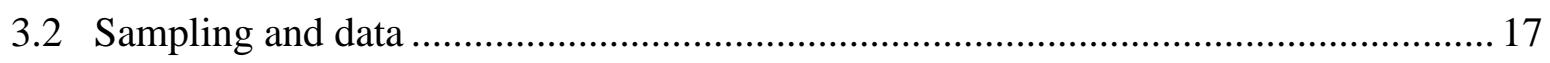

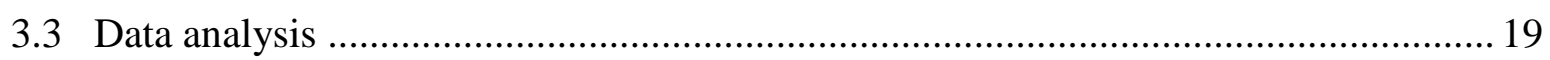

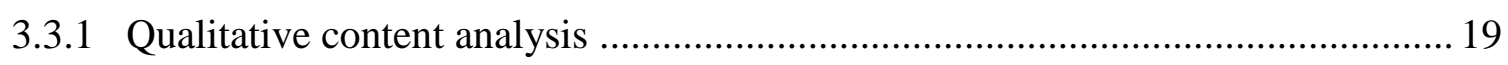

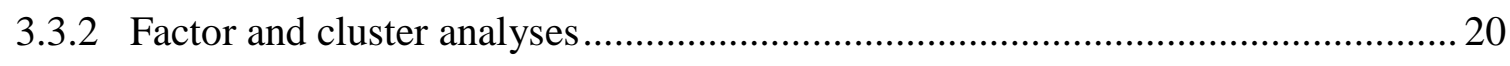

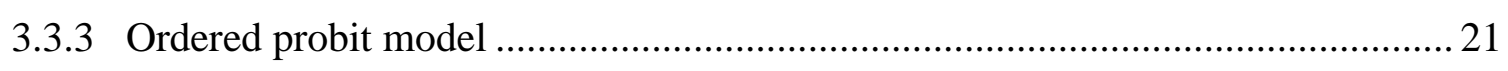

3.3.4 Multinomial logit, random parameter logit, and latent class logit models............ 21

4 "Everybody likes chicken" - A focus group study of consumers in Ghana

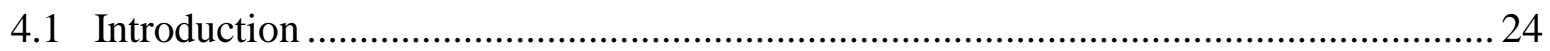

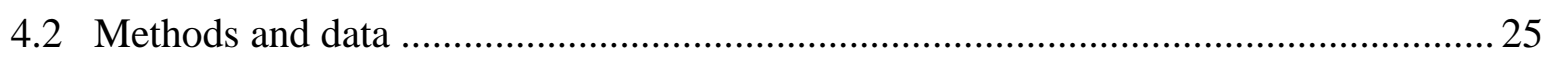


4.3.1 Attitudes and perceptions of domestic and imported chicken ............................. 27

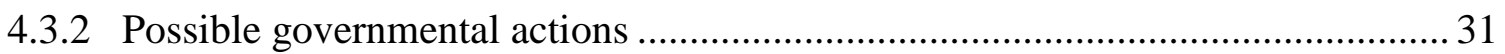

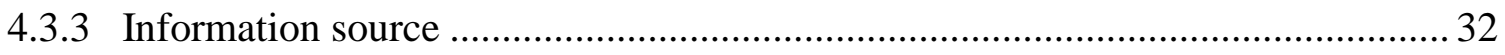

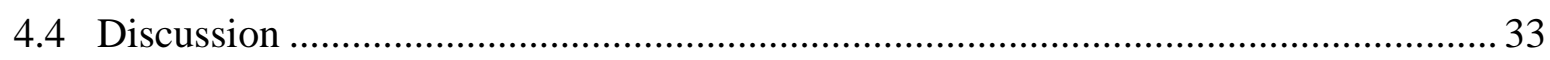

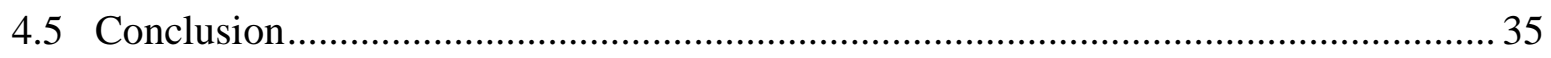

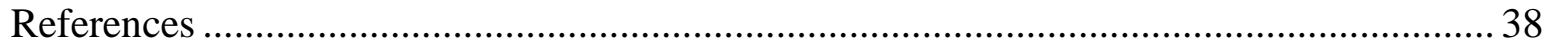

5 Imported versus domestic chicken consumption in Ghana: Do attitudes and perceptions matter? .............................................................................................39

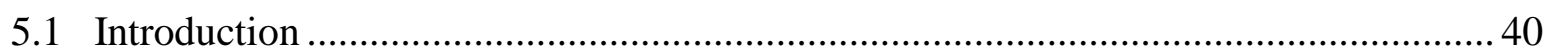

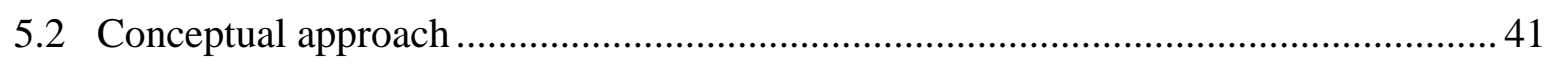

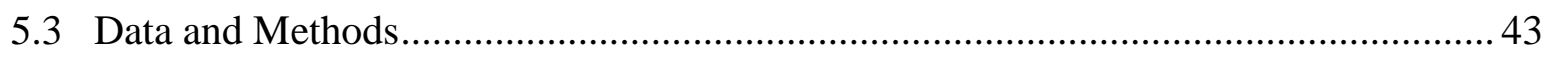

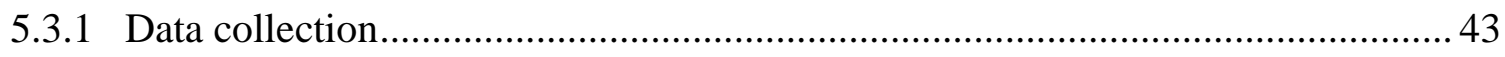

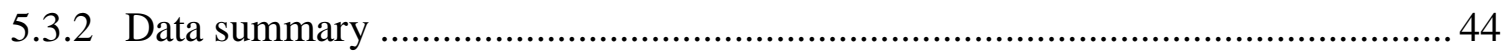

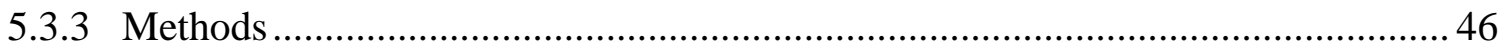

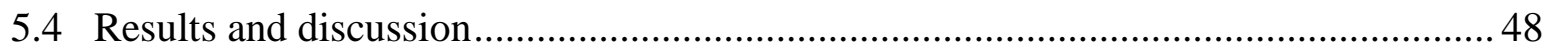

5.4.1 Exploratory factor analysis of attitudes and perceptions ................................... 48

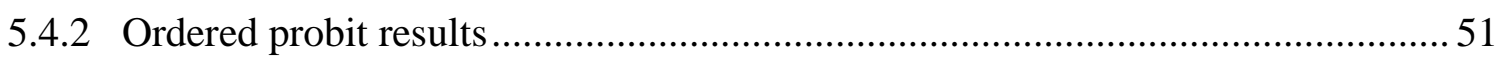

5.4.2.1 Factors influencing general chicken meat consumption ..............................53

5.4.2.2 Factors influencing domestic and imported chicken meat consumption ........54

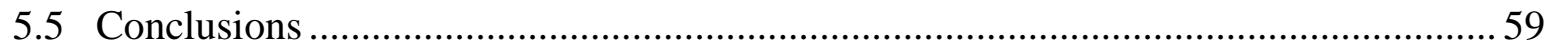

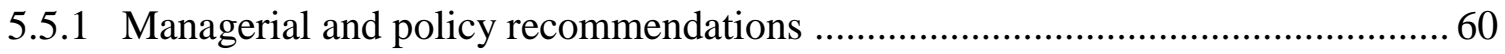

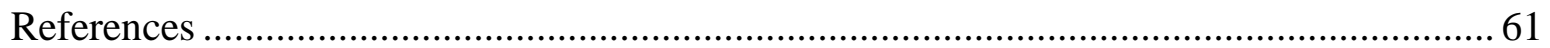

6 Is there hope for domestically produced poultry meat? A choice experiment of consumers in Ghana ......................................................................6 64

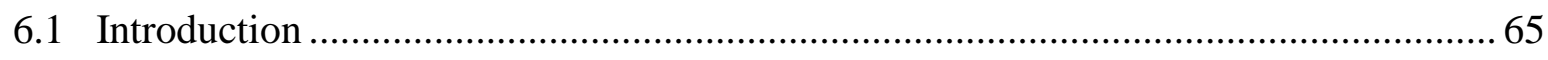

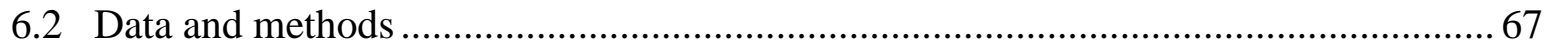

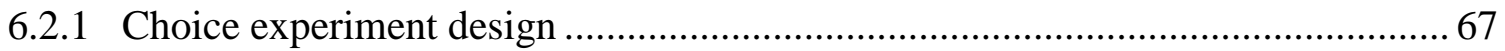

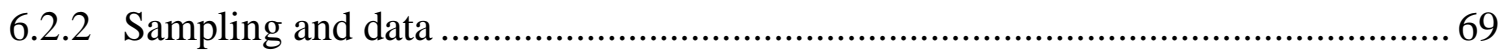

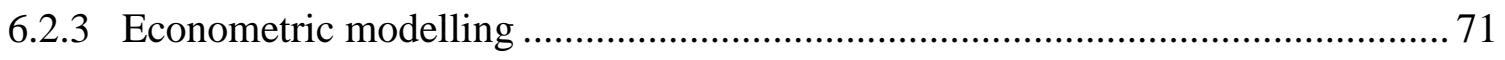

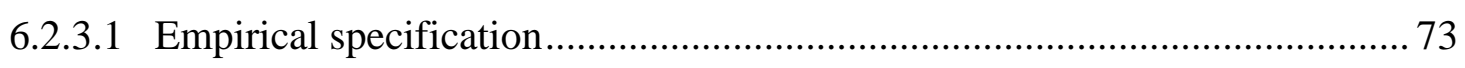

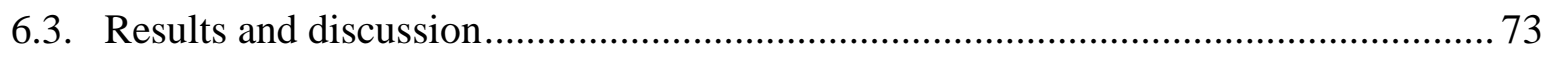

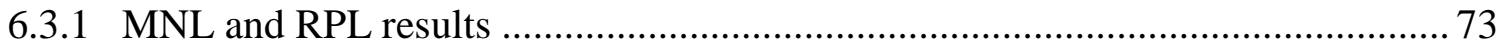




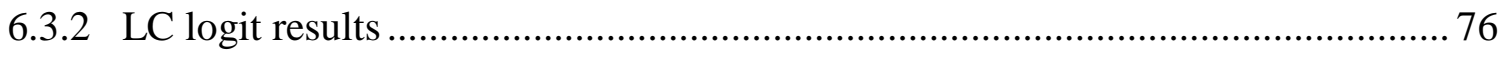

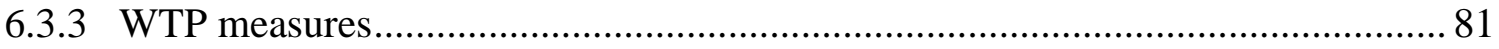

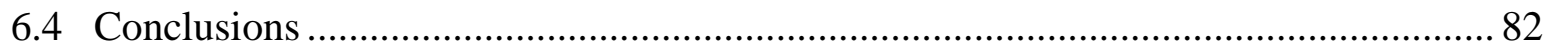

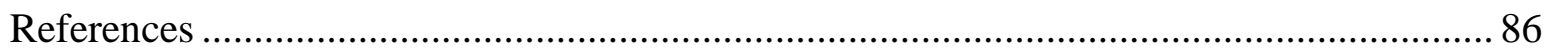

7 Profiling consumers based on information use and trust in a developing economy ........................................................................................................................................89

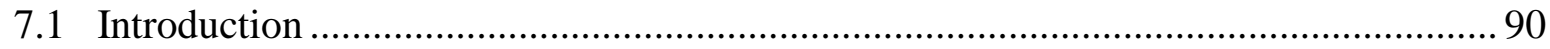

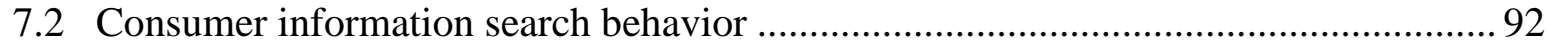

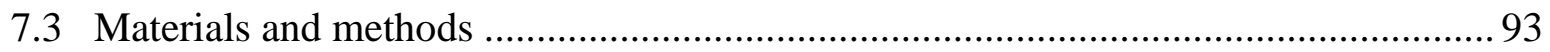

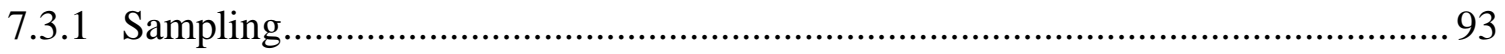

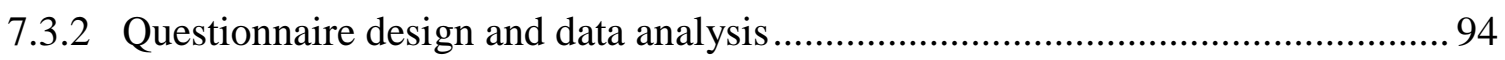

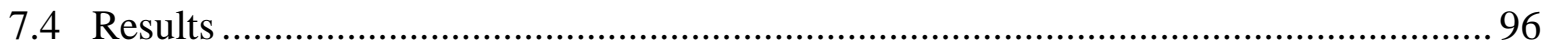

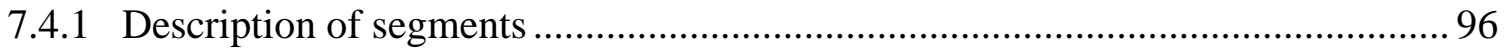

7.4.2 Types of information searched by consumers …................................................. 98

7.4.3 Sociodemographic profile of the segments ........................................................ 98

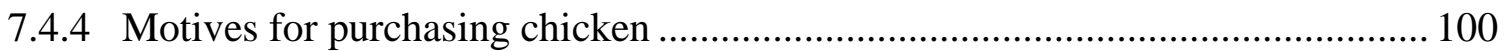

7.4.5 Differences in meat consumption between segments....................................... 101

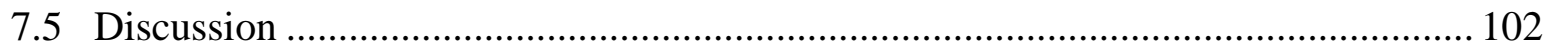

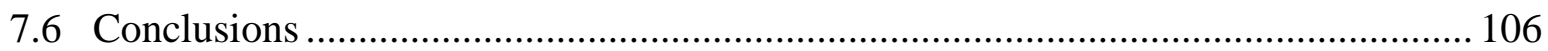

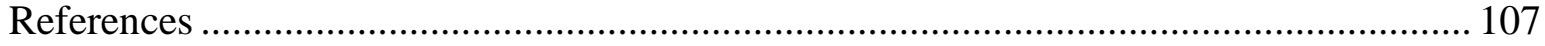

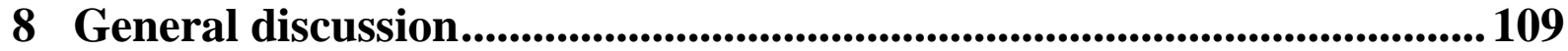

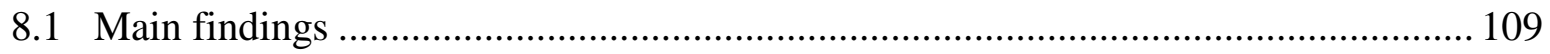

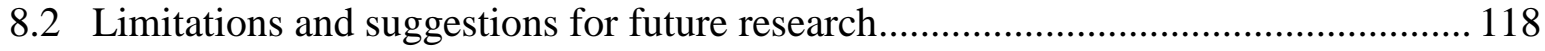

9 Conclusions and implications..........................................................120

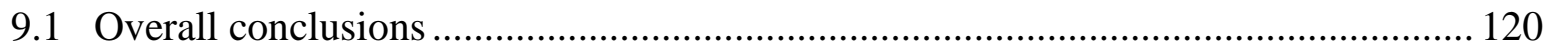

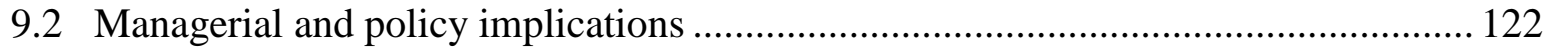

References .........................................................................................................................124

Appendices ............................................................................................................................. 131

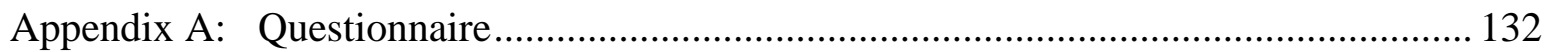




\section{List of Tables}

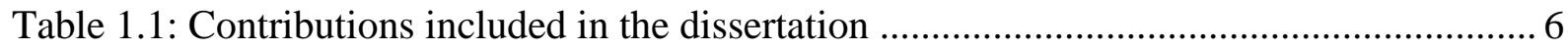

Table 4.1: Socio-demographic characteristics of focus group participants............................ 26

Table 5.1: Summary statistics and socio-demographic variables descriptions ....................... 45

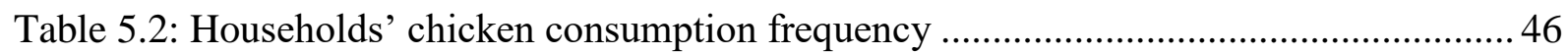

Table 5.3: Factor analysis of statements regarding food in general ...................................... 49

Table 5.4: Factor analysis of statements regarding domestic versus imported chicken ..........51

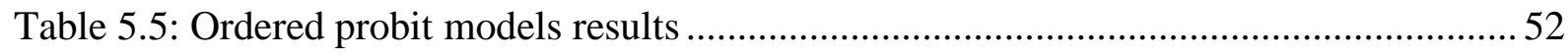

Table 5.6: Predicted probabilities and marginal effects from univariate ordered probit model of chicken consumption

Table 5.7: Predicted probabilities and marginal effects from the bivariate ordered probit model of imported and domestic chicken consumption

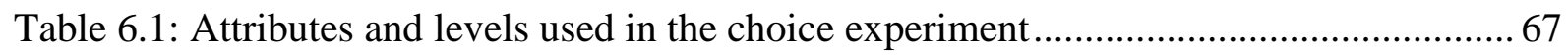

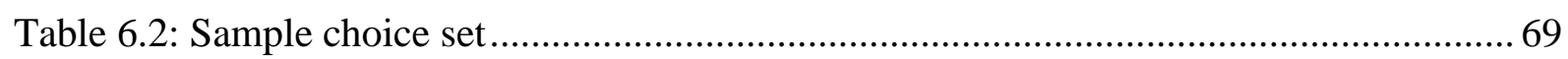

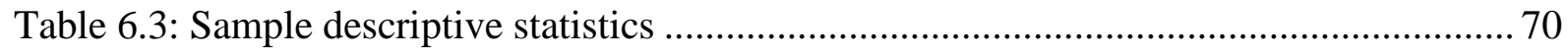

Table 6.4: Parameter estimates from the MNL and RPL models ........................................ 74

Table 6.5: Statistics for determining the optimal number of classes .................................... 77

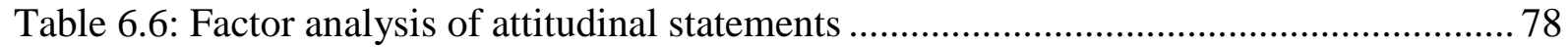

Table 6.7: Parameter estimates from the LC model ............................................................... 79

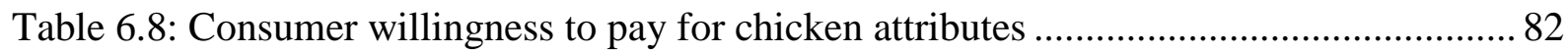

Table 7.1: Principal component analysis of use of information sources about chicken meat.. 95

Table 7.2: Principal component analysis of trust in information sources about chicken meat 96

Table 7.3: Mean scores of the segments on the classification variables ................................ 97

Table 7.4: Profile of the segments on the type of information searched for on chicken.......... 98

Table 7.5: Sociodemographic characteristics of consumers surveyed .................................. 100

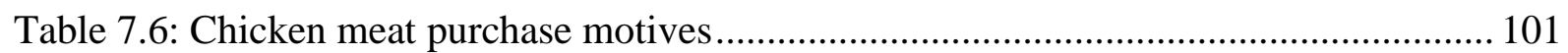

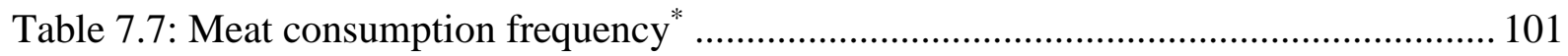




\section{List of Figures}

Figure 2.1: Neo-behavioristic stimulus-organism-response model .................................... 13

Figure 4.1: Poultry trade, production, and consumption in Ghana ....................................... 24

Figure 7.1: Overview of consumer's decision-making process .......................................... 93 


\section{General introduction}

\subsection{Background and problem statement}

Food demand in developing countries is rapidly transforming toward the consumption of more high-value products such as meat (Pingali, 2015). Especially in sub-Saharan Africa (SSA), a similar pace of nutrition transition toward meat products is occurring (Tschirley, Reardon, Dolislager, \& Snyder, 2015). According to the OECD-FAO (2018) agricultural outlook report, poultry meat accounts for a larger part of additional meat consumption in the region. Poultry meat is recognized as useful, particularly, in SSA because it is widely available, relatively cheap, and a good source of high-quality proteins, minerals, and vitamins (Farrell, 2013). For instance, in West Africa, poultry consumption has been stimulated by the availability of low cost alternatives for consumers (Hollinger \& Staatz, 2015). In particular, imported poultry meat products, which are mainly frozen parts such as leg quarters, wings, drumsticks, and backs have become popular with urban consumers, because they are cheap. These products are often sold below production cost because producers in exporting countries make their profits from the sale of high-value parts such as breasts, which are demanded by consumers in those countries (Johnson, 2011; Hollinger \& Staatz, 2015; Rudloff \& Schmieg, 2016).

As in other West African countries, poultry ${ }^{1}$ meat is increasingly becoming an important source of animal protein in Ghana. The country's recent economic growth and transition toward a lower-middle-income economy (World Bank, 2017a) coupled with increasing population and urbanization could explain the changes occurring in poultry meat consumption (World Bank, 2017b). For example, Sumberg, Jatoe, Kleih, and Flynn (2016) find that with increasing income, urban consumers in Ghana are spending a higher proportion of their food expenditures on poultry meat and other high-value products. Therefore, given a projected growth rate in Gross Domestic Product (GDP), consumer demand for poultry meat in Ghana is expected to increase further in the future.

The rising demand for poultry meat offers new opportunities for growth and investment in the value chains. However, local production has been inadequate to meet this growth in consumer demand, and as a consequence, the country currently depends heavily on imports to meet demand. The failure of local production to meet demand is largely due to the low productivity in the sector (World Bank, 2017b). Indeed, over the past five decades, the average

\footnotetext{
${ }^{1}$ In Ghana, poultry includes chickens, turkeys, guinea fowls, ducks, and ostriches (MoFA, 2016). However, chicken is synonymous with poultry because it constitutes more than 95 percent of poultry production (see Amanor-Boadu, Nti, \& Ross, 2016) and the poultry market. As such, this study focuses only on chicken meat.
} 
productivity is estimated at $0.14 \%$ per annum (Amanor-Boadu et al., 2016). Using the FAO statistics, domestic production accounted for only 35\% of the country's poultry meat consumption in 2017, with the remaining proportion coming from imports (FAO, 2019). The growing imports of poultry have been substantial over the past decades and have become an important policy debate, as concerns have grown over time. While imports fill the excess demand gap in the short-term, concerns have been expressed about the effects of imports on the domestic economy and producers in the long-term. Critics argue that imports threaten the competitiveness of the domestic industry, lead to an outflow of money to foreign countries, and could cause food crises, especially when countries are exposed to price fluctuations and volatility of global commodity markets (see Rudloff \& Schmieg, 2016; Sumberg, Awo, \& Kwadzo, 2017). For example, Sumberg et al. (2017) indicate that the language of unfair competition and dumping has become more evident in government policy documents in recent years. These concerns have led to pressure from farmer groups, non-governmental organizations (NGOs), and some stakeholders for increased import protection. Accordingly, the Ghanaian government has sought to protect domestic producers through the imposition of a $35 \%$ import tariff in 2016 (the level of the ECOWAS common external tariff) and focused its policy agenda on boosting domestic production and reducing the reliance on imports (see MoFA, 2010; USDA, 2017).

Yet, the issue of imports requires that policymakers find ways to balance competing interests such as employment creation, rural development, local income generation, and food security as well as the needs of consumers (Rudloff \& Schmieg, 2016). Very often, however, much of the policy discourse targeted at improving the competitiveness of local production has focused on trade-related measures such as import restrictions while neglecting consumer interests. Given this, there is a need to understand how consumers behave toward poultry meat and what the implications are for the future since consumers represent the final actors of the food supply chain (Font-i-Furnols \& Guerrero, 2014; Baba, Kallas, Costa-Font, Gil, \& Realini, 2016). This is important from a market development perspective as it would enable the domestic poultry industry to capture a larger share of the market by designing value-added products in response to consumers' expectations, preferences, and needs regardless of the competition. Moreover, from the policy perspective, a better understanding of consumer preferences is important for (indirectly) shaping trade policy and, for that matter, any strategy aimed at changing trade policy should also consider consumers' interests (Johnson, 2011).

Understanding consumer behavior is, however, a complex issue as it is characterized by a decision process (Furst, Connors, Bisogni, Sobal, \& Falk, 1996; Ben-Akiva et al., 1999; Font- 
i-Furnols \& Guerrero, 2014). The decision process includes all activities directly involved in searching for, evaluating, selecting, purchasing, consuming, and disposing of products and services (Schiffman \& Kanuk, 2007; Solomon, Bamossy, Askegaard, \& Hogg, 2010). In this case, the factors that influence consumer's behavior can be numerous. In particular, past research shows that consumers' perceptions and attitudes toward healthiness, safety, quality, convenience, and price are relevant factors driving food choices (Steptoe, Pollard, \& Wardle, 1995; McCarthy, O’Reilly, Cotter, \& de Boer, 2004; Kennedy, Stewart-Knox, Mitchell, \& Thurnham, 2004; Grunert, 2006; Font-i-Furnols \& Guerrero, 2014). For instance, using a qualitative study, Kennedy et al. (2004) find appearance and convenience as the most important factors influencing the purchase of chicken meat. They suggest that these factors reflect the perception of freshness, healthiness, and product versatility. Likewise, previous studies indicate that the origin of food plays an increasing role in food quality perceptions and has become more influential in consumers' choice decisions (Umberger, Feuz, Calkins, \& Sitz, 2003; Loureiro \& Umberger, 2005; Grunert, 2005; Vukasovič, 2010). According to Chambers, Lobb, Butler, Harvey, and Traill (2007), consumers usually perceive locally produced food to be of higher quality in terms of freshness and taste. Similarly, Pouta, Heikkilä, Forsman-Hugg, Isoniemi, and Mäkelä (2010) find that consumers in Finland prefer and are willing to pay more for domestically produced broiler meat.

Furthermore, preferences for food products, particularly meat, can be influenced by sociodemographic factors (Quagrainie, Unterschultz, \& Veeman, 1998; Jekanowski, Williams, \& Schiek, 2000; Guenther, Jensen, Batres-Marquez, \& Chen, 2005; Rimal, 2005; Bett, Peters, Nwankwo, \& Bokelmann, 2013; Escriba-Perez, Baviera-Puig, Buitrago-Vera, \& MonteroVicente, 2017; Udomkun et al., 2018). For example, Udomkun et al. (2018) find that gender and age are key drivers of consumer's preference and willingness to pay for meat products in the Democratic Republic of Congo. Examining the consumption frequency of different types of meat in Spain, Escriba-Perez et al. (2017) find that the consumption of chicken, pork, rabbit, and lamb depends only on sociodemographic factors such as sex, age, educational level, household size, presence of children in the household, among others. Rimal (2005) finds that respondents with high education are more likely than those with low education to purchase poultry meat frequently. Bett et al. (2013) also find that age, income, education, and family size influence consumers' willingness to pay for underutilized indigenous chicken products in Kenya.

Meanwhile, existing studies on Ghana focused only on the choice of poultry meat and mainly on the influence of search and experience (sensory) attributes such as price, taste, and 
convenience in the selection of poultry meat (Kwadzo, Dadzie, Osei-Asare, \& Kuwornu, 2013; Woolverton \& Frimpong, 2013; Al-Hassan, Larvoe, \& Adaku, 2014). While these studies provide important insights, food-related decisions do not depend only on product attributes but also on sociodemographic characteristics, psychological factors (e.g., perceptions and attitudes), and marketing aspects as already indicated (Steptoe et al., 1995; Furst et al., 1996; Verbeke, 2005; Font-i-Furnols \& Guerrero, 2014; Thong \& Solgaard, 2017; Escriba-Perez et al., 2017). Moreover, factors associated with a consumer's social and physical environment, such as information provision, can influence consumers' behavior (Verbeke, 2008). Thus, research into consumers' food choices and consumption behavior would benefit considerably if these factors are considered. Yet, there has been no comprehensive investigation of the effects of this wide-array of factors on consumer behavior vis-à-vis chicken meat in the Ghanaian context. Accordingly, this dissertation addresses this gap by presenting a holistic empirical analysis of the relative roles of these relevant factors in shaping not only the choice but also consumption patterns of chicken meat, by distinguishing between the origin of supply (i.e., domestic and imported). To accomplish this goal, this thesis employs a mixed methods design, involving the combination of qualitative and quantitative methods along with a discrete choice experiment (DCE).

Against this background, the contributions of this thesis are threefold. First, it provides valuable information to economic actors (such as producers and marketers) on poultry meat consumers, their characteristics, as well as the importance they attach to the various quality attributes of chicken meat. This will help poultry producers and marketers to effectively develop products and marketing strategies that respond to consumers' expectations and needs. Similarly, from a policy perspective, it provides valuable insights for government investment in the poultry industry. Furthermore, understanding consumers' attitudes and perceptions, as well as their information search behavior, will allow for the development of effective communication strategies that include targeted information provision and educational activities that will inform consumers so as to overcome inaccurate information.

Second, this thesis contributes to the empirical literature on consumer behavior toward food systems in developing countries and emerging markets. Third, from a methodological point of view, the mix of qualitative and quantitative methods provides a deeper and better understanding of consumers' behavior toward chicken meat products than either approach alone. In addition, the use of DCE, which is strongly consistent with economic demand theory (Louviere, Flynn, \& Carson, 2010), the application of random parameter (mixed) logit and latent class models that capture preference heterogeneity, and the identification of the sources 
of heterogeneity using psychological variables (attitudes) help to improve the behavioral explanations of consumer's choice behavior.

\subsection{Research objectives}

The overall objective of this Ph.D. thesis is to analyze consumers' attitudes, preferences, and willingness to pay (WTP) for quality attributes in chicken meat. To achieve this, the following four objectives are addressed in this dissertation:

1. Examine consumers' motives, perceptions, and attitudes toward chicken meat and determine whether they differ between domestic and imported.

2. Identify the role of personal factors (i.e., psychological and sociodemographic) in influencing the consumption patterns of chicken meat, in general, and in particular, domestic and imported chicken meat.

3. Analyze consumers' preferences and estimate the WTP for important attributes of chicken meat.

4. Identify possible distinct consumer groups based on the use of and trust in information sources and examine the differences between the segments in terms of information cues searched for, sociodemographic characteristics, and chicken consumption behavior.

\subsection{Outline of the dissertation}

To address these objectives, the thesis comprises a compilation of papers that have been published and accepted as contributions to international peer-reviewed journals and conference proceedings. This dissertation is organized into nine chapters. Following the introduction presented in Chapter 1, a theoretical framework on consumer behavior from an economic and behavioristic perspective is presented in Chapter 2. Chapter 3 describes and justifies the chosen methodological approach. Both qualitative and quantitative methods are applied, and the rationale for combining these methods is provided. Chapters $4,5,6$, and 7 present the four standalone, but related papers included in this thesis, which address each of the defined objectives. The four contributions are summarized in Table 1.1.

The first article, "Everybody likes chicken - A focus group study of consumers in Ghana" presented in Chapter 4 uses an exploratory approach to provide insight into consumers' perceptions and attitudes toward chicken meat and explore whether these attitudes differ between domestic and imported chicken meat. Finally, it identifies the relevant factors consumers consider when making purchases. The second article, "Imported versus domestic 
chicken consumption in Ghana: Do attitudes and perceptions matter?" presented in Chapter 5 aims at identifying whether and to what extent personal factors (psychological and sociodemographic) influence the frequency of chicken consumption. Chapter 6 contains the third article, "Is there hope for domestically produced poultry meat? A choice experiment of consumers in Ghana" that examines consumers' preferences for chicken meat attributes and how their attitudes affect these preferences. The willingness to pay for the attributes is also estimated.

Chapter 7 presents the fourth article, "Profiling consumers based on information use and trust in a developing economy", which analyzes information search behavior among consumers with regard to chicken purchases. It identifies and profiles three consumer segments based on their use of and trust in information sources. Chapter 8 contains the general discussions. Here, the key findings, limitations, and suggestions for further research are discussed. Finally, Chapter 9 concludes and provides implications for economic actors in the poultry sector and decision-makers.

Table 1.1: Contributions included in the dissertation

\begin{tabular}{llll}
\hline Article & \multicolumn{1}{c}{ Author } & \multicolumn{1}{c}{ Title } & \multicolumn{1}{c}{ Comment } \\
\hline (1) & $\begin{array}{l}\text { C., Asante-Addo } \\
\text { D., Weible }\end{array}$ & $\begin{array}{l}\text { "Everybody likes chicken" - A focus } \\
\text { group study of consumers in Ghana. }\end{array}$ & $\begin{array}{l}\text { Accepted for publication in the } \\
\text { proceedings Schriften der } \\
\text { Gesellschaft für Wirtschafts- und } \\
\text { Sozialwissenschaften des } \\
\text { Landbaus } \text {.V. } .\end{array}$ \\
(2) & $\begin{array}{l}\text { C., Asante-Addo } \\
\text { D., Weible }\end{array}$ & $\begin{array}{l}\text { Imported versus domestic chicken } \\
\text { consumption in Ghana: Do attitudes and } \\
\text { perceptions matter? }\end{array}$ & $\begin{array}{l}\text { Published in the Journal of } \\
\text { International Food \& } \\
\text { Agribusiness Marketing. }\end{array}$ \\
& $\begin{array}{l}\text { C., Asante-Addo } \\
\text { D., Weible }\end{array}$ & $\begin{array}{l}\text { Is there hope for domestically produced } \\
\text { poultry meat? A choice experiment of } \\
\text { consumers in Ghana. }\end{array}$ & $\begin{array}{l}\text { Published in Agribusiness: An } \\
\text { International Journal. }\end{array}$ \\
& $\begin{array}{l}\text { C., Asante-Addo } \\
\text { D., Weible }\end{array}$ & $\begin{array}{l}\text { Profiling consumers based on information } \\
\text { use and trust in a developing economy. }\end{array}$ & $\begin{array}{l}\text { Published in the International } \\
\text { Journal of Consumer Studies. }\end{array}$ \\
\hline
\end{tabular}




\section{Theoretical framework}

This chapter presents the theoretical underpinnings of this thesis. To provide a comprehensive theoretical framework, this thesis employed two theoretical concepts, namely microeconomic and behavioral psychology theories. The choice and consumption behavior, representing the final stage of the consumer's decision-making process, are captured using microeconomic theory, specifically the Lancaster and random utility theories. However, to understand that ultimate point (i.e., choices and consumption behavior), the preceding events, that is how consumers search for product information, evaluate product alternatives, and the influencing factors of choice and consumption decisions other than the attributes of the chicken meat are analyzed as well. These preceding events and influencing factors are examined by the application of the behavioral psychology theory (i.e., buyer decision-making process and stimulus-organism-response theory).

\subsection{Microeconomic theory of consumer behavior}

The microeconomic theory of consumer behavior provides the standard approach in modeling choice or consumption decisions. The theory is concerned about how consumers allocate their income and how this determines the demand for various goods and services. It assumes that the consumer is rational and that when faced with a set of feasible alternatives, he/she will at all times choose the most preferred bundle from the set of alternatives (Varian, 1984). The choice of an alternative is based on a decision rule known as utility maximization, which implies that when faced with two or more alternatives, the consumer chooses the alternative that will give him/her the highest possible utility (Ben-Akiva \& Lerman, 1985). However, to investigate consumer behavior toward different product alternatives (composed of discrete bundles of attributes) as in the case of this study, the traditional microeconomic theory of consumer behavior cannot be applied because it assumes homogeneous goods and utility as a function of the quantities of goods consumed and not attributes. Instead, discrete choice theories (i.e., Lancaster and random utility theories) provide a better framework for dealing with such discrete choice situations (Ben-Akiva \& Lerman, 1985). The theoretical foundations of discrete choice models are rooted in consumer theory developed by Lancaster (1966) and the random utility theory. 


\subsubsection{Lancaster's consumer theory}

Prior to Lancaster's new approach to consumer theory, the prevailing assumption was that goods are the direct objects of utility (Lancaster, 1966). However, Lancaster's approach deviates from the traditional microeconomic consumer theory, which indicates that goods are the direct objects of utility (Lancaster, 1966). The main departure of Lancaster's approach from the traditional microeconomic theory of consumer behavior is that utility is derived from the characteristics that goods possess rather than the goods per se (Lancaster, 1966). Lancaster's approach assumes that goods have more than one characteristic, and they can be used either singly or in combination to produce different characteristics from which the consumer derives utility. Lancaster (1966) assumed that utility orderings are rank collections of the characteristics that goods possess. In the context of this thesis, for example, chicken meat, the good of interest, can be viewed as a collection of its quality attributes such as the origin, product form, storage form, and the claim.

According to Lancaster (1966), a consumer possesses an ordinal utility function on attributes, $U(z)$ and that will select a situation that maximizes his/her $U(z)$, subject to the budget constraint $p x \leq k$, where $z$ is a vector of the $n$th attribute that the consumer obtains from the consumption of goods $\left(z_{1}, \ldots, z_{n}\right), p$ is a vector of prices for each of the goods, $x$ represents the goods, and $k$ is the consumer's income. A transformation between the utility function defined on the characteristics-space and the budget constraint defined on the goods-space is represented by the equation system $z=B x$, where $B$ is a matrix of constants. Additionally, the non-negativity constraints represented as $z, x \geq 0$ are assumed to hold initially. However, the non-negativity constraints may not always be part of the model in some applications. Simplifying the model and assuming a one-to-one correspondence between goods and activities, the consumer choice is given as:

$$
\begin{array}{ll}
\text { Maximize } & U(z) \\
\text { subject to } & p x \leq k \\
\text { with } & z=B x \\
& z, x \geq 0
\end{array}
$$

Meanwhile, Lancaster's theory assumes that goods are infinitely divisible, regularly purchased, and have low unit value. Nonetheless, many goods are not perfectly divisible, specifically goods that are important to discrete choice applications, which often are not purchased frequently (Louviere, Hensher, \& Swait, 2000). 


\subsubsection{Random utility theory}

To describe observed inconsistencies in patterns of individual behavior, the random utility theory (RUT) was proposed by Thurstone (1927) and further developed by McFadden (1974) from paired comparisons to multiple comparisons. Like traditional consumer theory, the RUT assumes that an individual will choose an alternative from a set of alternatives that will maximize his/her utility. The idea behind random utility theory is that there is a latent construct known as "utility" for each choice option, which is not observable but only exists in the mind of the decision-maker (Louviere et al., 2010). However, while a decision-maker may have perfect information in terms of his/her utility function, analysts (researchers) do not know what is in the mind of a decision-maker but can observe his/her choices and make inferences about the factors that drive such choices.

Unlike the traditional consumer theory, which assumes deterministic behavior, the RUT indicates that the latent utility individuals derive from a choice object can be decomposed into both deterministic (systematic) and random (unexplained) components (Louviere et al., 2000; Louviere et al., 2010). The deterministic or systematic component represents the attributes of the choice alternatives and the characteristics of the individual decision-makers that can be observed by the analyst, whereas the random component is the utility contributed by attributes unobserved by the analyst and captures uncertainty or all unidentified factors that influence choices (Louviere et al., 2000; Louviere et al., 2010). Following on from that, the utility that individual $n$ associates with alternative $j$ in the choice set $C_{n}$ is given by

$U_{j n}=V_{j n}+\varepsilon_{j n}$

where $U_{j n}$ is the unobservable utility that individual $n$ associates with choice alternative $j, V_{j n}$ is the deterministic component of utility that individual $n$ associates with alternative $j$ and $\varepsilon_{j n}$ is the random component associated with individual $n$ and alternative $j$, capturing the uncertainty. The individual will choose the alternative with the highest utility from the choice set. Therefore, it is possible to predict the probability that individual $n$ will choose alternative $j$, but not the exact alternative that individual $n$ will select (Louviere et al., 2010). The probability that individual $n$ chooses alternative $j$ from a set of competing options $C_{n}$ is equal to the probability that the utility of alternative $j$ is greater than the utility associated with alternative $k$ after evaluating each alternative in the choice set. This is given as follows:

$P\left(j / C_{n}\right)=\operatorname{Prob}\left[\left(V_{j n}+\varepsilon_{j n}\right)>\left(V_{k n}+\varepsilon_{k n}\right) \forall_{j} \in C_{n} ; j \neq k\right]$ 
Rearranging Equation (2.2) to put the observables and unobservable together gives:

$$
\begin{aligned}
P\left(j / C_{n}\right) & =\operatorname{Prob}\left[\left(V_{j n}-V_{k n}\right)>\left(\varepsilon_{k n}-\varepsilon_{j n}\right) \forall_{j} \in C_{n} ; j \neq k\right] \\
& =\operatorname{Prob}\left[\left(\varepsilon_{k n}-\varepsilon_{j n}\right)<\left(V_{j n}-V_{k n}\right) \forall_{j} \in C_{n} ; j \neq k\right]
\end{aligned}
$$

By assuming different probability distributions for the unobserved portion of utility, different probabilistic discrete choice models, such as the multinomial logit (MNL) model, can be derived from Equation (2.3). For the researcher, $\varepsilon_{j n}$ is a random variable and represents the utility contributed by the unobserved attributes (Train, 2009; Louviere et al., 2000). However, this does not imply that individuals maximize utility in a random manner but rather they can be deterministic utility maximizers (Louviere et al., 2000). Randomness occurs since the analyst does not know what is in the mind of each individual but fully observe the set of influencing factors and the complete decision calculus, suggesting that the analyst can only explain choice up to a probability of event selection (Louviere et al., 2000). According to Louviere et al. (2010), psychologists assume that individuals are not perfect measurement devices, and thus, the random component of the utility can additionally be explained by including sociodemographic or psychological factors that reflect the variability and differences in individual choices and not the choice options per se. Given that these factors are also important in explaining buying behavior, the microeconomic theory (i.e., discrete choice theory) applied in this thesis is extended to take into account other factors that may influence the choice and consumption of chicken meat.

\subsection{Behavioral psychology theory}

The underlying decisions of choice and consumption of chicken meat are based on consumer behavior. Solomon et al. (2010, p. 6) define consumer behavior as "the study of the processes involved when individuals or groups select, purchase, use or dispose of products, services, ideas or experiences to satisfy needs and desires." Consumer behavior has developed into an interdisciplinary field of research, which includes a very wide range of activities that influence consumer's decisions (Blackwell, Miniard, \& Engel, 2001; Solomon et al., 2010). During the formative years of consumer behavior modeling, consumer behavior models were useful in organizing different knowledge of social action into a rather subjective yet plausible process of intervening psychological, social, economic, and behavioral variables (Cooper, Fletcher, Fyall, Gilbert, \& Wanhill, 2005). 


\subsubsection{Consumer's decision-making process}

Consumer purchasing behavior is characterized by a decision process that includes problem/need recognition, information search, evaluation of alternatives, purchase decision, and post-purchase evaluation (Kotler \& Keller, 2012). The first stage, referred to as problem recognition, occurs when there is a significant difference between a consumer's state of affairs (status quo) and his/her desire or ideal state (Solomon et al., 2010). The need may be triggered by internal stimuli (e.g., hunger or thirst) or external stimuli such as advertisement, sight of an acquaintance's product, etc. (Roberts \& Lilien, 1993; Kotler \& Armstrong, 2011). In the second stage, the consumer search for information after a need is recognized. Information search is the process whereby a consumer assesses his/her environment for appropriate data to make a reasonable decision (Solomon et al., 2010). The search for information can be internal and external (Solomon et al., 2010). Internal search is when a consumer uses information already in his/her memory. In contrast, an external search is when a consumer seeks additional information from the environment, for example, information from personal (family, friends, colleagues), commercial (advertising), media, and public sources (Solomon et al., 2010; Kotler $\&$ Keller, 2012). This stage is what objective (4) seeks to examine, but focuses only on external (pre-purchase and ongoing) information search behavior.

The third stage sets in during the search and learning. Here, the consumer forms beliefs about the attributes of the alternative products that he/she consider (perceptions) as well as any associated uncertainties (Roberts \& Lilien, 1993). Based on those perceptions, the consumer determines his/her attitude toward the products to form the utility function (preferences), which entails valuing and trading off product attributes that are important to the decision (Roberts \& Lilien, 1993; Louviere et al., 2000). However, if the evaluation is not successful, the consumer begins to search again. Given beliefs or attitudes about attributes associated with product alternatives, the consumer at the fourth stage develops a preference ordering for products, and subject to budget and/or other constraints, he/she decides about whether to purchase (Louviere et al., 2000). Finally, if the consumer decides to purchase, there would be a post-choice evaluation of the purchase decision. The outcome of this evaluation is one of satisfaction or dissatisfaction, which may provide inputs for future purchase decisions. The satisfaction or dissatisfaction that a consumer has with a purchase depends on the relationship between his/her expectations and the perceived performance of the product (Kotler \& Armstrong, 2011). The consumer is disappointed if the product does not meet his/her expectations, satisfied if it meets expectations, and delighted if it exceeds expectations (Kotler \& Armstrong, 2011). 


\subsubsection{Neo-behavioristic theory - stimulus-organism-response}

In studying consumer choices or consumption behavior, analysts usually aim to find out, for instance, which product people choose among an available range of products, whether they differ in the evaluation of alternatives, and hence, in their choices or consumption. In this regard, several theories, including the Theory of Reasoned Action (TRA) and the Theory of Planned Behavior (TPB), have been used to examine the various factors influencing consumer's decision-making process, especially regarding food choice behavior (e.g., Furst et al., 1996; McCarthy et al., 2004; Tarkiainen \& Sundqvist, 2005; Verbeke \& Vackier, 2005; Chen, 2007; Zagata, 2012). However, the TRA aims to predict and comprehend the cause of behavior but does not take into account possible impediments to the performance of the behavior over the individual volitional control (Ajzen \& Fishbein, 1980). On the other hand, while the TPB is an expansion of TRA, it is applied to predict and explain behaviors that are not absolutely under volitional control and only added the construct perceived behavioral control (Ajzen \& Madden, 1986). Because TRA and TPB do not account for other variables such as environmental or economic factors that may influence a person's behavior, they are inappropriate to use in this study.

Therefore, to account for other multiple factors that may influence the choice and consumption patterns of chicken meat, the neo-behavioristic theory seems appropriate. The neo-behavioristic theory explains consumer behavior using the stimulus-organism-response (SO-R) paradigm (Foscht \& Swoboda, 2011), which is an extension of the stimulus-response (SR) from behavioristic theory (Kotler \& Keller, 2012). As opposed to the behavioristic approach, which indicates that external stimuli (S) lead to responses (R), the neo-behavioristic approach additionally considers the unobservable processes (organism) as a mediator between the observable stimuli and the response (Jacoby, 2002). By assuming that there are internal intervening variables, the unobservable processes can be measured directly or indirectly through indicators (Jacoby, 2002). The S-O-R model, therefore, enables researchers to examine both cognitive and affective influences on behavior (Lee \& Yun, 2015).

The basic S-O-R model (Figure 2.1) has three elements namely stimuli, organism, and response. Stimuli (S) are often regarded as external to the individual and include marketing and environmental stimuli. The marketing stimuli consist of the product price, other product attributes, communication, place of purchase, and availability. Environmental stimuli include economic, technological, social, and cultural factors. Organism $(\mathrm{O})$ is the internal state that describes the consumer's attitudes and preference formation induced by marketing and environmental stimuli. The organism (internal processes) can be categorized into activating and 
cognitive processes. Activating processes are attitudes, motivations, and emotions, while cognitive processes include perceptions, learning, and memory (Armstrong \& Kotler, 2009; Kroeber-Riel, Weinberg, \& Gröppel-Klein, 2009; Foscht \& Swoboda, 2011).

In the context of this thesis, consumer's attitudes toward food and perceptions about attributes of chicken meat, particularly imported and domestic chicken meat, which are captured by the observed attitudinal and perceptual indicators, represent the organism. These include attitudes and perceptions of phenomena such as safety, health, quality, convenience, availability, price, etc. The response $(\mathrm{R})$ refers to the outcome, in this case, the purchasing behavior (either choice of a product, purchase of a product, or quantity purchased/consumed). Therefore, based on this theoretical approach, consumer's choice and consumption behavior are a result of the interaction of differently observable factors and unobservable processes in the consumer's psyche.

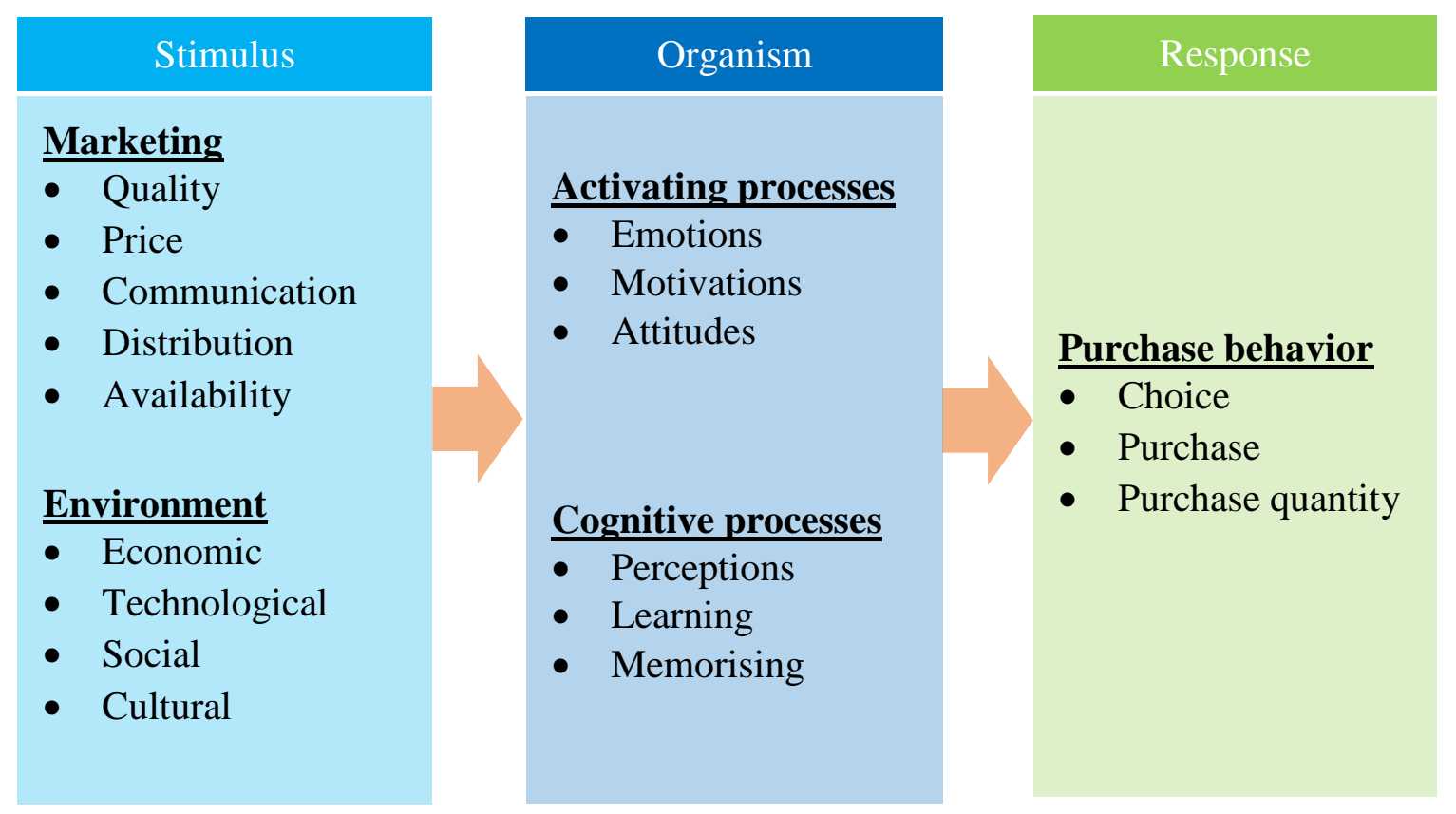

Figure 2.1: Neo-behavioristic stimulus-organism-response model

Source: Adapted from Kroeber-Riel et al. (2009) and Foscht and Swoboda (2011). 


\section{Methodology}

This chapter presents the methodology used for this dissertation. It provides a comprehensive description of and a rationale for the chosen data collection methods and sampling approach. In addition, the procedures and instruments used to collect the data as well as data analysis methods are described.

\subsection{Data collection methods}

This thesis employed a mixed methods study design. A mixed methods study involves the combination of both quantitative and qualitative research methods in a single study and includes integrating the data at one or more stages in the research process (Creswell, Plano Clark, Gutmann, \& Hanson, 2003; Johnson \& Onwuegbuzie, 2004). The reason for choosing the mixed methods approach is due to its ability to improve research results through the provision of informative, complete, and balanced results to the extent that either quantitative or qualitative method alone does not permit (Brewer \& Hunter, 1989; Tashakkori \& Teddlie, 1998; Johnson, Onwuegbuzie, \& Turner, 2007). This thesis used an exploratory sequential mixed methods approach, which is a type of design whereby qualitative and quantitative data are collected separately in two phases (Creswell et al., 2003; Creswell \& Plano Clark, 2011). In the first stage, qualitative data is collected to explore common themes relating to perceptions, attitudes, preferences, and information search behavior of consumers. The second phase involved a quantitative data collection of sampled consumers. The data from the qualitative study provided useful information to support the development of the subsequent quantitative survey.

\subsubsection{Qualitative data collection}

Qualitative research is often used to understand a complex phenomenon that cannot be meaningfully reduced through a few discrete variables and linear cause-and-effect relationships (Patton, 2002). Qualitative research explains human behavior from the perspectives of participants, and thus, it is important for gaining a better understanding of social realities (Flick, Von Kardorff, \& Steinke, 2004). Consequently, the use of qualitative studies to explore attitudes, beliefs, and opinions of a group of individuals and the factors that influence their consumption habits is increasingly being recognized (Munoz, 1998; Barrios \& Costell, 2004). Qualitative data collection methods comprise in-depth interviews, observation, and focus groups (Petty, Thomson, \& Stew, 2012). Among these methods, focus groups and in-depth 
interviews are widely used in social science research. Therefore, this thesis used the focus group method since it is one of the most widely used and efficient techniques for gathering qualitative data in market research (Morgan, 1996; Barrios \& Costell, 2004; Groves et al., 2009).

A focus group is a qualitative research method whereby a selected group of people, usually between six to twelve, are interviewed in a discussion setting under the guidance of a trained moderator and allows the moderator as well as participants to freely and openly discuss issues (Krueger \& Casey, 2000; Neuman, 2000; Creswell, 2007). This helps to provide more information than could be obtained using one-to-one interviews. Focus groups are considered to be relatively low in terms of cost and a flexible and efficient way to get information from a group of people than other methods (Krueger \& Casey, 2000; Finch \& Lewis, 2003; Groves et al., 2009). In addition, they allow for honest, sincere, and detailed discussions. The interactional context provides a key opportunity to explore and explain the dimensions of differences and diversity of views that occur during discussions (Krueger \& Casey, 2000; Finch \& Lewis, 2003). Focus groups are also useful in the initial stages of a questionnaire design to learn what respondents know about the topic of the survey (Groves et al., 2009). In spite of the advantages, focus groups are not always easy to conduct as they also present some limitations. Importantly, they are not suitable for making statistical generalizations since samples are usually both small and unrepresentative (Morgan \& Krueger, 1993; Casey \& Krueger, 1994). Also, they are timeconsuming in terms of identification and recruitment of participants (Morgan \& Krueger, 1993; Casey \& Krueger, 1994). Despite these limitations, results from the focus groups assisted in identifying the relevant attributes for the choice experiment and developing and refining the survey instrument for the quantitative study.

\subsubsection{Quantitative data collection}

Contrary to qualitative research, quantitative methods are designed to measure phenomena (Flick, 2009). Quantitative methods are theory-based and are concern about the causalities between two constructs or testing a conceptual/empirical hypothesis to examine the degree of association between measured indicators (Neuman, 2000; Flick, 2009). Quantitative methods use techniques that produce data in the form of numbers, which can be used to empirically describe abstract concepts (Neuman, 2000). The data are collected in a standardized and uniform format and analyzed using statistical tools. The strength of the quantitative method is that results can be generalized to the entire population (Neuman, 2000). Methods used to collect quantitative data include face-to-face interviews, mail, telephone, and internet surveys (Groves et al., 2009; Szolnoki \& Hoffmann, 2013). However, there are benefits and limitations 
associated with these survey methods, which vary across and within countries. Trading off the benefits and limitations of various survey methods, a face-to-face interview is chosen.

Face-to-face surveys involve an interaction between two persons in which one person (interviewer) meets with the other person (respondent) and conducts the interview (Loosveldt, 2008; Schröder, 2016). The interviewer asks questions using a questionnaire, and the respondent answers the questions. The questionnaire guides and standardizes the interaction between the interviewer and the respondent (Loosveldt, 2008; Schröder, 2016). Some of the common approaches used to conduct face-to-face interviews include paper-and-pencil interviewing (PAPI) and computer-assisted personal interviewing (CAPI) (De Leeuw, 2008; Schröder, 2016). The use of CAPI, in which survey questions are displayed on a computer screen, allows automatic filtering and leads to a substantial reduction in errors and improvement in data quality (De Leeuw, 2008).

Face-to-face surveys have many advantages. Specifically, they are the most flexible form of data collection methods and are suitable for longer interviews with more complex tasks (De Leeuw, 2008; Loosveldt, 2008; Szolnoki \& Hoffmann, 2013). They allow for the use of visual and auditory stimuli. Because they are characterized by personal interaction, the interviewer can give direct support to the respondent by explaining questions and tasks in more detail. In addition, the interviewer can probe for further information and encourage the respondent to answer every question (De Leeuw, 2008; Loosveldt, 2008). However, the presence of an interviewer does not only provide some additional advantages but also creates the risks of interviewer bias (Loosveldt, 2008; Schröder, 2016). A typical example of such bias is social desirability bias, which is the systematic over-reporting of socially approved behaviors and under-reporting of undesirable ones (Groves et al., 2009). In this case, respondents try to please the interviewer by providing answers that align with societal norms (Loosveldt, 2008). Other shortcomings include geographical restrictions, high cost per respondent, and time pressure on respondents (Alreck \& Settle, 2004; Holbrook, Green, \& Krosnick, 2003; Szolnoki \& Hoffmann, 2013). Nevertheless, in a developing country context like Ghana, face-to-face interviews provide a more practical way to collect quantitative data than mail, phone, or internet surveys, due to limited infrastructure (e.g., limited and unreliable internet and mail services).

\subsubsection{Discrete choice experiment}

In this thesis, a DCE (usually referred to as choice experiment) is used to elicit consumer preferences and estimate WTP values for the selected product attributes. DCE is one of the stated preference methods widely used for examining choice behavior. DCE is conceptually 
rooted in Lancaster's theory of consumer demand (Lancaster, 1966) and consistent with the random utility theory (McFadden, 1974). DCEs involve a stepwise process of identifying product attributes, specifying levels, generating experimental design, presenting choice alternatives to respondents, and estimating choice models (Hanley, Mourato, \& Wright, 2001; Hensher, Rose, \& Greene, 2005; Kløjgaard, Bech, \& Søgaard, 2012). Thus in DCEs, respondents are presented with a sequence of hypothetically constructed scenarios composed of two or more competing alternatives that vary in attributes. Respondents are then asked to make repeated choices between these alternatives. In doing so, respondents make trade-offs between the attributes (Hanley et al., 2001; Lusk \& Schroeder, 2004; Carson \& Louviere, 2011).

DCEs are widely applied in food preference studies to estimate the trade-off between different quality attributes (e.g., Lusk \& Schroeder, 2004; Loureiro \& Umberger, 2007; Pouta et al., 2010; Van Loo, Caputo, Nayga, Meullenet, \& Ricke, 2011; Ortega, Hong, Wang, \& Wu, 2016). The frequent use of DCEs could be explained by the fact that they are flexible since they can value multiple attributes simultaneously, unlike contingent valuation methods, and also the questions closely mirror real-life consumer purchasing decisions (Lusk \& Schroeder, 2004). However, DCEs are subject to hypothetical bias because respondents do not have to back up their stated choices with actual commitments (Lusk \& Schroeder, 2004). Besides, fatigue or learning may affect respondents' behavior as they are asked to respond to several repeated choice tasks (Bradley \& Daly, 1994; Day et al., 2012). To address these limitations, a "cheap talk script" is used to minimize the hypothetical bias. Also, the choice tasks are blocked into two versions to avoid respondent fatigue.

\subsection{Sampling and data}

The focus groups were conducted in Accra between August and September 2017. Participants were recruited from selected cold stores and a local market. Participants were contacted while buying chicken meat from these markets and were asked if they would be willing to participate in the discussion. In addition, few participants were recruited via snowballing, where existing participants gave referrals for other potential interviewees. Using these approaches for participants' recruitments ensured that a broader audience is reached. The telephone (mobile) numbers of those who indicated their willingness to participate in the discussions were taken and later contacted accordingly.

Inclusion in the discussions required consumption of chicken, aged 18 and above, and at least partially responsible for buying food in the household. The participants signed consent forms prior to the discussions. In total, 44 consumers participated in the discussions. Seven 
focus group discussions comprising six to eight participants per group were conducted. Before the start of each session, the moderator explained the purpose of the study, and afterward, participants introduced themselves to the group. Following the discussions, each participant completed a short demographic questionnaire, which included questions on education status, age, and household size. The discussions were conducted in a local language (Twi) and audiorecorded. In addition to the audio recordings, notes were taken. All discussions were subsequently transcribed and translated into English.

In the case of the face-to-face interviews, a cross-sectional survey was carried out between March and April 2018 in the two largest cities of Ghana, namely Accra and Kumasi. The study targeted a population of chicken consumers aged 18 and above and who are at least partly responsible for buying the food or taking decisions concerning food purchases in their homes. Given the urban nature of the chosen cities with complex household types and the absence of a list of all households, the two cities were divided into different administrative zones (sub-metro/district). In each city, five zones were randomly selected. The surveyed zones are Ga East, Adenta, Osu-Klottey, Ayawaso, and Okaikoi in Accra and Asokwa, Bantama, Oforikrom, Asawase, and Kwadaso in Kumasi. Within each zone, two communities were randomly selected from the lists of communities. Thus, data were collected in 20 communities consisting of 10 in each city. Finally, in those selected communities, a starting point was randomly selected, and respondents from every third household along the chosen route were interviewed using a random walk procedure.

Different days and times of the week for the visits were used to increase the chances of contact and to get a completed interview. Follow-ups were made as needed, such that some households were visited twice. In situations where a respondent was out of the scope of the target population (i.e., did not eat chicken), not available after two visits, or refused to participate in the survey, the next household was chosen. However, care was taken to avoid the easy replacement of respondents with the next household. Of the 563 respondents approached, 500 respondents (250 from each city) were successfully interviewed using CAPI. This represents a response rate of $88.8 \%$. The high response rate is due to revisits (follow-ups), varying times and days of visits, and appropriate fieldwork strategies adopted to persuade the target persons to participate in the survey. Prior to the data collection, informed consent was obtained.

In this thesis, a standardized questionnaire is used for the face-to-face interviews. The questionnaire was piloted with 15 randomly selected consumers and subsequently modified. The questionnaire consisted of six parts. It opened with screening questions - respondents who 
were not 18 years and above, did not eat chicken, and not responsible for food shopping or decisions on food purchasing are excused. The second part dealt with the simulated purchase scenario (discrete choice experiment). In the third part, questions regarding respondents' actual chicken purchase and consumption habits are captured. The fourth part consisted of questions with respect to attitudes and perceptions regarding food in general and chicken meat in particular. These attitudes and perceptions are covered by a series of statements measured with a five-point Likert scale. The fifth part concerned consumers' use and trust in various information sources. The questionnaire ended with the sociodemographic characteristics of the respondents.

\subsection{Data analysis}

\subsubsection{Qualitative content analysis}

A qualitative content analysis is used to analyze objective (1) of this thesis. Content analysis is a research technique used to systematically and objectively summarize large amounts of data (i.e., verbal, visual, or written) with the aim of analyzing complex situations by finding out patterns and trends of words used, their mode of occurrence, relationships, and the structures and discourses of communication (Downe-Wambolt, 1992; Gbrich, 2013). Data from the focus group study included written texts (i.e., field notes) and transcripts of the audio recordings. The transcription of the recordings followed repeated careful listening, as suggested by Bailey (2008), into written form. The transcripts and the field notes are combined and analyzed using content analysis. The content analysis of the focus groups consisted of several phases following steps outlined by Bengtsson (2016): decontextualization, recontextualization, categorization, and compilation.

The first step (decontextualization) involved familiarization with the data, by reading and rereading the data to get the sense of the entire data and noting down initials ideas. Each initial idea, which contains a list of issues to be analyzed, is coded in a process known as "open coding" (Berg, 2001). The final lists of codes emerged after thorough discussions about the exact content of the codes with colleague researchers. The next step (recontextualization) involved checking whether all aspects of the content have been covered based on the objective of the study by marking the original texts with colored markers alongside the lists of codes. Later, important texts that are unmarked are added and the rest discarded. In the third step (categorization), categories are created using the generated codes and questions used for the focus groups. In the process of categorization, themes and sub-themes are derived by looking 
for common associations, perceptions, opinions, and feelings across the focus groups. The last phase of the analysis (compilation) involved classifying and structuring the data per theme, summarizing themes and sub-themes, and relating findings to literature.

\subsubsection{Factor and cluster analyses}

Multivariate analysis methods are used together with other methods in analyzing objectives (2), (3), and (4) of this thesis. Multivariate analysis is a statistical method used to analyze multiple variables on individuals under inquiry simultaneously (Hair, Black, Babin, \& Anderson, 2010). In particular, they analyze relationships between or among more than two variables that are random and interrelated. Therefore, several multivariate analysis methods are considered as extensions of univariate and bivariate analyses (Hair et al., 2010).

Exploratory factor analysis and cluster analysis are examples of multivariate methods (Hair et al., 2010). Exploratory factor analysis examines interrelationships (correlations) among a large number of variables and identifies the structure underlying these variables. In doing so, it reduces a large number of variables into a smaller number of highly intercorrelated variables (factors) while minimizing the loss of information (Field, 2009; Hair et al., 2010). Since consumers' perceptions and attitudes, as well as their use of and trust in information, are captured using several variables, the method of principal component analysis (PCA) is used to extract the factors. The use of an exploratory factor analytic technique helps to avoid the problem of multicollinearity since variables that are correlated can be summarized by factors. The factors that emerged are used for subsequent analysis of objectives (2), (3), and (4).

Following the factor analysis on the information use and trust variables, cluster analysis is conducted using factor scores of individual respondents (objective 4). Cluster analysis is an analytical technique whose primary objective is to classify objects or individuals into a small number of mutually exclusive groups based on the characteristics they possess (Hair et al., 2010). In conducting the cluster analysis, a two-step clustering approach is employed. The first step identified how many groups exist using the hierarchical clustering method. The second step involved fine-tuning of the identified number of clusters using a non-hierarchical or partitional K-means clustering technique. The cluster profiles of the resulting segments are then determined using cross-tabulation with chi-square tests and one-way analysis of variance (ANOVA) with post-hoc Tukey comparison of mean scores. 


\subsubsection{Ordered probit model}

Following the microeconomic theory of consumer behavior, it is assumed that consumers are rational and make choices based on the derived utility. Therefore, the frequency at which an individual consumes chicken meat depends on his/her preference. The preference is also linked to the characteristics of the individual. Given this, both univariate and bivariate ordered probit models are used to analyze objective (2), which seeks to identify the factors influencing the frequency of (i) chicken consumption in general and (ii) imported and domestic chicken consumption, respectively.

The ordered probit model is used because the dependent variable (consumption frequency) takes on more than two outcomes, which are categorical and ordered rather than continuous or non-ordered categorical variables. In this context, using a multinomial logit model (MNL) would be inappropriate because it does not consider the ordered nature of the dependent variable, involves estimation of more parameters, and is associated with undesirable properties such as the independence of irrelevant alternatives (Ben-Akiva \& Lerman, 1985). Similarly, ordinary least squares regression estimation (OLS) is inappropriate as it assumes equal differences between categories of the dependent variable, which is not the case in ordered probit or logit where the dependent variable reflects a ranking (see Becker \& Kennedy, 1992; Daykin \& Moffatt, 2002). Therefore, using the MNL or OLS to analyze ordered dependent variables would lead to significantly different results than using the ordered probit or logit model (Becker \& Kennedy, 1992; Train, 2009). Likewise, the ordered nature of the dependent variable could be handled using a nested logit, mixed logit, or probit model that takes into consideration the pattern of similarity and dissimilarity among the alternatives. Nevertheless, while such a specification might give good results, in reality, it does not fit the structure of the data (Train, 2009).

\subsubsection{Multinomial logit, random parameter logit, and latent class logit models}

The multinomial logit (MNL), random parameter logit (RPL), and latent class (LC) models are used to analyze objective (3) by employing data from the choice experiment. These models are based the Lancaster and the random utility framework. The MNL, however, assumes homogenous taste for the observed attributes and is associated with restrictive assumptions such as independence of irrelevant alternatives (IIA) property and the assumption of independent errors over time (Hensher et al., 2005; Train, 2009). Nonetheless, empirical evidence from consumer studies shows that consumers have heterogeneous preferences, and therefore 
employing a model that allows for variation in taste is appropriate (Lusk, Roosen, \& Fox, 2003; Alfnes \& Rickertsen, 2003; Alfnes, 2004; Tonsor, Schroeder, Fox, \& Biere, 2005). Accounting for heterogeneity provides an unbiased estimation of individual preferences and improve the accuracy and reliability of demand estimations (Greene, 2008). Therefore, in this thesis, the RPL (also referred to as mixed logit model) and the LC logit models are introduced to investigate such heterogeneity in consumer preferences for the attributes of chicken meat.

The RPL model allows for taste heterogeneity, unrestrictive substitution patterns, and correlation in unobserved factors over time (Revelt \& Train, 1998; Train, 2009). However, the RPL model assumes continuous heterogeneity and it is not able to explain the sources of heterogeneity, as in most cases, these sources are attributed to the characteristics of individual consumers (Boxall \& Adamowicz, 2002). In contrast, the LC model assumes preference heterogeneity to occur discretely (Train, 2009) and accounts for the sources of heterogeneity. The LC model approach captures heterogeneity by simultaneously grouping consumers into relative homogenous classes and explaining the choice behavior of class members (Swait, 1994). In each latent class, preferences are assumed to be homogenous, but preferences can vary between classes. In determining the "optimal" number of classes, statistical criteria including the minimum Akaike Information Criterion (AIC) and the minimum Bayesian Information Criterion (BIC) are used (Boxall \& Adamowicz, 2002). In addition to the choice attribute data, individual sociodemographic characteristics and attitudes (using factor scores from the exploratory factor analysis of consumers' attitudes) are included in the LC model to explain the sources of heterogeneity. 


\title{
4 "Everybody likes chicken" - A focus group study of consumers in Ghana $^{2}$
}

\begin{abstract}
In sub-Saharan Africa, chicken meat is one of the important sources of protein and has great potential to enhance food security. The poultry sector, however, is challenged by rising imports, changing consumers' preferences, and increasing costs of production. Preference for domestic chicken will depend largely on product characteristics and purchase motives, but also on how consumers perceive and judge domestic chicken in comparison to imported chicken. This study provides insight into how consumers in Ghana perceive chicken meat and whether these perceptions differ between domestic and imported chicken as well as the drivers of purchase. We conducted seven focus group discussions involving a total of 44 participants. Among the purchasing criteria, price is the most important factor in consumers' decision-making process. Other factors include health/safety, convenience, taste, and freshness. Generally, consumers have strong beliefs toward domestic chicken as they perceive it to be fresher, tastier, healthier, and thus, better quality than imported chicken meat. Concerns about the use of growth hormones and antibiotics resulted in the low-quality perceptions of imported chicken meat. Nonetheless, imported chicken is seen as cheaper, convenient, and readily available. The results suggest that the higher price and inconvenience associated with domestic chicken may limit its future growth. Therefore, domestic producers must tailor their products to the characteristics that are important to consumers and build a marketing strategy that stresses more on good taste, freshness, and quality. Additionally, any policy aimed at the poultry industry should consider consumer concerns toward the safety, quality, and convenience of chicken.
\end{abstract}

Keywords: chicken meat, focus groups, Ghana, imported vs. domestic, perceptions and attitudes

\footnotetext{
${ }^{2}$ This chapter is accepted for publication in the proceedings Schriften der Gesellschaft für Wirtschafts- und Sozialwissenschaften des Landbaus e.V. It is co-authored with Daniela Weible (DW).

Authors' contributions: All authors jointly designed the research. I, Collins Asante-Addo (CAA), conducted the focus groups, transcribed, analyzed, and wrote the paper. DW commented at the various stages of the research and contributed to writing and revising the paper.
} 


\subsection{Introduction}

Although Ghanaian poultry production has grown continuously since the middle of the 1980s (except from a drop in 2009), Ghana is dependent on imported meat in recent years due to a rise in poultry meat imports since the beginning of the 2000s. The supply balance for Ghana illustrated in Figure 4.1 shows that the rise in poultry meat imports is much stronger than the rise in domestic production. On a 15 year-average (2000-15), imports increased by $14.3 \%$ (constant growth rates calculated), whereas domestic production rose by $7.1 \%$ in the same time. Thus, the self-sufficiency rate was on average at 35\%. Exports were marginal in the time period considered.

The failure to achieve self-sufficiency in poultry meat production is due to high costs of production (resulting from high feed, drugs and energy prices), inefficient production methods, lack of reliable access to inputs, limited knowledge of modern poultry management, and lack of processing facilities (see, for example, ANING ET AL., 2008; KILLEBREW and PLOTNICK, 2010; USDA, 2013). Imports are mainly from the United States, Brazil, and European Union (EU) countries. These countries are often criticized for exporting low-priced chicken cuts, which are not demanded by consumers in those countries. In this context, for example, the EU's agricultural and trade policies are seen as detrimental to production and markets in sub-Saharan African countries (RUDLOFF and SCHMIEG, 2016).

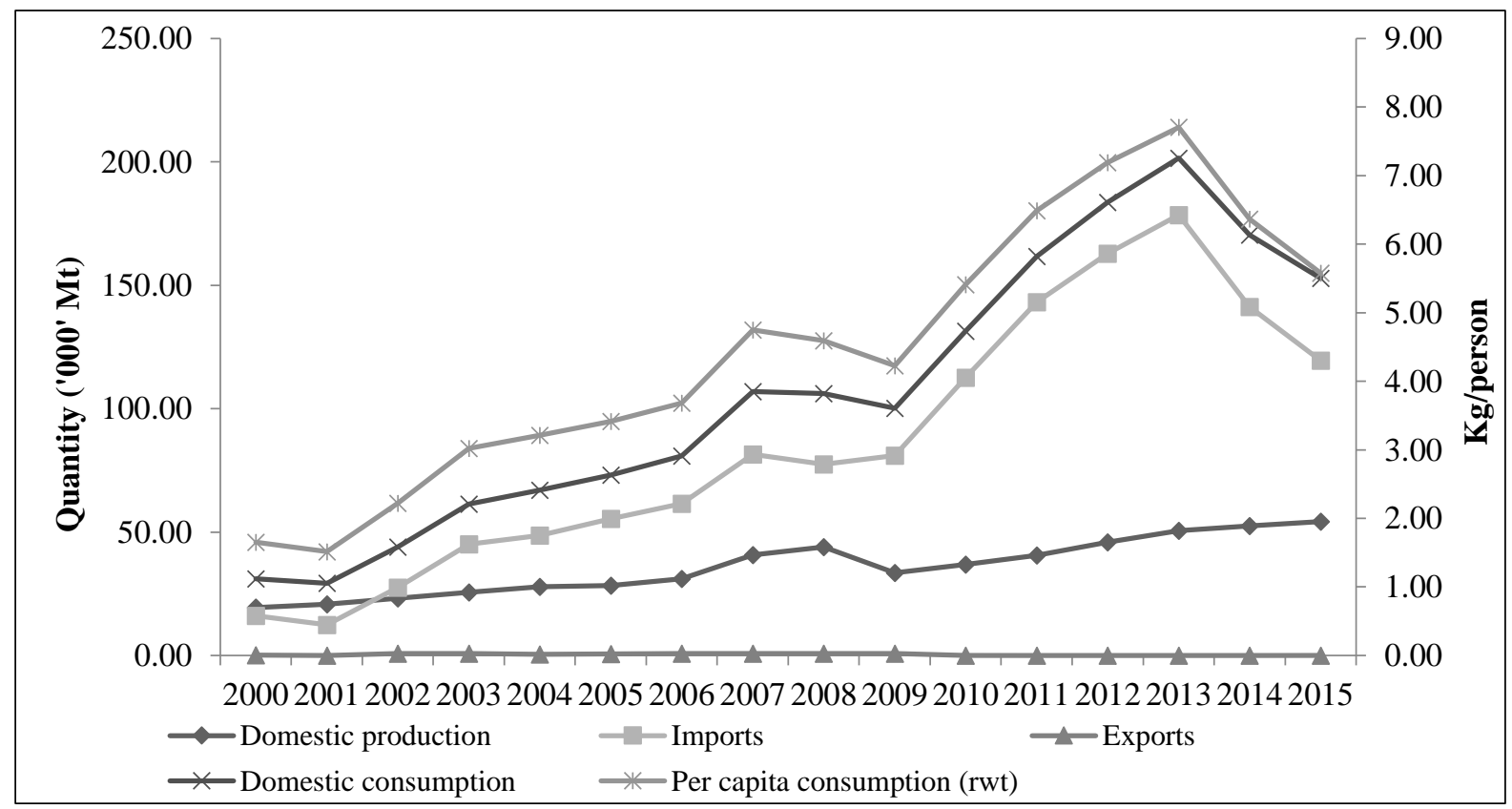

Figure 4.1: Poultry trade, production, and consumption in Ghana

Note: Per capita consumption expressed in retail weight (Carcass weight to retail weight conversion factor for poultry meat is 0.88 ).

Source: OECD-FAO (2017). 
On the demand side, the literature shows that imported products differ greatly in their properties and the type of distribution from domestic ones (KWADZO ET AL., 2013; WOOLVERTON and FRIMPONG, 2013). For example, domestic chicken is mostly available as live bird whereas the imported meat is sold as pre-cuts (gizzards, leg quarters, necks, and wings) or frozen whole-dressed. Against that heterogeneity, it is assumed that there are factors other than the price, which are essential for consumers at the point of sale. Previous studies on consumer preferences for chicken meat (e.g., EGYIR ET AL., 2012; KWADZO ET AL., 2013; WoOLVERTON and FRIMPONG, 2013) mainly used quantitative approaches and could not identify a clear and comprehensive picture of all the factors such as perceptions, beliefs, motives, and attitudes that consumers have about chicken meat, which at least determine their preferences.

Therefore, the objective of this study is to gain insight into how consumers in Ghana perceive chicken meat and whether these perceptions differ between domestic and imported chicken. In addition, the drivers of purchase, individual motivations, and how consumers search for information regarding chicken meat are explored using focus groups. Results of the study can help domestic producers to tailor their products to the characteristics that are important to consumers and build their marketing strategy on those characteristics. The paper is organized as follows: Section 4.2 explains the method and data, results are presented in Section 4.3 and discussed in Section 4.4. Finally, Section 4.5 provides the conclusion.

\subsection{Methods and data}

KRUEGER and CASEY (2009) define a focus group as a "carefully planned series of discussions to obtain perceptions on a defined area of interest in a permissive, non-threatening environment" (p. 2) The main aim of focus groups is to explore what people say and to get understandings into the sources of complex behaviors and motivations (MORGAN and KRUEGER, 1993). The use of focus groups offers several advantages. First, focus group method is an economical, fast, and efficient way of obtaining data from several participants (KRUEGER and CASEY, 2000). Second, the interactions that occur in focus groups enable participants to query and explain themselves to each other. This provides important data on the level of agreement and disagreement among the participants (MORGAN and KRUEGER, 1993). Finally, it enables researchers to explore differences among participants by asking them to compare their experiences and opinions (MORGAN, 1996). When used with other surveys, results from focus groups can serve as an input to the development of standardized questionnaires or even verify results gained from quantitative surveys (MORGAN, 1996). This focus group study is the first step within a research process, i.e., the results will also be used for developing a 
standardized questionnaire and, therefore, ensuring that all relevant aspects in the context of consumers' preferences, perceptions, and attitudes toward chicken meat are covered.

The focus groups were conducted between August and September 2017 in Accra (capital of Ghana). The recruitment of participants, the organization, and moderation of the focus groups were under the responsibility of the researchers. Participants were recruited at selected cold stores and a local market. Participants were contacted personally while buying chicken from these market places. Due to the difficulty faced in getting all the participants from these markets, few participants were recruited through snowballing. In this case, participants, who have been already contacted, were asked whether they know others who meet the set requirements for participation. The eligibility criteria for participation included consumption of chicken (both local and imported), aged 18 years and above, at least partly responsible for buying food in the household or having an influence on household's food shopping.

Table 4.1: Socio-demographic characteristics of focus group participants

\begin{tabular}{|c|c|c|}
\hline Characteristics & Frequency & Percent \\
\hline \multicolumn{3}{|l|}{ Gender } \\
\hline Female & 25 & 56.8 \\
\hline Male & 19 & 43.2 \\
\hline \multicolumn{3}{|l|}{ Age } \\
\hline $18-29$ years & 8 & 18.2 \\
\hline $30-39$ years & 17 & 38.6 \\
\hline $40-49$ years & 12 & 27.3 \\
\hline $50-59$ years & 4 & 9.1 \\
\hline 60 years and above & 3 & 6.8 \\
\hline \multicolumn{3}{|l|}{ Education } \\
\hline No education & 1 & 2.3 \\
\hline Basic education & 11 & 25.0 \\
\hline Secondary education & 14 & 31.8 \\
\hline Post-secondary education & 5 & 11.4 \\
\hline Bachelor's degree & 10 & 22.7 \\
\hline Master's or higher degree & 3 & 6.8 \\
\hline \multicolumn{3}{|l|}{ Household size } \\
\hline 1 & 4 & 9.1 \\
\hline 2 & 7 & 15.9 \\
\hline 3 & 7 & 15.9 \\
\hline 4 & 13 & 29.5 \\
\hline 5 & 9 & 20.5 \\
\hline 6 & 4 & 9.1 \\
\hline
\end{tabular}

Source: Own compilation.

In general, the focus groups consisted of seven mixed groups with between six to eight participants in each group. Overall, 44 participants were involved in the discussions. The participants were mostly females (56.8\%) and varied in age (ranging from 25 to 65 years), education, and household size, as indicated in Table 4.1. The focus groups were conducted on various days of the week and at various times throughout the day to ensure that a broad range of participants (e.g., working and non-working) is represented. To get participants' true 
perceptions, no information about the discussion topic was given in advance. Thus, participants could not inform themselves about the topic, and questions that came up during the discussions were answered afterward.

All discussions followed an interview guideline starting with questioning about the preferred types of meat in general, the frequency of consumption, and about the decision criteria for purchasing. Afterward, participants were asked to compare chicken meat with other meat types as well as to compare domestic with imported chicken meat in terms of quality, availability, pricing, the place of purchase, and the production process. Finally, participants were asked to indicate the channel of information they use when buying chicken meat and what they wish the government would do with respect to local and imported chicken meat. The discussions were held in a local language (Twi), lasted between 40-90 minutes, and were audiorecorded. After discussions, we provided an incentive to participants for their time. Based on verbatim transcripts, qualitative content analysis was used following open coding and categorization system (based on BERG, 2001; BENGTSSON, 2016).

\subsection{Results}

Although most of the participants stated that they consume various types of meat including chicken, goat meat, lamb/mutton, beef, pork, and fish, the majority of the participants expressed to consume fish and chicken the most. "Because chicken is cheap, I can say that if I consume meat ten times, about six times would be chicken", a female participant said. The daily or frequent consumption is normally from the imported chicken while the domestic chicken is less often consumed, as most participants associated it with weekends, holidays, and special occasions: "We have been eating imported chicken throughout the past week...on special occasions such as Christmas, we normally buy live chicken" (a male participant). When asked about the place of purchase, participants stated to buy on a regular basis from cold stores (only imported), traditional markets, and supermarkets and sometimes or during special occasions directly from farmers.

\subsubsection{Attitudes and perceptions of domestic and imported chicken}

Price is one of the most important themes that emerged from the discussion. Majority of the participants seem to be price-conscious as price tends to be one of the decision factors they use to make a purchasing decision: "You will always compare the prices in the market and see which one will be better for you based on your budget." In comparison with other meat types 
such as red meats, most of the participants were of the view that chicken is cheaper. Thus, chicken is seen to give good value for money compared with other meats. However, price was a typical domain in which participants used to distinguish domestic and imported chicken. Overall, most of the participants perceived domestic chicken as more expensive than imported chicken. Typical comments were: "Imported chicken is always available and very cheap such that with a little budget you can get enough for the entire family" (a male participant), and "You can get a full dressed imported chicken for about $\mathrm{GH} \phi 18$ to $\mathrm{GH} \phi 24$, while you would need about GHф30 to GHф50 to buy a local chicken" (a female participant). The higher price of the local chicken makes it difficult for them to purchase it on a regular basis, even though the majority expressed their wish for regular consumption. One female participant explained this by: "I would like to eat the local chicken often, but it is too expensive, so I cannot afford to buy it regularly. I only buy it when there is an occasion such as Christmas and Easter." Some participants also perceived the higher price to connote some level of quality: "A good quality chicken is also expensive or has a higher price, especially the local ones."

Furthermore, the issue of health was highlighted and repeated throughout the discussions. In general, the majority of the participants perceived chicken as healthy, regardless of its origin (i.e., domestic or imported). The healthiness of chicken is one of the major reasons why most Ghanaians buy it. A female participant captures this in an expression: "I always hear the phrase 'everybody likes chicken' from people." The discussions in relation to health generally focused on the leanness or low-fat content of chicken, which is good for their health. This makes chicken meat attractive to participants who were very conscious of their health. Some participants further indicated that fat could be removed from chicken before cooking, which is not possible or difficult with other meat types: "It is easier to peel off the skin and it is the skin that has the fat...so, when you peel off the skin, it becomes less fatty."

Despite the general perception of chicken as being healthier meat, most of the participants perceived imported chicken as less healthy than domestic chicken: "We believe that imported chicken is not healthy, but that is what we eat most because it is cheap." When asked why they believed that imported chicken is not healthy, participants indicated that they perceive imported chicken to be injected with growth hormones, certain chemicals such as antibiotics or contain certain additives, which they believe might not be good for their health: "We think the imported ones are injected with more chemicals and growth hormones that make them mature within a very short time." Some were also of the view that the lack of knowledge about the way imported chicken is produced and handled informs the perception of its unhealthiness. A typical comment was: "We do not get to see how the imported chicken is produced, but we know that 
they are very big in size and we believe they are given some drugs to make them grow big and this is very disturbing." Notwithstanding, the perceived health risks associated with imported chicken did not seem to prevent consumers from consuming imported chicken meat. Many of these perceptions are mainly based on hearsay and mass media reports or the internet through social media: "We thought chicken is the best meat for us, but of late, we see some documentaries on social media, in which injections are given to chicken, so it gives it a bad image."

The ease of preparation was mentioned by participants as another aspect when asked about the main differences between local and imported chicken meat. Almost all participants indicated that the imported chicken is very convenient and faster to prepare compared with the local chicken. The domestic chicken is mainly purchased live on the market, while the imported ones are available as frozen whole dressed and parts such as wings, leg quarters/thighs, gizzards, and backs. This is captured in the statement: "Imported chicken saves time; you do not need to buy and then take it home to kill, dip it in hot water before plucking the feathers, and then cut into pieces for stew or soup...so for convenience it is better." Furthermore, most of the participants perceived many relative advantages with respect to the variety that imported chicken brings, especially the availability of parts. Participants appreciated having the opportunity to choose among different types of imported chicken cuts. This gives participants the option to buy only a portion of chicken instead of the whole chicken and thus aiding in avoiding waste. Likewise, some participants believed that the portion size makes it possible to adopt "western-style" foods as opposed to the "traditional" food associated with the local chicken.

While most of the participants emphasized the convenience associated with imported chicken, others also indicated that live chicken can be slaughtered and processed on demand for a fee in local markets and that one must not necessarily take it home to slaughter. Thus, buying domestic chicken meat is becoming more convenient. However, most of the participants still believed that it is time-consuming, as indicated by a male participant: "You have to wait in the market for the seller to dress the chicken for you and you will normally spend about 30 minutes waiting." Another advantage that comes with the convenience of the imported chicken in terms of its availability in parts is the "free gift" consumers get from purchases. Some participants indicated that when buying imported chicken (i.e., parts), it is possible to bargain with the seller to add extra portion as a gift.

In regard to convenience, the availability of chicken meat at markets and shops was also an aspect that emerged during the discussions. Compared with the imported chicken, which is 
available at different shopping locations (i.e., traditional markets, cold stores, and supermarkets), some participants criticized that the local chicken is mainly available at the traditional markets. Here, participants would wish to have a more adequate distribution and supply at conveniently located places: "The local chicken is only in the traditional markets and poultry farms unlike the imported, which is readily available and can be found in almost every area ...you can get it anytime."

In terms of quality, most of the discussions mainly focused on the quality attributes of the local and imported chicken. Majority of the participants perceived the local chicken to be tastier than the imported: "When you compare with imported chicken, the local chicken is tastier." In most of the discussions, taste was often associated with freshness. Participants who believed the imported chicken is not tasty compared with domestic chicken attributed it to long freezing time. A typical statement given was: "As for the imported chicken, I do not really like because it has kept long in the fridge, thus making it not fresh. When used to cook, it is tasteless." However, not all participants agreed that all imported chicken is tasteless. Few of them believed that some of the imported chicken have better taste, exemplified by "I also think some of the imported ones are tastier." In addition, a clean and trustful environment, in which the chicken is sold, was particularly important to assess the quality of chicken. For example, two female participants stated: "Personally, I use the place of purchase and the surrounding environment to indicate the quality of the chicken," and "I like to go to the supermarket to buy chicken because I believe it is very good and the environment where it is being sold is clean and hygienic." Participants indicated that they rely on the color and physical form of chicken as primary criteria to infer quality at the point of purchase. Related to dressed or processed chicken, a discoloration would be an indicator of poor quality. For live chicken, characteristics such as weight and general physical wellbeing (e.g., wet droppings, loss of feathers, sleepiness, and weakness) are used to access quality.

With regard to local chicken, participants described the risk associated with the outbreaks of avian influenza by using words like "fear and panic," and "afraid and scared." Majority of the participants indicated that they stay away from purchasing or consuming local chicken for some weeks and divert to other meat types until they hear from the media or government sources that the problem had died down or been curtailed. Although this problem is only related to the domestic chicken, some of them also indicated not consuming imported chicken during these periods: "Normally it is announced on radio or television and when we hear that we stop consuming chicken altogether for a while." However, few participants who found it difficult to stop consuming chicken in these periods indicated strategies they have 
developed to mitigate the risk including cooking chicken for long hours. Participants offered some suggestions to the government that will help in minimizing the risk associated with chicken. These suggestions were that the "government should monitor the domestic poultry production processes (i.e., feeding, housing, etc.)," and the "government should equip the agencies responsible for checking the quality of chicken produced in the various poultry farms."

Origin also emerges as a theme due to the association of chicken to certain countries. Regarding the origin of imported chicken, some participants had a general knowledge of the countries they come from while others did not: "We know that there are some from U.S.A and Brazil, but the chicken we buy has no package or label on them to know exactly where they are originating from unless you buy the whole box, which has the branded names." Aside from the local chicken that is perceived to be of better quality, some participants in selecting the different types of imported chicken products use Brazilian chicken meat as criteria for good quality. For example, one female participant remarked: “... the hard one is from Brazil, so if I go to the cold store, I tell the seller I want Brazil and it will be given to me." This finding is consistent with a report by USDA (2017), which indicated that consumers in Ghana perceive the Brazilian chicken to be of better quality than those offered by the U.S. In addition, participants indicated that the production system is important since it will eventually lead to differences in meat quality. However, it became evident that majority, if not, all participants did not have deeper knowledge about the commercial production of domestic chicken and even nothing, if anything, about chicken production in other countries. Participants were therefore interested in more details about chicken production, for example, the type of feed, the usage of chemicals such as antibiotics and growth hormones. Despite the limited knowledge of the production systems, some participants trusted in the local production system and its ability to produce chicken that is safe as exemplified in the following remark: "We believe the local chicken is given better feed, but we do not know the kind of feed given to the imported chicken."

\subsubsection{Possible governmental actions}

When asked about what they wish the government should do, participants across all the groups expressed views about supporting local farmers. Thus, on the one hand, participants were of the view that the government's efforts should focus on reducing the cost of production and hence prices to make domestic poultry more competitive. Possible interventions to support poultry producers could be providing subsidies on inputs, credit, tackling the problem of feed availability, and setting up processing plants. Others also wanted the government to set up poultry farms in various districts across the country to increase production. Suggestions from 
participants are captured in the following statements: "Government should make the domestic poultry more attractive by subsidizing inputs ...this will result in lower prices for the domestic chicken and also help in creating employment," and "We have interests in the local chicken but it is expensive and usually not processed...so the government should help by investing in processing equipment at various local markets." Participants did not leave out farmers as they offered advice and suggestions such as adopting good production practices and producing goods that will match consumer demands. Some of the comments were: "We would encourage poultry farmers to expand and give good quality feed to the chicken to make them healthy for consumption," and "One thing most of the poultry farmers lack is processing...so they should consider integrating processing into their farm business."

On the other hand, some participants, particularly males, proposed that the government should implement protectionist measures and thus, ban imported chicken, as exemplified in the statements: "In order to boost the income of local farmers, the government should consider banning imported chicken because these farmers cannot compete with the imported ones," and "the government must do something to prevent importation or minimize it and help Ghanaians to patronize the locally produced chicken meat." In this regard, some participants showed patriotic emotions toward local products in general and local chicken as captured in the statement: "We would advise the government to promote made in Ghana products so that we eat what is produced in Ghana". Others believed that buying local chicken would help the economy: "We need to make sure that the money we use to import chicken stays here." Finally, some participants also disagreed with the notion of banning or restricting imports. In their view, banning imports may not be the best solution since the use of controls on imports would lead to low supply and consequently raise the retail price. Instead, they wanted the government to focus more on boosting domestic production as expressed in the statement: "If the government bans the imported ones and the local ones are not enough to supply the whole country, then it is not good...therefore, the government should help increase domestic production to make sure there are enough supplies, and this can also help to reduce imports."

\subsubsection{Information source}

Participants used a range of sources of information about chicken, including sellers/vendors, family and friends, radio, television, internet sources such as social media, and government sources. The discussions revealed that personal sources (i.e., family and friends, sellers/vendors) are an important means of obtaining external information. On the contrary, few participants indicated that they do not seek information from any source since, in their opinion, 
the purchase of chicken is a routine activity. Therefore, information search among these participants is characterized only by internal search. Information from family or friends is conveyed through word-of-mouth (WOM) or shared via social media platforms. Information from the media such as radio and television are mostly conveyed through various health talk programs.

In general, there was a feeling among participants that radio or television advertisements about chicken are not common - except during special occasions such as Christmas and Easter. Participants exemplified this in a statement: "Because most people like and know about chicken, it is not something that is advertised on television or radio." Particularly with the advent of avian influenza outbreaks, media sources serve a very important purpose: "We usually hear of bird flu outbreaks from the radio or television." In the period of outbreaks, information seeking by participants from these sources serve as a risk mitigating strategy. Participants usually seek information on prices, quality, health and safety issues, nutrition, and place of purchase. For instance, participants stated: “We ask sellers about prices... information on prices help to decide what your budget can afford." In terms of trust in information, some participants identified family and friends as providing the most reputable and trustworthy information, while others believed that firsthand information from sellers is more trustworthy. Also, some participants indicated their trust in information from radio or television sources.

\subsection{Discussion}

Consumers generally have strong beliefs toward Ghanaian produced chicken as they perceive it as fresher, tastier, healthier, and thus, of better quality compared with imported chicken meat. Imported meat is seen as less healthy due to the prevailing perception that a lot of antibiotics and growth hormones are used within the production process. This is the main concern of consumers regarding imported chicken meat leading to a low-quality perception. Another topic often mentioned in this context is the obvious price gap between domestic and imported meat. For those consumers who use the price as a cue for quality (in terms of that low prices mean low quality), this also consolidates the view of Ghanaian chicken to be of better quality compared with the imported. However, as there are many consumers who usually prefer low prices and, for them, the price is a major factor for their purchase decisions, low prices are a sign of good value (value for money). A high price will only guide the decision making of quality-driven consumers. However, consumers with low purchasing power benefit from lower prices due to the import of meat, suggesting an improvement in welfare and food security. Besides the low price, there are other reasons why imported chicken meat is preferred, which 
is its better availability and higher convenience. The freshness of the meat is also a major factor in distinguishing domestic from imported chicken meat. Consumers believe that the superiority of the Ghanaian chicken over the imported in terms of taste is a result of the latter's long storage (freezing) time, implying that the decreasing taste is related to increasing freezing time. Similar finding on the superiority of local poultry meat over imported in terms of taste has been observed. MAKANYEZA and DU TOIT (2016) found that consumers in Zimbabwe perceive local poultry meat to be of better taste than imported.

One of the major problems in the development of the poultry industry in Ghana is the lack of infrastructure for slaughtering and processing chicken into convenient forms such as cut portions or parts (USDA, 2017). Currently, only a few processing plants exist in the country. According to ANDAM ET AL. (2017), there is one major processing plant in Accra and three in Kumasi. As a result, much of the slaughtering occurs at home or in live bird markets as previously indicated. In view of this, our findings revealed that the frequency of consumption is linked to the convenience of the chicken meat. Imported chicken meat which can be sold as parts is particularly seen as 'daily meat' whereas domestic chicken, which is sold as live bird is mostly consumed occasionally (weekends, special events, and festive seasons). This is in accordance with JUST and GABRIELYAN (2016), who showed that the more convenient food is, the more likely its consumption. This explains why the imported chicken meat, which is seen to be more convenient, is more often consumed than the domestic chicken. Consequently, processing of chicken would be relevant for consumers who attach importance to convenience and hence, time-saving and ease of preparation.

Results show that consumers generally differ in their opinion about the use of protectionist measures in poultry trade. While some believed that banning or restricting imports is a better way to protect local poultry industries, others believed that imports are needed, especially when local supplies cannot meet the growing demand. In addition, the lower price of imports ensured that low-income households are able to buy. This suggests that people have a differentiated picture of the impact of chicken meat imports. Any policies aiming at restricting imports or otherwise, may thus not appeal to all consumers.

Moreover, the results also reveal a general distrust of the way chicken is produced and the government's regulatory, monitoring, and quality control systems in the poultry sector. This is highlighted by consumers' appeal for the provision of quality feed, better monitoring, and effective quality control systems. Consumers' lack of trust stems from the perception of antibiotic/hormone use as well as the frequent outbreaks of bird flu diseases. This finding largely demonstrates that consumers' knowledge of (commercial) chicken production systems 
is limited. Nonetheless, the expressed concerns of consumers regarding food safety and production issues do not mean that these have been necessarily reflected in consumers' behavior accordingly. However, as consumers become increasingly aware of these issues, it could lead to a possible change in behavior, especially for safety and animal welfare-oriented consumers.

Interestingly, the tendency to seek information from sellers was high among consumers. This is an indication of trust in sellers as a source of information. Information from government sources and the traditional media (i.e., radio and television) tends to be of importance when it is about food safety such as in times of bird flu outbreaks. Further, the use of the internet, especially social media (i.e., Facebook, Youtube, etc.) and Whatsapp platforms for sharing information is revealed. This might suggest that as mobile phones become increasingly available for consumers (see, e.g., PORTER ET AL., 2015), social media will become an increasingly important source of information.

Finally, the strong preference for chicken shows that a range of market opportunities exists for the poultry meat sector in Ghana, starting from product differentiation based on these attributes. Lack of adequate consumer-oriented information may partly account for the negative perceptions and mistrust of the production systems. In this context, provision of proper and objectively verifiable information about the system of production and quality assurance systems through trusted sources is very crucial to assisting informed purchase decisions by consumers and gaining a commercial advantage over competitors. In addition, it requires that monitoring and regulatory systems that are in place are effective and trustworthy.

Before drawing any conclusions, the findings of this study should be interpreted, considering its limitations. First, the recruitment of participants was limited to people who resided in Accra. Thus, these findings have limitations for transferability to consumers who live in other, especially rural areas of Ghana. Second, the use of focus groups is a qualitative means of exploring and understanding different attitudes, beliefs, perceptions, behaviors, and habits that exist among Ghanaian consumers. On the basis of these results, no quantification nor generalization are possible. However, the results of the focus group study could serve as a good basis for developing a quantitative study as well as aid in the interpretation of results arising out of a quantitative approach.

\subsection{Conclusion}

This study provides insight into how consumers in a developing country like Ghana perceive chicken meat, whether these perceptions differ between chicken produced in own country and those imported, and the factors that influence consumers purchasing decisions. This is relevant 
in the context of increasing imports of chicken meat and the current debate about the impact of chicken imports on developing countries poultry industries.

Overall, the results of the focus group study showed that participants perceived chicken be healthful, cheaper, tastier, versatile, and easier to prepare than other meat types. Consequently, these factors were very instrumental in participants' actual and future chicken purchases. In comparison with imported chicken, there is a strong preference for domestic chicken because it is fresher, tastier, healthier, and of good quality. Notwithstanding, the focus groups acknowledged key barriers to purchasing domestic chicken including price, convenience, and availability. As a result, domestic chicken, which is distributed mainly through local markets as live is consumed mostly on special occasions, and not as part of everyday meals. In contrast, imported chicken is viewed as cheaper, convenient, easily available, and providing many choices in terms of portion sizes, making it possible to avoid waste. These factors make it easier for the imported chicken to be used as part of everyday meals, hence contributing to its frequent purchases. Although the frequency of purchasing domestic chicken is low, all groups indicated at least some willingness to buy often if some of these barriers are removed.

The focus groups also evoked several spontaneous responses in terms of risk and safety concerns. Specifically, concerns about the use of growth hormones and chemicals such as antibiotics generated negative images for imported chicken. With respect to domestic chicken, the major concern was the outbreak of avian influenza. Within the period of outbreaks, there was no or reduced consumption of domestic chicken and sometimes the imported for a few weeks until situations returned to normal. Finally, the discussions revealed that consumers wish the government would support the local poultry industry, especially the processing of chicken meat. In doing so, domestic chicken meat will get more popular and replace imports.

Our findings may have some important implications for policymakers and the poultry industry. First, any policy aimed at the poultry industry should take into account all aspects of consumer needs and concerns toward the safety, quality, and convenience of chicken. Second, participants who preferred imported chicken did so mainly because it is cheaper, convenient, and available in cut-up parts. Consequently, promoting these attributes may compensate for the ethnocentric preferences of the population in Ghana and lead to improving its market share. However, deficits with regard to perceived product quality and the (over)use of antibiotics and growth hormones still exist. Finally, the higher price of domestic chicken and the inconvenience associated with it may limit the future growth of the domestic chicken market. Therefore, domestic producers must be able to link their products to characteristics that are important to 
the consumer; otherwise, they will not be competitive. A successful marketing strategy should stress more on better taste, freshness, and quality to help increase demand as well as competitiveness. 


\section{References}

Andam, K. S., Johnson, M. E., Ragasa, C., KufOalor, D. S., and Das GuPTA, S. (2017): A chicken and maize situation: The poultry feed sector in Ghana. IFPRI Discussion Paper 1601. International Food Policy Research Institute, Washington DC.

ANING, K. G., TURKSON, P. K., and ASUMING-BREMPONG S. (2008): Pro-poor HPAI risk reduction strategies in Ghana-Background paper. Africa/Indonesia Region Report 2. International Food Policy Research Institute (IFPRI), Washington DC.

BERG, B. L. (2001): Qualitative research methods for the social sciences. Boston: Allyn and Bacon.

Bengtsson, M. (2016): How to plan and perform a qualitative study using content analysis. NursingPlus Open, 2, 8-14.

EGYIR, I. S., ADU-NYAKO, K., and OKAFOR, R. (2012): The "made in USA poultry label" and consumer choice in Ghana. Paper Presented at the Southern Agricultural Economics Association, Annual Meeting, Birmingham, Alabama, February 4-7.

JUST, D. R., and GABRIELYAN, G. (2016): Food and consumer behavior: why the details matter. Agricultural Economics, 47(S1), 73-83.

Killebrew, K., and Plotnick, R. (2010): Poultry market in West Africa: Ghana. EPAR Brief No. 83. Seattle, WA: Evans School Policy Analysis and Research, University of Washington.

Krueger, R. A., and CASEY, M. A. (2000): Focus groups: A practical guide for applied researchers (3rd ed.). Thousand Oaks, CA: Sage Publications.

KRUEGER, R. A., and CASEY, M. A. (2009): Focus groups: A practical guide for applied research (4th ed.). Thousand Oaks, CA: Sage Publications.

Kwadzo, G. T.-M., Dadzie, F., Osei-Asare, Y. B., and Kuwornu, J. K. M. (2013): Consumer preference for broiler meat in Ghana: A conjoint analysis approach. International Journal of Marketing Studies, 5(2), 66-73.

MAKANYEZA, C., and DU TOIT, F. (2016): Factors influencing consumers' choice of imported poultry meat products in a developing market: Lessons from Zimbabwe. Agrekon, 55(3), 191-215.

Morgan, D. L. (1996): Focus groups. Annual Review of Sociology, 22, 129-152.

Morgan, D. L., and KRUEGER, R. A. (1993): When to use focus groups and why. In D. L. Morgan (Ed.), Successful focus groups: Advancing the state of the art (pp. 3-19). Thousand Oaks, CA: Sage Publications.

OECD-FAO (2017): Agricultural Outlook 2017-2026. OECD Publishing, Paris. Available at: http://dx.doi.org/10.1787/agr_outlook-2017-en.

Porter, G., HAMPShire, K., Milner, J., Munthali, A., Robson, E., LANnoy, A., ... and Abane, A. (2016): Mobile phones and education in sub-Saharan Africa: From youth practice to public policy. Journal of International Development, 28(1), 22-39.

RUDLOFF, B., and SCHMIEG, E. (2016): More bones to pick with the EU? Controversial poultry exports to Africa: sustainable trade policy as a task for the G20. SWP Comments 57. German Institute for International and Security Affairs, Berlin.

USDA (United States DePartment OF AGRICUlture) (2013): Ghana poultry report annual. Accra, Ghana: (United States Department of Agriculture).

USDA (United StATES DEPARTMENT OF AgRiculture) (2017): Ghana poultry report annual. Accra, Ghana: (United States Department of Agriculture).

WoOlverton, E. A., and Frimpong, S. (2013): Consumer demand for domestic and imported broiler meat in urban Ghana: Bringing non-price effects into the equation. British Journal of Marketing Studies, 1(3), 16-31. 


\title{
5 Imported versus domestic chicken consumption in Ghana: Do attitudes and perceptions matter? ${ }^{3}$
}

\begin{abstract}
Growth in the worldwide consumption of poultry meat, especially in developing countries, has resulted in increasing trade, raising concerns and criticisms about imports. Such concerns and criticisms include the potential to collapse the domestic industry and lead to job losses. This paper, therefore, analyzes the role of personal factors in driving the frequency of chicken meat consumption in general and, in particular, domestic and imported chicken. Results from a survey of 500 urban consumers in Ghana show that attitudes and perceptions are key factors influencing chicken meat consumption. Specifically, concerns about food safety, price, and the lack of convenience reduce regular domestic chicken consumption, while perceived quality and ethnocentrism increase regular consumption. Regarding imported chicken, price, convenience, and availability influence frequent consumption. Promotional activities that highlight the quality aspects in terms of taste and freshness of domestic chicken meat can give domestic actors a competitive advantage.
\end{abstract}

Keywords: attitudes, chicken, consumption frequency, imported vs. domestic, ordered probit model, perceptions

JEL codes: D12, Q13

\footnotetext{
${ }^{3}$ This chapter has been published in the Journal of International Food \& Agribusiness Marketing (Taylor \& Francis). https://doi.org/10.1080/08974438.2020.1751767. It is joint work with Daniela Weible (DW).

Authors' contributions: All authors jointly designed the research. I (CAA) collected the data, analyzed, and wrote the manuscript. DW commented at the various stages of the research and contributed to writing and revising the manuscript.
} 


\subsection{Introduction}

Global consumption of meat and meat products has experienced a significant increase in recent decades due to rapid population growth, rising incomes, and urbanization (Cranfield, Hertel, Eales, \& Preckel, 1998; Delgado, 2003; Meade \& Thome, 2017). The growth has been particularly strong for poultry meat. With an estimated mean worldwide consumption of 14.2 $\mathrm{kg} /$ capita in 2018, poultry meat is currently the most widely consumed meat in the world, outstripping pork (12.3 kg/capita) as the preferred animal protein (OECD-FAO, 2019a). The growing demand for poultry meat products has led to an increasing proportion of the total poultry meat production traded on the international market. By 2028, it is expected that demand will further rise and growth rates in consumption are projected to be faster in developing countries (OECD-FAO, 2019b).

These described trends can also be observed in Ghana, which is the focus country of this paper. Poultry meat is a common part of the Ghanaian diet. Between 2000 and 2017, poultry meat consumption increased from 1.7 to $6.1 \mathrm{~kg}$ per capita (OECD-FAO, 2017), which is more than double the average for sub-Saharan Africa. This rapid growth was accompanied by or, respectively, due to the strong increase in imports during the observed period. For example, imports $^{4}$ into Ghana increased from 16,167 metric tons in 2000 to 150,366 metric tons in 2017 - representing an annual growth rate of $14 \%$. Additionally favoring the situation, the imported poultry products are sold at prices markedly lower than those produced in Ghana (USDA, 2017). It is also expected that the consumption of poultry meat will further rise.

Despite the huge potential for poultry meat production in Ghana, the current levels of supply and consumption of domestic poultry meat are markedly lower in comparison to imported ones (USDA, 2017). The lack of competitiveness in the domestic sector has led to calls for intervention policies to support domestic production (Chisenga, Entsua-Mensah, \& Sam, 2007; FAO 2014). To address this issue, policymakers will have to look at a mix of policy actions taking into account food security, local production, and the interest of consumers. But most often, actions by governments are focused on boosting local production (see MoFA, 2007) with little or no attention to consumer interests. Understanding consumers' poultry meat consumption behavior, therefore, can assist producers and policymakers to respond effectively to the continued growth in demand and match current preferences.

\footnotetext{
4 Data on imports were retrieved from the United Nations Commodity Trade Statistics Database (UN COMTRADE). Available at https://comtrade.un.org/data (accessed on 19 September 2018).
} 
In general, however, consumers' food choices are influenced by many interrelated factors, such as product properties, marketing (environmental factors), and personal (i.e., psychological and sociodemographic characteristics) factors (Furst, Connors, Bisogni, Sobal, \& Falk, 1996; Verbeke, 2005; Font-i-Furnols \& Guerrero, 2014; Thong \& Solgaard, 2017). Among these, personal factors are very critical in driving food choice behavior (Furst et al., 1996; Thong \& Solgaard, 2017). The influence of personal factors on meat consumption behavior has been the subject of many studies worldwide. Existing studies that account for these factors have focused on fish (Hall \& Amberg, 2013; Rortveit \& Olsen, 2009; Thong \& Solgaard, 2017; Verbeke \& Vackier, 2005), pork (Grebitus, Yue, Bruhn, \& Jensen, 2011; McCarthy, O'Reilly, Cotter, \& de Boer, 2004; Schmid et al., 2017), and beef (McCarthy, de Boer, O' Reilly, \& Cotter, 2003; Schmid et al., 2017). Although previous studies have investigated the role of personal factors on meat consumption behavior, few have focused on poultry meat. However, existing studies on poultry meat concentrated mainly on sociodemographic factors, nutrition knowledge, and attributes such as labels but disregard psychological factors, e.g., attitudes and perceptions (Guenther, Jensen, Batres-Marquez, \& Chen, 2005; Rimal, 2005; Tambi, 2001; Yen, Lin, \& Davis, 2008). In the case of Ghana, no study to our knowledge has yet investigated the influence of personal factors on poultry meat consumption patterns. Therefore, this paper fills this research gap by considering the direct influence of these interrelated factors (both psychological and sociodemographic variables) on poultry meat consumption.

Against this background, the objective of this paper is to investigate the influence of sociodemographic factors, perceptions, and attitudes on the frequency of chicken meat consumption. The innovation of this paper is characterized by the application of a probabilistic model and accounting for the different sources of chicken meat supply (i.e., both domestic and imported). The results of these analyses will not be only important for supply chain actors in developing effective consumer-oriented marketing strategies in Ghana, but also actors in other African countries facing similar situations with substantial imports of meat products. This paper proceeds as follows: Section 5.2 presents the conceptual approach; Section 5.3 describes data and methods of the empirical analysis; Section 5.4 presents the results and discussion; and Section 5.5 offers conclusions.

\subsection{Conceptual approach}

Consumers, who decide to buy chicken meat in Ghana, can choose between imported and domestic chicken at the point of sale. Domestic chickens are mainly sold as live birds, whereas 
imported ones are mainly sold as frozen parts. Since these products differ greatly in their properties and the type of distribution, it is assumed that the underlying determinants of consumption also differ between them. The literature agrees that these products should be treated as heterogeneous products (Kwadzo, Dadzie, Osei-Asare, \& Kuwornu, 2013; Woolverton \& Frimpong, 2013). This article intends to explain consumption patterns of households regarding chicken, in general, as well as to identify differences in consumption patterns between imported and domestic chicken meat. Thus, the frequency of (imported/domestic) chicken meat consumption in a household serves as the dependent variable in the model. Frequency as a measure of consumption has been widely used (e.g., Hall \& Amberg, 2013; Grebitus et al., 2011; Olsen, 2003; Thong \& Olsen, 2012; Thong \& Solgaard, 2017) and regarded as sufficient to establish relative food intake (Cade, Thompson, Burley, \& Warm, 2002). It is expected that the consumption of imported and domestic chicken is not independent of each other.

Since well-known theoretical models (e.g., the stimulus-organism-response (S-O-R) model developed by Kroeber-Riel, Weinberg, \& Gröppel-Klein, 2009) emphasize the importance of psychological constructs, such as attitudes, beliefs, and perceptions, in determining consumption behaviors, the conceptual framework of this study comprehensively accounts for these constructs along with sociodemographic variables while controlling for other factors such as distance. The underlying idea is that the purchase decisions of a household are mainly dependent on the interaction among household members and on how roles are distributed between them (Kroeber-Riel et al., 2009). Preferences and hence, consumption patterns of a household may be expressed by the primary decision-maker (Swait, 1994), in this case, the person responsible for food shopping and/or preparation, or at least making decisions on food purchases in the household. The responsible persons' attitudes, perceptions, and sociodemographic characteristics, in turn, determine the preferences (Swait, 1994; KroeberRiel et al., 2009).

The underlying assumptions for the psychological factors are as follows: some consumers may prefer a chicken product that is processed or portioned, while others may not. Therefore, it is assumed that the importance that an individual attaches to the degree of processing determines how frequent (imported/domestic) chicken is bought. Also, the availability and accessibility (i.e., distance to the nearest chicken market and the perceived expensiveness) may play a central role in consumers' purchase decisions. Furthermore, the conceptual framework accounts for the perceived quality of chicken meat and especially assumes that imported and domestic chicken products are perceived to be of different quality. 
Quality can encompass the leanness or fattiness of the meat, nutritional value, other health aspects, or even taste and freshness. Due to recurrent bird flu cases in the country, food safety concerns may negatively influence the consumption of chicken meat (especially domestic chicken). Individuals' general attitudes toward the import of goods and, in consequence, the purchase of foreign-made products may also be a determinant for differing consumption frequencies of the imported and domestic chicken. This is because in Ghana imported chicken is discussed as a barrier and threat to a growing domestic poultry sector as evidenced in the media reporting. Hence, an individual's beliefs and opinions about necessary political actions or what the government could do (e.g., taxation of imports) are assumed to have an influence. Consumer's belief about the appropriateness and morality of purchasing foreign-made products versus their loyalty toward products made in their own country is known as ethnocentrism (Shimp \& Sharma, 1987). According to Shimp and Sharma (1987), ethnocentric consumers object to food products from other countries because, in their minds, it is unpatriotic and detrimental to the domestic economy and domestic employment.

Finally, in addition to the described psychological factors, the conceptual model accounts for gender, age, education, marital status, and employment status of the respondent as well as the presence of children in the household and net income.

\subsection{Data and Methods}

\subsubsection{Data collection}

Primary data were collected through a consumer household survey in urban Ghana because most of the increase in poultry consumption is expected around large cities. We selected Accra (the capital city of Ghana) and Kumasi for this study because of their highly urbanized nature, ethnic diversity, and geographic location. Additionally, these cities play hosts to most commercial poultry operations. The target population was chicken consumers responsible for food shopping or decisions concerning food purchases in the household and aged 18 years and above.

We employed a multistage sampling approach. First, we divided each city into 10 administrative units (i.e., sub-metros/districts) ${ }^{5}$, of which five were randomly selected from each city. Second, within each sub-metro/district, two communities were selected. Finally, from

\footnotetext{
5 Districts are second-level administrative subdivisions in Ghana, below the level of region (first-level administrative unit). Sub-metros are smaller units that are created within a metropolitan assembly, which is also a second-level administrative unit.
} 
each of the selected communities, households were selected using systematic random sampling. To select a household, we followed a randomly generated route (random walk procedure), and respondents from every third household along the route were interviewed. Where a respondent in a target household did not eat chicken, was not available (after two visits) or not interested in participating, the next household was chosen. In total, 500 chicken meat consumers consisting of 250 respondents from each city were interviewed.

The questionnaire solicited information on respondents' actual chicken buying and consumption habits. In addition, it consisted of two sets of statements based on 20 and 26 items, respectively and measured on a five-point Likert scale ranging from 1 ("strongly disagree") to 5 (“strongly agree") to capture respondents' general attitudes and perceptions regarding food and in particular, domestic versus imported chicken meat. The statements were developed based on insights gained from focus group discussions and literature. Specifically, seven focus group discussions were conducted in Accra, involving 44 participants between August and September 2017. The focus group elicited discussions on consumers' motives, perceptions, and attitudes about chicken meat in general, and in particular, domestic and imported chicken meat. Likewise, the attributes influencing their chicken meat purchases, perceptions of knowledge of poultry production, shopping and consumption habits (e.g., purchasing behavior, frequency of purchasing and consumption, place of purchase, etc.) as well as opinions about necessary political actions in the poultry sector were covered.

Transcripts from the focus groups were analyzed, and statements concerning health, safety, quality, price, availability, convenience, and ethnocentrism aspects of food (including chicken meat) were generated. Additionally, some statements were selected from existing literature (Shimp \& Sharma, 1987; Gil, Gracia, \& Sanchez, 2000; Roininen et al., 2001; Verhoef, 2005; Michaelidou \& Hassan, 2008) and adapted to chicken meat and the Ghanaian context. Finally, the questionnaire captured respondents' sociodemographic characteristics (e.g., gender, age, education, income, etc.). The questionnaire was pretested with a small sample of individuals (15) for feasibility and clarity and modified for easy understanding and consistent responses. The survey was undertaken with the help of trained enumerators between March and April 2018 using Computer-Assisted Personal Interviewing.

\subsubsection{Data summary}

Table 5.1 presents summary statistics and descriptions of the sociodemographic variables. The average age of respondents is 38 years. The majority of the respondents are females (85\%), which reflects the situation where women are mostly responsible for either food shopping or 
decisions concerning food purchases in Ghana. About $72 \%$ of the respondents have children under 18 years of age, and $60 \%$ of the respondents are married. About $43 \%$ of the respondents have completed post-secondary or higher education, $40 \%$ are formally employed either full time or part-time and more than half of the respondents (58\%) are in the $\mathrm{GH} \phi 600-\mathrm{GH} \phi 1,799$ income bracket.

Table 5.1: Summary statistics and sociodemographic variables descriptions

\begin{tabular}{|c|c|c|c|}
\hline Variables & Description & Mean & SD \\
\hline Age & Age of respondent in years & 38.33 & 11.65 \\
\hline Gender & $1=$ female, 0 otherwise & 0.85 & 0.35 \\
\hline Children & $\begin{array}{l}1=\text { if children }<18 \text { years present in respondent's } \\
\text { household, } 0 \text { otherwise }\end{array}$ & 0.72 & 0.45 \\
\hline Married & $1=$ if respondent is married, 0 otherwise & 0.60 & 0.49 \\
\hline Tertiary & $\begin{array}{l}1=\text { if respondent has completed post-secondary or } \\
\text { higher education , } 0 \text { otherwise }\end{array}$ & 0.43 & 0.50 \\
\hline Formally employed & $\begin{array}{l}1=\text { if respondent is fully or part time employed, } 0 \\
\text { otherwise }\end{array}$ & 0.40 & 0.49 \\
\hline Low income & $\begin{array}{l}1=\text { if respondent's monthly household net income is } \\
<\mathrm{GH} \varnothing 600 \text { (base), } 0 \text { otherwise }\end{array}$ & 0.19 & 0.39 \\
\hline Middle income & $\begin{array}{l}1=\text { if respondent's monthly household net income is } \\
\mathrm{GH} \phi 600-\mathrm{GH} \phi 1,799,0 \text { otherwise }\end{array}$ & 0.58 & 0.49 \\
\hline High income & $\begin{array}{l}1=\text { if respondent's monthly household net income is } \\
\mathrm{GH} \phi 1,800 \text { and above, } 0 \text { otherwise }\end{array}$ & 0.23 & 0.42 \\
\hline Distance & $\begin{array}{l}\text { Travel time to the nearest chicken market by vehicle in } \\
\text { minutes }\end{array}$ & 22.10 & 14.70 \\
\hline
\end{tabular}

Note: Exchange rate as at the time of survey: 1 US $\$=4.4022$ Ghana Cedis $(\mathrm{GH} \phi)$.

Source: Own calculation based on survey data (2018).

To measure chicken meat consumption in a household, respondents were provided with frequency options and were asked to select the frequency of consumption that best fits their usual consumption pattern. Out-of-home eating was neglected in the study. Results from Table 5.2 show that more than one-quarter $(26 \%)$ of the respondents stated that they consume chicken meat 2-3 times in a month, while $23 \%$ consume chicken twice a week or more. Comparing domestic chicken to its imported counterpart, the results show that domestic chicken consumption is highly skewed toward a lower frequency. Specifically, more than half $(56 \%)$ of the respondents stated that they consume domestic chicken occasionally compared to $22 \%$ for imported chicken meat. While all respondents indicated that they consume domestic chicken meat, about $15 \%$ did not consume imported chicken meat. Nonetheless, the results generally show that consumption of imported chicken among respondents is more regular in comparison to domestic ones. 
Table 5.2: Households' chicken consumption frequency

\begin{tabular}{|c|c|c|c|c|c|c|}
\hline & \multicolumn{2}{|c|}{ Chicken } & \multicolumn{2}{|c|}{ Domestic chicken } & \multicolumn{2}{|c|}{ Imported chicken } \\
\hline & Frequency & $\%$ & Frequency & $\%$ & Frequency & $\%$ \\
\hline Never & - & - & 0 & 0.0 & 74 & 14.8 \\
\hline Occasionally & 68 & 13.6 & 279 & 55.8 & 111 & 22.2 \\
\hline Once a month & 80 & 16.0 & 88 & 17.6 & 59 & 11.8 \\
\hline 2-3 times a month & 129 & 25.8 & 59 & 11.8 & 110 & 22.0 \\
\hline Once a week & 110 & 22.0 & 48 & 9.6 & 70 & 14.0 \\
\hline Twice a week or more & 113 & 22.6 & 26 & 5.2 & 76 & 15.2 \\
\hline Total & 500 & 100.0 & 500 & 100.0 & 500 & 100.0 \\
\hline
\end{tabular}

Source: Own calculation

\subsubsection{Methods}

The frequency at which an individual consumes chicken meat depends on his/her preferences. Specifically, the individual is asked to reveal the strength of his/her preferences over an outcome, which is discrete and ordinal, $0,1, \ldots, \mathrm{J}$. Given that the consumption frequency as a dependent variable is categorical (i.e., never; occasionally; once a month; 2-3 times a month; once a week; or 2 times a week or more), the ordered probit (or logit) model provides an efficient approach to recover the model parameters (Greene \& Hensher, 2010). The ordered probit model is an extension of the binary probit model that can be applied when responses are ordinal as distinct from numerical, such as frequencies (Daykin \& Moffatt, 2002).

Other studies have used the ordered probit model to analyze the factors influencing purchasing or consumption frequency of food (Dumortier, Evans, Grebitus, \& Martin, 2017; Kumar, Quagrainie, \& Engle, 2008; Thong \& Solgaard, 2017). Following these studies, the ordered probit model as developed by McKelvey \& Zavoina (1975) is adopted for this study to estimate the influence of consumers' attitudes, perceptions, and sociodemographic characteristics on chicken consumption frequency. The ordered probit model estimates the probability of an outcome as a linear function of the selected independent variables in addition to the predicted threshold values and is built around a latent regression like that of the binomial probit model (Greene, 2002). For consumer $i(i=1, \cdots N)$, let $y_{i}^{*}$ represent the unobserved continuous dependent variable such that

$y_{i}^{*}=x_{i}^{\prime} \beta+\varepsilon_{i}$

where $x_{i}$ is a matrix of known values of the independent explanatory variables (e.g., consumer perceptions, attitudes, and characteristics) for consumer $i, \beta$ is a vector of parameters reflecting the relationship between $y_{i}^{*}$ and the variables in $x_{i}$, and $\varepsilon_{i}$ is an unobserved random variable assumed to be independent and identically distributed with a standard normal distribution, that 
is, $\varepsilon_{i} \sim N(0,1)$. The continuous variable, $y_{i}^{*}$ is unobserved. Rather, what we observe is the stated frequency decision of an individual, say $y_{i}$, which has $J$ categories. Thus, the probability that consumer $i$ has a consumption frequency falling within a particular ordinal outcome $j$ $(j=0,1,2 \cdots J)$ is given as:

$\operatorname{Prob}\left(y_{i}=0 \mid x_{i}\right)=\Phi\left(-x_{i}^{\prime} \beta\right)$

$\operatorname{Prob}\left(y_{i}=1 \mid x_{i}\right)=\Phi\left(\mu_{1}-x_{i}^{\prime} \beta\right)-\Phi\left(-x_{i}^{\prime} \beta\right)$

$\operatorname{Prob}\left(y_{i}=2 \mid x_{i}\right)=\Phi\left(\mu_{2}-x_{i}^{\prime} \beta\right)-\Phi\left(\mu_{1}-x_{i}^{\prime} \beta\right)$

$\vdots$

$\operatorname{Prob}\left(y_{i}=J \mid x_{i}\right)=1-\Phi\left(\mu_{J-1}-x_{i}^{\prime} \beta\right)$

where the parameters $\mu_{j}, j=1, \cdots, J-1$ are the cut points or unknown threshold parameters defining potential ordered outcomes for $y_{i}$ and $\Phi(\cdot)$ is a standard normal cumulative density function. These probabilities enter the log-likelihood function, and the thresholds $\mu_{j}$ are estimated simultaneously by an iterative procedure of the maximum likelihood estimation (MLE) method, which can be expressed as:

$\log L=\sum_{i=1}^{n} \ln \left[\operatorname{Prob}\left(y_{i}\right)\right]=\sum_{i=1}^{n} \ln \left[\Phi\left(\mu_{j}-x_{i}^{\prime} \beta\right)-\Phi\left(\mu_{J-1}-x_{i}^{\prime} \beta\right)\right]$

The maximization of the likelihood function provides estimates of the parameters $\beta$ along the threshold parameters $\mu_{1}, \mu_{2}, \mu_{3}, \cdots, \mu_{J-1}$. The parameters $\beta$ are interpreted as the impact of the explanatory variables on the consumption frequency.

We used a univariate ordered probit for the analysis of overall chicken consumption. With respect to the domestic and imported, a bivariate ordered probit is used. The bivariate ordered probit allows us to estimate the consumption of domestic and imported chicken simultaneously (Greene \& Hensher, 2010) because consumption frequencies of these meat types might not be independent of each other. Under the assumption of a bivariate normal distribution of the error terms $\left(\varepsilon_{1 i}\right.$ and $\left.\varepsilon_{2 i}\right)$, the joint probability of the frequency of domestic $\left(y_{1 i}=j=1, \cdots, 5\right)$ and imported chicken $\left(y_{2 i}=k=1, \cdots, 6\right)$ consumption can be expressed as follows:

$$
\begin{aligned}
\operatorname{Pr}\left(y_{1 i}=j, y_{2 i}=k\right) & =\Phi_{2}\left(\mu_{1 j}-\beta_{1}^{\prime} x_{1 i},\left(\mu_{2 k}-\beta_{2}^{\prime} x_{2 i}\right), \rho\right) \\
& -\Phi_{2}\left(\mu_{1 j-1}-\beta_{1}^{\prime} x_{1 i},\left(\mu_{2 k}-\beta_{2}^{\prime} x_{2 i}\right), \rho\right)
\end{aligned}
$$




$$
\begin{aligned}
& -\Phi_{2}\left(\mu_{1 j}-\beta_{1}^{\prime} x_{1 i},\left(\mu_{2 k-1}-\beta_{2}^{\prime} x_{2 i}\right), \rho\right) \\
& +\Phi_{2}\left(\mu_{1 j-1}-\beta_{1}^{\prime} x_{1 i},\left(\mu_{2 k-1}-\beta_{2}^{\prime} x_{2 i}\right), \rho\right)
\end{aligned}
$$

where $\Phi$ is the standard bivariate normal cumulative distribution function. $\rho$ is an unknown correlation between $\varepsilon_{1 i}$ and $\varepsilon_{2 i}$ to be estimated. The probabilities enter the log-likelihood for a maximum likelihood estimator of the parameters. If the error terms are uncorrelated $(\rho=0)$, then the decisions to consume domestic and imported chicken are independent and that using two independent univariate ordered probit models would be appropriate. However, the bivariate ordered probit model is preferred if $\rho$ is significant.

To identify the underlying latent structure and to reduce the attitudinal and perceptual statements from a larger number of more or less highly correlated variables into a few unrelated and independent factors, we used an exploratory factor analysis. Factor scores generated from the exploratory factor analysis are used as the independent variables in addition to sociodemographic variables, distance to the nearest market, and location of households.

\subsection{Results and discussion}

\subsubsection{Exploratory factor analysis of attitudes and perceptions}

Two factor analyses were performed using the principal component analysis (PCA) with varimax rotational strategies to evaluate (1) consumers' general attitudes toward food and chicken meat, and (2) consumers' perceptions and attitudes toward domestic versus imported chicken meat. Before the factor analyses, we performed a series of diagnostic measures to access internal consistency. First, we checked for the inter-item correlation (correlation among items). Based on this, three and four items were respectively, not included in the first and second factor analyses, due to low correlation coefficients, which are below the acceptable threshold of 0.30 (Hair, Black, Babin, \& Anderson, 2010). In the end, we included 17 and 22 survey statements in the first and second factor analyses, respectively. All factors with eigenvalues greater than 1 were retained. Since the reliability was measured using Cronbach's alpha $(\alpha)$ with a critical score of 0.60 (Hair, Black, Babin, Anderson, \& Tatham, 2006), the fifth factor $(\alpha=0.45)$ in the first factor analysis (not shown in the Table) was excluded from subsequent regression analysis. Tables 5.3 and 5.4 report the Kaiser Meyer Olkin (KMO) values, final items with their respective factor loadings, explained variance, and reliability coefficients. 
Table 5.3 contains statements regarding consumers' general attitudes toward food and chicken meat. It includes four factors that explain $52.4 \%$ of the error variance. Factor one (food safety concern) comprises four statements that represent safety-consciousness and related behaviors aimed at mitigating different food safety-related risks. The second factor (interest in human health and production standards) is composed of five statements and reflects consumers concerns about health-related issues with regard to meat and food consumption in general. Factor three (availability and convenience) is made up of three statements concerning attitudes toward the availability of chicken meat as well as the ease of preparing chicken meat compared to other meat types. The fourth factor (price consciousness) emphasizes two statements that are associated with concern about prices such as "price is the most important factor for me when I am shopping."

Table 5.3: Factor analysis of statements regarding food in general

\begin{tabular}{|c|c|c|c|c|}
\hline Items & Mean & $\begin{array}{l}\text { Factor } \\
\text { loadings }\end{array}$ & $\begin{array}{c}\% \text { of } \\
\text { variance } \\
\text { explained }\end{array}$ & $\begin{array}{l}\text { Cronbach's } \\
\text { alpha }\end{array}$ \\
\hline Factor 1: Food safety concern & & & 15.51 & 0.81 \\
\hline $\begin{array}{l}\text { I am very concerned about the use of antibiotics and } \\
\text { hormones in food. }\end{array}$ & 3.97 & 0.892 & & \\
\hline $\begin{array}{l}\text { I would pay a premium for antibiotic-free and } \\
\text { hormone-free chicken. }\end{array}$ & 4.04 & 0.917 & & \\
\hline The safety of meat concerns me a lot. & 4.16 & 0.729 & & \\
\hline $\begin{array}{l}\text { I reject all types of chicken during times of bird flu } \\
\text { disease outbreaks. }\end{array}$ & 4.81 & 0.510 & & \\
\hline $\begin{array}{l}\text { Factor 2: Interest in human health and production } \\
\text { standards }\end{array}$ & & & 14.71 & 0.71 \\
\hline $\begin{array}{l}\text { It is good that chicken is available because it is low in } \\
\text { fat. }\end{array}$ & 4.09 & 0.541 & & \\
\hline I reflect a lot about my health. & 4.36 & 0.811 & & \\
\hline I take care of what I eat because of health reasons. & 4.32 & 0.769 & & \\
\hline $\begin{array}{l}\text { It is important that animals are well fed, raised, and } \\
\text { healthy. }\end{array}$ & 4.54 & 0.655 & & \\
\hline $\begin{array}{l}\text { Government should monitor and ensure good animal } \\
\text { husbandry practices and standards in the production } \\
\text { and processing of meat. }\end{array}$ & 4.49 & 0.533 & & \\
\hline Factor 3: Availability and convenience & & & 12.54 & 0.72 \\
\hline $\begin{array}{l}\text { It is important for me to have chicken available } \\
\text { throughout the year at markets/stores close to where I } \\
\text { live or work. }\end{array}$ & 3.86 & 0.732 & & \\
\hline Chicken is easy to prepare compared to other meats. & 3.88 & 0.780 & & \\
\hline $\begin{array}{l}\text { It is easier to obtain chicken than other meats } \\
\text { (excluding fish). }\end{array}$ & 4.16 & 0.828 & & \\
\hline Factor 4: Price consciousness & & & 9.64 & 0.71 \\
\hline $\begin{array}{l}\text { Price is the most important factor for me when I am } \\
\text { shopping. }\end{array}$ & 3.68 & 0.872 & & \\
\hline $\begin{array}{l}\text { It is mainly the price that influences my choice of } \\
\text { chicken. }\end{array}$ & 3.10 & 0.858 & & \\
\hline
\end{tabular}

Notes: Kaiser-Meyer-Olkin Test for sampling adequacy $=0.716$.

Bartlett's test of sphericity $\chi^{2}=0.000$. Only factor loadings with absolute value above 0.50 are presented. 
Regarding consumers' perceptions and attitudes toward domestic versus imported chicken meat, six factors emerged, which account for $62.6 \%$ of the explained variance (Table 5.4). We label the first factor "convenience of imported chicken" as it emphasizes three statements suggesting that imported chicken is more convenient than domestic chicken. The second factor (domestic chicken safer and healthier) comprises a mix of four items related to perceived safety and healthiness of domestic chicken compared to imported chicken. Factor three (domestic chicken of higher quality) consists of three items that capture respondents' perceptions that domestic chicken relative to its imported counterpart has better quality, suggesting that it is tastier and fresher. The fourth factor (imported chicken more affordable) includes three items that measure the affordability of domestic and imported chicken. Factor five consists of three statements which make an appeal to consumers to buy foreign food products when domestic products are not available or domestic supply are lower than demand, suggesting an association with "pragmatism". We refer to this factor as pragmatism because it reflects a practical attitude by the respondents who are not closed to food imports when necessary (Schnettler, Miranda, Lobos, Sepúlveda, \& Denegri, 2011). The last factor (ethnocentrism) is composed of three items that reflect consumers' fear, and a general dislike for foreign food products. 
Table 5.4: Factor analysis of statements regarding domestic versus imported chicken

\begin{tabular}{|c|c|c|c|c|}
\hline Items & Mean & $\begin{array}{l}\text { Factor } \\
\text { loadings }\end{array}$ & $\begin{array}{c}\% \text { of variance } \\
\text { explained }\end{array}$ & $\begin{array}{l}\text { Cronbach's } \\
\text { alpha }\end{array}$ \\
\hline Factor 1: Convenience of imported chicken & & & 11.91 & 0.85 \\
\hline $\begin{array}{l}\text { Domestic chicken is difficult to prepare and time- } \\
\text { consuming compared to imported chicken. }\end{array}$ & 3.76 & 0.832 & & \\
\hline $\begin{array}{l}\text { For me, imported chicken is everyday food but not } \\
\text { for special occasions. }\end{array}$ & 3.40 & 0.846 & & \\
\hline $\begin{array}{l}\text { For special occasions, I would only buy domestic } \\
\text { chicken. }\end{array}$ & 3.64 & 0.800 & & \\
\hline Factor 2: Domestic chicken safer and healthier & & & 11.35 & 0.76 \\
\hline $\begin{array}{l}\text { Domestic chicken is completely safe to eat } \\
\text { compared to imported chicken. }\end{array}$ & 4.09 & 0.852 & & \\
\hline $\begin{array}{l}\text { Domestic chicken has no antibiotics, hormones or } \\
\text { additives. }\end{array}$ & 3.92 & 0.857 & & \\
\hline $\begin{array}{l}\text { Imported chicken has no antibiotics, hormones or } \\
\text { additives }^{\text {a }} \text {. }\end{array}$ & 3.63 & 0.551 & & \\
\hline $\begin{array}{l}\text { I consider domestic chicken to be healthier than } \\
\text { imported chicken. }\end{array}$ & 4.13 & 0.753 & & \\
\hline Factor 3: Domestic chicken of higher quality & & & 11.1 & 0.82 \\
\hline $\begin{array}{l}\text { I consider imported chicken to be of less quality } \\
\text { than domestic chicken. }\end{array}$ & 4.10 & 0.803 & & \\
\hline $\begin{array}{l}\text { I prefer domestic chicken because of its good taste } \\
\text { and freshness. }\end{array}$ & 4.45 & 0.726 & & \\
\hline For me, imported chicken is not tasty. & 3.93 & 0.825 & & \\
\hline Factor 4: Imported chicken more affordable & & & 9.55 & 0.71 \\
\hline $\begin{array}{l}\text { Domestic chicken is more expensive than } \\
\text { imported chicken. }\end{array}$ & 4.07 & 0.763 & & \\
\hline The price of domestic chicken is too high for me & 3.20 & 0.789 & & \\
\hline Imported chicken is the cheapest meat you can get. & 3.71 & 0.733 & & \\
\hline Factor 5: Pragmatism & & & 9.49 & 0.71 \\
\hline $\begin{array}{l}\text { Only those food products that are not available in } \\
\text { Ghana should be imported. }\end{array}$ & 3.75 & 0.899 & & \\
\hline $\begin{array}{l}\text { Foreign food products should be imported when } \\
\text { domestic supply cannot meet the demand. }\end{array}$ & 4.41 & 0.514 & & \\
\hline $\begin{array}{l}\text { Food products that our farmers cannot produce } \\
\text { cheaply should be imported so that they can } \\
\text { concentrate on producing other things that make } \\
\text { them competitive and improve our food situation }{ }^{\text {a }} \text {. }\end{array}$ & 3.78 & 0.861 & & \\
\hline Factor 6: Ethnocentrism & & & 9.18 & 0.70 \\
\hline $\begin{array}{l}\text { It is good to import foreign food products so that } \\
\text { we can get cheaper alternatives }{ }^{\mathrm{a}} \text {. }\end{array}$ & 2.78 & 0.655 & & \\
\hline $\begin{array}{l}\text { Ghanaians should not buy foreign food products, } \\
\text { because this hurts Ghanaian business and causes } \\
\text { unemployment. }\end{array}$ & 3.16 & 0.792 & & \\
\hline $\begin{array}{l}\text { Foreign products should be taxed heavily to reduce } \\
\text { their entry into Ghana. }\end{array}$ & 3.24 & 0.792 & & \\
\hline
\end{tabular}

Notes: Kaiser-Meyer-Olkin Test for sampling adequacy $=0.727$.

Bartlett's test of sphericity $\chi^{2}=0.000$. Only factor loadings above 0.50 are presented.

a Item is reverse coded ( $1=$ "strongly agree" to 5 = "strongly disagree").

\subsubsection{Ordered probit results}

We estimated the univariate ordered probit model for overall chicken consumption and the bivariate ordered probit model for domestic and imported chicken consumption using STATA (version 14) econometric software. Table 5.5 presents the results estimated from the models. The correlation coefficient $(\rho 12)$ from the bivariate model is -0.24 and statistically significant 
at $1 \%$ level, justifying the use of the bivariate model in favor of two independent estimations using the univariate model. The negative correlation also indicates that an increase in consumption of one type of chicken would decrease the consumption of the other.

Table 5.5: Ordered probit models results

\begin{tabular}{|c|c|c|c|}
\hline & \multirow{2}{*}{$\begin{array}{c}\text { Univariate } \\
(1) \\
\text { Chicken } \\
\text { (All) }\end{array}$} & \multicolumn{2}{|c|}{$\begin{array}{l}\text { Bivariate } \\
\text { (2) }\end{array}$} \\
\hline & & $\begin{array}{l}\text { Domestic } \\
\text { chicken }\end{array}$ & $\begin{array}{c}\text { Imported } \\
\text { chicken }\end{array}$ \\
\hline Gender (female) & $-0.346^{* *}(0.143)$ & $-0.180(0.154)$ & $-0.277^{*}(0.147)$ \\
\hline Age & $-0.004(0.004)$ & $0.000(0.005)$ & $-0.000(0.004)$ \\
\hline Married & $-0.045(0.114)$ & $0.054(0.120)$ & $-0.079(0.109)$ \\
\hline Children (<18 years) & $0.289^{* *}(0.119)$ & $0.139(0.129)$ & $0.189^{*}(0.109)$ \\
\hline Tertiary & $0.157(0.120)$ & $-0.017(0.140)$ & $0.042(0.114)$ \\
\hline Formally employed & $0.012(0.109)$ & $-0.064(0.123)$ & $0.220^{* *}(0.109)$ \\
\hline Middle income (GH $\varnothing 600-\mathrm{GH} \varnothing 1,799)$ & $0.140(0.148)$ & $0.144(0.165)$ & $0.145(0.134)$ \\
\hline High income $(\geq \mathrm{GH} \notin 1,800)$ & $0.346^{*}(0.189)$ & $0.388^{*}(0.209)$ & $0.043(0.192)$ \\
\hline Distance (in minutes) & $-0.029^{* * *}(0.004)$ & $-0.012^{* * *}(0.004)$ & $-0.028^{* * *}(0.004)$ \\
\hline Location (1=Accra) & $0.113(0.122)$ & $0.126(0.148)$ & $0.087(0.127)$ \\
\hline Food safety concern & $-0.107^{* *}(0.055)$ & $-0.108^{*}(0.058)$ & $-0.086(0.057)$ \\
\hline $\begin{array}{l}\text { Interest in human health and production } \\
\text { standards }\end{array}$ & $0.024(0.065)$ & $0.037(0.065)$ & $0.017(0.059)$ \\
\hline Availability and convenience & $0.304^{* * *}(0.058)$ & $0.019(0.060)$ & $0.362^{* * *}(0.060)$ \\
\hline Price consciousness & $-0.010(0.055)$ & $-0.121^{* * *}(0.062)$ & $0.110^{*}(0.058)$ \\
\hline Convenience of imported chicken & & $-0.169^{* * *}(0.058)$ & $0.120^{* *}(0.056)$ \\
\hline Domestic chicken safer $\&$ healthier & & $-0.060(0.060)$ & $-0.087(0.056)$ \\
\hline Domestic chicken of higher quality & & $0.128^{* *}(0.056)$ & $-0.188^{* * *}(0.056)$ \\
\hline Imported chicken more affordable & & $-0.218^{* * * *}(0.058)$ & $0.066(0.061)$ \\
\hline Pragmatism & & $0.031(0.053)$ & $-0.028(0.047)$ \\
\hline Ethnocentrism & & $0.248^{* * * *}(0.057)$ & $-0.200^{* * * *}(0.053)$ \\
\hline \multicolumn{4}{|l|}{ Cut-points } \\
\hline$\mu 1$ & $-1.896^{* * *}(0.262)$ & $0.090(0.272)$ & $-1.882^{* * *}(0.249)$ \\
\hline$\mu 2$ & $-1.185^{* * *}(0.253)$ & $0.629^{* *}(0.275)$ & $-0.909^{* * *}(0.250)$ \\
\hline$\mu 3$ & $-0.401(0.253)$ & $1.103^{* * *}(0.279)$ & $-0.503^{* *}(0.253)$ \\
\hline$\mu 4$ & $0.273(0.256)$ & $1.742^{* * *}(0.291)$ & $0.205(0.256)$ \\
\hline$\mu 5$ & & & $0.729^{* * *}(0.262)$ \\
\hline$\rho 12$ & & $-0.243^{* * *}$ & \\
\hline \multirow[t]{2}{*}{ Chi-squared } & 126.00 & 307.90 & \\
\hline & $(p<0.000)$ & $(p<0.000)$ & \\
\hline Log-likelihood & -723.98 & -1362.66 & \\
\hline Number of obs. & 500 & 500 & \\
\hline
\end{tabular}

Notes: *,**,*** Indicates statistical significance at the 10\%, 5\% and 1\% level, respectively. Robust standard errors are presented in parentheses.

Since estimated coefficients from the ordered probit models do not have direct interpretation per se (Greene \& Hensher, 2010), we only discuss the marginal effects, which are calculated for both models subsequently. The marginal effects represent the effect of a change in an explanatory variable on the predicted chicken consumption level. For the ordered probit, the estimated marginal effects sum to zero for each variable across the categories of consumption frequency (Kumar et al., 2008). Thus, an increase in the probability of an individual choosing one category must be offset by a decrease in the probability of choosing at least one of the other categories (Kumar et al., 2008). 


\subsubsection{Factors influencing general chicken meat consumption}

Table 5.6 shows the marginal effects and the predicted probabilities of the consumption frequency categories evaluated at the sample means of the data. The average probability values of a respondent consuming chicken meat occasionally, once a month, 2-3 times a month, once a week, and twice a week or more are $13.5 \%, 16.9 \%, 25.9 \%, 21.0 \%$, and $22.7 \%$, respectively. Comparing the predicted values with the actual (see Table 5.2), we find that the predicted probabilities are similar to the actual. Therefore, we can conclude that the model reasonably fits the data.

Table 5.6: Predicted probabilities and marginal effects from univariate ordered probit model of chicken consumption

\begin{tabular}{|c|c|c|c|c|c|}
\hline & Occasionally & $\begin{array}{l}\text { Once a } \\
\text { month }\end{array}$ & $\begin{array}{l}\text { 2-3 times a } \\
\text { month }\end{array}$ & $\begin{array}{l}\text { Once a } \\
\text { week }\end{array}$ & $\begin{array}{l}2 \text { times or } \\
\text { more a week }\end{array}$ \\
\hline Predicted prob. & 0.135 & 0.169 & 0.259 & 0.210 & 0.227 \\
\hline Gender (female) & $0.060^{* *}$ & $0.057^{* *}$ & $0.018^{* *}$ & $-0.041^{* *}$ & $-0.094^{* *}$ \\
\hline Age & 0.001 & 0.001 & 0.000 & -0.001 & -0.001 \\
\hline Married & 0.008 & 0.007 & 0.002 & -0.005 & -0.012 \\
\hline Children (<18 years) & $-0.050^{* *}$ & $-0.047^{* *}$ & $-0.015^{* *}$ & $0.035^{* *}$ & $0.078^{* *}$ \\
\hline Tertiary & -0.027 & -0.026 & -0.008 & 0.019 & 0.043 \\
\hline Formally employed & -0.002 & -0.002 & -0.001 & 0.001 & 0.003 \\
\hline Middle income & -0.024 & -0.023 & -0.008 & 0.017 & 0.038 \\
\hline High income & $-0.060^{*}$ & $-0.057^{*}$ & -0.018 & $0.041^{*}$ & $0.094^{*}$ \\
\hline Distance (in minutes) & $0.005^{* * *}$ & $0.005^{* * *}$ & $0.002^{* * *}$ & $-0.003^{* * *}$ & $-0.008^{* * *}$ \\
\hline Location (1=Accra) & -0.020 & -0.019 & -0.006 & 0.014 & 0.031 \\
\hline Food safety concern & $0.019^{*}$ & $0.018^{*}$ & $0.006^{*}$ & $-0.013^{*}$ & $-0.029^{* *}$ \\
\hline $\begin{array}{l}\text { Interest in human health and } \\
\text { production standards }\end{array}$ & -0.004 & -0.004 & -0.001 & 0.003 & 0.007 \\
\hline Availability \& convenience & $-0.053^{* * *}$ & $-0.050^{* * *}$ & $-0.016^{* * *}$ & $0.036^{* * *}$ & $0.082^{* * *}$ \\
\hline Price consciousness & 0.002 & 0.002 & 0.001 & -0.001 & -0.003 \\
\hline
\end{tabular}

Note: ${ }^{*},{ }^{* *},{ }^{* * *}$ Indicates statistical significance at the $10 \%, 5 \%$ and $1 \%$ level, respectively.

Among the significant sociodemographic variables, female respondents compared to their male counterparts have a higher probability of consuming chicken occasionally by 6.0 percentage points, implying that male consumers are more likely to consume chicken meat frequently. This result could be attributed to the role of meat as a sign of prestige, power, and wealth. In this case, men are more attracted to meat and as a result, consume more meat than women (see, e.g., Guenther et al., 2005; Leahy, Lyons, \& Tol, 2011). This result is consistent with studies in other countries (e.g., Guenther et al., 2005; Yen et al., 2008). The presence of children in the household is associated with a significantly higher probability of consuming chicken twice a week or more. A possible explanation is that households with children may identify chicken meat as low-fat and high-quality protein sources with essential vitamins and minerals that are important for the growth and development of children. The result is in contrast 
to the finding by Rimal (2005) on poultry in the U.S. Rimal (2005) finds that households with children are likely to consume poultry meat less frequently.

High-income households compared to low-income households have a significantly higher probability of consuming chicken twice a week or more by 9.4 percentage points. This result suggests that growth in income will be accompanied by growth in demand for chicken meat. This is in line with an observation by Ecker and Fang (2016) that with increasing income, animal-based proteins are likely to increase among Ghana's growing urban middle class. This result is also consistent with that of Tambi (2001), which indicates that higher income levels have positive effects on chicken consumption in Cameroon. As expected, a 1-minute increase in the travel time (a proxy for distance) to the nearest chicken market decreases the probability of the average respondent frequently consuming chicken meat by 0.8 percentage points. This implies that with decreased time distance, respondents will be able to access markets easily, which may lead to increased frequency of purchase and consumption of chicken meat.

With regard to consumers' attitudes, we find that concerns about food safety negatively influence the frequency of chicken consumption. That is, safety-conscious consumers are 2.9 percentage points less likely to consume chicken meat twice a week or more. The perception of antibiotics and hormones use in chicken production, frequent outbreaks of bird flu diseases, coupled with media reports about arsenic materials in some poultry products, may have accounted for the negative effect on consumption. The finding that food safety concern leads to a reduction in chicken consumption is consistent with other studies (Huang, Goh, \& Mohaidin, 2014; McCarthy et al., 2004).

The attitude toward the availability and convenience of chicken meat has a statistically strong positive influence on the frequency of consumption. A 1-unit increase (equivalent to one standard deviation in the sample) increases the probability of consuming chicken twice a week or more by 8.2 percentage points. This result suggests that further efforts to enhance the relative availability and the convenience of chicken meat compared to other meat products will lead to increased consumption.

\subsubsection{Factors influencing domestic and imported chicken meat consumption}

Regarding the predicted probabilities for domestic and imported chicken consumption frequency categories, the results show that the average probability values of a respondent consuming domestic and imported chicken occasionally are $55.6 \%$ and $23.5 \%$, respectively (Table 5.7). The remaining probabilities are spread across the other categories of consumption 
frequency. For example, $17.8 \%$ is assigned to the category "once a month" for domestic chicken and $21.7 \%$ to the category " $2-3$ times a month" for imported chicken.

Focusing on the marginal effects of the bivariate ordered probit model, we find that women are less likely to consume imported chicken frequently than men do. Having children in the household significantly increases the probability of consuming imported chicken twice a week or more by 3.7 percentage points. The presence of children in the household suggests a higher financial burden in terms of total expenditure and limited timespan. Hence, households with children may consume imported chicken frequently because it is cheaper and more convenient. Compared to respondents that are not formally employed, the probability of consuming imported chicken twice a week or more will be higher by 4.3 percentage points among formally employed respondents. Being employed may limit the amount of time available for meal preparation, and therefore, lead to more frequent consumption of imported chicken because it is more convenient and easy to prepare.

The results further show that income significantly influences the consumption of domestic chicken but not imported chicken. In particular, high-income households compared to low-income households are 3.7 percentage points more likely to consume domestic chicken twice a week or more. This finding suggests that in the future, with income growth, the consumption of domestic chicken will also increase accordingly. The distance to the nearest market is negative and significantly related to the consumption of both domestic and imported chicken. This result suggests that as consumers spend more time commuting to the nearest chicken markets, they are less likely to consume both imported and domestic chicken frequently due to increased access costs (transportation and time costs).

Interestingly, for the attitudinal and perceptual variables, the results show that safetyconscious consumers are 3.9 percentage points more likely to consume domestic chicken occasionally. The exposure of consumers over the past decade to numerous incidences of avian flu diseases in Ghana could explain the negative association between consumers' food safety concerns and domestic chicken consumption. Moreover, respondents who are interested in the regular availability and showed favorable attitudes toward the convenience of chicken meat, in general, have a significantly higher probability of consuming imported chicken twice a week or more. The effect on domestic chicken consumption is not statistically significant. However, the marginal effects of the variable "convenience of imported chicken" show that consumers who perceived imported chicken as more convenient relative to domestic chicken are more likely to consume imported chicken frequently and seldom domestic chicken. These results, in 
general, emphasize the importance of convenience in the consumption decisions of consumers regarding both chicken products.

A strong price consciousness decreases the probability of frequent consumption of domestic chicken but increases the probability of imported chicken consumption. Specifically, price sensitive consumers have a higher probability of occasionally (twice a week or more) consuming domestic (imported) chicken by 4.3 (2.1) percentage points. Since prices of domestic chicken meat are higher than imported chicken meat in Ghana, it is understandable that consumers who are price conscious will consume domestic chicken less frequently compared to imported chicken. This result is also confirmed by the variable "imported chicken more affordable", which captures the perceived affordability of imported and domestic chicken. Notably, consumers who perceived imported chicken meat as more affordable compared to domestic chicken are also less likely to consume domestic chicken frequently. The effect on the imported chicken is in line with our expectations but statistically insignificant. Collectively, both results emphasize that price is of utmost importance for the consumption of imported and domestic chicken meat products.

Furthermore, perceived quality positively (negatively) influences domestic (imported) chicken consumption, indicating that domestic chicken meat is regularly consumed compared with imported chicken among consumers who perceive it to be of better quality. This result is plausible since, for consumers, Ghanaian chicken means domestic production and freshness, which is often linked to better taste, whereas imported means long-distance transportation of frozen products and loss of taste. Finally, the average marginal effects indicate that ethnocentric consumers are 2.4 percentage points more likely to consume domestic chicken twice a week or more, and 3.4 percentage points more likely never to consume imported chicken meat. This suggests that consumer ethnocentrism is a significant driver of domestic chicken consumption and a barrier for imported chicken consumption. This result agrees with previous studies regarding the relationship between consumer ethnocentrism and domestic food consumption (e.g., Kavak \& Gumusluoglu, 2007; Vida \& Reardon, 2008). It is also consistent with Makanyeza \& du Toit (2016), who find that ethnocentrism negatively influences consumer attitude toward imported poultry products in Zimbabwe. 
Table 5.7: Predicted probabilities and marginal effects from the bivariate ordered probit model of imported and domestic chicken consumption

\begin{tabular}{|c|c|c|c|c|c|c|}
\hline & Never & Occasionally & Once a month & 2-3 times a month & Once a week & 2 times or more a week \\
\hline \multicolumn{7}{|l|}{ Imported chicken } \\
\hline Predicted prob. & 0.141 & 0.235 & 0.128 & 0.217 & 0.124 & 0.154 \\
\hline Gender (female) & $0.047^{*}$ & $0.037^{*}$ & $0.005^{*}$ & $-0.013^{*}$ & $-0.022^{*}$ & $-0.054^{*}$ \\
\hline Age & 0.000 & 0.000 & 0.000 & 0.000 & 0.000 & 0.000 \\
\hline Married & 0.014 & 0.011 & 0.002 & -0.004 & -0.006 & -0.016 \\
\hline Children (<18 years) & $-0.032^{*}$ & $-0.025^{*}$ & -0.004 & $0.009^{*}$ & $0.015^{*}$ & $0.037^{*}$ \\
\hline Tertiary & -0.007 & -0.006 & -0.001 & 0.002 & 0.003 & 0.008 \\
\hline Formally employed & $-0.037^{* *}$ & $-0.029^{* *}$ & $-0.004^{*}$ & $0.011^{*}$ & $0.018^{* *}$ & $0.043^{* *}$ \\
\hline Middle income & -0.025 & -0.019 & -0.003 & 0.007 & 0.012 & 0.028 \\
\hline High income & -0.007 & -0.006 & -0.001 & 0.002 & 0.003 & 0.008 \\
\hline Distance (in minutes) & $0.005^{* * *}$ & $0.004^{* * *}$ & $0.001^{* * *}$ & $-0.001^{* * *}$ & $-0.002^{* * *}$ & $-0.006^{* * *}$ \\
\hline Location $(1=$ Accra $)$ & -0.015 & -0.012 & -0.002 & 0.004 & 0.007 & 0.017 \\
\hline Food safety concern & 0.015 & 0.011 & 0.002 & -0.004 & -0.007 & -0.017 \\
\hline Interest in human health and production standards & -0.003 & -0.002 & 0.000 & 0.001 & 0.001 & 0.003 \\
\hline Availability \& convenience & $-0.062^{* * *}$ & $-0.048^{* * *}$ & $-0.007^{* * *}$ & $0.017^{* * *}$ & $0.029^{* * *}$ & $0.071^{* * *}$ \\
\hline Price consciousness & $-0.019^{*}$ & $-0.015^{*}$ & $-0.002^{*}$ & $0.005^{*}$ & $0.009^{*}$ & $0.021^{*}$ \\
\hline Convenience of imported chicken & $-0.020^{* *}$ & $-0.016^{* *}$ & $-0.002^{*}$ & $0.006^{*}$ & $0.010^{* *}$ & $0.023^{* *}$ \\
\hline Domestic chicken safer \& healthier & 0.015 & 0.012 & 0.002 & -0.004 & -0.007 & -0.017 \\
\hline Domestic chicken of higher quality & $0.032^{* * *}$ & $0.025^{* * *}$ & $0.004^{* * *}$ & $-0.009^{* * *}$ & $-0.015^{* * *}$ & $-0.037^{* * *}$ \\
\hline Imported chicken more affordable & -0.011 & -0.009 & -0.001 & 0.003 & 0.005 & 0.013 \\
\hline Pragmatism & 0.005 & 0.004 & 0.001 & -0.001 & -0.002 & -0.006 \\
\hline Ethnocentrism & $0.034^{* * *}$ & $0.027^{* * *}$ & $0.004^{* * *}$ & $-0.010^{* * *}$ & $-0.016^{* * *}$ & $-0.039^{* * *}$ \\
\hline \multicolumn{7}{|l|}{ Domestic chicken } \\
\hline Predicted prob. & & 0.556 & 0.178 & 0.119 & 0.094 & 0.052 \\
\hline Gender (female) & & 0.064 & -0.011 & -0.016 & -0.020 & -0.017 \\
\hline Age & & 0.000 & 0.000 & 0.000 & 0.000 & 0.000 \\
\hline Married & & -0.019 & 0.003 & 0.005 & 0.006 & 0.005 \\
\hline Children (<18 years) & & -0.049 & 0.008 & 0.012 & 0.015 & 0.013 \\
\hline Tertiary & & 0.006 & -0.001 & -0.001 & -0.002 & -0.002 \\
\hline Formally employed & & 0.023 & -0.004 & -0.006 & -0.007 & -0.006 \\
\hline Middle income & & -0.051 & 0.009 & 0.013 & 0.016 & 0.014 \\
\hline High income & & $-0.138^{*}$ & $0.024^{*}$ & $0.035^{*}$ & $0.043^{*}$ & $0.037^{*}$ \\
\hline Distance (in minutes) & & $0.004^{* * *}$ & $-0.001^{* * *}$ & $-0.001^{* *}$ & $-0.001^{* *}$ & $-0.001^{* * *}$ \\
\hline Location (1=Accra) & & -0.045 & 0.008 & 0.011 & 0.014 & 0.012 \\
\hline Food safety concern & & $0.039^{*}$ & $-0.007^{*}$ & $-0.010^{*}$ & $-0.012^{*}$ & $-0.010^{*}$ \\
\hline Interest in human health and production standards & & -0.013 & 0.002 & 0.003 & 0.004 & 0.004 \\
\hline
\end{tabular}




\begin{tabular}{|c|c|c|c|c|c|c|}
\hline & Never & Occasionally & Once a month & 2-3 times a month & Once a week & 2 times or more a week \\
\hline Availability \& convenience & & -0.007 & 0.001 & 0.002 & 0.002 & 0.002 \\
\hline Price consciousness & & $0.043^{* *}$ & $-0.007^{*}$ & $-0.011^{*}$ & $-0.013^{*}$ & $-0.012^{*}$ \\
\hline Convenience of imported chicken & & $0.060^{* * *}$ & $-0.010^{* * *}$ & $-0.015^{* * *}$ & $-0.019^{* * *}$ & $-0.016^{* * *}$ \\
\hline Domestic chicken safer \& healthier & & 0.021 & -0.004 & -0.005 & -0.007 & -0.006 \\
\hline Domestic chicken of higher quality & & $-0.046^{* *}$ & $0.008^{* *}$ & $0.011^{* *}$ & $0.014^{* *}$ & $0.012^{* *}$ \\
\hline Imported chicken more affordable & & $0.078^{* * *}$ & $-0.013^{* * *}$ & $-0.019^{* * *}$ & $-0.024^{* * *}$ & $-0.021^{* * *}$ \\
\hline Pragmatism & & -0.011 & 0.002 & 0.003 & 0.003 & 0.003 \\
\hline Ethnocentrism & & $-0.088^{* * *}$ & $0.015^{* * *}$ & $0.022^{* * *}$ & $0.027^{* * *}$ & $0.024^{* * *}$ \\
\hline
\end{tabular}

Note: ${ }^{*}, * *, * *$ Indicates statistical significance at the $10 \%, 5 \%$ and $1 \%$ level, respectively. 


\subsection{Conclusions}

This paper investigated the role of personal factors in explaining chicken meat consumption with particular emphasis on domestic and imported chicken using survey data of Ghanaian households. Ordered probit models are used to explain the frequency of consumption. Results from a bivariate ordered probit model confirm that domestic and imported chicken products are not independent of each other since there is a significant weak negative correlation between them. This also implies that both products can be regarded as (weak) substitutes than as complements. Overall, the results confirm that personal factors especially, consumers' perceptions and attitudes matter in the consumption of chicken meat.

The paper has the following main results. First, chicken consumption is sensitive to food safety concerns. In particular, we find that food safety concerns negatively influence the consumption of domestic chicken. Second, consumers' attitudes toward the availability of chicken meat positively influence the consumption of imported chicken meat. However, more frequent consumption of both imported and domestic chicken is discouraged the longer consumers have to travel to reach their markets of choice. Third, price is obviously an important factor influencing the frequency of chicken meat consumption. In this study, price concern, perceived affordability of imported chicken relative to domestic chicken as well as household income are significant barriers for domestic chicken consumption.

Fourth, convenience is an important driver of chicken meat consumption. For instance, consumers who perceived imported chicken as more convenient compared to domestic chicken meat, including consumers who are employed, avoid eating domestic chicken regularly. Fifth, consumers strongly emphasized the importance of sensory quality, and perceived domestic chicken meat to outperform imported alternatives on this attribute. Specifically, the perception that domestic chicken meat is fresher, tastier, and of good quality increases (decreases) the frequency of domestic (imported) chicken consumption. Finally, ethnocentrism is also identified as an influencing factor; the more ethnocentric consumers are, the more likely they are to consume domestic chicken regularly and seldom consume imported chicken.

A possible limitation of this study is that the dependent variable captures stated consumption frequency. That is, neither quantities are reported, nor real consumption is observed. Notwithstanding, the findings have important marketing and policy implications, especially when the objectives are to increase the consumption of domestic food products and to shift more frequent consumption from imported to domestic products, amidst increasing imports. 


\subsubsection{Managerial and policy recommendations}

This study clearly shows that not only should strategies or policies be aimed at the supply-side, but also demand-side actions could be beneficial. Market segmentation strategies based on the significant sociodemographic factors may be necessary. For example, marketers of domestic chicken could specifically target affluent (high-income) consumers. Since the perception of the inconvenience of domestic chicken relative to imported chicken negatively influences its consumption, providing a convenient chicken product could be one possibility to influence consumers' consumption decisions for domestic chicken.

Given that consumers who are concerned about food safety are less likely to consume domestic chicken frequently, there is a need for effective collaboration between the government and actors in the supply chain to address the safety needs of consumers. For instance, effective communication strategies through advertising or improving consumers' accessibility of useful and objective information on the process of production might help increase consumer confidence and lead to a change in consumption patterns away from imported toward domestic chicken.

Moreover, the finding that the perceived quality of domestic chicken meat is positively associated with its consumption is meaningful. For the domestic poultry sector, this is an important piece of information in a market that is increasingly being internationalized. Promotional activities that highlight the quality aspect of domestic chicken meat (in terms of taste and freshness) are likely to give domestic actors a competitive advantage and to offset the negative association between domestic chicken consumption and safety concerns. The findings on distance and attitudes toward the availability of chicken meat provide evidence in support of expanding chicken markets closer to consumers. This may lead to an increase in the frequency of purchase and perhaps an increase in the consumption of domestic chicken meat.

The finding on ethnocentrism from a managerial point of view indicates that the domestic poultry industry could benefit from appealing to the ethnocentric tendencies of consumers as an attribute to differentiate itself from the competition offered by imports in the internal market. However, the price of domestic chicken meat may limit future market growth. Thus, the government's efforts could target at reducing the price gap between domestic and imported chicken meat products because a ban on imports in the short term is not seen as the best solution since consumers would ultimately carry the burden of having less and expensive domestic chicken meat. 


\section{References}

Cade, J., Thompson, R., Burley, V., \& Warm, D. (2002). Development, validation and utilization of food-frequency questionnaires - A review. Public Health Nutrition, 5(04), 567-587.

Chisenga, J., Entsua-Mensah, C., \& Sam, J. (2007, August). Impact of globalization on the information needs of farmers in Ghana: a case study of small-scale poultry farmers. Paper presented at the World Library and Information Congress: 73rd International Federation of Library Associations General Conference and Council. Durban, South Africa.

Cranfield, J. A. L., Hertel, T. W., Eales, J. S., \& Preckel, P. V. (1998). Changes in the structure of global food demand. American Journal of Agricultural Economics, 80(5), 1042-1050.

Daykin, A. R., \& Moffatt, P. G. (2002). Analyzing ordered responses: A review of the ordered probit model. Understanding Statistics, 1(3), 157-166.

Delgado, C. L. (2003). Rising consumption of meat and milk in developing countries has created a new food revolution. The Journal of Nutrition, 133(11), 3907S-3910S.

Dumortier, J., Evans, K. S., Grebitus, C., \& Martin, P. A. (2017). The influence of trust and attitudes on the purchase frequency of organic produce. Journal of International Food and Agribusiness Marketing, 29(1), 46-69.

Ecker, O., \& Fang, P. (2016). Economic development and nutrition transition in Ghana: Taking stock of food consumption patterns and trends. In N. Covic \& S. L. Hendriks (Eds.), Achieving a nutrition revolution for Africa: The road to healthier diets and optimal nutrition (pp.28-50). International Food Policy Research Institute, Washington, DC.

FAO (Food and Agriculture Organization of the United Nations). (2014). Poultry sector Ghana (Report No. 6). FAO Animal Production and Health Livestock Country Reviews. Rome: Food and Agriculture Organization of the United Nations.

Font-i-Furnols, M., \& Guerrero, L. (2014). Consumer preference, behavior and perception about meat and meat products: an overview. Meat Science, 98(3), 361-371.

Furst, T., Connors, M., Bisogni, C. A., Sobal, J., \& Falk, L. W. (1996). Food choice: a conceptual model of the process. Appetite, 26(3), 247-266.

Grebitus, C., Yue, C., Bruhn, M., \& Jensen, H. H. (2011). Perceived quality in organic and conventional pork markets in Germany. Food Economics - Acta Agriculturae Scandinavica, Section C, 8(4), 187-199.

Greene, W. H. (2002). Econometric analysis (5th ed.). Upper Saddle River, NJ: Prentice Hall.

Greene, W. H., \& Hensher, D. A. (2010). Modeling ordered choices: a primer. Cambridge: Cambridge University Press.

Gil, J. M., Gracia, A., \& Sanchez, M. (2000). Market segmentation and willingness to pay for organic products in Spain. International Food and Agribusiness Management Review, 3(2), 207-226.

Guenther, P. M., Jensen, H. H., Batres-Marquez, S. P., \& Chen, C. F. (2005). Sociodemographic, knowledge, and attitudinal factors related to meat consumption in the United States. Journal of the American Dietetic Association, 105(8), 1266-1274.

Hair, J. F., Black, W. C., Babin, B. J., Anderson, R. E. (2010). Multivariate data analysis (7th ed.). Upper Saddle River, NJ: Prentice-Hall.

Hair, J. F., Black, W. C., Babin, B. J., Anderson, R. E., \& Tatham, R. L. (2006). Multivariate data analysis. New Jersey: Pearson University Press.

Hall, T. E., \& Amberg, S. M. (2013). Factors influencing consumption of farmed seafood products in the Pacific northwest. Appetite, 66, 1-9.

Huang, L. C., Goh, Y. N., \& Mohaidin, Z. (2014). Factors influencing consumer intentions to avoid broiler chicken meat and products in Malaysia. International Food Research 
Journal, 21(1), 181-188.

Kavak, B., \& Gumusluoglu, L. (2007). Segmenting food markets - The role of ethnocentrism and lifestyle in understanding purchasing intentions. International Journal of Market Research, 49(1), 71-94.

Kroeber-Riel, W., Weinberg, P., \& Gröppel-Klein, A. (2009). Konsumentenverhalten [Consumer behavior] (9th ed.). München: Vahlen.

Kumar, G., Quagrainie, K., \& Engle, C. (2008). Factors that influence frequency of purchase of catfish by U.S. households in selected cities. Aquaculture Economics \& Management, 12(4), 252-267.

Kwadzo, G. T.-M., Dadzie, F., Osei-Asare, Y. B., \& Kuwornu, J. K. M. (2013). Consumer preference for broiler meat in Ghana: A conjoint analysis approach. International Journal of Marketing Studies, 5(2), 66-73.

Leahy, E., Lyons, S., \& Tol, R. S. J. (2011). Determinants of vegetarianism and meat consumption frequency in Ireland. Economic and Social Review, 42(4), 407-436.

Makanyeza, C., \& du Toit, F. (2016). Factors influencing consumers' choice of imported poultry meat products in a developing market: Lessons from Zimbabwe. Agrekon, 55(3), 191-215.

McCarthy, M., de Boer, M., O’Reilly, S., \& Cotter, L. (2003). Factors influencing intention to purchase beef in the Irish market. Meat Science, 65(3), 1071-1083.

McCarthy, M., O'Reilly, S., Cotter, L., \& de Boer, M. De. (2004). Factors influencing consumption of pork and poultry in the Irish market. Appetite, 43(1), 19-28.

McKelvey, R. D., \& Zavoina, W. (1975). A statistical model for the analysis of ordinal level dependent variables. The Journal of Mathematical Sociology, 4(1), 103-120.

Meade, B., \& Thome, K. (2017). International food security assessment, 2017-2027. GFA28, U.S. Department of Agriculture, Economic Research Service.

Michaelidou, N., \& Hassan, L. M. (2008). The role of health consciousness, food safety concern and ethical identity on attitudes and intentions towards organic food. International Journal of Consumer Studies, 32(2), 163-170.

MoFA (Ministry of Food and Agriculture) (2007). Food and Agriculture Development Policy (FASDEP II). Accra: Accra: Ministry of Food and Agriculture.

OECD-FAO (Organization for Economic Cooperation and Development and the Food and Agriculture Organization of the United Nations). (2017). OECD-FAO agricultural outlook (edition 2017), OECD agriculture statistics (database). OECD Publishing, Paris. Retrieved from https://doi.org/10.1787/d9e81f72-en (accessed on 19 September 2018).

OECD-FAO (2019a). OECD-FAO agricultural outlook (edition 2019), OECD agriculture statistics (database). OECD Publishing, Paris. Retrieved from https://doi.org/10.1787/eed409b4-en (accessed on 30 December 2019).

OECD-FAO (2019b). OECD-FAO agricultural outlook 2019-2028. OECD Publishing, Paris. Available at https://doi.org/10.1787/agr_outlook-2019-en.

Olsen, S. O. (2003). Understanding the relationship between age and seafood consumption: The mediating role of attitude, health and involvement and convenience. Food Quality and Preference, 14(3), 199-209.

Rimal, A. (2005). Meat labels: Consumer attitude and meat consumption pattern. International Journal of Consumer Studies, 29(1), 47-54.

Roininen, K., Tuorila, H., Zandstra, E. H., de Graaf, C., Vehkalahti, K., Stubenitsky, K., \& Mela, D. J. (2001). Differences in health and taste attitudes and reported behaviour among Finnish, Dutch and British consumers: A cross-national validation of the Health and Taste Attitude Scales (HTAS). Appetite, 37(1), 33-45.

Rortveit, A. W., \& Olsen, S. O. (2009). Combining the role of convenience and consideration set size in explaining fish consumption in Norway. Appetite, 52(2), 313-317. 
Schmid, A., Gille, D., Piccinali, P., Bütikofer, U., Chollet, M., Altintzoglou, T., ... Stoffers, H. (2017). Factors predicting meat and meat products consumption among middleaged and elderly people: evidence from a consumer survey in Switzerland. Food and Nutrition Research, 61(1), 1308111.

Schnettler, B., Miranda, H., Lobos, G., Sepúlveda, J., \& Denegri, M. (2011). A study of the relationship between degree of ethnocentrism and typologies of food purchase in supermarkets in central-southern Chile. Appetite, 56(3), 704-712.

Shimp, T., \& Sharma, S. (1987). Consumer ethnocentrism. Construction and validation of the CETSCALE. Journal of Marketing Research, 24(3), 280-289.

Swait, J. (1994). A structural equation model of latent segmentation and product choice for cross sectional revealed preference choice data. Journal of Retailing and Consumer Services, 1(2), 77-89.

Tambi, N. E. (2001). Analysis of household attitudes toward the purchase of livestock products and fish in Cameroon. Agricultural Economics, 26(2), 135-147.

Thong, N. T., \& Olsen, S. O. (2012). Attitude toward and consumption of fish in Vietnam. Journal of Food Products Marketing, 8(2), 79-95.

Thong, N. T., \& Solgaard, H. S. (2017). Consumer's food motives and seafood consumption. Food Quality and Preference, 56, 181-188.

USDA (United States Department of Agriculture). (2017). Ghana poultry report annual. United States Department of Agriculture, Accra.

Verbeke, W. (2005). Consumer acceptance of functional foods: Socio-demographic, cognitive and attitudinal determinants. Food Quality and Preference, 16(1), 45-57.

Verbeke, W., \& Vackier, I. (2005). Individual determinants of fish consumption: Application of the theory of planned behaviour. Appetite, 44(1), 67-82.

Verhoef, P. C. (2005). Explaining purchases of organic meat by Dutch consumers. European Review of Agricultural Economics, 32(2), 245-267.

Vida, I., \& Reardon, J. (2008). Domestic consumption: Rational, affective or normative choice? Journal of Consumer Marketing, 25(1), 34-44.

Woolverton, E. A., \& Frimpong, S. (2013). Consumer demand for domestic and imported broiler meat in urban Ghana: Bringing non-price effects into the equation. British Journal of Marketing Studies, 1(3), 16-31.

Yen, S. T., Lin, B.-H., \& Davis, C. G. (2008). Consumer knowledge and meat consumption at home and away from home. Food Policy, 33(6), 631-639. 


\title{
6 Is there hope for domestically produced poultry meat? A choice experiment of consumers in Ghana ${ }^{6}$
}

\begin{abstract}
Over the past few decades, the opening up of trade has often put producers in developing countries under competitive pressure from food imports, particularly in the case of poultry products. Consequently, raising numerous concerns about the continued growth of domestic poultry production, especially in sub-Saharan Africa. Therefore, this paper assesses consumers' preferences and willingness to pay for chicken meat of domestic and imported origins and other quality attributes. We used data conducted among 500 consumers in Ghana. Results from both a random parameter logit and a latent class models show that consumers have heterogeneous preferences for chicken meat attributes. Specifically, findings indicate that consumers prefer domestic to imported chicken and are willing to pay a premium for domestic chicken. In addition, antibiotic/hormone-free, fresh, and cuts are preferred with antibiotic/hormone-free having a larger impact on choices. Furthermore, consumers' preferences differ across segments and are largely based on their attitudes toward food.
\end{abstract}

Keywords: chicken, choice experiment, preference heterogeneity, willingness to pay

JEL codes: C25, D12, Q13

\footnotetext{
6 This chapter has been published in Agribusiness (2020): 36(2), 281-298 (Wiley Periodicals, Inc.). https://doi.org/10.1002/agr.21626. It is co-authored with Daniela Weible (DW).

Authors' contributions: All authors jointly designed the research. I (CAA) collected the data, analyzed, and wrote the paper. DW commented at the various stages of the research and contributed to writing and revising the paper.
} 


\subsection{Introduction}

The growing internationalization of agricultural and food markets often put producers, especially in developing countries under substantial competitive pressure from food imports. The implications of rising imports, in general, could be positive or negative. In some case, it implies a decrease in price and increase in product choices for consumers (Rakotoarisoa, Sharma, \& Hallam, 2011) and hence important for achieving food security. On the other hand, it may lead to a decline in domestic production by lowering farm prices, resulting in decreasing farmers' production incentives and consequently leading to job losses (Rakotoarisoa et al., 2011). Very often, however, some analysts, policymakers, and industry players have focused on the negative aspects of import surge and overlooked some of its benefits. This has been the case, particularly in the trading of poultry meat. In this regard, agricultural and trade policies in the exporting countries (e.g., European Union countries) are often criticized for their detrimental effects on domestic poultry industries, especially in sub-Saharan Africa (SSA) (see, e.g., Mari, 2015; Rudloff \& Schmieg, 2016).

To address this issue, this paper provides an economic assessment of consumers' preferences for several product attributes of poultry meat covering imported and domestic meat. Evaluation of consumers' preferences for domestic and foreign food products is often done using the country-of-origin attribute. The country-of-origin is a cognitive, affective, and normative cue that consumers use to infer the quality of a product (Verlegh \& Steenkamp, 1999) by linking the product to their knowledge and beliefs regarding the place of production (Grunert, 2005; Lim, Hu, Maynard, \& Goddard, 2014). A number of studies have examined the country-of-origin effects on consumers' preferences. Most of these studies carried out in different countries suggest a general preference for domestic products (Verlegh \& Steenkamp, 1999; Loureiro \& Umberger, 2005; Chambers, Lobb, Butler, Harvey, \& Traill, 2007; Chung, Boyer, \& Han, 2009; Font i Furnols et al., 2011; Lim et al., 2014). However, studies that examined the country-of-origin effect on consumer preference for poultry meat are very limited and focused on developed countries (Loureiro \& Umberger, 2005; Pouta, Heikkilä, ForsmanHugg, Isoniemi, \& Mäkelä, 2010; Balcombe, Bradley, Fraser, \& Hussein, 2016).

Therefore, our study focuses on developing countries using the case of the poultry sector in Ghana. We focus on the poultry sector because the demand for poultry meat has increased rapidly over the past decades in SSA, and also in Ghana, and this is expected to continue in the future. For example, between 2000 and 2017, poultry meat consumption in SSA increased from 1.5 to $2.1 \mathrm{~kg}$ per capita, representing an increase of about $40 \%$. Within the same period, consumption levels in Ghana increased at a rate of $258.8 \%$ from 1.7 to $6.1 \mathrm{~kg}$ per capita (OECD- 
FAO, 2017). With the rising demand, domestic poultry production has also experienced growth over the years but largely failed to match growth in demand. As a result, the deficit has been increasingly compensated by rising food imports making Ghana a net importer and the third largest importer of poultry meat products in SSA. Interestingly, product attributes of imported chicken meat differ greatly in their main characteristics from domestic chicken meat. Indeed, one of the reasons behind these concerns is the large price difference between domestic and imported poultry meat. Generally, the prices of domestic poultry meat are about 30-40\% higher than imported poultry meat (USDA, 2017). As a consequence, while poultry consumption is rising amid increasing imports, there are concerns about the impact of low-priced imports on the domestic poultry industry and the desire to develop the industry are revealed in various government policy measures and programs implemented over the years. These include tariffs on imports, removal of customs duties on inputs (feed, additives, drugs, and vaccines), and facilitation of improved access to veterinary services (Aning, 2006; Andam, Johnson, Ragasa, Kufoalor, \& Das Gupta, 2017). Other policy measures are in the form of "indirect" support such as the recently implemented Planting for Food and Jobs (PFJ) Program that targets crop farmers with incentives to increase maize and soybean production (MoFA 2017), which are major components of poultry feed. Nevertheless, the ability of domestic poultry production to contribute to improved farm incomes and the effectiveness of the government's policies and programs depend on whether consumers are willing to pay a premium for domestic poultry meat and its attributes.

In this context, this study provides an assessment of consumers' preferences and willingness to pay (WTP) for the country-of-origin as well as other value-added attributes (i.e., product form, storage form, and production claim) using a choice experiment approach. In addition, it accounts for heterogeneity in consumers' preferences and further identifies consumer segments using attitudinal factors. Our results can help actors in the supply chain to tailor-design their products and develop effective marketing strategies based on consumers' preferences. Moreover, the results might be useful for policymakers in the ongoing effort to improve the competitiveness of domestic meat products in Ghana and by extension other West African countries. 


\subsection{Data and methods}

\subsubsection{Choice experiment design}

We used a discrete choice experiment to assess consumers' preferences for chicken meat attributes. We employed this technique because it has become a popular tool to analyze the value of food attributes (e.g., Lusk \& Schroeder, 2004; Loureiro \& Umberger, 2007; Pouta et al., 2010; Van Loo, Caputo, Nayga, Meullenet, \& Ricke, 2011; Ortega, Hong, Wang, \& Wu, 2016), particularly in situations where market data are unreliable or non-existent (Tonsor, Olynk, \& Wolf, 2009) such as in the case of poultry meat in Ghana. Moreover, this method has the ability to value multiple product attributes (existing or non-existing) simultaneously, and it is more similar to real-life purchasing decisions (Lusk \& Schroeder, 2004).

In Ghana, chicken is typically sold as live, whole-dressed, and parts such as leg quarters/thighs, wings, backs, and breast. For the experiment, we standardized the product based on weight. We used an average weight of $1.3 \mathrm{~kg}$, which is equivalent to the average weight of a whole-dressed chicken in the markets. The product attributes, and their corresponding levels used in the experimental design were selected based on a literature review and focus groups conducted prior to the experiment and quantitative survey. Table 6.1 presents the complete set of attributes and their respective levels employed in the choice experiment.

Table 6.1: Attributes and levels used in the choice experiment

\begin{tabular}{lll}
\hline Attribute & Level & Description \\
\hline Country-of-origin & $\begin{array}{l}\text { Ghana (ref) } \\
\text { Foreign }\end{array}$ & $\begin{array}{l}\text { Indicates whether the chicken was produced in Ghana } \\
\text { or another country. }\end{array}$ \\
Product form & $\begin{array}{l}\text { Whole-dressed (ref) } \\
\text { Cuts/Parts }\end{array}$ & $\begin{array}{l}\text { Refers to whether the chicken is whole dressed or has } \\
\text { been cut into parts. }\end{array}$ \\
Storage form & $\begin{array}{l}\text { Frozen (ref) } \\
\text { Fresh (chilled) }\end{array}$ & $\begin{array}{l}\text { Indicates whether chicken is fresh or has been stored } \\
\text { frozen. }\end{array}$ \\
Production claim & $\begin{array}{l}\text { No claim (ref) } \\
\text { Antibiotic/hormone-free }\end{array}$ & $\begin{array}{l}\text { Refers to claims of whether the chicken was raised } \\
\text { with or without the use of antibiotics or synthetic } \\
\text { growth hormones. }\end{array}$ \\
Price $(\mathrm{GH} \phi / 1.3 \mathrm{~kg})$ & $14,26,38,50$ & \begin{tabular}{l} 
Refers to the retail price of chicken in the markets. \\
\hline
\end{tabular}
\end{tabular}

The levels for price attribute were determined based on a pre-survey assessment of prevailing market prices for chicken. These prices were confirmed by the focus groups. The price attribute comprised four levels with the range reflecting both the low-end and high-end prices of $1.3 \mathrm{~kg}$ marketed chicken meat. The two middle levels were set adding $\mathrm{GH} \phi 12$ between the minimum and maximum price levels. For the country-of-origin, two levels were included: 
Ghana (domestically produced) and foreign to represent imported chicken ${ }^{7}$. The product form offered for consideration in the survey were chosen to reflect the level of convenience. From the available chicken products on the markets, we selected whole-dressed and cuts (parts). Fresh and frozen were selected as the relevant storage form levels since chicken products available in the markets are either fresh (including live) or frozen. Finally, as it emerged from the focus groups that consumers were concerned about food safety issues, particularly the use of antibiotics and/or growth hormones in chicken production, we selected "antibiotic/hormonefree" production claim and "no claim".

The Ngene software (ChoiceMetrics, 2014) was used to generate the choice sets. A preliminary pilot study assuming zero priors (Hensher, Rose, \& Greene, 2005) was carried out with 27 consumers in Ghana. These individuals made their selections and provided feedback for improvement of the final choice experiment. The pilot survey data were analyzed to obtain Bayesian priors for the main design. Then, we generated a D-efficient experimental design using parameter priors from the pilot study, and this was optimized on the D-error. In total, 12 choice sets were generated with three alternatives: two experimentally designed alternatives representing the chicken products and an opt-out (none of these) option, which allowed respondents not to choose either of the two chicken products. The inclusion of the opt-out option prevents making the choice set conditional, and it allows the estimation of true demand models, rather than conditional models (Louviere, Hensher, \& Swait, 2000). An example of a choice set is presented in Table 6.2.

The 12 choice sets were blocked into two groups of six. Respondents were randomly assigned to one of the two blocks and chose one alternative in each of the six choice scenarios. In addition, we randomized the order of the products presented to the respondents to minimize any ordering or carryover effects in the data collected. Since the experiment was hypothetical, we used a modified "cheap-talk" strategy prior to administration of the choice tasks to reduce hypothetical bias (Cummings \& Taylor, 1999; Lusk, 2003). Finally, since the attribute levels "foreign" and "fresh" cannot occur together (all foreign chicken products are imported as frozen), the occurrence of this combination as a potential profile was constrained.

\footnotetext{
${ }^{7}$ Imported chicken in Ghana mainly come from U.S., Brazil, and European countries.
} 


\begin{tabular}{lccc}
\hline & Option A & Option B & Option C \\
\hline Country-of-origin & Foreign & Ghana & \\
Product form & Whole dressed & Cuts/Parts & None of these \\
Storage form & Frozen & Fresh & \\
Production claim & Antibiotic/Hormone free & No claim & \\
Price $(\mathrm{GH} \phi / 1.3 \mathrm{~kg})$ & GH $\notin 26$ & GH $₫ 38$ & \\
I prefer & $\square$ & $\square$ & $\square$ \\
\hline
\end{tabular}

\subsubsection{Sampling and data}

We administered the survey in Accra and Kumasi between March and April 2018. We selected these two cities because of their highly urbanized nature, ethnic diversity, and geographic location and most of the increase in poultry consumption is expected to occur in these areas. In addition, these cities represent two of the ten administrative regions (i.e., Greater Accra and Ashanti) where commercial poultry operations are mostly found. The study targeted chicken consumers who were responsible for buying or taken decisions concerning food purchase in the household and aged 18 years and above.

We employed a multistage sampling approach. First, we divided each city into 10 administrative units (i.e., sub-metros/districts). Second, to ensure greater representation within the study areas we randomly selected five sub-metros/districts from each city. Within each submetro/district, a random sample of communities was drawn. Two communities per submetro/district were selected. Finally, from each of the selected communities, households from which respondents were drawn were selected using systematic random sampling. To select a household, we followed a randomly generated route (random walk procedure), and respondents from every third household along the route were interviewed. Where a respondent in a target household did not eat chicken, was not available (after two visits) or not interested in participating, the next household was chosen. In total, 500 respondents were interviewed. The sample size considerations were informed by parameters of our choice experiment design and theoretical sample size requirements as indicated by Bliemer and Rose (2005). In addition to the choice experiment, the questionnaire captured data on consumers' chicken meat consumption habits, statements measured on a 5-point Likert scale ranging from "strongly disagree" to "strongly agree" to capture their general attitudes, and sociodemographic characteristics.

Table 6.3 presents the summary statistics of the sociodemographic characteristics of respondents. The majority of the respondents were females $(85 \%)$, which is higher than the national proportion of females (51\%) (GSS, 2013). The higher proportion of females compared to the population was expected since females in Ghana are the primary food shoppers in most 
households and are, therefore, responsible for food choices. The average age of respondents was 38 years, which is higher than the national average of 24 years (GSS, 2013). The average age of respondents should be higher than the overall national average, since only adults were surveyed.

Table 6.3: Sample descriptive statistics

\begin{tabular}{|c|c|c|}
\hline & Mean & Std. Dev. \\
\hline \multicolumn{3}{|l|}{ Gender (\%) } \\
\hline Female & 85.40 & \\
\hline Male & 14.60 & \\
\hline Age & 38.33 & 11.65 \\
\hline Household size & 4.20 & 1.85 \\
\hline Children ( $=1$ if children $<18$ years in household) & 0.72 & 0.45 \\
\hline \multicolumn{3}{|l|}{ Family status $(\%)$} \\
\hline Married & 60.0 & \\
\hline Single & 24.0 & \\
\hline Divorced/separated & 6.4 & \\
\hline Widowed & 5.0 & \\
\hline Living together/cohabiting & 4.6 & \\
\hline \multicolumn{3}{|l|}{ Education $(\%)$} \\
\hline No formal education & 4.0 & \\
\hline Primary & 8.0 & \\
\hline Junior secondary education & 24.0 & \\
\hline Secondary education & 20.6 & \\
\hline Post-secondary & 19.6 & \\
\hline Bachelor's degree & 18.8 & \\
\hline Master's or higher degree & 5.0 & \\
\hline \multicolumn{3}{|l|}{ Employment $(\%)$} \\
\hline Full-time employed & 32.0 & \\
\hline Part-time employed & 7.6 & \\
\hline Self-employed & 49.0 & \\
\hline Unemployed & 3.8 & \\
\hline Retired & 2.2 & \\
\hline Household duties (Homemaker) & 3.6 & \\
\hline Student & 1.8 & \\
\hline \multicolumn{3}{|l|}{ Household monthly income $(\%)$} \\
\hline $\mathrm{GH} \varnothing<200$ & 1.4 & \\
\hline $\mathrm{GH} \varnothing 200$ to $<600$ & 17.6 & \\
\hline $\mathrm{GH} \varnothing 600$ to $<1,000$ & 27.2 & \\
\hline $\mathrm{GH} \varnothing 1,000$ to $<1,400$ & 19.0 & \\
\hline $\mathrm{GH} \varnothing 1,400$ to $<1,800$ & 12.0 & \\
\hline $\mathrm{GH} \varnothing 1,800$ to $<2,200$ & 8.0 & \\
\hline $\mathrm{GH} \varnothing 2,200$ to $<2,600$ & 6.8 & \\
\hline $\mathrm{GH} \varnothing 2,600$ and above & 8.0 & \\
\hline
\end{tabular}

Source: Own calculation based on survey data (2018).

The average education level of the respondents is equivalent to a middle or junior high school graduate, which is consistent with the average education level in Ghana. The mean number of people living in the respondents' households was 4.2, which is a good representation of the average household size of 4.4 in Ghana (GSS, 2013). The majority of respondents were married (60\%) and had children under the age of 18 years living in their households $(72 \%)$. 
Majority of the respondents (27\%) stated that they had a net household monthly income between $\mathrm{GH} \varnothing 600$ and GHф 999 (US\$136.3 - US\$226.9).

\subsubsection{Econometric modelling}

The random utility model (McFadden, 1974) is a standard economic framework used to understand consumer's choice of goods. According to the random utility theory (RUT), the latent utility individuals derive from a choice object can be decomposed into a systematic (deterministic) component and a random (unexplainable) component. The systematic component represents the attributes of the choice alternatives and the characteristics of the individual decision-makers, whereas the random component captures uncertainty or all unidentified factors that influence choices (Louviere et al., 2000; Louviere, Flynn, \& Carson, 2010). Therefore, the utility function for person $n$ choosing option $j$ in a choice situation $t$, can be analyzed with a multinomial logit (MNL) model consisting of the deterministic $\left(V_{n j t}\right)$ and random components $\left(\varepsilon_{n j t}\right)$ :

$U_{n j t}=V_{n j t}+\varepsilon_{n j t}=\beta x_{n j t}+\varepsilon_{n j t}$

where $x_{n j t}$ represents a vector of chicken attributes related to alternative $j$ in choice situation $t$; $\beta$ is the row vector of individual parameters; $\varepsilon_{n j t}$ is the random component associated with individual $n$ and option $j$, which is assumed to be independent of $\beta$ and $x$.

Traditionally, the random utility-based choices are modeled using the MNL model due to its convenience. However, the MNL model is accompanied by some rather restrictive assumptions. These include (i) independence of irrelevant alternatives (IIA) property (i.e., choosing one alternative over another is not affected by the presence of any other alternative), (ii) the assumption of preference homogeneity, implying all respondents have the same taste for attributes and (iii) the assumption of independent errors over time (Hensher et al., 2005; Train, 2009). To relax these assumptions and allow for preference heterogeneity, the random parameter/mixed logit model has been developed. The random parameter logit (RPL) model accounts for taste heterogeneity by allowing parameters in the model to vary randomly across individuals (Train, 1998). Under the RPL, the general random utility model of Equation (6.1) can be expressed as:

$$
U_{n j t}=\beta_{n}^{\prime} x_{n j t}+\varepsilon_{n j t}
$$


where $\beta_{n}$ is a vector of random parameters, which has its own mean and variance, representing individual preferences, and $x_{n j t}$ is the vector of attributes found in the $j$ th alternative. Following Train (2009), the probability of individual $n$ 's observed choice sequence $y_{n}=\left\{y_{n 1}, \ldots, y_{n T}\right\}$ from $J$ alternatives of choice set $C$ in situation $t$ is given by

$P\left(y_{n} / x_{n}, b, W\right)=\int \prod_{t=1}^{T}\left\{\left[\exp \left(\beta_{n}^{\prime} x_{n y_{n}}\right)\right] /\left[\sum_{j \in J} \exp \left(\beta_{n}^{\prime} x_{n j t}\right)\right]\right\} \cdot \phi(\beta / b, W) d \beta$

where $\phi(\beta / b, W)$ is the normal density with mean $b$ and covariance $W$. Because Equation (6.3) lacks a closed form solution, simulated maximum likelihood estimation techniques are used to estimate the parameters of the model.

Nevertheless, in cases of very distinct preferences, heterogeneity could be examined by looking at discrete groups with a latent class (LC) approach (Train, 2009). The LC model assumes that individuals can be intrinsically sorted into a number of latent classes, each composed of homogenous preferences, but preferences are heterogeneous across classes (Boxall \& Adamowicz, 2002). The utility is given in the form:

$U_{n j t \mid s}=\beta_{s}^{\prime} x_{n j t}+\varepsilon_{n j t \mid s}$

The utility expression in Equation (6.4) can be decomposed into two parts: one for the choice model and the other for the class membership model. Therefore, the unconditional joint probability that a consumer $n$ will select alternative $j$, conditional on being in segment $s$ is expressed as:

$\operatorname{Pr}_{n j t \mid s}=\sum_{s=1}^{S}\left(\frac{\exp \left(\lambda_{s}^{\prime} Z_{n}\right)}{\sum_{s=1}^{S} \exp \left(\lambda_{s}^{\prime} Z_{n}\right)}\right) \cdot\left(\frac{\exp \left(\beta_{s}^{\prime} x_{n j t}\right)}{\sum_{k=1}^{K} \exp \left(\beta_{s}^{\prime} x_{n k t}\right)}\right)$

where the first term in parenthesis on the right-hand side represents the allocation of individual $n$ to the $s$ class (probability of class $s$ ). The second term is the choice probability that individual $n$, conditional on belonging to class $s(s=1, \cdots, S)$, chooses alternative $j$ from a particular set $C$, comprised of $J$ alternatives, in a particular choice occasion $t . Z_{n}$ is a vector of segmentation variables consisting of attitudes or sociodemographic characteristics; $\lambda_{s}$ is a vector of segmentspecific parameters; $x_{n j t}$ is a vector of observable attributes associated with chicken product $j$ and $\beta_{s}$ is a vector of class-specific coefficient used to capture heterogeneity in preference across classes. The determination of the "optimal" number of segments depends on a combination of 
statistical criteria, model parsimony, and researcher's judgment on the interpretability of coefficients (Boxall \& Adamowicz, 2002; Scarpa \& Thiene, 2011). In this study, we used principal component analysis (PCA) to reduce the dimension of attitudinal statements and the scores extracted from the components were incorporated into the class membership function.

\subsubsection{Empirical specification}

The final specification of the utility function included the different attribute levels and the alternative specific constant (ASC) for the opt-out option. The utility function is formulated as follows:

$U_{n j t}=A S C+\beta_{1}$ Foreign $+\beta_{2} C u t+\beta_{3}$ Fresh $+\beta_{4}$ Ant_claim $+\beta_{5}$ Price $+\varepsilon_{n j t}$

where Foreign, Cut, Fresh, Ant_claim (antibiotic/hormone-free claim), and Price represent the attribute levels as indicated in Table 6.1. The parameter estimates from both the RPL and the LC models provides information necessary to calculate the willingness to pay (WTP). The WTP for an attribute is the price change associated with a change in a given attribute. It is estimated as the negative ratio of the partial derivative of the utility function with respect to the attribute of interest, divided by the derivative of the utility function with respect to the coefficient of the price (Morrison, Bennett, Blamey, \& Louviere, 2002; Gracia, Loureiro, \& Nayga, 2009):

$W T P_{\text {Attribute }}=\left(\frac{\partial U_{n j t}}{\partial \text { Attribute }} / \frac{\partial U_{n j t}}{\partial \text { Price }}\right)$

The confidence intervals for the WTP estimates were calculated using the Delta method (Hole, 2007; Bliemer \& Rose, 2013).

\subsection{Results and discussion}

\subsubsection{MNL and RPL results}

We analyzed the choice experiment data using the MNL, RPL, and LC models in NLOGIT 5.0. Table 6.4 presents results of the MNL and RPL model specifications. The first column shows the MNL model with all parameters fixed. In the second column, the RPL model is presented. We estimated the RPL model using 1,000 Halton draws for the simulations as this was needed to produce stable results. The results show that all the attribute coefficients for the two specifications have the expected signs and are statistically significant justifying the appropriate choice of the attributes. 
However, we observed some differences with regard to the results of the storage form and production claim attributes. Specifically, in the MNL model, fresh has the highest marginal utility while the antibiotic/hormone-free claim is the highest in the RPL model. Comparing the specifications, we find that the goodness-of-fit measures (i.e., log-likelihood, Pseudo $\mathrm{R}^{2}$, Akaike Information Criterion (AIC), and Bayesian Information Criterion (BIC)) significantly improved with the RPL model.

Table 6.4: Parameter estimates from the MNL and RPL models

\begin{tabular}{|c|c|c|c|c|}
\hline \multirow[b]{2}{*}{ Variables } & \multicolumn{2}{|c|}{ MNL model } & \multicolumn{2}{|c|}{ RPL model } \\
\hline & Coeff. & SE & Coeff. & SE \\
\hline Foreign & $-0.463^{* * *}$ & $(0.088)$ & $-1.963^{* * *}$ & $(0.330)$ \\
\hline Cut & $0.401^{* * *}$ & $(0.066)$ & $1.031^{* * *}$ & $(0.223)$ \\
\hline Fresh & $1.079^{* * *}$ & $(0.100)$ & $2.950^{* * *}$ & $(0.308)$ \\
\hline Ant_claim & $0.958^{* * *}$ & $(0.085)$ & $3.064^{* * *}$ & $(0.349)$ \\
\hline Price & $-0.023^{* * *}$ & $(0.004)$ & $-0.065^{* * *}$ & $(0.010)$ \\
\hline ASC (Opt-out) & $-1.799^{* * *}$ & $(0.149)$ & $-1.570^{* * *}$ & $(0.302)$ \\
\hline \multicolumn{5}{|c|}{ Diagonal values in Cholesky matrix } \\
\hline Foreign & & & $3.331^{* * *}$ & $(0.327)$ \\
\hline Cut & & & $2.579^{* * *}$ & $(0.249)$ \\
\hline Fresh & & & $2.738^{* * *}$ & $(0.284)$ \\
\hline Ant_claim & & & $2.511^{* * *}$ & $(0.283)$ \\
\hline \multicolumn{5}{|c|}{ Standard deviations of parameter distributions } \\
\hline Foreign & & & $3.331^{* * *}$ & $(0.327)$ \\
\hline Cut & & & $2.604^{* * *}$ & $(0.244)$ \\
\hline Fresh & & & $2.759^{* * *}$ & $(0.284)$ \\
\hline Ant_claim & & & $3.891^{* * *}$ & $(0.319)$ \\
\hline Log-likelihood & -2190.3 & & -1804.4 & \\
\hline McFadden Pseudo- $\mathrm{R}^{2}$ & 0.151 & & 0.453 & \\
\hline AIC & 4392.6 & & 3640.9 & \\
\hline $\mathrm{BIC}$ & 2214.3 & & 1868.5 & \\
\hline Number of choice obs. & 3,000 & & 3,000 & \\
\hline
\end{tabular}

Note: ${ }^{* * *}$ Denotes statistical significance at the $1 \%$ level.

Since the RPL model fits the data better than the MNL model, we limit our discussion to the results from the RPL model. In line with assumptions usually employed in the literature, we assumed that all the attributes (i.e., country-of-origin, product form, storage form, and production claim) except price and the opt-out option are random and normally distributed. Making the price parameter fixed is in line with other empirical studies (e.g., Rigby \& Burton, 2005; Tonsor et al., 2009; Ortega et al., 2016). The price is fixed to avoid problems in the derivation of WTPs if the distribution of the price coefficient is close to or contains zero (Rigby $\&$ Burton, 2005). For the analysis, we converted the price variable from per $1.3 \mathrm{~kg}$ to per $\mathrm{kg}$. Results from the RPL model show that all of the estimated coefficients for foreign, cuts (parts), fresh, and antibiotic/hormone-free claim, are statistically significant at the $1 \%$ level.

Associated with each of the mean coefficient estimates of the random parameters are estimated standard deviations, which indicates the amount of variation around the sample population. The significance of the standard deviations of the attribute coefficients shows 
whether taste differences vary significantly across the population of consumers. The estimated standard deviation of each random parameter coefficient is significantly different from zero at the $1 \%$ level. This implies that there is heterogeneity in the preferences for the various chicken meat attributes. To evaluate further preference heterogeneity in the RPL model, we allowed for correlation among the random chicken attribute parameters. The diagonal values in the Cholesky matrix denote the true standard deviation of each random parameter after the crosscorrelated parameter terms have been unconfounded (Hensher et al., 2005). As shown in Table 6.4 , the values in the diagonal of the Cholesky matrix were all statistically significant, indicating evidence of persistence preference heterogeneity, even after allowing cross-correlations to exist among attribute parameters.

As expected, there is clear evidence against the opt-out option. The ASC parameter, which represents the 'none of these' option, is negative and significant. This indicates that the surveyed respondents tended to highly prefer any of the chicken products presented (i.e., either Option A or Option B), as opposed to the 'none of these' option regardless of the levels of the attributes in Options A and B. The fixed price parameter is negative and statistically significant, which is consistent with economic theory. The negative sign indicates that the likelihood of purchase would decline as the price increased.

Considering the country-of-origin with Ghana as the reference, we observe that the estimated coefficient for foreign is statistically significant and negative. This suggests that respondents perceive domestic chicken as a more valuable product than imported chicken. This is generally consistent with findings reported in the literature regarding the importance of country-of-origin and a preference for domestic meat. For instance, Pouta et al. (2010) reported that consumers in Finland value domestically produced broiler meat over that from Denmark, Brazil, and Thailand. Similarly, Balcombe et al. (2016) found that UK consumers place a high value on chicken breast from the UK over other countries in the EU or outside the EU. Thus, the preferences exhibited by respondents in this study are generally in accordance with the previous literature. This finding can be attributed to consumer ethnocentrism (Shimp \& Sharma, 1987; Orth \& Firbasová, 2003), consumer sense of identity and feeling of belongingness (Verlegh \& van Ittersum, 2001) or consumer relating domestic products to freshness, taste, and high quality (Chambers et al., 2007).

The positive and significant coefficient related to the product form (cuts) shows that on average consumers prefer chicken cuts to whole-dressed chicken. However, the effect of cuts is relatively small, which might be due to the fact that both cuts and whole-dressed are all convenient forms of chicken meat compared to live birds - the form in which domestic 
chickens are mainly sold. Another possible explanation for the relatively small marginal utility could be due to uncertainty among respondents in the cuts they were buying. For instance, the significant heterogeneity found in the cuts could imply that respondents have preferences for different cuts (such as leg quarters/thighs, wings, backs, etc.), which were not captured by this study. Notwithstanding, cuts appear to come with a higher level of convenience in comparison to whole-dressed, especially with regard to the ease and amount of time spent in preparation. Hence, it is not surprising that they are preferred over the whole-dressed chicken. Consumer preference for convenient chicken is consistent with previous studies in Ghana (Woolverton \& Frimpong, 2013) and Kenya (Bett, Peters, Nwankwo, \& Bokelmann, 2013). In contrast, Kwadzo, Dadzie, Osei-Asare, and Kuwornu (2013) found that households in Ghana preferred whole-dressed to chicken cuts (parts). However, compared to live birds, they found that chicken parts are the most preferred.

Freshness is an important quality cue used by consumers to assess the safety of meat products (Becker, Benner, \& Glitsch, 2000). In this regard, the estimated coefficient of the storage form attribute reveals that consumers prefer fresh to frozen chicken meat. The preference for fresh chicken meat over frozen shows that freshness is an important quality attribute for consumers and hence a year-round supply of fresh chicken meat in retail markets is essential. The result is consistent with Bett et al. (2013) who found that consumers in Kenya preferred fresh to frozen chicken meat. Consumers received the highest marginal utility from the production assurance. Specifically, the coefficient of the attribute level antibiotic/hormonefree claim is positive and statistically significant. This implies that consumer utility increases when an antibiotic/hormone-free claim is made for a chicken meat product. The result suggests that consumers in Ghana are similarly concerned about food safety as those in developed countries. Owusu-Sekyere, Owusu, and Jordaan (2014) reported a similar observation of consumer concern for safety in beef. Therefore, it would appear that in Ghana irrespective of the meat type, safety plays a major role in consumers' meat choice. The result is also consistent with similar findings of food safety concern among consumers in Asia and Africa (Jabbar, Baker, \& Fadiga, 2010).

\subsubsection{LC logit results}

The LC analysis aims to segment respondents based on their preferences for the product attributes. We estimated models with one through five classes. For each model, we calculated different criteria, Akaike Information Criterion (AIC), the modified Akaike Information Criterion (AIC3) and the Bayesian Information Criterion (BIC) to determine the optimal 
number of classes (Boxall \& Adamowicz, 2002). However, as indicated by Swait (1994) and Scarpa and Thiene (2011), the optimal number of latent segments to select must not only be looking at different multiple statistical criteria but also requires the discretion of the researcher and must account for the significance of parameter estimates and meaningfulness of parameter sign, with the overall aim of attaining segment parsimony. Following this, we considered Classes 2 and 3 but the indirect utilities for these classes had a high number of insignificant parameter estimates. Five or more classes also led to extremely large standard errors, which is considered as an indication to stop looking for more classes (Louviere et al., 2000). We hence chose only to report the LC model estimate for four classes, which is associated with the minimum BIC value (Table 6.5) and showed the most significant parameter estimates.

Table 6.5: Statistics for determining the optimal number of classes

\begin{tabular}{lcccccc}
\hline $\begin{array}{l}\text { Number } \\
\text { of classes }\end{array}$ & $\begin{array}{c}\text { Number of } \\
\text { parameters (P) }\end{array}$ & $\begin{array}{c}\text { Log likelihood at } \\
\text { convergence (LL) }\end{array}$ & Pseudo- R & AIC $^{\text {a }}$ & AIC $^{\text {b }}$ & BIC $^{\mathrm{c}}$ \\
\hline 1 & 6 & -2190.29 & 0.151 & 4392.60 & 4389.59 & 2214.31 \\
2 & 20 & -2051.57 & 0.378 & 4143.10 & 4133.13 & 2131.63 \\
3 & 34 & -1888.82 & 0.427 & 3845.60 & 3828.65 & 2024.93 \\
4 & 48 & -1795.10 & 0.455 & 3686.20 & 3662.20 & 1987.25 \\
5 & 62 & -1779.82 & 0.460 & 3683.60 & 3652.65 & 2028.02 \\
\hline
\end{tabular}

Number of choices $(N)=3000$. Log likelihood evaluated at zero is -3295.84 .

${ }^{a}$ AIC (Akaike Information Criterion) is calculated using $-2(L L-P)$.

${ }^{\mathrm{b}}$ AIC3 (Bozdogan Akaike Information Criterion) is calculated using $-2 L L+3 P$.

${ }^{\mathrm{c}} \mathrm{BIC}$ (Bayesian Information Criterion) is calculated using $-L L+[(P / 2) \ln (N)]$.

To link preferences to respondents' characteristics in the LC model, we introduced respondents' attitudes and sociodemographic characteristics (as covariates) as determinants of class membership ${ }^{8}$. The sociodemographic variables introduced in the model included age, family status (single), and the presence of children in the household. Regarding the attitudes, 18 statements were analyzed with PCA. The factor analysis resulted in a five-factor solution using the eigenvalue greater than one criterion. For subsequent analysis, we dropped Factor 5 because the alpha value (0.45) is below the threshold value for a satisfactory scale (Hair, Black, Babin, Anderson, \& Tatham, 2006), leaving us with four factors that accounted for $53.4 \%$ of the error variance. We defined the factors as (1) food safety; (2) human health and production standards interests; (3) availability and convenience; and (4) price consciousness. The list of items and the corresponding factor loading using Varimax rotation are presented in Table 6.6.

The first factor "food safety" is highly related to the statements about the safety of food products including the use of antibiotics and hormones as well as related behavior aimed at mitigating different food safety-related risks such as avoiding chicken meat during avian flu

\footnotetext{
${ }^{8}$ We tested several models by introducing other sociodemographic variables as covariates in the LC model. However, due to insignificance and poor model fit, we excluded them from the estimation.
} 
outbreaks. This factor explains $15.5 \%$ of the variance and the Cronbach's alpha $(0.81)$ shows high internal consistency. The second factor "human health and production standards interests" deals with two aspects. First, it measures the respondent's health-consciousness, that is, an interest in eating healthily. Second, it deals with possible actions on the part of producers and the government to ensure good animal production practices. Factor 3 "availability and convenience" consists of statements related to the belief about the availability of chicken meat and the desire to have chicken meat available at convenient locations. In addition, it measures the ease of preparing chicken compared to other meat types. The fourth factor "price consciousness" highlights the statements that are associated with concern about prices and the influence of price on respondent's product choice decisions such as "price is the most important factor for me when I am shopping" and "it is mainly the price that influences my choice of chicken meat."

Table 6.6: Factor analysis of attitudinal statements

\begin{tabular}{|c|c|c|c|c|c|}
\hline Variable & F1 & $\mathrm{F} 2$ & F3 & F4 & F5 \\
\hline $\begin{array}{l}\text { I am very concerned about the use of antibiotics and } \\
\text { hormones in food }\end{array}$ & 0.8921 & & & & \\
\hline $\begin{array}{l}\text { I would pay a premium for antibiotic-free and hormone- } \\
\text { free chicken }\end{array}$ & 0.9166 & & & & \\
\hline The safety of meat concerns me a lot & 0.7289 & & & & \\
\hline It is good that chicken is available because it is low in fat & & 0.5413 & & & \\
\hline I reflect a lot about my health & & 0.8110 & & & \\
\hline I take care of what I eat because of health reasons & & 0.7689 & & & \\
\hline $\begin{array}{l}\text { It is important for me to have chicken available } \\
\text { throughout the year at markets/stores close to where I } \\
\text { live or work }\end{array}$ & & & 0.7323 & & \\
\hline Chicken is easy to prepare compared to other meats & & & 0.7796 & & \\
\hline $\begin{array}{l}\text { It is easier to obtain chicken than other meats (excluding } \\
\text { fish) }\end{array}$ & & & 0.8282 & & \\
\hline $\begin{array}{l}\text { Price is the most important factor for me when I am } \\
\text { shopping }\end{array}$ & & & & 0.8719 & \\
\hline $\begin{array}{l}\text { It is mainly the price that influences my choice of } \\
\text { chicken }\end{array}$ & & & & 0.8583 & \\
\hline $\begin{array}{l}\text { It is important to me to cook daily fresh food for my } \\
\text { family and me }\end{array}$ & & & & & 0.6763 \\
\hline $\begin{array}{l}\text { I do not care whether chicken is produced in Ghana or in } \\
\text { other countries }\end{array}$ & & & & & 0.5883 \\
\hline $\begin{array}{l}\text { It is important for me to know the country where the } \\
\text { chicken I eat comes from }\end{array}$ & & & & & 0.6397 \\
\hline $\begin{array}{l}\text { I reject all types of chicken during times of bird flu } \\
\text { disease outbreaks }\end{array}$ & 0.5096 & & & & \\
\hline I have much experience in buying chicken & & & & & \\
\hline $\begin{array}{l}\text { It is important that animals are well fed, raised, and } \\
\text { healthy }\end{array}$ & & 0.6548 & & & \\
\hline $\begin{array}{l}\text { Government should monitor and ensure good animal } \\
\text { husbandry practices and standards in the production and } \\
\text { processing of meat }\end{array}$ & & 0.5325 & & & \\
\hline Variance explained $(\%)$ & 15.51 & 14.71 & 12.54 & 9.64 & 9.46 \\
\hline Cronbach's alpha & 0.81 & 0.71 & 0.72 & 0.71 & 0.45 \\
\hline
\end{tabular}

Notes: Kaiser-Meyer-Olkin Test for sampling adequacy $=0.716$.

Bartlett's test of sphericity $\chi^{2}=0.000$. Only factor loadings with absolute value above 0.50 are presented. 
The preference heterogeneity found in the RPL is also revealed in the LC with significant differences among members of different classes (Table 6.7). Moreover, the loglikelihood estimates show that the LC model has a slightly higher fit than the RPL estimates presented earlier. Thus, justifying the use of the LC to identify the source of heterogeneity in preferences across segments. The class membership coefficients for the fourth class were normalized to zero for model identification. Hence, the results of the other classes must be described relative to this class (Boxall \& Adamowicz, 2002). Results from Table 6.7 show that $27,17,35$, and $21 \%$ of the respondents have fitted probability to belong to Classes $1,2,3$, and 4 , respectively.

Table 6.7: Parameter estimates from the LC model

\begin{tabular}{|c|c|c|c|c|}
\hline & Class 1 & Class 2 & Class 3 & Class 4 \\
\hline & $\begin{array}{c}\text { Domestic chicken } \\
\text { advocates }\end{array}$ & $\begin{array}{c}\text { Foreign } \\
\text { chicken lovers } \\
\end{array}$ & $\begin{array}{c}\text { Claim } \\
\text { conscious }\end{array}$ & $\begin{array}{l}\text { Random } \\
\text { choosers }\end{array}$ \\
\hline \multicolumn{5}{|l|}{ Utility function estimates } \\
\hline Foreign & $\begin{array}{c}-2.059^{* * * *} \\
(0.397)\end{array}$ & $\begin{array}{c}1.222^{* * * *} \\
(0.403)\end{array}$ & $\begin{array}{c}0.425 \\
(0.483)\end{array}$ & $\begin{array}{c}-3.169^{* *} \\
(1.274)\end{array}$ \\
\hline Cut & $\begin{array}{c}1.669^{* * * *} \\
(0.382)\end{array}$ & $\begin{array}{l}1.075^{* * *} \\
(0.229)\end{array}$ & $\begin{array}{c}0.201 \\
(0.334)\end{array}$ & $\begin{array}{l}-0.301 \\
(0.335)\end{array}$ \\
\hline Fresh & $\begin{array}{l}1.121^{* * *} \\
(0.372)\end{array}$ & $\begin{array}{c}0.847^{* * * *} \\
(0.285)\end{array}$ & $\begin{array}{c}2.331^{* * *} \\
(0.389)\end{array}$ & $\begin{array}{c}8.754 \\
(7.136)\end{array}$ \\
\hline Ant_claim & $\begin{array}{c}1.082^{* * *} \\
(0.296)\end{array}$ & $\begin{array}{c}-0.570^{* *} \\
(0.262)\end{array}$ & $\begin{array}{c}4.100^{* * *} \\
(0.493)\end{array}$ & $\begin{array}{c}2.272 \\
(2.641)\end{array}$ \\
\hline Price & $\begin{array}{c}-0.031^{* *} \\
(0.015)\end{array}$ & $\begin{array}{c}-0.043^{* * * *} \\
(0.013)\end{array}$ & $\begin{array}{c}-0.080^{* * * *} \\
(0.017)\end{array}$ & $\begin{array}{c}0.109 \\
(0.142)\end{array}$ \\
\hline ASC (Opt-out) & $\begin{array}{c}-1.446^{* * *} \\
(0.452)\end{array}$ & $\begin{array}{l}-2.915^{* * *} \\
(0.695)\end{array}$ & $\begin{array}{l}-0.703 \\
(0.879)\end{array}$ & $\begin{array}{c}2.195 \\
(4.220)\end{array}$ \\
\hline Class membership estimates & & & & \\
\hline Constant & $\begin{array}{l}-0.165 \\
(0.691)\end{array}$ & $\begin{array}{c}-1.343 \\
(0.876)\end{array}$ & $\begin{array}{l}-0.296 \\
(0.615)\end{array}$ & \\
\hline Food safety & $\begin{array}{c}0.329^{*} \\
(0.190)\end{array}$ & $\begin{array}{c}-0.387^{* *} \\
(0.183)\end{array}$ & $\begin{array}{c}0.015 \\
(0.147)\end{array}$ & \\
\hline Health and production interests & $\begin{array}{c}0.264^{*} \\
(0.160)\end{array}$ & $\begin{array}{c}0.139 \\
(0.243)\end{array}$ & $\begin{array}{c}0.205 \\
(0.141)\end{array}$ & \\
\hline Availability and convenience & $\begin{array}{c}0.247 \\
(0.163)\end{array}$ & $\begin{array}{l}0.483^{* *} \\
(0.211)\end{array}$ & $\begin{array}{c}0.494^{* * *} \\
(0.144)\end{array}$ & \\
\hline Price consciousness & $\begin{array}{c}0.295^{*} \\
(0.165)\end{array}$ & $\begin{array}{l}-0.088 \\
(0.211)\end{array}$ & $\begin{array}{l}0.353^{* *} \\
(0.158)\end{array}$ & \\
\hline Family status ( $1=$ Single $)$ & $\begin{array}{c}0.483 \\
(0.441)\end{array}$ & $\begin{array}{c}1.039^{*} \\
(0.542)\end{array}$ & $\begin{array}{c}0.216 \\
(0.412)\end{array}$ & \\
\hline Age (years) & $\begin{array}{l}-0.004 \\
(0.015)\end{array}$ & $\begin{array}{c}0.002 \\
(0.019)\end{array}$ & $\begin{array}{c}0.016 \\
(0.013)\end{array}$ & \\
\hline Children (<18 years) & $\begin{array}{l}0.608^{*} \\
(0.366)\end{array}$ & $\begin{array}{l}0.995^{*} \\
(0.512)\end{array}$ & $\begin{array}{c}0.260 \\
(0.317) \\
\end{array}$ & \\
\hline Class probability & 0.27 & 0.17 & 0.35 & 0.21 \\
\hline Log-likelihood & -1795.1 & & & \\
\hline McFadden Pseudo- $\mathrm{R}^{2}$ & 0.455 & & & \\
\hline Number of choice obs. & 3,000 & & & \\
\hline
\end{tabular}


The first class (27\% of the population) is characterized by a preference for cuts, fresh, and antibiotic/hormone-free claim but negative utility for foreign chicken. The disutility for foreign chicken shows that members of this class have a very strong domestic preference. As a result, we refer to consumers in this group as domestic chicken advocates. In addition, members of this segment show a relatively high preference for chicken cuts, indicating a group of consumers that are more convenient-oriented. The positive and significant class membership estimates for the components representing food safety and health and production interests suggest that members of this class are more concerned about food safety issues and interested in their health as well as good production practices compared with Class 4. Furthermore, they are likely to be households with children. The presence of children in the household means more time to prepare food for consumption. Thus, the likelihood of households with children to be in this segment is in accordance with their preferences for chicken cuts (convenience) and consistent with a study by Harris and Shiptsova (2007).

The second class is the smallest group (17\% of the population) and is different from the first in terms of their preference for the country-of-origin, and production claim. Utility coefficients for the second class indicate a preference for foreign, cuts, and fresh chicken but diminishing marginal utility for the antibiotic/hormone-free-claim. These preferences, however, appear to be dominated by a significantly negative ASC parameter. This means that consumers who value chicken the most characterize this class. Because members of this group value chicken the most and obtain higher utility from chicken meat of foreign origin, we refer to them as foreign chicken lovers. Class 2 membership coefficients indicate that members of this class show a negative attitude toward food safety (are not concern about food safety) relative to Class 4. This may contribute to their lower utility for the antibiotic/hormone-free claim. Besides, Class 2 members are more likely to agree with the availability and convenience component. Hence, they agree to statements that chicken meat should be available throughout the year at convenient locations, easy to obtain, and easy to prepare. Relative to Class 4, Class 2 members are likely to be single (never married) living in households with children. The presence of singles with children in this group may explain the positive preference for cuts. This is consistent with findings that single consumers and households with children tend to be more convenient-oriented as they are interested in meals that are easy to prepare (Candel, 2001; Harris \& Shiptsova, 2007). Given the likely presence of children in this class, we would have expected that Class 2 members would opt for chicken with antibiotics/hormone-free claim. One possible explanation is that members of this class may have based their preferences on perceived nutritional benefits of chicken rather than food safety. Alternatively, because members in this 
class have a high utility for fresh chicken, they may associate freshness with safety, reassurance (Becker et al., 2000; Wang, Zhang, Mu, Fu, \& Zhang, 2009), and superior quality (Olsen, 2004; Jabbar et al., 2010).

Class 3 is the largest group (35\% of the population). For members of this class, the country-of-origin and product form attributes are not important. Instead, respondents in this class displayed a relatively strong preference for the antibiotic/hormone-free claim. They also show a high preference for fresh chicken meat. The results for this class also indicate that the price of chicken meat appears to be important for these consumers. This suggests that the increase in the demand for the other important chicken meat attributes is still limited by the importance that consumers attach to the price in the selection of chicken meat product. Notwithstanding, since members of this class base their chicken purchasing decisions more on the production claim, we refer to consumers in this group as claim conscious. Relative to Class 4 , the probability of belonging to this segment is positively influenced by attitude toward availability and convenience and price. The fourth class ( $21 \%$ of the population) appears to be only concerned about the country-of-origin attribute. The insignificance of the other attribute coefficients as well as being rather indifferent to maintaining chicken in their choice set compels us to refer to this class as random choosers.

\subsubsection{WTP measures}

To assess consumer valuation for each of the attributes, we calculated the marginal WTP using simulation with 5,000 random draws. We discuss the results in relative terms using the RPL and the LC. The WTP values are presented in Table 6.8. Results indicate that the WTP for the country-of-origin attribute was relatively modest (GH $\notin 30.0 / \mathrm{kg}$ (US\$6.8/kg) of chicken) for the whole sample. The negative WTP for foreign chicken suggests that holding other factors constant, most consumers need to be compensated, either in price or in favorable attribute, for choosing foreign chicken over domestic chicken. Concerning the product form attribute, the results indicate that "cuts" carry a lower premium compared to the other attributes but decisionmakers value this attribute and are willing to pay a premium of GH $\not 15.8 / \mathrm{kg}$ (US\$3.6/kg). The quality cue provided by the attribute "fresh" has a premium of about GHф45.1/kg (US\$10.3/kg), which is the second highest. On average, the credence quality attribute "antibiotic/hormonefree claim" commanded a strong GH $\notin 46.9$ (US\$10.6) premium as compared with a product without a claim. The large magnitude of this premium reflects strong demand for food safety in Ghana and is reflective of the dire food safety situation in the country. 
Table 6.8: Consumer willingness to pay for chicken attributes

\begin{tabular}{|c|c|c|c|c|c|}
\hline \multirow[t]{2}{*}{ Attribute } & \multirow{2}{*}{$\begin{array}{c}\text { Random } \\
\text { parameter logit }\end{array}$} & \multicolumn{4}{|c|}{ Latent class model } \\
\hline & & $\begin{array}{c}\text { Domestic chicken } \\
\text { advocates }\end{array}$ & $\begin{array}{c}\text { Foreign chicken } \\
\text { lovers }\end{array}$ & $\begin{array}{c}\text { Claim } \\
\text { conscious }\end{array}$ & $\begin{array}{l}\text { Random } \\
\text { choosers }\end{array}$ \\
\hline Foreign & $\begin{array}{c}-30.02^{* * *} \\
{[-44.87,-15.17]}\end{array}$ & $\begin{array}{c}-65.74^{*} \\
{[-143.24,11.76]}\end{array}$ & $\begin{array}{c}28.70^{* * * *} \\
{[12.03,45.36]}\end{array}$ & $\begin{array}{c}5.29 \\
{[-4.89,15.47]}\end{array}$ & na \\
\hline Cut & $\begin{array}{c}15.76^{* * *} \\
{[9.88,21.64]}\end{array}$ & $\begin{array}{c}53.30^{* *} \\
{[12.51,94.09]}\end{array}$ & $\begin{array}{c}25.26^{* * *} \\
{[10.26,40.27]}\end{array}$ & $\begin{array}{c}2.51 \\
{[-5.08,10.09]}\end{array}$ & na \\
\hline Fresh & $\begin{array}{c}45.11^{* * *} \\
{[31.30,58.91]}\end{array}$ & $\begin{array}{c}35.78^{*} \\
{[-0.95,72.51]}\end{array}$ & $\begin{array}{c}19.89^{* * *} \\
{[3.97,35.81]}\end{array}$ & $\begin{array}{c}29.02^{* * *} \\
{[15.19,42.85]}\end{array}$ & na \\
\hline Ant_claim & $\begin{array}{c}46.86^{* * *} \\
{[28.55,65.17]}\end{array}$ & $\begin{array}{c}34.55^{*} \\
{[-6.12,75.21]}\end{array}$ & $\begin{array}{c}-13.39^{* * *} \\
{[-23.18,-3.59]}\end{array}$ & $\begin{array}{c}51.05^{* * *} \\
{[25.19,76.92]}\end{array}$ & na \\
\hline
\end{tabular}

Notes: ${ }^{*},{ }^{* *},{ }^{* * *}$ Denotes statistical significance at the 10\%, 5\%, and $1 \%$ levels, respectively. 95\% confidence intervals are in parenthesis. All presented values are in $\mathrm{GH} \phi / \mathrm{kg}$ units. Exchange rate as at the time of survey: 1 US $\$=4.4022$ Ghana Cedis $(\mathrm{GH} \phi)$.

na: WTP for Class 4 is not indicated because price is not statistically significant.

However, the premium differed by consumer segment. The first segment (domestic chicken advocates) presented a higher WTP for the country-of-origin attribute. Members in this class display a negative preference for foreign chicken and would be willing to accept up to GH $₫ 65.7$ (US\$14.9) as compensation for utility reduction to choose foreign chicken meat over domestic chicken. Furthermore, they show a positive and high WTP for cuts and positive WTP for fresh and antibiotic/hormone-free chicken. Class 2 mainly associated with foreign chicken lovers, are WTP GHф28.7 (US\$6.5) for imported chicken meat. However, they obtain lower utility from chicken with antibiotic/hormone-free claim and would be willing to accept compensation of up to GHф13.4 (US\$3.0). Members of this class also show positive WTP for cuts and fresh chicken meat. Class 3 reveals the highest WTP of GHф51.1 (US\$11.6) for the antibiotic/hormone-free claim although members in this class are likely to be more price sensitive. One would think such price sensitivity should lead to a low WTP. This seems to be caused by the very high utility for antibiotic/hormone-free chicken, suggesting that members of this class base their chicken meat purchasing decision more on the production claim attribute than on price. We did not compute the WTP for Class 4 because the price attribute was not statistically significant.

\subsection{Conclusions}

In this study, we investigated Ghanaian consumers' preferences and WTP for the country-oforigin and other value-added attributes in chicken meat using a choice experiment. Our findings revealed significant heterogeneity in preferences for chicken meat among consumers, signifying the importance of allowing for preference heterogeneity in choice modeling. In particular, consumers showed high preferences for domestic chicken, which is highly convenient, fresh, 
free of antibiotics and/or hormones, and has a lower price. These attributes are therefore important in consumers' decisions.

In the RPL, the effect of the country-of-origin was modest in comparison with the production claim and the storage form attributes. However, regardless of the importance of the origin attribute in the purchase decision, there was a marked consumer preference for domestic chicken. Similarly, the results emphasize the importance of storage form, indicating that consumers are willing to pay for fresh chicken meat since they obtain high utility from it. Although the marginal WTP for the product form attribute for the whole sample was relatively low, it is clear from our findings that consumers are willing to pay for convenient chicken, which is generally not available for domestic chicken meat. Not surprisingly, the attribute that indicates the claim of whether the chicken is produced with or without the use of antibiotics and/or hormones had the highest mean premium relative to the other attributes. The significantly high marginal WTP for chicken with an antibiotic/hormone-free claim is reflective of consumer's sensitivity to food safety issues.

In spite of these overall results, it is noteworthy that consumers' preferences for the chicken meat attributes differed by segments of consumers. The results of the LC model revealed the presence of identifiable segments within the population. Specifically, we identified four distinct classes of consumers in the sample population, each displaying different preferences for the same set of chicken attributes. The classes include domestic chicken advocates, foreign chicken lovers, claim conscious, and random choosers. Although the majority of respondents (48\%) preferred domestic chicken, about $27 \%$ belonging to Class 1 (domestic chicken advocates) were willing to pay a premium for domestic chicken meat. Moreover, the results of the LC generally indicate that preference heterogeneity is related to consumer attitudes (safety, health and production interests, availability and convenience, and price) and sociodemographic characteristics. However, segmenting the classes based on sociodemographic characteristics provided in general only a weak explanation for the existence of the heterogeneity. This means that consumers' attitudes would largely drive preferences for the different attributes of the chicken products.

Following on from the findings, we can draw some key implications for producers and marketers. First, the results from the RPL indicate consumers' preferences for domestic chicken meat. Likewise, in the LC model, a majority of respondents who were willing to pay for the country-of-origin attribute belonged to Class 1 . This class showed a strong preference for domestic chicken, implying that domestic chicken meat has a large potential for growth. Thus, it would be successful for producers to differentiate the domestically produced chicken meat 
from imported ones and target this group (about one quarter) of consumers who positively value the domestic origin. Second, given that consumers have a high preference for fresh chicken suggest that domestic producers can earn significant premiums if they focus efforts and promotional campaigns on highlighting the freshness attribute, which is not offered by the imported alternatives. Third, the form of the chicken product matters, with cuts commanding a premium compared to whole-dressed. Hence, an opportunity exists for domestic chicken meat producers to expand their market share by introducing value-added chicken products.

Finally, this finding highlighting consumers' inclination toward production claims (i.e., antibiotic/hormone-free claim) reflects strong demand for food safety. This could serve as an important entry point for marketing in the future. In this case, a new product development, which focuses on chicken meat products that comply with the criteria for the use of production claims, can be a promising avenue. However, communicating these claims through either advertising or labeling will come at a cost. In the short-term, this will remain a challenge for domestic producers who are already faced with a high cost of production. But if realized, such claims will provide higher value to consumers and restore confidence in the meat produced.

Our findings also have important implications for policymakers, especially with the government's aim of increasing domestic production and reducing imports to contribute to food security, create employment, and generate income. The finding that consumers, on the whole, are willing to pay for chicken products with antibiotic-free claim calls for the direct involvement of the government in designing protection measures to ensure food safety. One possible way could be setting up mandatory public production standards for the poultry industry. Mandatory standards are obligations to be followed by all producers, and all consumers have to buy. In that case, labeling would not be necessary, and costs accrued could be probably covered by the chain. However, since consumers are heterogeneous in their preferences for the production claim attribute, the standards could also be voluntary. This will ensure that not only consumers who prefer the claim but also those who have no preference for it are considered. In this regard, consumers could choose between products with and without the claim. Thus, only those consumers interested in the higher standards will pay a price premium. Besides, since the additional costs are covered by the price premium, producers who will produce under the standards are those who can do so at the lowest costs. For these producers, the standards could be part of their strategy (product differentiation).

Furthermore, as consumers prefer more convenient chicken products, the government should create an enabling environment to attract private sector participation in the form of investment in infrastructure for processing (slaughtering, cutting, and packaging), storage (cold 
chain systems), and marketing. To be preferred over imported chicken parts, the domestic industry has to establish a well-functioning value and cold chain up to the point of sale with an adequate environment to sell the fresh (chilled) chicken parts. Once all of these interventions are in place, it will require deliberate investment to increase production output sufficient to meet the capacity of the processing industry to ensure its survival. Indeed, although our results reveal that there is a general preference for domestic chicken, results from the segmentation analysis indicate that there is a minority group (foreign chicken lovers) who prefer imported chicken and are willing to pay for it. This suggests that any attempt on the part of policymakers to control imports through the imposition of higher tariffs will increase costs for these consumers and consequently impact negatively on the policy's food security objective.

Coming back to the concerns about the import surge of poultry meat in developing countries and the low competitiveness of domestic products mentioned in the introduction, we conclude that there is hope for domestic poultry meat products if producers, processors, marketers, and the government respond to consumers' needs and preferences.

Since we cannot completely rule out hypothetical bias, future studies using nonhypothetical experiments such as experimental auctions are needed to validate the WTP estimates in this study and to enhance our understanding. Likewise, introducing some heterogeneity in the cuts might be informative for future demand analysis. Finally, while an understanding of consumers' preferences is important for drafting and implementing food policies, consumers' preferences might not necessarily be optimal from the production and policy perspectives. Therefore, future research looking at the effectiveness of the production claim attribute from the production and policy point of views would be useful. 


\section{References}

Andam, K. S., Johnson, M. E., Ragasa, C., Kufoalor, D. S., \& Das Gupta, S. (2017). A chicken and maize situation: The poultry feed sector in Ghana. IFPRI Discussion Paper 1601. International Food Policy Research Institute, Washington DC.

Aning, K. G. (2006). The structure and importance of the commercial and village based poultry in Ghana. Food and Agriculture Organization of the United Nations, Rome.

Balcombe, K., Bradley, D., Fraser, I., \& Hussein, M. (2016). Consumer preferences regarding country of origin for multiple meat products. Food Policy, 64, 49-62.

Becker, T., Benner, E., \& Glitsch, K. (2000). Consumer perception of fresh meat quality in Germany. British Food Journal, 102(3), 246-266.

Bett, H. K., Peters, K. J., Nwankwo, U. M., \& Bokelmann, W. (2013). Estimating consumer preferences and willingness to pay for the underutilised indigenous chicken products. Food Policy, 41, 218-225.

Bliemer, M. C. J., Rose, J. M. (2005). Efficiency and sample size requirements for stated choice studies. ITLS Working Paper 05-08. Institute of Transport \& Logistics Studies, Sydney.

Bliemer, M. C. J., \& Rose, J. M. (2013). Confidence intervals of willingness-to-pay for random coefficient logit models. Transportation Research Part B: Methodological, $58,199-214$.

Boxall, P. C., \& Adamowicz, W. L. (2002). Understanding heterogeneous preferences in random utility models: a latent class approach. Environmental and Resource Economics, 23, 421-446.

Candel, M. J. J. M. (2001). Consumers' convenience orientation towards meal preparation: Conceptualization and measurement. Appetite, 36(1), 15-28.

Chambers, S., Lobb, A., Butler, L., Harvey, K., \& Traill, W. B. (2007). Local, national and imported foods: A qualitative study. Appetite, 49(1), 208-213.

ChoiceMetrics (2014). Ngene 1.1.2 User Manual \& Reference Guide. ChoiceMetrics, Sydney.

Chung, C., Boyer, T., \& Han, S. (2009). Valuing quality attributes and country of origin in the Korean beef market. Journal of Agricultural Economics, 60(3), 682-698.

Cummings, R. G., \& Taylor, L. O. (1999). Unbiased value estimates for environmental goods: A cheap talk design for the contingent valuation method. American Economic Review, 89(3), 649-665.

Font i Furnols, M., Realini, C., Montossi, F., Sañudo, C., Campo, M. M., Oliver, M. A., ... Guerrero, L. (2011). Consumer's purchasing intention for lamb meat affected by country of origin, feeding system and meat price: A conjoint study in Spain, France and United Kingdom. Food Quality and Preference, 22(5), 443-451.

Gracia, A., Loureiro, M. L., \& Nayga, R. M. (2009). Consumers' valuation of nutritional information: A choice experiment study. Food Quality and Preference, 20(7), 463471.

Grunert, K. G. (2005). Food quality and safety: consumer perception and demand. European Review of Agricultural Economics, 32(3), 369-391.

GSS (Ghana Statistical Service). (2013). 2010 population and housing census: National analytical report. Accra, Ghana.

Hair, J. F., Black, W. C., Babin, B. J., Anderson, R. E., \& Tatham, R. L. (2006). Multivariate data analysis. New Jersey: Pearson University Press.

Harris, J. M., \& Shiptsova, R. (2007). Consumer demand for convenience foods: Demographics and expenditures. Journal of Food Distribution Research, 38(3), 2236.

Hensher, D. A., Rose, J. M., \& Greene, W. H. (2005). Applied choice analysis: a primer. Cambridge: Cambridge University Press. 
Hole, A. R. (2007). A comparison of approaches to estimating confidence intervals for willingness to pay measures. Health Economics, 16(8), 827-840.

Jabbar, M. A., Baker, D., \& Fadiga, M. L. (2010). Demand for livestock products in developing countries with a focus on quality and safety attributes: evidence from Asia and Africa. ILRI Research Report 24. International Livestock Research Institute, Addis Ababa.

Kwadzo, G. T.-M., Dadzie, F., Osei-Asare, Y. B., \& Kuwornu, J. K. M. (2013). Consumer preference for broiler meat in Ghana: A conjoint analysis approach. International Journal of Marketing Studies, 5(2), 66-73.

Lim, K. H., Hu, W., Maynard, L. J., \& Goddard, E. (2014). A taste for safer beef? How much does consumers' perceived risk influence willingness to pay for country-of-origin labeled beef. Agribusiness, 30(1), 17-30.

Loureiro, M. L., \& Umberger, W. J. (2005). Assessing consumer preferences for country-oforigin labeling. Journal of Agricultural and Applied Economics, 37(01), 49-63.

Loureiro, M. L., \& Umberger, W. J. (2007). A choice experiment model for beef: What US consumer responses tell us about relative preferences for food safety, country-of-origin labeling and traceability. Food Policy, 32(4), 496-514.

Louviere, J. J., Flynn, T. N., \& Carson, R. T. (2010). Discrete choice experiments are not conjoint analysis. Journal of Choice Modelling, 3(3), 57-72.

Louviere, J. J., Hensher, D.A., \& Swait, J. (2000). Stated choice methods: analysis and application. Cambridge: Cambridge University Press.

Lusk, J. L. (2003). Effects of cheap talk on consumer willingness-to-pay for golden rice. American Journal of Agricultural Economics, 85(4), 840-856.

Lusk, J. L., \& Schroeder, T. C. (2004). Are choice experiments incentive compatible? A test with quality differentiated beef steaks. American Journal of Agricultural Economics, $86(2), 467-482$.

Mari, F. J. (2015, August 16). EU meat exports: high development costs. D+C Development and Cooperation. Retrieved from https://www.dandc.eu/en/article/eu meat-exports.

McFadden, D. (1974) Conditional logit analysis of qualitative choice behaviour. In Zarembka, P. E. (Ed.) Frontiers in econometrics (pp. 105-142). New York: Academic Press.

MoFA (Ministry of Food and Agriculture). (2017). Planting for food and jobs: Strategic plan for implementation (2017-2020). Ministry of Food and Agriculture, Accra

Morrison, M., Bennett, J., Blamey, R., \& Louviere, J. (2002). Choice modeling and tests of benefit transfer. American Journal of Agricultural Economics, 84(1), 161-170.

OECD-FAO (Organization for Economic Cooperation and Development and the Food and Agri-culture Organization of the United Nations). (2017). OECD agriculture statistics (database): OECD-FAO agricultural outlook (edition 2017). OECD Publishing, Paris. Retrieved from https://doi.org/10.1787/d9e81f72-en.

Olsen, S. O. (2004). Antecedents of seafood consumption behavior: An overview. Journal of Aquatic Food Product Technology, 13(3), 79-91.

Ortega, D. L., Hong, S. J., Wang, H. H., \& Wu, L. (2016). Emerging markets for imported beef in China: Results from a consumer choice experiment in Beijing. Meat Science, $121,317-323$.

Orth, U. R., \& Firbasová, Z. (2003). The role of consumer ethnocentrism in food product evaluation. Agribusiness, 19(2), 137-153.

Owusu-Sekyere, E., Owusu, V., \& Jordaan, H. (2014). Consumer preferences and willingness to pay for beef food safety assurance labels in the Kumasi Metropolis and Sunyani Municipality of Ghana. Food Control, 46, 152-159.

Pouta, E., Heikkilä, J., Forsman-Hugg, S., Isoniemi, M., \& Mäkelä, J. (2010). Consumer choice of broiler meat: The effects of country of origin and production methods. Food Quality and Preference, 21(5), 539-546. 
Rakotoarisoa, M. A., Sharma, R. P., \& Hallam, D. (2011). Agricultural import surges in developing countries: analytical framework and insights from case studies. Food and Agriculture Organization of the United Nations (FAO), Rome.

Rigby, D., \& Burton, M. (2005). Preference heterogeneity and GM food in the UK. European Review of Agricultural Economics, 32(2), 269-288.

Rudloff, B., \& Schmieg, E. (2016). More bones to pick with the EU? Controversial poultry exports to Africa: sustainable trade policy as a task for the G20. SWP Comments 57. German Institute for International and Security Affairs, Berlin.

Scarpa, R., \& Thiene, M. (2011). Organic food choices and protection motivation theory: Addressing the psychological sources of heterogeneity. Food Quality and Preference, 22(6), 532-541.

Shimp, T. A., \& Sharma, S. (1987). Consumer ethnocentrism: Construction and validation of the CETSCALE. Journal of Marketing Research, 24(3), 280-289.

Swait, J. (1994). A structural equation model of latent segmentation and product choice for cross-sectional revealed preference choice data. Journal of Retailing and Consumer Services, 1(2), 77-89.

Tonsor, G. T., Olynk, N., \& Wolf, C. (2009). Consumer preferences for animal welfare attributes: The case of gestation crates. Journal of Agricultural and Applied Economics, 41(3), 713-730.

Train, K. E. (1998). Recreation demand models with taste differences over people. Land Economics, 74(2), 230-239.

Train, K. E. (2009). Discrete choice methods with simulation. Cambridge: Cambridge University Press.

USDA (United States Department of Agriculture). (2017). Ghana poultry report annual. United States Department of Agriculture, Accra.

Van Loo, E. J., Caputo, V., Nayga, R. M., Meullenet, J. F., \& Ricke, S. C. (2011). Consumers' willingness to pay for organic chicken breast: Evidence from choice experiment. Food Quality and Preference, 22(7), 603-613.

Verlegh, P. W. J., \& Steenkamp, J.-B. E. M. (1999). A review and meta-analysis of countryof-origin research. Journal of Economic Psychology, 20(5), 521-546.

Verlegh, P. W. J., \& van Ittersum, K. (2001). The origin of the spices: The impact of geographic product origin on consumer decision making. In L. J. Frewer, E. Risvik, \& H. Schifferstein (Eds.), Food, people and society. A European perspective of consumers' food choices (pp. 267-279). Berlin, Heidelberg, New York: SpringerVerlag.

Wang, F., Zhang, J., Mu, W., Fu, Z., \& Zhang, X. (2009). Consumers' perception toward quality and safety of fishery products, Beijing, China. Food Control, 20(10), 918-922.

Woolverton, E. A., \& Frimpong, S. (2013). Consumer demand for domestic and imported broiler meat in urban Ghana: Bringing non-price effects into the equation. British Journal of Marketing Studies, 1(3), 16-31. 


\title{
$7 \quad$ Profiling consumers based on information use and trust in a developing economy ${ }^{9}$
}

\begin{abstract}
In the wake of the intense debate about the effect of poultry imports on domestic poultry industries in sub-Saharan Africa, information campaigns have evolved to encourage consumption of domestic poultry meat products. Nevertheless, consumers use numerous channels to find information, and thus, the extent to which resources should be allocated to these channels to reach segments of consumers is vital. The purpose of this paper is to identify consumer groups based on use and trust in information sources and then profile the segments using sociodemographic variables, purchase motives, and meat consumption. Face-to-face interviews were used to collect data among 500 urban consumers in Ghana, which were analyzed with factor analysis and two-step cluster analysis. Results show that consumers frequently use personal sources of information about chicken. Cluster analysis revealed three consumer segments: cautious consumers (18.2\%), enthusiastic consumers $(53.0 \%)$, and optimistic consumers $(28.8 \%)$. The segments differed significantly regarding the type of information searched for, sociodemographic characteristics, purchase motives, and chicken meat consumption patterns. The findings can aid actors and institutions seeking to increase the consumption of domestic poultry meat in developing targeted communication strategies that suit the characteristics, motivations, and information needs of different consumers.
\end{abstract}

Keywords: cluster analysis, consumer segmentation, factor analysis, information sources, motives, poultry meat, trust

\footnotetext{
${ }^{9}$ This chapter has been published in the International Journal of Consumer Studies (2020): 44(3), 285-295. https://doi.org/10.1111/ijcs.12565. It is co-authored with Daniela Weible (DW).

Authors' contributions: All authors jointly designed the research. I (CAA) collected the data, analyzed, and wrote the paper. DW commented at the various stages of the research and contributed to writing and revising the paper.
} 


\subsection{Introduction}

Several strategies are used to influence consumers' food consumption behavior, including policies, prices, and information (Niva, Vainio, \& Jallinoja, 2017; Vainio, 2019). Regarding these strategies, information provision is considered vital as knowledge is a necessary although not a sufficient condition for making food choices (Verbeke, 2008; Peschel, Grebitus, Steiner, \& Veeman, 2016; Vainio, 2019). According to Verbeke (2008), information assists consumers in deriving satisfaction from food products and know the origin and environmental, ethical, and technological conditions under which these products are produced and processed. Nevertheless, evidence suggests that any effect of information will depend on consumers, their preferences and factors such as the food product, the communicated information and the potential health or safety risk (Jungermann et al., 1996; Grunert and Wills, 2007). Besides, information can guarantee actual benefits for consumers only if they have sufficient motivation and ability to look for, process, and evaluate its relevance and quality (Hung, Grunert, Hoefkens, Hieke, \& Verbeke, 2017; Vainio, 2019).

Moreover, information received by consumers must be reliable and trustworthy (Salaun and Flores, 2001). Accurate dissemination of information can strengthen consumer trust by reducing information asymmetry between producers/sellers and consumers as well as perceived concerns about the quality and safety of food products (Verbeke \& Ward, 2006). Morrow, Hansen, and Pearson (2004, p. 49) define trust as "the extent to which one believes that others will not act to exploit one's vulnerabilities." From this, trust can be conceptualized as a multidimensional concept comprising of cognitive, affective, and behavioral manifestations that combine into a unitary social experience (Lewis \& Weigert, 1985). According to Thiede (2005), trust plays a critical role in the utilization of provided information. Hence, the value of information becomes zero, or even negative if the source of information is not trusted (Thiede, 2005).

Various studies examined consumer information search behavior regarding food products (Pieniak, Verbeke, Scholderer, Bruns $\varnothing$, \& Olsen, 2007; Zander and Hamm, 2012; Pieniak, Vanhonacker, \& Verbeke, 2013; Visschers, Hartmann, Leins-Hess, Dohle, \& Siegrist, 2013; Liu, Pieniak, \& Verbeke, 2014; Kuttschreuter et al., 2014; Żakowska-Biemans et al., 2017). Previous studies focused largely in developed countries (i.e., European countries). However, relatively little is known about type of information and sources that consumers use as well as their trust in these sources in a developing country context.

To the authors' knowledge, no study has examined consumers' information search behavior in the context of food products in Africa, especially meat. This study therefore, aims 
to shed light on these issues and contribute to this line of research in an African setting. Understanding consumers' use of information sources is crucial for developing effective communication and marketing strategies for food products in the face of increasing competition resulting from increased international trade and globalization.

Against this background, we conducted a household survey of consumers in Ghana, focusing on poultry meat. Poultry meat is an ideal commodity for the purpose of this study because it has become a popular food for people in Ghana and can be adapted to a wide variety of dishes. As a result, its consumption has been increasing over the past decades. The rise in poultry consumption, however, has not reflected in a corresponding increase in the consumption of domestically produced poultry meat (see, e.g., Asante-Addo \& Weible, 2019). Consequently, consumer-focused campaigns have recently emerged. One of such initiatives is the nationwide campaign dubbed "Eat Ghana Chicken." This initiative was launched in 2018 as a joint project between the Ghana Poultry Project (GPP) under the auspices of the Ministries of Trade and Industry, Health, Food and Agriculture, and the Ghana National Association of Poultry Farmers (Daily Graphic, 2018). The primary goal of the campaign is to encourage Ghanaian consumers to purchase more domestically produced chicken. With stronger, reliable demand, it is expected that this will bolster farmer commitments and capacity to increase their supply and thus create a sustainable and commercially competitive poultry industry.

However, consumers may be selective or nonselective in their use of information sources and therefore need different communication approaches to be informed effectively (Kornelis et al., 2007; Visschers et al., 2013). An approach where different communication and information provision strategies are targeted at different consumer segments has been found to impact food consumption behavior (Verbeke, 2008). Besides, the provision of credible information to consumers imposes significant costs on producers and policymakers. Thus, finding innovative and effective ways to provide information to consumers and at the same time reducing search costs is critical to achieve this objective.

Therefore, this paper attempts to answer some key questions: (a) what are the different sources of information that consumers' use and to what extent do they trust these sources? (b) Can consumers be segmented based on their use and trust in food information? (c) Do the identified segments differ in terms of information cues searched for, sociodemographic characteristics, and consumption behavior? These questions are relevant for producers, marketers in the poultry industry as well as policymakers for better targeting of information and communication and support development of strategies aimed at increasing domestic poultry meat consumption. 


\subsection{Consumer information search behavior}

A standard economic justification for information provision relates to the presence of market failures linked to the supply of high-quality goods in markets (Akerlof, 1970; Teisl \& Roe, 1998). For example, in buying food products, a buyer can have information about the prices of the products in the market. However, he/she may not have the same depth of information about the quality of the product as the seller leading to an information asymmetry between the two parties. If sellers are unable to credibly communicate the quality or attributes of their products to consumers, the predicament of Akerlof's (1970) lemons problem may prevail, leading to only low-quality products being sold.

From a marketing perspective, consumers go through different stages in purchasing and marketers are interested to learn how consumers behave at each stage, to influence their decisions at each stage (Solomon, Bamossy, Askegaard, \& Hogg, 2010; Kotler \& Armstrong, 2011). However, the decision-making process is a complex one and could be influenced by several factors such as environmental, psychological (personal), the properties of the product itself (Font-i-Furnols \& Guerrero, 2014). Various models have been proposed for understanding consumer behavior. One such model is the stimuli-response model, which indicates that marketing and environmental stimuli enter the consumer's consciousness and a set of psychological processes interact with certain consumer characteristics in the decision-making process and lead to a certain purchase decision (Kotler \& Keller, 2012). According to Kotler and Keller (2012), this model seeks to explain the process that unfolds within consumer consciousness from the arrival of the outside marketing stimuli to the point of making the ultimate purchase decisions.

Based on the consumer behavior model, the purchase decision can be broadly classified into five stages: (i) problem or need recognition (ii) information search (iii) evaluation and comparison of alternatives (iv) purchase (choice) decision and (v) post-purchase behavior as depicted in Figure 7.1 (Kotler and Keller, 2012). This model shows that the buying process begins long before the actual purchase and has consequences after the purchase. However, consumers do not always seem to engage in some logical or sequential activities when making purchasing decisions as suggested by this model (Solomon et al., 2010). Kotler and Keller (2012) suggest that some consumers may simply skip or reverse some of these stages. This is especially the case in low-involvement purchases such as food, which are characterized by limited problem-solving or seen as routinized or habitual decisions (see, e.g., Grunert, 2005; Solomon et al., 2010). 


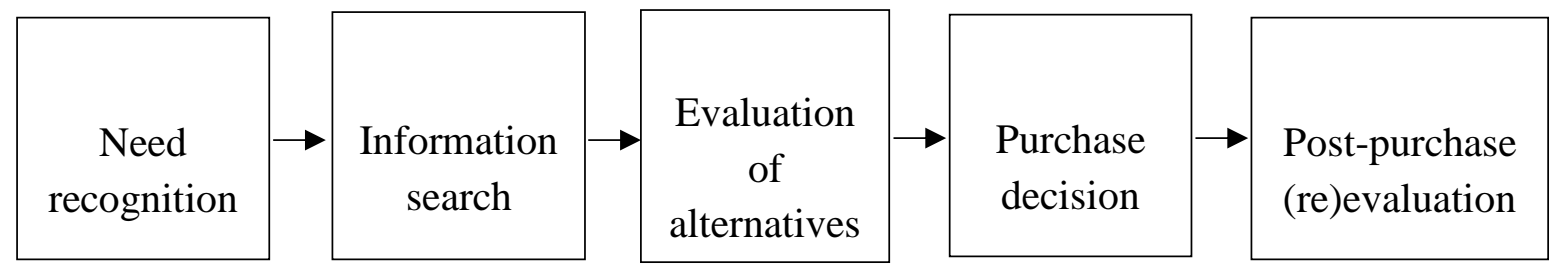

Figure 7.1: Overview of consumer's decision-making process Source: Adapted from Kotler and Keller (2012).

The mechanism by which purchase occurs according to the five-stage model is as follows. First, the consumer becomes aware of a problem or need to be solved. This need can be triggered by internal and external stimuli (Kotler \&Armstrong, 2011). Second, after a problem or a need is recognized, a period of information search follows, which is the focus of this study. At this stage, the consumer learns about the products that can satisfy the need or solve the problem. The search for information can be either internal or external (Engel, Blackwell, \& Miniard, 1993; Solomon et al., 2010). Internal search is when a consumer use information already stored in his/her memory and is determined by past experience with the product (Engel et al., 1993). For example, if a consumer buys or consumes a certain type of chicken meat product and found it a pleasurable experience, the memory will assist in future decision making. However, if this information is not enough for a purchasing decision the consumer seeks additional information in an external search, which involves seeking information from the environment (Engel et al., 1993; Loudon \& Della Bitta, 1993).

Consumers often search for a limited range of information (Solomon et al., 2010). Regarding these searches, Kotler and Keller (2012) distinguished between two levels of involvement. First, consumers who search for information with relatively weak intensity known as heightened attention. Consumers at this level, simply become more receptive to information about a product. Second, consumers who actively search for information, for instance by looking for reading materials, contacting friends, going to websites, and visiting stores to learn more about the product. This group of consumers typically belong to the high-involvement learning state (Kotler \& Keller, 2012).

\subsection{Materials and methods}

\subsubsection{Sampling}

To collect data, we used a structured questionnaire designed based on consumer focus groups. The focus groups were used to obtain insights into consumer preferences and particularly the channels used to get information about poultry products. Only consumers aged 18 years and 
above, responsible for buying food or deciding what food to buy, and consuming chicken products were included in the survey. The survey was carried out in the two largest cities of Ghana: Accra and Kumasi. These cities were selected because most of the increase in poultry consumption is expected to occur in urban areas. Additionally, they represent two of the ten administrative regions (i.e., Greater Accra and Ashanti) where commercial poultry operations are mostly found.

We employed a multistage sampling approach. First, we divided each city into 10 administrative units (i.e., sub-metros/districts). Second, to ensure greater representation within the study areas we randomly selected five sub-metros/districts from each city. Within each submetro/district, a random sample of communities was drawn. Two communities per submetro/district were selected. Finally, from each of the selected communities, households from which respondents were drawn were selected using systematic random sampling. To select a household, we followed a randomly generated route (random walk procedure), and respondents from every third household along the route were interviewed. Where a respondent in a target household did not eat chicken, was not available or not interested in participating, the next household was chosen. The structured survey was administered between March and April 2018. Altogether, 500 respondents were interviewed using Computer-Assisted Personal Interviewing. The questionnaire solicited information on respondents' actual chicken buying and consumption habits, sets of statements that capture respondents' attitudes and perceptions regarding food and in particular, domestic versus imported chicken meat, use and trust in information about chicken products, and respondents' sociodemographic characteristics.

\subsubsection{Questionnaire design and data analysis}

To assess the use of information sources, respondents were asked to evaluate how often they use different sources of information (family and friends, sellers, government, health professionals, television, radio, newspaper, magazines, and internet) regarding the purchase and consumption of chicken meat on a 5-point Likert scale with 5 being "very often" and 1 "never". Likewise, respondents were asked to indicate their trust in each of the identified information sources. The respondents had to rate the extent to which they trust information about chicken meat from these sources on 5-point Likert scales ranging from "completely distrust" (1) to "completely trust" (5).

The analysis of consumer information search behavior follows a two step-method in sequence. First, factor analysis using principal components with Varimax rotation was performed to discover the basic structure underlying the channels for information seeking about 
chicken and consumers trust in these sources. The Kaiser-Meyer-Olkin (KMO) values (0.70 and 0.71 ) and the Bartlett's tests of sphericity were highly significant, indicating that the data matrix was suitable for factor analysis. Regarding the sources of information, three factors emerged: (1) use of official and commercial sources, (2) use of personal sources, and (3) use of electronic media sources. The factors explained about $65 \%$ of the variance in the original data (Table 7.1). The Cronbach's alpha, which is a measure of reliability or internal consistency for each dimension ranged from 0.71 to 0.85 and thus were satisfactory (Hair, Black, Babin, Anderson, \& Tatham, 2006).

Table 7.1: Principal component analysis of use of information sources about chicken meat

\begin{tabular}{|c|c|c|c|c|}
\hline \multirow[b]{2}{*}{ Variable } & \multirow{2}{*}{$\begin{array}{l}\text { Mean } \\
\text { values }\end{array}$} & Factor 1 & Factor 2 & Factor 3 \\
\hline & & $\begin{array}{c}\text { Official \& } \\
\text { commercial } \\
\text { sources }\end{array}$ & $\begin{array}{c}\text { Personal } \\
\text { sources }\end{array}$ & $\begin{array}{c}\text { Electronic } \\
\text { media } \\
\text { sources }\end{array}$ \\
\hline Television & 3.25 & & & 0.838 \\
\hline Radio & 3.39 & & & 0.888 \\
\hline Newspapers & 1.73 & 0.768 & & \\
\hline $\begin{array}{l}\text { Health professional (e.g., medical doctor, } \\
\text { nurse, nutritionist, etc.) }\end{array}$ & 2.73 & 0.612 & & \\
\hline Family, friends, and colleagues & 4.57 & & 0.912 & \\
\hline Sellers/Vendors & 3.61 & & 0.917 & \\
\hline Government sources & 2.37 & 0.590 & & \\
\hline Internet/Social media & 2.51 & 0.677 & & \\
\hline Magazines, pamphlets, and flyers & 1.44 & 0.682 & & \\
\hline Variance explained $(\%)$ & & 0.25 & 0.21 & 0.19 \\
\hline Cronbach's $\alpha$ internal reliability & & 0.71 & 0.85 & 0.75 \\
\hline
\end{tabular}

Note: KMO measure of sampling adequacy $=0.70$. Bartlett's test of sphericity $\chi^{2}=0.000$

Factor loadings and reliability estimates for the trust in information sources are presented in Table 7.2. The factor analysis yielded four distinct factors that explained $77 \%$ of the variance in the initial data. The Cronbach's alpha, for each dimension was satisfactory, except factor four, which had a value below the satisfactory scale $(0.48)$ and thus was not included in interpretation and subsequent analysis. The factors can be described as 1) trust in commercial sources 2) trust in electronic media sources 3) trust in personal sources. 
Table 7.2: Principal component analysis of trust in information sources about chicken meat

\begin{tabular}{|c|c|c|c|c|c|}
\hline & Mean & Factor 1 & Factor 2 & Factor 3 & Factor 4 \\
\hline Variable & values & $\begin{array}{c}\text { Trust in } \\
\text { commercial } \\
\text { sources }\end{array}$ & $\begin{array}{c}\text { Trust in } \\
\text { electronic } \\
\text { media sources }\end{array}$ & $\begin{array}{c}\text { Trust in } \\
\text { personal } \\
\text { sources }\end{array}$ & - \\
\hline Television & 3.63 & & 0.893 & & \\
\hline Radio & 3.62 & & 0.907 & & \\
\hline Newspapers & 3.17 & 0.736 & & & \\
\hline $\begin{array}{l}\text { Health professional (e.g., medical } \\
\text { doctor, nurse, nutritionist, etc.) }\end{array}$ & 4.14 & & & & 0.839 \\
\hline Family, friends, and colleagues & 3.89 & & & 0.829 & \\
\hline Sellers/Vendors & 3.34 & & & 0.856 & \\
\hline Government sources & 3.73 & & & & 0.736 \\
\hline Internet/Social media & 2.76 & 0.827 & & & \\
\hline Magazines, pamphlets, and flyers & 3.08 & 0.860 & & & \\
\hline Variance explained (\%) & & 0.23 & 0.22 & 0.17 & 0.15 \\
\hline Cronbach's $\alpha$ internal reliability & & 0.82 & 0.87 & 0.65 & 0.48 \\
\hline
\end{tabular}

Note: KMO measure of sampling adequacy $=0.71$. Bartlett's test of sphericity $\chi^{2}=0.000$

Second, a two-step clustering (Wedel \& Kamakura, 2000) based on the use of and trust in various information sources was applied to identify consumer segments. Ward's hierarchical clustering method (using squared Euclidian distance) was used to identify distinctive homogenous segments using factor scores resulting from the exploratory factor analyses. Based on the proportionate increase in heterogeneity and inspection of the dendogram, three clusters were determined as the optimum number. After identifying the optimal number of clusters, the clustering was fine-tuned using the non-hierarchical K-means clustering technique (Hair et al., 2006). The K-means clustering is a relocation method that is widely used in segmentation studies. The profiles of the resulting segment were determined using cross-tabulation with chisquare tests and one-way analysis of variance (ANOVA) with post-hoc Tukey comparison of mean scores. The segments were compared based on use of information cues when purchasing chicken meat, sociodemographic characteristics, purchase motives (captured as a multiple response variable), and meat consumption. Meat consumption was a self-reported item and measured with a question "How often do you eat the following meat types in your household?" The answers ranged from 0 (never) to 6 (four times or more a week).

\subsection{Results}

\subsubsection{Description of segments}

In general, respondents' self-reported use of information and trust appeared moderate. The most frequently used sources of information were personal (average rating 4.09), followed by electronic media (3.32). Likewise, electronic media (3.62) and personal (3.61) sources about chicken meat were most trusted. Information from official and commercial sources such as 
health professionals, government, newspapers, internet, and magazines including pamphlets and flyers, were the least used with scores below the average of the scale (2.16). Based on the cluster analysis, three distinct consumer groups were identified. The respective sizes and mean scores of the segments are reported in Table 7.3.

Table 7.3: Mean scores of the segments on the classification variables

\begin{tabular}{|c|c|c|c|c|c|c|c|}
\hline & \multirow{2}{*}{$\begin{array}{c}\text { Total } \\
\text { sample }\end{array}$} & \multicolumn{3}{|c|}{ Clusters } & \multirow[t]{2}{*}{ F-Value } & \multirow[t]{2}{*}{$p$-Value } & \multirow[t]{2}{*}{$\mathrm{Eta}^{2}$} \\
\hline & & 1 & 2 & 3 & & & \\
\hline Sample size $(\%)$ & 100 & 18.2 & 53.0 & 28.8 & & & \\
\hline $\begin{array}{l}\text { Use of official \& commercial } \\
\text { sources }\end{array}$ & 2.16 & $1.78^{\mathrm{c}}$ & $2.61^{\mathrm{b}}$ & $1.55^{\mathrm{a}}$ & 240.98 & $<0.001$ & .492 \\
\hline Use of personal sources & 4.09 & $3.70^{\mathrm{b}}$ & $4.32^{\mathrm{c}}$ & $3.93^{\mathrm{a}}$ & 28.09 & $<0.001$ & .102 \\
\hline Use of electronic media sources & 3.32 & $2.15^{\mathrm{b}}$ & $3.58^{\mathrm{a}}$ & $3.58^{\mathrm{a}}$ & 209.57 & $<0.001$ & .458 \\
\hline Trust in commercial sources & 3.00 & $2.26^{\mathrm{c}}$ & $3.54^{\mathrm{b}}$ & $2.49^{\mathrm{a}}$ & 215.67 & $<0.001$ & .465 \\
\hline Trust in electronic media sources & 3.62 & $2.49^{\mathrm{b}}$ & $3.84^{\mathrm{a}}$ & $3.94^{\mathrm{a}}$ & 146.79 & $<0.001$ & .371 \\
\hline Trust in personal sources & 3.61 & $3.11^{\mathrm{c}}$ & $3.81^{\mathrm{b}}$ & $3.58^{\mathrm{a}}$ & 29.96 & $<0.001$ & .108 \\
\hline
\end{tabular}

Segment 1 is the smallest group and accounts for approximately $18.2 \%$ of the sample. This segment is characterized by relatively low use of available information sources and low trust levels in the various sources. This means that consumers in this segment are rather passive in their search for information about chicken meat and rather distrustful. For this reason, we labelled this segment as cautious consumers.

Consumers in Segment 2 were characterized by high use and trust in information sources. Consumers in this segment scored the highest on the use of all information sources about chicken and also on trust except for electronic media. Therefore, we referred to this segment as enthusiastic consumers. Although the factor "use of official and commercial sources" has the lowest absolute value (2.61) compared with to other factors within this segment, this segment has the highest use of official and commercial sources by far. This segment was the largest segment accounting for more than half (53.0\%) of the sample.

Segment 3 contained consumers with moderate use but high trust (except for commercial sources) in the presented information channels. Individuals in this segment rely on personal and electronic media sources, but have the lowest use in terms of official and commercial sources of information. Their use of electronic media sources is comparable to those in Segment 2. In addition, they have the highest trust for these sources but not significantly different from those in Segment 2. This segment contained $28.8 \%$ of the respondents and is referred to as optimistic consumers. 


\subsubsection{Types of information searched by consumers}

Considering the interest in potential information cues, health, safety, and quality information were the most important cues consumers usually searched for regarding chicken, while method of preparation and the country of origin (for imported chicken products) were the least (see Table 7.4).

Not surprisingly, Segment 2 scored the highest and differed significantly on all eight potential information cues, except price. This imply that, consumers belonging to this segment were simply very interested in obtaining information about chicken. Specifically, they were interested in information about health, quality, safety, and nutritional information than price, country of origin, method of preparation and place of purchase. Segment 3 consumers were more interested in searching for information related to credence qualities such as health and safety. With the exception of price, consumers belonging to Segment 1 scored the lowest (below the neutral point of the scale) on all the cues as compared to the other segments. Consumers belonging to this segment were more interested in price information than any other information and scored the highest on this score. Although this segment scored the highest on price information, there was no significant difference between the segments. In addition, the score on information about country of origin and place of purchase were not significantly different from those in Segment 2.

Table 7.4: Profile of the segments on the type of information searched for on chicken

\begin{tabular}{lccccccc}
\hline & $\begin{array}{c}\text { Total } \\
\text { sample }\end{array}$ & Cautious & Enthusiastic & Optimistic & $\begin{array}{c}\text { F- } \\
\text { Value }\end{array}$ & $\begin{array}{c}p- \\
\text { Value }^{2}\end{array}$ & Eta $^{2}$ \\
\hline Price & 2.88 & 3.07 & 2.87 & 2.79 & 1.30 & 0.274 & .005 \\
Safety issues & 3.47 & $2.30^{\mathrm{c}}$ & $3.88^{\mathrm{b}}$ & $3.44^{\mathrm{a}}$ & 90.20 & $<0.001$ & .266 \\
Quality & 3.34 & $2.32^{\mathrm{c}}$ & $3.89^{\mathrm{b}}$ & $2.97^{\mathrm{a}}$ & 91.35 & $<0.001$ & .269 \\
Nutritional information & 3.31 & $2.24^{\mathrm{c}}$ & $3.86^{\mathrm{b}}$ & $2.97^{\mathrm{a}}$ & 88.76 & $<0.001$ & .263 \\
Health benefits & 3.57 & $2.30^{\mathrm{c}}$ & $4.06^{\mathrm{b}}$ & $3.47^{\mathrm{a}}$ & 103.52 & $<0.001$ & .294 \\
Country of origin (i.e., & 2.22 & $1.95^{\mathrm{a}}$ & $2.45^{\mathrm{b}}$ & $1.96^{\mathrm{a}}$ & 11.40 & $<0.001$ & .044 \\
imported) & & & & & & & \\
Place of purchase & 2.64 & $2.54^{\mathrm{a}}$ & $2.85^{\mathrm{b}}$ & $2.33^{\mathrm{a}}$ & 9.61 & $<0.001$ & .037 \\
Method of preparation/ & 2.36 & $2.23^{\mathrm{c}}$ & $2.74^{\mathrm{b}}$ & $1.76^{\mathrm{a}}$ & 35.79 & $<0.001$ & .126 \\
Cooking recommendations & & & & & & &
\end{tabular}

Note: different lower case superscripts indicate significantly different means between the segments using independent sample one-way analysis of variance followed by Tukey's HSD test.

\subsubsection{Sociodemographic profile of the segments}

Table 7.5 presents the sociodemographic characteristics of the segments. As compared to the distribution in the total sample, there were more men to women among Segment 1 and more women to men among Segment 3. The gender distribution of Segment 2 was very similar to the one of the total sample. Likewise, Segment 2 were the youngest segment with more of the 
youngest respondents and less of the older ones (55 years and above). However, gender and age were not significantly different between the segments. Sociodemographic factors found to be significant in distinguishing the consumer information segments were education, employment, and income. These factors will be important in determining consumers' information search decisions and thus should be considered in the context of information campaigns. In terms of education, the results show that the educational level of Segment 2 was significantly higher than the average of the other segments. This segment includes the largest shares of tertiary education (i.e., Post-secondary and above) and relatively more employed in the formal sector compared to the other segments. Compared with the total distribution in the sample, Segments 1 and 3 are composed of significantly higher proportion of consumers who are self-employed with Segment 1 having the highest. In comparison with the other clusters, Segment 1 had a significantly higher proportion of consumers in the low income category. A higher proportion of the high income households belong to Segment 2 relative to the other groups and Segment 3 has more households in the middle income category. 
Table 7.5: Sociodemographic characteristics of consumers surveyed

\begin{tabular}{|c|c|c|c|c|c|c|}
\hline & $\begin{array}{c}\text { Total } \\
\text { sample }\end{array}$ & Cautious & Enthusiastic & Optimistic & $\begin{array}{l}\text { F-Value } / \\
\text { Chi-square }\end{array}$ & $p$-Value \\
\hline Gender (\%) & & & & & 2.674 & 0.263 \\
\hline Male & 14.6 & 18.7 & 15.1 & 11.1 & & \\
\hline Female & 85.4 & 81.3 & 84.9 & 88.9 & & \\
\hline Age $(\text { average })^{D}$ & 38.3 & 39.1 & 37.4 & 39.7 & 2.04 & 0.131 \\
\hline Age (\% category) & & & & & 5.876 & 0.209 \\
\hline $18-34$ & 44.6 & 39.6 & 49.4 & 38.9 & & \\
\hline $35-54$ & 44.2 & 46.2 & 40.8 & 49.3 & & \\
\hline 55 and above & 11.2 & 14.3 & 9.8 & 11.8 & & \\
\hline Education (\%) & & & & & 173.126 & $<0.001$ \\
\hline None & 4.0 & 5.5 & 1.1 & 8.3 & & \\
\hline Primary & 8.0 & 14.3 & 4.9 & 9.7 & & \\
\hline Junior secondary & 24.0 & 47.3 & 7.6 & 39.6 & & \\
\hline Secondary education & 20.6 & 28.6 & 18.5 & 19.4 & & \\
\hline Post-secondary & 19.6 & 2.2 & 30.6 & 10.4 & & \\
\hline Bachelor's degree & 18.8 & 2.2 & 30.2 & 8.3 & & \\
\hline Master's or higher degree & 5.0 & 0.0 & 7.2 & 4.2 & & \\
\hline Employment status (\%) & & & & & 53.468 & $<0.001$ \\
\hline Full-time employed & 32.0 & 22.0 & 41.9 & 20.1 & & \\
\hline Part-time employed & 7.6 & 2.2 & 10.2 & 6.3 & & \\
\hline Self-employed & 49.0 & 64.8 & 35.9 & 63.2 & & \\
\hline Unemployed & 3.8 & 6.6 & 3.8 & 2.1 & & \\
\hline Retired & 2.2 & 2.2 & 2.3 & 2.1 & & \\
\hline Household duties (Homemaker) & 3.6 & 2.2 & 3.0 & 5.6 & & \\
\hline Student & 1.8 & 0.0 & 3.0 & 0.7 & & \\
\hline $\begin{array}{l}\text { Household net monthly income } \\
(\%)\end{array}$ & & & & & 37.277 & $<0.001$ \\
\hline Low $(<\mathrm{GH} \varnothing 600)$ & 19.0 & 33.0 & 14.7 & 18.1 & & \\
\hline Middle (GHф600 - GHф1,799) & 58.2 & 58.2 & 53.2 & 67.4 & & \\
\hline High $(\mathrm{GH} \not 1,800 \&$ above $)$ & 22.8 & 8.8 & 32.1 & 14.6 & & \\
\hline Family status (\%) & & & & & 7.889 & 0.444 \\
\hline Married & 60.0 & 58.2 & 60.0 & 61.1 & & \\
\hline Single & 24.0 & 26.4 & 25.3 & 20.1 & & \\
\hline Divorced & 6.4 & 6.6 & 6.0 & 6.9 & & \\
\hline Widowed & 5.0 & 6.6 & 3.0 & 7.6 & & \\
\hline Living together & 4.6 & 2.2 & 5.7 & 4.2 & & \\
\hline
\end{tabular}

Note: ${ }^{\mathrm{D}} \mathrm{F}$-value for the age (average), Chi-square for other tests.

\subsubsection{Motives for purchasing chicken}

Respondents' reasons for buying chicken meat are presented in Table 7.6. In general, consumers attached greater importance to sensory aspects (taste) and suitability for preparation of many dishes. Low fat content or leanness of chicken meat seems not to be important motives to choose chicken meat among respondents. Segment 1 has the highest preference for taste and price. Consumers in this segment do not seem to consider health and nutritional value of chicken meat as important motives for their purchase. Segment 2 scored significantly higher on all motives compared to the other segments. This segment not only puts a high value on taste, suitability of chicken for many dishes, but also convenience and health motives. In contrast, low values are found for low price. Among respondents in Segment 3, low price was the most important motive for buying chicken. Low values are given to low fat content and health. Significant difference 
between respondents belonging to all segments was observed for a factor related to the availability of chicken meat.

Table 7.6: Chicken meat purchase motives

\begin{tabular}{lcccccc}
\hline & Total sample & Cautious & Enthusiastic & Optimistic & F-Value & $p$-Value \\
\hline Suits many dishes & 0.56 & $0.37^{\mathrm{a}}$ & $0.68^{\mathrm{b}}$ & $0.46^{\mathrm{a}}$ & 18.80 & $<0.001$ \\
Healthy/nutritious & 0.47 & $0.29^{\mathrm{a}}$ & $0.64^{\mathrm{b}}$ & $0.27^{\mathrm{a}}$ & 38.21 & $<0.001$ \\
Easy to prepare & 0.48 & $0.30^{\mathrm{a}}$ & $0.65^{\mathrm{b}}$ & $0.30^{\mathrm{a}}$ & 34.86 & $<0.001$ \\
Readily available & 0.41 & $0.32^{\mathrm{c}}$ & $0.57^{\mathrm{b}}$ & $0.19^{\mathrm{a}}$ & 33.36 & $<0.001$ \\
Cheap & 0.45 & $0.45^{\mathrm{a}, \mathrm{b}}$ & $0.40^{\mathrm{b}}$ & $0.53^{\mathrm{a}}$ & 3.25 & 0.039 \\
Low fat/lean & 0.34 & $0.24^{\mathrm{a}}$ & $0.45^{\mathrm{b}}$ & $0.22^{\mathrm{a}}$ & 14.60 & $<0.001$ \\
Tasty & 0.59 & $0.55^{\mathrm{a}}$ & $0.68^{\mathrm{b}}$ & $0.47^{\mathrm{a}}$ & 8.69 & $<0.001$ \\
Suitable for feast (e.g., & 0.47 & $0.33^{\mathrm{a}}$ & $0.52^{\mathrm{b}}$ & $0.46^{\mathrm{a}, \mathrm{b}}$ & 5.30 & 0.005 \\
parties, other occasions) & & & & & &
\end{tabular}

Note: different lower case superscripts indicate significantly different means between the segments using independent sample one-way analysis of variance followed by Tukey's HSD test.

\subsubsection{Differences in meat consumption between segments}

The results in Table 7.7 show the consumption frequency of different meat types among the segments. Overall, fish is consumed frequently than any of the other meat products, followed by chicken, beef, and goat meat. Pork and lamb (mutton) are the least consumed meat among respondents. Significant differences between segments are observed for chicken meat, beef, and lamb. Segment 1 had a lower consumption of chicken, than the other two groups and a lower consumption of lamb compared with the third segment. Consumers in Segment 2 together with Segment 3 displayed significantly high consumption frequency of chicken meat compared those in Segment 1. However, Segment 2 had a significantly lower consumption frequency of beef than the other clusters. The third segment seem to have a high frequency of beef and lamb consumption. Their consumption levels for beef differ significantly from Segment 2 but not segment one. Additionally, they consumed relatively frequent lamb than Segment 1. Concerning domestic and imported chicken meats, the results show that imported chicken is consumed more often than domestic chicken. However, the consumption of imported and domestic chicken did not differ significantly between the segments.

Table 7.7: Meat consumption frequency*

\begin{tabular}{lcccccc}
\hline & Total sample & Cautious & Enthusiastic & Optimistic & F-Value & $p$-Value \\
\hline Chicken & 3.29 & $3.07^{\mathrm{b}}$ & $3.44^{\mathrm{a}}$ & $3.17^{\mathrm{a}, \mathrm{b}}$ & 3.21 & 0.041 \\
$\quad$ Imported & 2.48 & 2.34 & 2.57 & 2.39 & 0.87 & 0.418 \\
$\quad$ Domestic & 1.91 & 1.89 & 1.93 & 1.88 & 0.08 & 0.926 \\
Beef & 2.55 & $2.65^{\mathrm{a}, \mathrm{b}}$ & $2.39^{\mathrm{a}}$ & $2.77^{\mathrm{b}}$ & 2.70 & 0.068 \\
Fish & 5.37 & 5.27 & 5.32 & 5.53 & 2.27 & 0.105 \\
Pork & 0.87 & 0.98 & 0.88 & 0.83 & 0.07 & 0.933 \\
Goat & 1.59 & 1.58 & 1.65 & 1.49 & 0.68 & 0.506 \\
Lamb & 0.83 & $0.68^{\mathrm{b}}$ & $0.82^{\mathrm{a}, \mathrm{b}}$ & $0.96^{\mathrm{a}}$ & 2.86 & 0.058 \\
\hline
\end{tabular}

Note: ${ }^{*}$ Range is from 0 (never) to 6 (four times or more a week). Different lower case superscripts indicate significantly different means between the segments using independent sample one-way analysis of variance followed by Tukey's HSD test. 


\subsection{Discussion}

The present study provides insight into the use of information channels by consumers to seek information on chicken meat as well as the trust in these sources. In particular, we investigated whether consumers can be segmented based on their use and trust in information sources and on which aspects these segments differ from each other in terms of the information they searched for, their sociodemographic characteristics, and chicken meat consumption.

In general, consumers used external information to guide their purchase decisions. In particular, the results show that personal sources were the most frequently used channels for seeking information about chicken meat. Personal sources include the respondent's social environment (i.e., friends, family, colleagues, and sellers). These sources are often used by respondents, especially in terms of everyday information seeking. This result could be explained in the context of the Ghanaian culture. Ghana is a collectivist country, where people particularly emphasize on social relations and bonding and thus are more likely to share information with their close reference groups. This is also reflected in the perceived trustworthiness of such sources. Indeed, previous research has shown consumers tend to rely most on personal sources. For instance, Pieniak et al. (2007) found that European consumers frequently used personal sources of information such as family and friends, and fishmonger about fish. In contrast, other studies found governmental institutions, official websites and brochures, and culinary sources (i.e., cooking books and cooking programs) as the most important source of information for food consumers in the Netherlands, Switzerland, and Poland, respectively (Kornelis et al., 2007; Visschers et al., 2013; Żakowska-Biemans et al., 2017). However, it is worth mentioning that all of these studies found personal sources to be the second most important channel of information. Thus, we can conclude from these findings that regardless of the geographic region and food type, personal sources (word-of-mouth) still play a vital role in making informed decisions about food.

The electronic media sources (i.e., television and radio) also play important role in respondents' information seeking. These were the second most frequently used channels of information. Information from media sources such as television or radio may be acquired purposively or incidentally. However, when encountered incidentally, it could act as a catalyst of information seeking (Williamson, 1998). Since mass media messages are able to reach large audiences, informational campaigns targeting consumers through the electronic media sources would be effective.

On the other hand, official and commercial sources such as health professionals, government, newspapers, internet, and magazines were less frequently used as information 
channels about chicken. The low use of official sources such as health professionals and the government is consistent with other studies (Pieniak et al., 2007; Visschers et al., 2013). However, this finding is in marked contrast to the study of Kornelis et al. (2007), where governmental institutions were the most important sources of information. Given the low use of these sources, it would not seem useful to target consumers with information about chicken through these sources. Nevertheless, health professionals and institutions of government were reported as highly trusted sources despite their low usage. Therefore, they can serve as complementary channels for the dissemination of information, especially those related to health and safety. Since they are trusted, identifying, and removing the obstacles to their regular use, are of paramount interest. In relation to information cues, consumers were much interested in searching for information about health, safety, and quality. These factors will be more critical in their purchasing and consumption decisions. Thus, information campaign emphasizing health, safety, and quality will be important.

Based on the sequence variables, we identified three distinct consumer segments: cautious consumers (18.2\%), enthusiastic consumers (53.0\%), and optimistic consumers $(28.8 \%)$. The number of clusters identified compares equally with previous studies in European countries, which employed information use and trust variables in clustering fish and beef consumers (Pieniak et al., 2007; Żakowska-Biemans et al., 2017). The identified groups also differed significantly with respect to the type of information they seek and various characteristics such as education, employment, income, and chicken consumption.

Consumers belonging to Segment 1 (cautious consumers) displayed low use and trust in external information sources. The segment of cautious consumers was perhaps convinced that the information they needed was at least available through personal sources and were less willing to engage actively in seeking information from other sources. Besides, it was the least interested in information cues about chicken and constituted the smallest group. This result is in line with past research on European consumers (Visschers et al., 2013; Kuttschreuter et al., 2014). Visschers et al. (2013) identified four consumer groups namely "official information users", "internet users", "moderate users" and "uninterested" based nutrition information use. The uninterested segment (28\%) was the least interested in using nutrition tables or other sources for nutrition information and displayed the lowest usage of nutrition information sources. Likewise, Kuttschreuter et al. (2014) identified four segments based on their inclination to use different channels to seek information about food-related risks and labelled the segments as "high cross-channel inclination," "established channel inclination," "moderate cross-channel inclination," and "low cross-channel inclination." They found that the low cross-channel 
inclination (19\%) was the least interested in seeking additional information about vegetable risks. Against this background, Segment 1 members may not be only cautious but also uninterested.

Enthusiastic consumers (Segment 2) are perhaps relatively easy to reach for communicators as they exhibited high use and trust in information channels. This is a substantial segment in our study, accounting for more than half of the sample. Consumers in this segment searched actively for information about chicken products (high involvement) and seemed to be the most demanding in terms of information type such as health, quality, safety, and nutrition information. A similar group of consumers who are very active in their search and use of information and are particularly interested in health, quality, and nutrition information has also been identified in previous literature (Pieniak et al., 2007; Kuttschreuter et al., 2014; ŻakowskaBiemans et al., 2017). Pieniak et al. (2007) and Żakowska-Biemans et al. (2017) also referred to this group of consumers as "enthusiasts". This group mainly demonstrated their interests in the use of personal (friends, colleagues, family, and sellers) and electronic media (TV and radio) sources. Compared to the other segments (Segments 1 and 3), consumers in Segment 2 have a strong tendency to use information from official and commercial sources. Furthermore, consumers in this segment were more highly educated compared to the cautious and optimistic consumers. This result is in agreement with the study of Pieniak et al. (2007). In contrast, however, Żakowska-Biemans et al. (2017) found a low level of education amongst members of the highly involved segment. Similar to Segment 2, the first two sources used by consumers in Segment 3 (optimistic consumers) are personal and electronic media. However, examination of the trust levels revealed that this group has a strong tendency to consult electronic media sources due to the high level of trust in these sources.

Consumers are inspired to select food products for an increasing number of motives. Therefore, understanding the motives behind consumer purchase decisions is important for communicating simple messages to consumers. To this end, our study shows that taste, suitability to prepare many dishes, convenience, and healthiness were indicated as primary motives to buy chicken meat. Taste and suitability to prepare many dishes were reported as primary motives to buy other meat products such as beef (Żakowska-Biemans et al., 2017). The results on consumers' motivations, however, varied according to cluster membership. For example, price was the least factor affecting purchasing decisions of consumers in Segment 2, but it was the second and first most important factor for Segments 1 and 3, respectively. This emphasizes the importance of considering different combinations of motives that matter to consumers when communicating messages. Thus, marketers who want to tailor their products 
to a specific segment should communicate a combination of motives that matter to consumers in that segment, to increase consumer preference and consumption.

Concerning the consumption frequency of meat products, the results show that fish, followed by chicken meat, and beef are the most frequently consumed meat products. The result is in agreement with Sumberg, Jatoe, Kleih, and Flynn (2016), who found that half of the Ghanaian households' expenditure on meat products is allocated to fish, followed by poultry and beef with the same share. Focusing on chicken meat, which is the interest of this study, we find that the segment characterized by low information seeking and trust (cautious consumers) portrayed a lower consumption of chicken meat. Therefore, a possible explanation for their low inclination to seek additional information about chicken meat could be attributed to a lower level of consumer involvement and consumption (Verbeke, 2005). In agreement with previous studies where consumers with a high level of involvement were associated with the highest level of consumption (Pieniak et al., 2007; Kuttschreuter et al., 2014), our findings show that consumers characterized by high information usage and trust (enthusiasts) had the highest level of chicken consumption.

Given that consumers make many food-related decisions every day, coupled with the diversity of food products, they are unlikely to allocate substantial cognitive effort and time to each decision (Adamowicz \& Swait, 2013; Ardeshiri, Sampson, \& Swait, 2019). Similarly, consumers are uncertain about the quality and safety of food products (Verbeke, 2005). Nevertheless, this does not suggest that consumers are asking for the provision of very detailed and too many information cues as this might lead to the risk of information overload and potential adverse effects resulting from consumer indifference or loss of confidence (Verbeke, 2005). In the case of meat, it has been shown that consumers are selective in paying attention to information in general (Verbeke \& Ward, 2006). This is also demonstrated by our findings as we find that different consumer segments pay attention to different types of information. Therefore, information provision about chicken to consumers are likely to be effective when it is targeted and meets the needs and expectations of the target audience.

Our study has some limitations that should be noted when interpreting the results and its contributions. First, our study focused on urban consumers, which limits the potential to generalize the findings to the Ghanaian population. Second, we were unable to link the information cues to specific information channels. For example, whether consumers usually get price information from sellers or safety information from radio, etc. In future research it would be interesting to match the type of information consumers seek to the source. Last, since respondents were asked to report their behavior (self-reporting), responses may be affected by 
recall bias (e.g., frequency of information use and consumption) and social desirability bias (e.g., trust in information sources), which is inherent in most face-face surveys.

\subsection{Conclusions}

To conclude, the current blanket nationwide campaign which aims to provide information to consumers to increase the consumption of domestic chicken meat may appeal to certain consumers, but not all, as our results suggest. When the aim is to reach all consumers, "cautious consumers" require special attention as they are likely to become unaware of the provided information. With their low usage of various information sources, low trust, and low interest in various information cues, trying to consciously stimulate and educate this group with general information about chicken will not improve their consumption behavior. Based on the findings, personal sources (e.g., sellers) may be more useful to target consumers in this segment since these sources were the most consulted and trusted. Likewise, informational campaigns emphasizing taste and price may be more effective to change this segment's chicken consumption behavior. In addition, communication strategies ought to ensure that the tone and language of the message match the education levels of the consumer groups. Since members in this group have low levels of education, the messages should be easily interpretable and understandable.

Information campaigns that target consumers in Segment 2 (enthusiastic consumers) are likely to succeed in increasing the consumption of domestic chicken. This is because members of this group are relatively easy to reach through the various information sources, higher educated and with high-income level than the other groups. Moreover, they are not much concerned about prices and have a favorable disposition towards chicken meat consumption. However, they attached high importance to health, quality, safety, and nutritional information and are primarily motivated by taste to buy chicken. This means that providing unambiguous and more accurate information on these aspects about chicken could improve their consumption. The third segment (optimistic consumers) may also not be very difficult to reach by communicators because of their use and high trust in certain channels such as electronic media. For this group, advertisements and information campaigns through radio and television may be most effective because they are regarded as reliable information sources. On the whole, the identification of three distinct groups of poultry consumers based on information use and trust, provide evidence to communicators to carefully target relevant information that aligns with the background of recipients. Finally, the findings from this study also contribute to consumer behavior literature from a developing country perspective. 


\section{References}

Adamowicz, W. L., \& Swait, J. D. (2013). Are food choices really habitual? Integrating habits, variety-seeking, and compensatory choice in a utility-maximizing framework. American Journal of Agricultural Economics, 95(1), 17-41.

Akerlof, G. A. (1970). The market for "lemons": Quality uncertainty and the market mechanism. The Quarterly Journal of Economics, 84(3), 488-500.

Ardeshiri, A., Sampson, S., \& Swait, J. (2019). Seasonality effects on consumers' preferences over quality attributes of different beef products. Meat Science, 157, 107868.

Asante-Addo, C., \& Weible, D. (2019, September). "Everybody likes chicken" - A focus group study of consumers in Ghana. Paper presented at the 59th Annual Conference of the German Association of Agricultural Economists (GEWISOLA), Braunschweig, Germany. Retrieved from https://ageconsearch.umn.edu/record/292291

Daily Graphic (2018, August 30). 'Eat Ghana chicken campaign' to boost local poultry production. Daily Graphic. Retrieved from https://www.graphic.com.gh/

Engel, J. F., Blackwell, R. D., \& Miniard, P. W. (1993). Consumer Behavior (8th ed.) Fort Worth: Dryden Press.

Field, A. (2009). Discovering statistics using SPSS. Los Angeles: Sage.

Font-i-Furnols, M., \& Guerrero, L. (2014). Consumer preference, behavior and perception about meat and meat products: an overview. Meat Science, 98(3), 361-371.

Grunert, K. G. (2005). Food quality and safety: Consumer perception and demand. European Review of Agricultural Economics, 32(3), 369-391.

Grunert, K. G., \& Wills, J. M. (2007). A review of European research on consumer response to nutrition information on food labels. Journal of Public Health, 15(5), 385-399.

Hair, J., Black, W., Babin, B., Anderson, R., \& Tatham, R. (2006). Multivariate data analysis. New Jersey: Pearson Education, Inc.

Hung, Y., Grunert, K. G., Hoefkens, C., Hieke, S., \& Verbeke, W. (2017). Motivation outweighs ability in explaining European consumers' use of health claims. Food quality and preference, 58, 34-44.

Jungermann, H., Pfister, H. R., \& Fischer, K. (1996). Credibility, information preferences, and information interests. Risk analysis, 16(2), 251-261.

Kornelis, M., De Jonge, J., Frewer, L., \& Dagevos, H. (2007). Consumer selection of foodsafety information sources. Risk Analysis, 27(2), 327-335.

Kotler, P. \& Armstrong, G. (2011). Principals of marketing (13th ed.). Upper Saddle River: Pearson.

Kotler, P. \& Keller, K. L. (2012). Marketing management (14th ed.). London: Pearson Education.

Kuttschreuter, M. Ô., Rutsaert, P., Hilverda, F., Regan, Á., Barnett, J., \& Verbeke, W. (2014). Seeking information about food-related risks: The contribution of social media. Food Quality and Preference, 37, 10-18.

Lewis, J. D., \& Weigert, A. J. (1985). Social atomism, holism, and trust. The sociological Quarterly, 26(4), 455-471.

Liu, R., Pieniak, Z., \& Verbeke, W. (2014). Food-related hazards in China: Consumers' perceptions of risk and trust in information sources. Food Control, 46, 291-298.

Loudon, D. L., \& Della Bitta, A. J. (1993). Consumer behavior: concepts and applications (4th ed.). New York: McGraw-Hill.

Morrow Jr, J. L., Hansen, M. H., \& Pearson, A. W. (2004). The cognitive and affective antecedents of general trust within cooperative organizations. Journal of Managerial Issues, 16(1), 48-64.

Niva, M., Vainio, A., \& Jallinoja, P. (2017). Barriers to increasing plant protein consumption in Western populations. In F. Mariotti (Ed.). Vegetarian and plant-based diets in 
health and disease prevention (pp. 157-171). Elsevier, Academic Press.

Peschel, A. O., Grebitus, C., Steiner, B., \& Veeman, M. (2016). How does consumer knowledge affect environmentally sustainable choices? Evidence from a cross-country latent class analysis of food labels. Appetite, 106(1), 78-91.

Pieniak, Z., Vanhonacker, F., \& Verbeke, W. (2013). Consumer knowledge and use of information about fish and aquaculture. Food Policy, 40, 25-30.

Pieniak, Z., Verbeke, W., Scholderer, J., Bruns $\varnothing$, K., \& Olsen, S. O. (2007). European consumers' use of and trust in information sources about fish. Food Quality and Preference, 18(8), 1050-1063.

Salaün, Y., \& Flores, K. (2001). Information quality: Meeting the needs of the consumer. International Journal of Information Management, 21(1), 21-37.

Solomon, M. R., Bamossy, G., Askegaard, S., \& Hogg, M. K. (2010). Consumer behaviour: a European perspective (4th ed.). New York: Prentice Hall/Financial Times.

Sumberg, J., Jatoe, J., Kleih, U., \& Flynn, J. (2016). Ghana's evolving protein economy. Food Security, 8(5), 909-920.

Teisl, M. F., \& Roe, B. E. (1998). The economics of labeling: An overview of the issures for health and environmental disclosure. Agricultural and Resource Economics Review, $27(2), 140-150$.

Thiede, M. (2005). Information and access to health care: Is there a role for trust? Social Science \& Medicine, 61(7), 1452-1462.

Vainio, A. (2019). How consumers of meat-based and plant-based diets attend to scientific and commercial information sources: Eating motives, the need for cognition and ability to evaluate information. Appetite, 138, 72-79.

Verbeke, W. (2005). Agriculture and the food industry in the information age. European Review of Agricultural Economics, 32(3), 347-368.

Verbeke, W. (2008). Impact of communication on consumers' food choices. Proceedings of the Nutrition Society, 67(03), 281-288.

Verbeke, W., \& Ward, R. W. (2006). Consumer interest in information cues denoting quality, traceability and origin: An application of ordered probit models to beef labels. Food Quality and Preference, 17(6), 453-467.

Visschers, V. H. M., Hartmann, C., Leins-Hess, R., Dohle, S., \& Siegrist, M. (2013). A consumer segmentation of nutrition information use and its relation to food consumption behaviour. Food Policy, 42, 71-80.

Wedel, M., \& Kamakura,W. A. (2000). Conceptual and methodological foundations. Boston: Kluwer.

Williamson, K. (1998). Discovered by chance: The role of incidental information acquisition in an ecological model of information use. Library \& Information Science Research, 20(1), 23-40.

Żakowska-Biemans, S., Pieniak, Z., Gutkowska, K., Wierzbicki, J., Cieszyńska, K., Sajdakowska, M., \& Kosicka-Gębska, M. (2017). Beef consumer segment profiles based on information source usage in Poland. Meat Science, 124, 105-113.

Zander, K., \& Hamm, U. (2012). Information search behaviour and its determinants: the case of ethical attributes of organic food. International Journal of Consumer Studies, 36(3), 307-316. 


\section{General discussion}

This chapter takes the results of all four papers into consideration, discusses the findings of the dissertation, and relates the findings to the relevant literature. Additionally, it presents the limitations of the current research and provides directions for future research.

\subsection{Main findings}

This dissertation emphasizes the importance of understanding consumer behavior toward meat products in the context of a developing country. Thus, it contributes to the consumer behavior literature, especially regarding the role of country-of-origin, personal (i.e., psychological and sociodemographic) factors, and information in explaining food choice and consumption behaviors. It also contributes to the debate on the role of food imports in developing countries by focusing on chicken meat, of which a large part of consumption is met by imports, particularly in SSA. In the following paragraphs, the main findings of this dissertation are discussed based on the research objectives outlined at the beginning of the study.

The first article, which addresses objective (1), explores consumers' motivations, perceptions, and attitudes toward chicken meat as well as the decision criteria for purchasing chicken. A qualitative approach using focus groups is used to elicit this information. The focus groups are conducted in Accra, the capital of Ghana. The focus group discussions provided valuable insights into motivations, perceptions, and attitudes toward chicken meat, particularly regarding domestic and imported chicken. In addition, the results of the focus group discussions further informed the design of the quantitative survey.

In general, participants mentioned a wide range of factors, which they consider when purchasing chicken meat. These include origin, price, taste, freshness, ease of preparation (convenience), safety and health concerns, availability, tenderness, and color. Comparing chicken to other meat products, the focus groups induced many positive perceptions of chicken meat, such as good value for money, healthful, tasty, versatile, and readily available. The versatility of usage and the ease of preparation associated with chicken meat are in line with Verlegh and Candel (1999), who indicate that the demand for convenience may account for the rise in the consumption of poultry meat products compared to other meat products such as beef.

Regarding the origin (i.e., domestic vs. imported) of chicken meat, considerable differences in consumers' perceptions and preferences emerge. For instance, consumers have a positive perception of the quality of domestic chicken. They evaluate domestic chicken more highly than imported chicken on the aspects of freshness, taste, and healthiness. They mainly 
associate good taste with the freshness of the product. Thus, it is not surprising that imported chicken products, which are available on the Ghanaian market as frozen, are associated with a loss of taste, resulting in the negative perception of quality. This finding aligns with Chambers et al. (2007), who indicate that food quality (i.e., taste and freshness) plays a key role in local food purchases. In contrast, the focus group participants evaluate the price, convenience, and availability of domestic chicken less favorably than imported chicken. For example, regarding price, most of the participants perceive domestic chicken meat as expensive compared to the imported ones, thus limiting the frequency of purchase and consumption thereof. However, the availability of low-priced imports provided those participants with low-income access to cheaper alternatives, which is essential for improving their welfare and food security status.

In most cases, participants associate domestic chicken with special occasions, such as Christmas, Easter, Islamic festivities, etc., suggesting that domestic chicken might be conceptualized as a product for specific occasions as opposed to everyday meals. This implies that the consumption decisions of domestic chicken meat may be influenced by perceived situational appropriateness. This finding is in agreement with Piqueras-Fiszman and Jaeger (2014), who indicate that product-context appropriateness influences consumers' emotional associations to the consumption of a product. Besides, most participants link the infrequent consumption of domestic chicken meat to inconvenience, as it is largely unprocessed.

In terms of production methods, issues about the use of antibiotics and growth promoters (e.g., hormones) in poultry production are the major concerns of consumers. Participants also expressed concerns about the reliability and integrity of the chicken meat supply system due to the recurrent outbreaks of avian influenza. These safety concerns are strong indications that consumers are becoming more interested in how their chickens are produced and kept. Consequently, some expressed the desire to consume chicken meat with "no antibiotics" or "no hormones". Concerning the domestic production system, the majority of the participants have limited knowledge about the system of commercial poultry production. As a result, there is a general distrust of the way chickens are produced and the government's regulatory, monitoring, and quality control systems. Despite the limited knowledge, some participants trust in the domestic production system and its ability to produce safe chicken.

Meanwhile, the perceptions of the (over)use of antibiotics and growth hormones are particularly strong for imported chicken. This is especially the case given that participants generally do not know about the production systems in other countries. It is interesting to note, however, that while antibiotics are used in poultry production, growth hormones are not used. Especially in major exporting countries such as the U.S. and the EU, the use of hormones in 
poultry production is prohibited (FDA, 2019; European Commission, n.d.). However, the finding clearly shows that consumers' perceptions of the use of hormones differ from reality. These perceptions are largely driven by sensational and over-amplifying reports from mass media or social media and hearsays. Since consumers are not privy to how chickens are produced in exporting countries, they tend to rely on information from these sources, which in turn feeds into their perceptions. Interestingly, the perception or myth that growth hormones are used in chicken production has increased globally and not only peculiar to consumers in Ghana. Indeed, similar perceptions have been documented among consumers in Malaysia and the U.S. (Chamhuri \& Batt, 2013; Yang, Raper, \& Lusk, 2017). For example, Yang et al. (2017) find that on average, U.S. consumers underestimate the use of hormones in beef production but overestimate their use in poultry production, even though hormones are allowed for the production of beef and not for poultry.

The second article deals with objective (2). Specifically, it identifies consumer chicken consumption patterns in terms of the frequency of consumption and examines whether personal factors influence these patterns. At a purely descriptive level, the results show that approximately $45 \%$ of respondents claim to consume chicken meat at least weekly or more. This finding underscores the importance of chicken as an important source of animal protein in urban Ghanaian diets. Interestingly, about $15 \%$ of the respondents do not consume imported chicken. Notwithstanding, 29\% consume imported chicken once or more a week. On the other hand, more than half of the respondents (56\%) consume domestic chicken meat occasionally (less than once a month), while only $15 \%$ consume domestic chicken at least once or more a week. These findings together suggest that domestic chicken meat is consumed less frequently compared to imported chicken. The relatively infrequent consumption of domestic chicken meat agrees with the findings of the focus groups and suggests opportunities for building interest in the domestic poultry sector.

To identify the factors influencing the frequency of consumption, ordered probit (i.e., univariate and bivariate) regressions are employed for model specification. The ordered probit regressions are estimated using factor scores of attitudes and perceptions in addition to sociodemographic characteristics as explanatory variables while controlling for the place of residence and distance. Results from the bivariate ordered probit model reveal a statistically significant weak correlation (-0.24) between the consumption of imported and domestic chicken, suggesting that both products are more often consumed exclusively than in conjunction, and therefore, can be regarded as (weak) substitutes. In other words, as respondents 
consume, for example, imported chicken more regularly, they are likely to reduce their consumption of domestic chicken and vice versa.

Importantly, the findings reveal the relationship between the frequency of chicken consumption and sociodemographic characteristics, psychological, and physical environment (i.e., travel distance to the nearest market) factors. For domestic chicken, however, sociodemographic factors do not significantly influence consumption as only income has a significant effect. Regarding the sociodemographic factors, the findings show that, overall, chicken consumption is less frequent among women compared to men. In terms of domestic and imported, the effect of gender is only significant and negative for imported chicken, indicating that women are less likely to consume imported chicken frequently compared to men. The presence of children in the household significantly influences the frequency of imported chicken consumption, while the effect on domestic chicken consumption is statistically insignificant. The significance of the effect on imported chicken suggests that households with children are more likely than those without children to consume imported chicken meat frequently.

Moreover, previous studies used employment status to capture the opportunity cost of time (e.g., Kinsey, 1983; Horton \& Campbell, 1991). Similarly, employment status is included, and the findings show that respondents who are employed are more likely to consume imported chicken frequently. This finding is not surprising considering that imported chicken products are available in cut-up parts that make them quicker and easier to prepare and better suited to time-constrained urban lifestyles. The effect of employment status on the consumption of domestic chicken is statistically insignificant. In addition, household income, which is the primary economic factor, has a significant and positive effect on consumers' overall chicken meat consumption. The effect of household income is only significant for the consumption of domestic chicken but not imported. In particular, high-income households consume domestic chicken frequently compared to low-income households. This finding may be because domestic chicken products are more expensive, and therefore are more affordable for high-income households.

Concerning the psychological factors, the findings reveal that attitudes toward food safety negatively influence chicken consumption, particularly domestic chicken. As revealed in the focus group discussions, consumers stopped or reduced consumption of domestic chicken during periods of avian influenza outbreaks. Therefore, the negative effect could be related to the intermittent outbreaks of avian influenza diseases in the country. Likewise, the finding shows a positive and significant effect of perceived convenience on imported chicken 
consumption but negative on domestic chicken consumption. Consistent with the expectation, price is a critical consideration in consumption decisions. The findings indicate that pricesensitive consumers are more likely to consume imported chicken frequently but less likely to consume domestic chicken regularly. Similarly, the results show that as consumers perceive domestic chicken as more expensive relative to imported chicken, they are less likely to consume domestic chicken frequently. These findings suggest that the price of domestic chicken may potentially limit the future growth of the domestic chicken market. The results support the earlier finding on the relationship between income and the consumption of domestic chicken, indicating that high-income households compared to low-income households can afford regular consumption. Given these findings, domestic chicken meat ought to be made available to the consumer at an affordable price. In light of increasing consumer demand for chicken meat, domestic production is likely to increase further, which could lead to a decrease in price. However, in the short-term, the price will still be high since the supply may not be able to match the rapidly growing consumer demand.

Furthermore, Henchion, McCarthy, Resconi, and Troy (2014) suggest that quality will become a significant factor in consumer's food choices, while income and price factors are likely to decline over time. Yet, quality is a subjective matter as it based on measures of perception (Steenkamp, 1990). In this regard, the findings show that the frequency of domestic chicken consumption is positively influenced by quality perceptions. The effect is equally significant but negative for imported chicken. In other words, the more strongly the consumer believes that domestic chicken is of higher quality than imported, the higher is the probability of being a regular consumer of domestic chicken meat compared to imported chicken. This finding is in agreement with Loureiro and Umberger (2003), who indicate that consumers prefer domestic products due to higher perceived quality.

Generally, the factor analysis identified some consumers who believe in protecting domestic industries, jobs, and the domestic economy. These consumers are labelled as ethnocentric consumers. Ethnocentric consumers are known to show loyalty toward products made in their own country and hence tend to prefer domestic to imported products (Shimp \& Sharma, 1987; Chambers et al., 2007). In agreement with the literature, the results reveal a significant effect of consumer ethnocentrism on the frequency of consumption. In particular, ethnocentric consumers are more likely to consume domestic chicken frequently compared to imported chicken. This implies that positive attitudes toward domestic food products positively drive their purchase, irrespective of the level of economic development of the country. This 
finding should give producers and government confidence and serve as an incentive to appeal to consumers based on their loyalty toward domestic products.

The third article captures objective (3) of this thesis. Here, econometric estimates of consumers' preferences and willingness to pay (WTP) for quality attributes in chicken meat (i.e., origin, storage form, product form, production claim, and price) using data from a choice experiment are performed. The multinomial logit (MNL) model is estimated and used as the base model. In addition to the MNL, the random parameter logit (RPL) and latent class (LC) logit models are estimated because they relax the independence of irrelevant alternatives (IIA) assumption and allow for preference heterogeneity. Based on the goodness-of-fit measures (i.e., log-likelihood, Pseudo $\mathrm{R}^{2}$, AIC, and BIC), the MNL model is rejected in favor of the RPL, which better fits the data.

The RPL model reveals heterogeneity for all of the attributes and confirms the findings of the qualitative study regarding the importance of origin, freshness, convenience, and food safety in the selection of chicken meat products. The attributes except price are coded as dummy variables. Therefore, a positive coefficient indicates a preference for the desired attribute level, whereas a negative coefficient indicates a preference for the based-level attribute.

For the product origin, the finding shows that, on average, consumers prefer domestically (Ghana) produced chicken to those from foreign countries (imported). This finding suggests that product origin does matter for consumers of chicken meat. The WTP estimates from the RPL model show that foreign chicken is discounted GH $₫ 30$. In other words, consumers are willing to pay a positive premium of $\mathrm{GH} \phi 30 / \mathrm{kg}$ for domestic chicken compared to foreign chicken. As evidenced by the focus group paper, consumers often value domestic chicken meat more because they associate it with superior quality. The demand for a domestic chicken attribute in Ghana mirrors the trend observed in developed countries (e.g., Vida \& Reardon, 2008; Pouta et al., 2010).

The product form attribute has the lowest impact on the choice decision. However, the finding that consumers prefer and are willing to pay a positive premium for chicken cuts compared to whole-dressed chicken is meaningful. Consumers' preferences for chicken cuts may stem from the associations of this attribute level with a higher level of convenience. With a growing number of people living and working in urban areas and increasingly pressed for time, providing a highly convenient chicken product (i.e., quicker and easier to prepare) constitutes a response to the transformation in their consumption habits. The storage form attribute is the second most important, indicating that freshness is a salient quality attribute for consumers. In this regard, consumers are willing to pay a price premium of GHф45/kg for fresh 
(chilled) chicken meat. The strong preference for freshness is in agreement with the literature that fresh meat is more preferred and valued than frozen meat (Lambooij et al., 2019).

Moreover, the positive and significant estimate for the antibiotic/or hormone-free claim indicates that chicken meat assured with this claim tends to generate higher utility for the respondents. This claim appears to have the highest impact on consumers' choices, and therefore, provides the largest room for gaining a price premium ( $\mathrm{GH} \not 46.9 / \mathrm{kg}$ of chicken) in the market compared to the other attributes. The high impact of the production claim attribute on consumers' choice decisions typifies their concerns about the way chicken is produced, as expressed in the qualitative part of this study. In this case, an antibiotic/hormone-free claim provides a strong signal to consumers and increases their confidence in the purchase of chicken products. Introducing this claim can be economically effective in reducing asymmetric information between consumers and producers, and in particular, remedying the "misinformation" regarding the use of hormones in poultry production. A similar strong preference for food safety labels in Ghana is documented in previous research on beef (OwusuSekyere, Owusu, \& Jordaan, 2014). Collectively, these findings reflect the developing nature of consumers' preferences in Ghana in the sense that consumers have rising awareness of food safety.

Furthermore, as the RPL results indicate, there is substantial heterogeneity in consumers' preferences for all attributes. However, the overall results may not give a complete picture of the whole story. Therefore, the LC segmentation is used to explain the sources of heterogeneity in preferences. The findings show that consumers' heterogeneous preferences are explained largely by attitudes (i.e., food safety concerns, health and production interests, price consciousness, and availability and convenience orientation) than sociodemographic characteristics. The LC segmentation reveals four distinct market segments, namely domestic chicken advocates (27\% of the respondents), foreign chicken lovers (17\%), claim conscious (35\%), and random choosers $(21 \%)$.

Domestic chicken advocates attach high importance to chicken produced in Ghana. This segment constitutes the second largest and shows a strong preference for domestic chicken. Compared to the fourth segment random choosers, domestic chicken advocates are likely to be concerned about food safety, human health and production standards, and tend to have children in their households. The class WTP estimates show that they are willing to pay a premium of $\mathrm{GH} \not 65.7 / \mathrm{kg}$ for domestic chicken, which is more than double the average for the whole sample (i.e., WTP from the RPL). They are also willing to pay premiums for chicken cuts, fresh, and antibiotic-free chicken products. In contrast, foreign chicken lovers who constitute the smallest 
segment prefer foreign chicken meat and are willing to pay a premium of GHф $27.7 / \mathrm{kg}$. This finding agrees with the qualitative results that despite the generally positive perceptions of domestic chicken in terms of quality, some consumers still prefer imported chicken meat. This is an interesting finding, suggesting that consumers have a differentiated picture of the impact of chicken meat imports. Likewise, the foreign chicken lovers prefer a "no claim" to antibioticfree claim. The preference for a "no claim" is reflected in their attitudes toward food safety as they display a general lack of concern about food safety-related issues.

The claim conscious consumers who constitute the largest group, are willing to pay the highest premium for the production claim attribute specifically, an antibiotic-free claimed chicken (GH $\not 51.1 / \mathrm{kg})$. This segment could be a relevant target for producers who wish to adopt antibiotic-free production practices. Besides, they are also willing to pay more for fresh chicken products. Compared to the fourth segment, their preferences are significantly influenced by their attitudes toward availability. The random choosers are only concerned about the countryof-origin attribute. The other attributes are not important in their choice decisions. In particular, the price coefficient is not statistically significant, and hence, the WTP values are not estimated. Therefore, based on the price range considered in this study, it can be concluded that consumers in this group are not willing to pay a premium for domestic chicken meat, although they prefer it.

Finally, there is no doubt that information influences consumers' food choice behavior. Accordingly, the fourth article analyzes consumers' use of and trust in information sources about chicken (objective 4 of this thesis). The findings show that informal (personal) information channels such as family and friends, or sellers/vendors are the most frequently used information sources. Personal sources of information, in this case, refer to information obtained via word-of-mouth communication from family, friends, or colleagues and sellers (Borgatti \& Cross, 2003; Brown, Barry, Dacin, \& Gunst, 2005).

Electronic media channels such as radio and television (TV) are the second-highest sources of information used by consumers. This finding underscores the growing importance and the unique role of the media in transmitting information to mass audiences in Ghana. Therefore, electronic media sources could play a pivotal role in campaigns aimed at promoting domestic chicken consumption. In addition, as indicated in the focus groups, these sources are critical in the dissemination of food safety-related information such as bird flu outbreaks. On the other hand, official (health professionals and government) and commercial (newspapers, internet, and magazines) sources are the least used. Concerning trust in the information sources, personal and electronic media sources are highly trusted compared to commercial sources. This 
perhaps may have contributed to the high use and further affirms the claim that trust is very critical for using provided information (Verbeke, 2008).

Based on the use of and trust in information sources, three different consumer segments are identified using cluster analysis: cautious consumers (18.2\%), enthusiastic consumers (53.0\%), and optimistic consumers (28.8\%). These consumer groups are then profiled based on socio-demographics, information cues searched for, purchase motives, and consumption behavior. The findings show that these groups respond differently to marketing strategies. In particular, cautious consumers who represent the smallest proportion of the sample are characterized by low-involvement. Specifically, they have the lowest use and trust in all information sources. They also show the least interest in available information cues, such as safety, health, and nutritional information. However, they focus on tangible considerations such as price and are more receptive to information from personal sources.

Alternatively, enthusiastic consumers are characterized by high-involvement because they exhibit the highest interest in all information sources. Consumers belonging to this segment consider intangible attributes when making purchases such as safety, health, quality, and nutrition. These findings clearly show that the search behavior of the "enthusiasts" is in sharp contrast to that of cautious consumers. The difference in search behavior is in line with McEachern and Schröder (2002), who indicate that low-involvement consumers seek information about tangible attributes that can be verified through experience, while highinvolvement consumers spend effort and time to get information on intangible quality attributes that are not immediately obvious and verifiable. Moreover, the "enthusiasts" show high trust levels for all information sources and consist of a greater proportion of more educated, wealthy, and relatively young consumers.

The optimistic consumers constitute the second largest. For this group, there is no dominant first source of information. The frequency of electronic media usage among members of this group is comparable to "enthusiasts". However, the level of trust in electronic media sources is relatively higher for this group compared to the other segments, implying that electronic media has a higher potential to be consulted frequently by optimistic consumers. Notably, this group has more females than the other groups and more likely to belong to the middle-income category. Like "enthusiasts", optimistic consumers are also interested in health and safety information. Nonetheless, their motives for buying chicken meat are primarily driven by price. Regarding chicken meat consumption, "enthusiasts" consume more frequently, followed by optimistic and cautious consumers. Notwithstanding, there are no significant differences between the groups in terms of the frequency of imported and domestic chicken 
consumption. This finding suggests that all three groups could be relevant communication targets in terms of improving the consumption of domestic chicken meat. However, reaching the enthusiastic and optimistic consumers would be relatively easy for communicators because of their interest in information compared to cautious consumers.

\subsection{Limitations and suggestions for future research}

Admittedly, while this thesis contributes to the literature on consumer behavior, it is subject to some limitations that need to be pointed out. First, the study only focused on urban consumers. This limits the potential to generalize the findings to consumers living in rural areas of Ghana where the availability of imported chicken products is very low, and almost every household mostly keep or raise chickens, mainly for home consumption and cash income. Second, the consumption patterns analyzed in this thesis are limited to chicken meat consumed at home and relied on frequencies rather than quantities. However, given that the period of interest spans more than a month, it would have been difficult for respondents to assess accurately the quantities of chicken meat consumed, which may have led to possible measurement biases. For robustness, further research should incorporate chicken eaten away from home. In addition, further studies that examine substitution elasticities between domestic and imported chicken using consumption quantities will be beneficial.

Third, as is the case with any stated preference survey, the choice experiment questions are based on hypothetical scenarios. Therefore, it is likely that respondents may have acted differently than they would have in real market settings while facing the same choice options. To minimize this hypothetical bias in the responses, a "cheap talk script" is used to remind respondents of their budget constraints when choosing between the alternatives in the choice tasks. However, the WTP estimates may still suffer from some degree of hypothetical bias and thus be overestimated. Therefore, further research is needed to validate the WTP estimates in this study using, for example, incentive-aligned mechanisms.

Fourth, it is clear from the findings that consumers prefer chicken cuts but are heterogeneous in their preferences. However, the choice experiment did not consider different chicken cuts such as leg quarters, wings, backs, drumsticks, breasts, etc. Given this, it is not possible to know which specific cuts consumers may prefer and whether they are willing to pay price premiums for the preferred cuts. Therefore, future research should consider offering different cuts to consumers in the experiment. This will allow the industry players to know which specific cuts consumers prefer and command price premiums to guide their processing decisions. Last, although some consumers are willing to pay a premium for the production claim 
attribute (e.g., antibiotic-free claim), the economic viability of adopting a new production method and introducing such claims remains to be seen. In this regard, further research could explore the industry costs of implementing such production standards as well as how these standards could affect the industry's incentives. 


\section{Conclusions and implications}

In this chapter, the conclusions drawn from the findings of this thesis are provided. Based on these conclusions, some implications are derived. Implications for producers, as well as policymakers, are presented.

\subsection{Overall conclusions}

In Ghana, poultry meat (mainly chicken) consumption has increased dramatically over the past decades. However, the bulk of the consumption is met by imports, and this has generated intense debate leading to criticisms, especially about the potential of imports to displace domestic production and cause job losses. Therefore, this dissertation seeks to understand the underlying factors of consumer behavior toward chicken meat products. Specifically, it examines urban consumers' attitudes, preferences, and demand for chicken meat, taking into account the origin of supply (domestic vs. imported). In pursuit of this objective, this dissertation uses an exploratory sequential mixed methods approach involving both qualitative (focus group discussion) and quantitative (face-to-face survey) research methods. Combining both qualitative and quantitative research methods compensates for the weaknesses of each approach and ensures that the unique strengths of each method are captured to gain a deeper understanding of consumer behavior regarding chicken meat. This further enhances the significance of derived implications and recommendations.

Overall the results tell an interesting story and underscore the importance of chicken meat in urban Ghanaian diets. Hence, critical for contributing to the national protein supply and food security. Compared to other meat products, the findings indicate that consumers prefer chicken because of its taste, affordability, convenience, and versatility. Regarding imported and domestic chicken meat consumption, the joint estimation of the consumption decisions using a bivariate ordered probit model shows that these products could be regarded as (weak) substitutes rather than complements. The findings also emphasize the importance of psychological factors such as perceptions and attitudes in shaping consumers' choices and consumption behavior. On the other hand, sociodemographic variables such as gender, presence of children, employment, and income are important factors influencing the frequency of chicken consumption. However, the impact of psychological factors specifically on the consumption of domestic chicken and, in general, on the choice of chicken meat attributes outweighs that of sociodemographic factors. 
Altogether, the findings highlight the importance of quality and origin in consumers' choice decisions. As revealed by the qualitative results, consumers assign a higher quality to domestically produced compared to imported chicken, particularly regarding taste, freshness, and healthiness. Despite positive perceptions about domestic chicken, some barriers (e.g., inconvenience, low availability, and higher price) preventing consumers from regular purchases remain. Nevertheless, the findings of the choice experiment show that consumers, in general, value freshness and domestic chicken, although preferences are heterogeneous. Further analysis using the latent segmentation reveals that although some consumers (foreign chicken lovers) derive significant utility from imported chicken meat and are willing to pay for it, others (domestic chicken advocates) are also willing to pay a much higher premium for domestic chicken. Nonetheless, the proportion of those willing to pay for domestic chicken meat is higher than those willing to pay for imported. These findings overall suggest that indeed there is a potential for domestically produced chicken and signal hope for the domestic poultry industry.

Moreover, the findings show that food safety is very important for consumers in Ghana. In particular, consumers are concerned about the (over)use of antibiotics and growth hormones as well as other food safety incidences such as avian influenza outbreaks. In agreement with the focus groups, findings from the quantitative survey show that consumers' safety concerns translate into decreased consumption of chicken meat, especially domestic chicken. As a consequence, and revealed in the choice experiment, the underlying safety concerns of consumers are reflected in their preferences and willingness to pay a higher premium for an antibiotic/hormone-free claimed chicken meat. Convenience is mentioned as an important factor for the purchase of chicken in the qualitative part of this study. The finding from the choice experiment further collaborates with that of the focus groups, as consumers preferred chicken cuts. As such, they are willing to pay a positive premium for chicken cuts as opposed to whole-dressed chicken, which requires further processing.

Concerning information search, respondents use different sources of information about chicken meat. These include information from family and friends, sellers/vendors, radio, TV, government, health professionals, newspapers, and the internet. Among these sources, consumers frequently use personal sources, followed by electronic media (radio and TV). They actively search for information on health, safety, and quality. A cluster analysis reveals a threecluster solution based on consumers' use of different information sources and trust thereof. The three clusters are defined as cautious, enthusiastic, and optimistic consumers. These clusters mainly differ regarding their sociodemographic characteristics, motivations for purchasing chicken meat, interest in information cues, and the frequency of chicken consumption. The 
findings, therefore, support the need for a segmented communication strategy in reaching out to all groups and focusing on the source of information used, their characteristics, and the relevant factors they consider when buying chicken meat.

\subsection{Managerial and policy implications}

Based on the findings, important implications for stakeholders in Ghana's poultry industry can be drawn. The findings show that perceived quality (i.e., taste and freshness) influences domestic chicken consumption positively. Likewise, the choice experiment reveals a market potential for domestic chicken and preference for freshness. With the opening up of the Ghanaian poultry market to more competition from imports, the Ghanaian origin label may become a more relevant assurance for domestic origin to consumers who value this type of assurance. As an example, domestic producers can build a strong domestic brand to target the "domestic chicken advocates" who have the highest WTP for the country-of-origin label. In doing so, better taste, freshness, and domestically produced should be emphasized and used as a unique selling proposition to target this segment of consumers. In addition, since ethnocentrism positively influences domestic chicken consumption, communication strategies should target ethnocentric consumers by appealing to their sense of local pride. Possible strategies that emphasize the potential benefits to the development of the domestic economy might also be a successful approach.

With the increasing concerns about the safety of meat produced, providing consumers with assurance should be a major priority for producers. In this case, setting up of private safety standards such as production claims (antibiotic-free) would be one way to attract consumers who are willing to pay a premium for such claims. Another way is to provide continuous and objective information through advertisements to change consumers' safety risk perceptions and to induce positive attitudes among consumers since attitudes are formed over long periods. In doing so, communication strategies should ensure that the tone and language of the message match the characteristics of the targeted consumer groups as the findings show that they differ regarding how they process and evaluate the provided information.

Moreover, convenience is a significant barrier to the consumption of domestic chicken. Given that meat consumption is mostly concentrated in urban areas, which comprise of mainly the working class spending less time preparing meals at home, domestic chicken consumption will increase further if domestic producers can provide processed products (chicken cuts). Furthermore, the findings highlight the role of price and income in influencing consumption decisions. Specifically, price consciousness and perceived expensiveness negatively affect 
domestic chicken meat consumption. It is in this light that regular consumption of domestic chicken meat is associated with high-income households rather than low-income households. This implies that in the short term, it might be very difficult for domestic producers to compete at the lower end of the market. However, one promising way to increase consumption is by targeting high-income households. Over time, this will enable the industry to gain more market share and compete at the lower end of the market.

From the policy perspective, the findings show that consumers expect and demand food safety, as they are concerned about the potential safety risks associated with the use of antibiotics, growth hormones, and outbreaks of avian flu. Therefore, to remedy these concerns, government intervention through investments in food safety standards (voluntary or mandatory) that can cope with safety issues in the supply chain (e.g., antibiotic-free or hormone-free claim) is necessary. Such food safety standards and traceability systems can help to improve consumers' knowledge about the production system, decrease ambiguity, increase trust, and assure their safety needs. Likewise, a successful communication strategy is needed to increase the knowledge of consumers. This might then lead to better-informed choices, and ultimately, generate effective market demand. There is also the need for effective monitoring and enforcement of existing quality control systems to ensure that safe chicken products are delivered to consumers.

Since price is one of the major barriers to domestic chicken consumption, appropriate policy interventions should aim at reducing the price gap between domestic and imported chicken products. One possible way to reduce the price gap is to reduce the cost of production to lower the selling price. As the higher price of domestic chicken meat is mainly a reflection of higher production costs, notably the cost of feed, the government could provide subsidies on feed. This might then reduce production costs while increasing output and reducing the market price of domestic chicken. To be effective, however, such subsidies should be designed to minimize leakages and diversion.

Finally, public policies should aim at creating an enabling environment and the necessary conditions to attract private sector investments. These should include investments in infrastructure for processing (slaughtering, cutting, and packaging), storage (cold chains), and marketing. In parallel, there is a need for prudent investment to boost production output that will match the capacity of the processing industry to ensure that the industry does survive. 


\section{References}

Ajzen, I., \& Fishbein, M. (1980). Understanding attitudes and predicting social behavior. Englewood-Cliffs, NJ: Prentice-Hall.

Ajzen, I., \& Madden, T. J. (1986). Prediction of goal-directed behavior: Attitudes, intentions, and perceived behavioral control. Journal of Experimental Social Psychology, 22(5), 453-474.

Alfnes, F. (2004). Stated preferences for imported and hormone-treated beef: Application of a mixed logit model. European Review of Agricultural Economics, 31(1), 19-37.

Alfnes, F., \& Rickertsen, K. (2003). European consumers' willingness to pay for US beef in experimental auction markets. American Journal of Agricultural Economics, 85(2), 396-405.

Al-Hassan, R. M., Larvoe, N., \& Adaku, A. A. (2014). Hedonic price analysis of dressed chicken in Ghana. International Journal of Business and Social Science, 5(12), 215223.

Alreck, P. L., \& Settle, R. B. (2004). The survey research handbook (3rd ed.). Irwin: McGraw Hill.

Amanor-Boadu, V., Nti, F. K., \& Ross, K. (2016). Structure of Ghana's chicken industry in 2015. Department of Agricultural Economics, Kansas State University, Manhattan, KS.

Armstrong, G., \& Kotler, P. (2009). Marketing: An introduction (9th ed.). Upper Saddle River, NJ: Pearson Prentice Hall.

Baba, Y., Kallas, Z., Costa-Font, M., Gil, J. M., \& Realini, C. E. (2016). Impact of hedonic evaluation on consumers' preferences for beef attributes including its enrichment with n-3 and CLA fatty acids. Meat Science, 111, 9-17.

Bailey, J. (2008). First steps in qualitative data analysis: Transcribing. Family Practice, 25(2), $127-131$.

Barrios, E. X., \& Costell, E. (2004). Use of methods of research into consumers' opinions and attitudes in food research. Food Science and Technology International, 10(6), 359-371.

Becker, W. E., \& Kennedy, P. E. (1992). A graphical exposition of the ordered probit. Econometric Theory, 8(1), 127-131.

Ben-Akiva, M., \& Lerman, S. R. (1985). Discrete choice analysis: Theory and application to travel demand. London: MIT Press.

Ben-Akiva, M., McFadden, D., Gärling, T., Gopinath, D., Walker, J., Bolduc, D., ... \& Polydoropoulou, A. (1999). Extended framework for modeling choice behavior. Marketing Letters, 10(3), 187-203.

Bengtsson, M. (2016). How to plan and perform a qualitative study using content analysis. NursingPlus Open, 2, 8-14.

Berg, B. L. (2001). Qualitative research methods for the social sciences. Boston: Allyn and Bacon.

Bett, H. K., Peters, K. J., Nwankwo, U. M., \& Bokelmann, W. (2013). Estimating consumer preferences and willingness to pay for the underutilised indigenous chicken products. Food Policy, 41, 218-225.

Blackwell, R. D., Miniard, P.W., \& Engel, J. F. (2001). Consumer behavior (9th ed.). Ft. Worth, Texas: Dryden Press, Harcourt Brace.

Borgatti, S. P., \& Cross, R. (2003). A relational view of information seeking and learning in social networks. Management Science, 49(4), 432-445.

Boxall, P. C., \& Adamowicz, W. (2002). Understanding heterogeneous preferences in random utility models: A latent class Approach. Environmental \& Resource Economics, 23(4), 421-446.

Bradley, M., \& Daly, A. (1994). Use of the logit scaling approach to test for rank-order and fatigue effects in stated preference data. Transportation, 21(2), 167-184. 
Brewer, J., \& Hunter, A. (1989). Multimethod research: A synthesis of styles. Newbury Park, CA: Sage.

Brown, T. J., Barry, T. E., Dacin, P. A., \& Gunst, R. F. (2005). Spreading the word: Investigating antecedents of consumers' positive word-of-mouth intentions and behaviors in a retailing context. Journal of the Academy of Marketing Science, 33(2), 123-138.

Carson, R. T., \& Louviere, J. J. (2011). A common nomenclature for stated preference elicitation approaches. Environmental and Resource Economics, 49(4), 539-559.

Casey M. A., \& Krueger R. A. (1994). Focus group interviewing. In H. J. H. MacFie \& Thomson D. M. (Eds.), Measurement of food preferences (pp. 77-96). London: Blackie Academic and Professional.

Chambers, S., Lobb, A., Butler, L., Harvey, K., \& Traill, W. B. (2007). Local, national and imported foods: A qualitative study. Appetite, 49(1), 208-213.

Chamhuri, N., \& Batt, P. J. (2013). Understanding the relationship between perceived quality cues and quality attributes in the purchase of meat in Malaysia. Journal of International Food \& Agribusiness Marketing, 25(3), 187-208.

Chen, M. F. (2007). Consumer attitudes and purchase intentions in relation to organic foods in Taiwan: moderating effects of food-related personality traits. Food Quality and Preference, 18(7), 1008-1021.

Cooper, C., Fletcher, J., Fyall, A., Gilbert, D., \& Wanhill, S. (2005). Tourism: Principles and practice (3rd ed.). Upper Saddle River, NJ: Financial Times Prentice Hall.

Creswell, J. W. (2007). Qualitative inquiry and research design: Choosing among five approaches (2nd ed.). Thousand Oaks, CA: Sage.

Creswell, J. W., \& Plano Clark, V. L. (2011). Designing and conducting mixed methods research (2nd ed.). Thousand Oaks, CA: Sage.

Creswell, J. W., Plano Clark, V. L., Gutmann, M. L. \& Hanson, W. E. (2003). Advanced mixed methods research designs. In A. Tashakkori \& C. Teddlie (Eds.), Handbook on mixed methods in the behavioral and social sciences (pp. 209-240). Thousand Oaks, CA: Sage Publications.

Day, B., Bateman, I. J., Carson, R. T., Dupont, D., Louviere, J. J., Morimoto, S., ... \& Wang, P. (2012). Ordering effects and choice set awareness in repeat-response stated preference studies. Journal of Environmental Economics and Management, 63(1), 7391.

Daykin, A. R., \& Moffatt, P. G. (2002). Analyzing ordered responses: A review of the ordered probit model. Understanding Statistics, 1(3), 157-166.

De Leeuw, E. D. (2008). Choosing the method of data collection. In E. D. De Leeuw, J. J. Hox, \& D. A. Dillman (Eds.), International handbook of survey methodology (pp. 113-135). New York: Lawrence Erlbaum.

Downe-Wamboldt, B. (1992). Content analysis: Method, applications, and issues. Health Care for Women International, 13(3), 313-321.

Escriba-Perez, C., Baviera-Puig, A., Buitrago-Vera, J., \& Montero-Vicente, L. (2017). Consumer profile analysis for different types of meat in Spain. Meat Science, 129, 120 126.

European Commission. (n.d.). Hormones in meat. Retrieved from https://ec.europa.eu/food/safety/chemical_safety/meat_hormones_en

FAO (Food and Agriculture Organization of the United Nations). (2019). FAO statistical database. FAO, Rome. Retrieved from http://www.fao.org/faostat/en/\#data/QL (accessed 30 October 2019).

Farrell, D. (2013). The role of poultry in human nutrition. Poultry Development Review (pp. 2 3). Food and Agriculture Organization of the United Nations (FAO), Rome.

FDA (Food and Drug Administration). (2019). Steroid hormone implants used for growth in 
food-producing animals. Retrieved from https://www.fda.gov/animalveterinary/product-safety-information/steroid-hormone-implants-used-growth-foodproducing-animals

Field, A. (2009). Discovering statistics using SPSS: Introducing statistical methods (3rd ed.). Thousand Oaks, CA: Sage Publications.

Finch, H., \& Lewis, J. (2003). Focus groups. In J. Ritchie \& J. Lewis (Eds.), Qualitative research practice: A guide for social science students and researchers (pp. 170-198). London: Sage.

Flick, U. (2009). An introduction to qualitative research (4th ed.). London, UK: Sage Publications.

Flick, U., Von Kardorff, E., \& Steinke, I. (2004). A companion to qualitative research. Thousand Oaks (CA): Sage.

Font-i-Furnols, M., \& Guerrero, L. (2014). Consumer preference, behavior and perception about meat and meat products: An overview. Meat Science, 98(3), 361-371.

Foscht, T., \& Swoboda, B. (2011). Käuferverhalten: Grundlagen - Perspektiven Anwendungen [Buyer behavior: Basics - perspectives - applications]. Wiesbaden: Springer Gabler.

Furst, T., Connors, M., Bisogni, C. A., Sobal, J., \& Falk, L. W. (1996). Food choice: A conceptual model of the process. Appetite, 26(3), 247-266.

Gbrich, C. (2013). Qualitative data analysis: An introduction (2nd ed.). London: Sage Publications.

Greene, W. H. (2008). Econometric analysis (6th ed.). New York: Prentice Hall.

Groves, R. M., Fowler, F. J., Couper, M. P., Lepkowski, J. M., Singer, E., \& Tourangeau, R. (2009). Survey methodology (2nd ed.). Hoboken, NJ: Wiley.

Grunert, K. G. (2005). Food quality and safety: Consumer perception and demand. European Review of Agricultural Economics, 32(3), 369-391.

Grunert, K. G. (2006). Future trends and consumer lifestyles with regard to meat consumption. Meat Science, 74(1), 149-160.

Guenther, P. M., Jensen, H. H., Batres-Marquez, S. P., \& Chen, C. (2005). Sociodemographic, knowledge, and attitudinal factors related to meat consumption in the United States. Journal of the American Dietetic Association, 105, 1266-1274.

Hair, J. F., Black, W. C., Babin, B. J., \& Anderson, R. E. (2010). Multivariate data analysis (7th ed.). Upper Saddle River, NJ: Prentice-Hall.

Hanley, N., Mourato, S., \& Wright, R. E. (2001). Choice modelling approaches: A superior alternative for environmental valuation? Journal of Economic Surveys, 15(3), 435-462.

Henchion, M., McCarthy, M., Resconi, V. C., \& Troy, D. (2014). Meat consumption: Trends and quality matters. Meat Science, 98(3), 561-568.

Hensher, D. A., Rose, J. M., \& Greene, W. H. (2005). Applied choice analysis: A primer. Cambridge: Cambridge University Press.

Holbrook, A. L., Green, M. C. \& Krosnick, J. A. (2003). Telephone versus face-to-face interviewing of national probability samples with long questionnaires: Comparisons of respondent satisficing and social desirability response bias. Public Opinion Quarterly, 67(1), 79-125.

Hollinger, F., \& Staatz, J. M. (2015). Agricultural growth in West Africa, market and policy drivers. Food and Agriculture Organization of the United Nations (FAO), Rome.

Horton, S., \& Campbell, C. (1991). Wife's employment, food expenditures, and apparent nutrient intake: Evidence from Canada. American Journal of Agricultural Economics, 73(3), 784-794.

Jacoby, J. (2002). Stimulus-organism-response reconsidered: An evolutionary step in modeling (consumer) behavior. Journal of Consumer Psychology, 12(1), 51-57.

Jekanowski, M. D., Williams, D. R., \& Schiek, W. A. (2000). Consumers' willingness to 
purchase locally produced agricultural products: An analysis of an Indiana survey. Agricultural and Resource Economics Review, 29(8). 43-53.

Johnson, M. C. (2011). Lobbying for trade barriers: A comparison of poultry producers' success in Cameroon, Senegal and Ghana. Journal of Modern African Studies, 49(4), 575-599.

Johnson, R. B., \& Onwuegbuzie, A. J. (2004). Mixed methods research: A research paradigm whose time has come. Educational Researcher, 33(7), 14-26.

Johnson, R. B., Onwuegbuzie, A. J., \& Turner, L. A. (2007). Toward a definition of mixed methods research. Journal of Mixed Methods Research, 1(2), 112-133.

Kennedy, O. B., Stewart-Knox, B. J., Mitchell, P. C., \& Thurnham, D. I. (2004). Consumer perceptions of poultry meat: A qualitative analysis. Nutrition \& Food Science, 34(3), $122-129$.

Kinsey, J. (1983). Working wives and the marginal propensity to consume food away from home. American Journal of Agricultural Economics, 65(1), 10-19.

Kløjgaard, M. E., Bech, M., \& Søgaard, R. (2012). Designing a stated choice experiment: The value of a qualitative process. Journal of Choice Modelling, 5(2), 1-18.

Kotler, P., \& Armstrong, G. (2011). Principles of marketing (13th ed.). Upper Saddle River: Pearson.

Kotler, P., \& Keller, K. L. (2012). Marketing management (14th ed.). London: Pearson Education.

Kroeber-Riel, W., Weinberg, P., \& Gröppel-Klein, A. (2009). Konsumentenverhalten [Consumer behavior] (9th ed.). München: Vahlen.

Krueger, R. A., \& Casey, M. A. (2000). Focus groups: A practical guide for applied research (3rd ed.). Thousand Oaks, CA: Sage Publications.

Kwadzo, G., Dadzie, F., Osei-Asare, Y., \& Kuwornu, J. K. M. (2013). Consumer preference for broiler meat in Ghana: A conjoint analysis approach. International Journal of Marketing Studies, 5(2), 66-73.

Lambooij, M. S., Veldwijk, J., van Gils, P., Mangen, M. J. J., Over, E., Suijkerbuijk, A., ... \& Opsteegh, M. (2019). Consumers' preferences for freezing of meat to prevent toxoplasmosis-A stated preference approach. Meat Science, 149, 1-8.

Lancaster, K. J. (1966). A new approach to consumer theory. Journal of Political Economy, 74(2), 132-157.

Lee, H. J., \& Yun, Z. S. (2015). Consumers' perceptions of organic food attributes and cognitive and affective attitudes as determinants of their purchase intentions toward organic food. Food Quality and Preference, 39, 259-267.

Loosveldt, G. (2008). Face-to-face interviews. In E. D. De Leeuw, J. J. Hox, \& D. A. Dillman (Eds.), International handbook of survey methodology (pp. 201-220). New York: Lawrence Erlbaum.

Loureiro, M. L., \& Umberger, W. J. (2003). Estimating consumer willingness to pay for country-of-origin labeling. Journal of Agricultural and Resource Economics, 28(2), 287-301.

Loureiro, M. L., \& Umberger, W. J. (2005). Assessing consumer preferences for country-of origin labeling. Journal of Agricultural and Applied Economics, 37(01), 49-63.

Loureiro, M. L., \& Umberger, W. J. (2007). A choice experiment model for beef: What US consumer responses tell us about relative preferences for food safety, country-of-origin labeling and traceability. Food Policy, 32(4), 496-514.

Louviere, J. J., Flynn, T. N., \& Carson, R. T. (2010). Discrete choice experiments are not conjoint analysis. Journal of Choice Modelling, 3(3), 57-72.

Louviere, J. J., Hensher, D. A., \& Swait, J. D. (2000). Stated choice methods: Analysis and applications. Cambridge: Cambridge University Press.

Lusk, J. L., \& Schroeder, T. C. (2004). Are choice experiments incentive compatible? A test 
with quality differentiated beef steaks. American Journal of Agricultural Economics, 86(2), 467-482.

Lusk, J. L., Roosen, J., \& Fox, J. A. (2003). Demand for beef from cattle administered growth hormones or fed genetically modified corn: A comparison of consumers in France, Germany, the United Kingdom, and the United States. American Journal of Agricultural Economics, 85(1), 16-29.

McCarthy, M., O’Reilly, S., Cotter, L., \& de Boer, M. (2004). Factors influencing consumption of pork and poultry in the Irish market. Appetite, 43(1), 19-28.

McEachern, M. G., \& Schröder, M. J. (2002). The role of livestock production ethics in consumer values towards meat. Journal of Agricultural and Environmental Ethics, 15(2), 221-237.

McFadden, D. (1974). Conditional logit analysis of qualitative choice behaviour. In P. E. Zarembka (Ed.) Frontiers in econometrics (pp. 105-142). New York: Academic Press.

MoFA (Ministry of Food and Agriculture) (2010). Medium term agriculture sector investment plan (METASIP) 2011-2015. Ministry of Food and Agriculture, Accra.

MoFA (Ministry of Food and Agriculture) (2016). Ghana livestock development policy strategy. Ministry of Food and Agriculture, Accra.

Morgan, D. L. (1996). Focus groups. Annual Review of Sociology, 22(1), 129-152.

Morgan, D. L., \& Krueger, R. A. (1993). When to use focus groups and why. In D. L. Morgan (Ed.), Successful focus groups: Advancing the state of the art (pp. 3-19). Newbury Park, CA: Sage.

Munoz, A. M. (1998). Consumer perceptions of meat. Understanding these results through descriptive analysis. Meat Science, 49(1), 287-295.

Neuman, W. L. (2000). Social research methods: Qualitative and quantitative approaches $\left(4^{\text {th }}\right.$ ed.). Boston: Allyn \& Bacon.

OECD-FAO (Organization for Economic Cooperation and Development and the Food and Agriculture Organization of the United Nations) (2017). OECD agriculture statistics (database): OECD-FAO agricultural outlook (edition 2017). Paris: OECD Publishing. Retrieved from https://doi.org/10.1787/d9e81f72-en

OECD-FAO (Organization for Economic Cooperation and Development and the Food and Agriculture Organization of the United Nations). (2018). OECD-FAO Agricultural Outlook 2018-2027. Retrieved from http://www.fao.org/3/i9166e/i9166e_Chapter6_Meat.pdf

Ortega, D. L., Hong, S. J., Wang, H. H., \& Wu, L. (2016). Emerging markets for imported beef in China: Results from a consumer choice experiment in Beijing. Meat Science, 121, 317-323.

Owusu-Sekyere, E., Owusu, V., \& Jordaan, H. (2014). Consumer preferences and willingness to pay for beef food safety assurance labels in the Kumasi Metropolis and Sunyani Municipality of Ghana. Food Control, 46, 152-159.

Patton, M. Q. (2002). Qualitative research and evaluation methods (3rd ed). Thousand Oaks, CA: Sage.

Petty, N. J., Thomson, O. P., \& Stew, G. (2012). Ready for a paradigm shift? Part 2: Introducing qualitative research methodologies and methods. Manual Therapy, 17(5), 378-384.

Pingali, P. (2015). Agricultural policy and nutrition outcomes - getting beyond the preoccupation with staple grains. Food Security, 7(3), 583-591.

Piqueras-Fiszman, B., \& Jaeger, S. R. (2014). The impact of the means of context evocation on consumers' emotion associations towards eating occasions. Food Quality and Preference, 37, 61-70.

Pouta, E., Heikkilä, J., Forsman-Hugg, S., Isoniemi, M., \& Mäkelä, J. (2010). Consumer choice of broiler meat: The effects of country of origin and production methods. Food Quality and Preference, 21(5), 539-546. 
Quagrainie, K. K., Unterschultz, J., \& Veeman, M. (1998). Effects of product origin and selected demographics on consumer choice of red meats. Canadian Journal of Agricultural Economics, 46(2), 201-219.

Revelt, D., \& Train, K. (1998). Mixed logit with repeated choices: Households' choices of appliance efficiency level. Review of Economics and Statistics, 80(4), 647-657.

Rimal, A. P. (2005). Meat labels: Consumer attitude and meat consumption pattern. International Journal of Consumer Studies, 29(1), 47-54.

Roberts, J. H., \& Lilien, G. L. (1993). Explanatory and predictive models of consumer behavior. In J. Eliashberg \& G. L. Lilien (Eds.), Handbooks in operations research and management science (pp. 27-82). Amsterdam: North-Holland.

Rudloff, B., \& Schmieg, E. (2016). More bones to pick with the EU? Controversial poultry exports to Africa: Sustainable trade policy as a task for the G20. SWP Comments 57. German Institute for International and Security Affairs, Berlin.

Schiffman, L. G., \& Kanuk, L. L. (2007). Consumer behavior (9th ed.). New Jersey: Pearson Prentice Hall.

Schröder, J. (2016). Face-to-face surveys. GESIS Survey Guidelines. Mannheim, Germany: GESIS -Leibniz Institute for the Social Sciences.

Shimp, T., \& Sharma, S. (1987). Consumer ethnocentrism: Construction and validation of the CETSCALE. Journal of Marketing Research, 24(3), 280-289.

Solomon, M. R., Bamossy G., Askegaard, S., \& Hogg, M. K. (2010). Consumer behaviour: A European perspective (4th ed.). New York: Prentice Hall/Financial Times.

Steenkamp, J. B. E. (1990). Conceptual model of the quality perception process. Journal of Business Research, 21(4), 309-333.

Steptoe, A., Pollard, T. M., \& Wardle, J. (1995). Development of a measure of the motives underlying the selection of food: the food choice questionnaire. Appetite, 25(3), 267284.

Sumberg, J., Awo, M., \& Kwadzo, G. T.-M. (2017). Poultry and policy in Ghana: Lessons from the periphery of an agricultural policy system. Development Policy Review, 35(3), 419438.

Sumberg, J., Jatoe, J., Kleih, U., \& Flynn, J. (2016). Ghana's evolving protein economy. Food Security, 8(5), 909-920.

Swait, J. (1994). A structural equation model of latent segmentation and product choice for cross-sectional revealed preference choice data. Journal of Retailing and Consumer Services, 1(2), 77-89.

Szolnoki, G., \& Hoffmann, D. (2013). Online, face-to-face and telephone surveys - Comparing different sampling methods in wine consumer research. Wine Economics and Policy, 2(2), 57-66.

Tarkiainen, A., \& Sundqvist, S. (2005). Subjective norms, attitudes and intentions of Finnish consumers in buying organic food. British Food Journal, 107(11), 808-822.

Tashakkori, A., \& Teddlie, C. (1998). Mixed methodology: Combining qualitative and quantitative approaches. Thousand Oaks, CA: Sage.

Thong, N. T., \& Solgaard, H. S. (2017). Consumer's food motives and seafood consumption. Food Quality and Preference, 56, 181-188.

Thurstone, L. L. (1927). A law of comparative judgment. Psychological Review, 34(4), $273-$ 286.

Tonsor, G. T., Schroeder, T. C., Fox, J. A., \& Biere, A. (2005). European preferences for beef steak attributes. Journal of Agricultural and Resource Economics, 30(2), 367-380.

Train, K. E. (2009). Discrete choice methods with simulation (2nd ed.). Cambridge: Cambridge University Press.

Tschirley, D., Reardon, T., Dolislager, M., \& Snyder, J. (2015). The rise of a middle class in 
East and Southern Africa: Implications for food system transformation. Journal of International Development, 27(5), 628-646.

Udomkun, P., Ilukor, J., Mockshell, J., Mujawamariya, G., Okafor, C., Bullock, R., ... \& Vanlauwe, B. (2018). What are the key factors influencing consumers' preference and willingness to pay for meat products in Eastern DRC? Food Science \& Nutrition, 6(8), 2321-2336.

Umberger, W. J., Feuz, D. M., Calkins, C. R., \& Sitz, B. M. (2003). Country-of-origin labeling of beef products: US consumers' perceptions. Journal of Food Distribution Research, 34(3), 103-116.

USDA (United States Department of Agriculture). (2017). Ghana poultry report annual. United States Department of Agriculture, Accra.

Van Loo, E. J., Caputo, V., Nayga, R. M., Meullenet, J. F., \& Ricke, S. C. (2011). Consumers' willingness to pay for organic chicken breast: Evidence from choice experiment. Food Quality and Preference, 22(7), 603-613.

Varian, H. R., (1984). Microeconomic analysis (2nd ed.). New York: W.W. Norton \& Company.

Verbeke, W. (2005). Consumer acceptance of functional foods: Socio-demographic, cognitive and attitudinal determinants. Food Quality and Preference, 16(1), 45-57.

Verbeke, W. (2008). Impact of communication on consumers' food choices. Proceedings of the Nutrition Society, 67(03), 281-288.

Verbeke, W., \& Vackier, I. (2005). Individual determinants of fish consumption: Application of the theory of planned behaviour. Appetite, 44(1), 67-82.

Verlegh, P. W., \& Candel, M. J. (1999). The consumption of convenience foods: Reference groups and eating situations. Food Quality and Preference, 10(6), 457-464.

Vida, I., \& Reardon, J. (2008). Domestic consumption: Rational, affective or normative choice? Journal of Consumer Marketing, 25(1), 34-44.

Vukasovič, T. (2010). Buying decision-making process for poultry meat. British Food Journal, 112(2), 125-139.

Woolverton, E. A., \& Frimpong, S. (2013). Consumer demand for domestic and imported broiler meat in urban Ghana: Bringing nonprice effects into the equation. British Journal of Marketing Studies, 1(3), 16-31.

World Bank. (2017a). World development indicators 2017. World Bank, Washington, DC. Retrieved from https://openknowledge.worldbank.org/handle/10986/26447. License: CC BY 3.0 IGO.

World Bank. (2017b). Ghana - Agriculture sector policy note: transforming agriculture for economic growth, job creation and food security. World Bank, Washington, DC.

Yang, R., Raper, K. C., \& Lusk, J. L. (2017, February). The impact of hormone use perception on consumer meat preference. Paper presented at the Southern Agricultural Economics Association Annual Meeting, Mobile, AL, US.

Zagata, L. (2012). Consumers' beliefs and behavioural intentions towards organic food: Evidence from the Czech Republic. Appetite, 59(1), 81-89. 
Appendices 


\section{Appendix A: Questionnaire}

\section{CONSUMER SURVEY QUESTIONNAIRE}

\section{Consent to participate in the survey}

You are kindly invited to take part in a survey being conducted by Collins Asante-Addo, a researcher at Thuenen Institute for Market Analysis and Ph.D. student at the University of Goettingen, Germany. The purpose of this survey is to understand Ghanaian consumers' behavior toward chicken meat. Participation in this survey is voluntary and your responses will remain strictly confidential and anonymous. Your responses would be combined with other hundreds of respondents who are also being interviewed and used for research purposes. Completion of the questionnaire below will represent informed consent in this survey. Your cooperation is greatly valued. Thank you for your time and consideration.

I agree that my data may also be used for future research projects.

I am informed that my data will be passed on to other project partners and evaluated by them as part of the research project.

\section{IDENTIFICATION}

DATE OF INTERVIEW:

$\tau_{\text {Day }} \frac{/}{\text { Month }} / 2018$

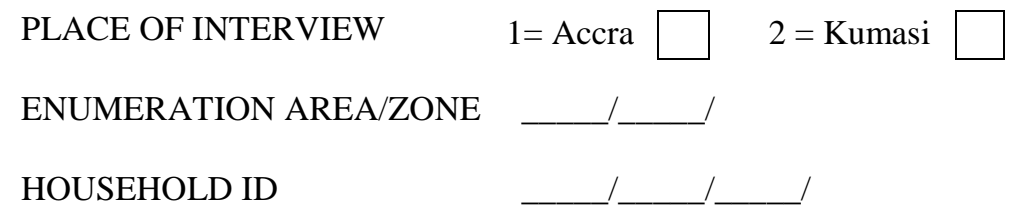

NAME OF INTERVIEWER

\section{SECTION A: SCREENING QUESTIONS}

A-1. In what year were you born? (If year born is after 1999, stop interview)

A-2. Do you eat chicken? $1=$ Yes $\square \quad 2=$ No $\square \rightarrow$ stop interviewing

A-3. Who is responsible for food shopping in your household?

$1=$ Myself alone

2 = Myself together with other(s)

$3=$ Someone else

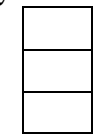

If respondent's answer in question $A-3=1$ or 2 , skip to Section $B$.

A-4. Are you responsible for food purchase decisions in your household? (Ask only if question A-3 =3)

$1=$ Yes $\square \quad 2=$ No $\square \longrightarrow$ stop interviewing 


\title{
SECTION B: CHOICE EXPERIMENT
}

\author{
Cheap Talk Script
}

Please take the time to read the following instructions before proceeding to answer the questions in this section

In a moment we are going to show you some different chicken products, and we want you to choose one of them in each case. However, before you answer this question, we would like you to read the following information.

Our experiences from previous studies show that people say that they are willing to pay a higher price than they actually do in practice. For example, a recent study reveals that $80 \%$ of people indicated that they would buy a new food product, which actually was not on the market. However, when the food product came on the market, only $43 \%$ of people bought it. Therefore, it is important that you make each of your selections in this study as you would if you were actually facing these choices in the market and had to pay for the product, taking into account the limited amount of money you have.

\section{Situation:}

Imagine you are shopping in your usual market and considering the purchase of chicken meat. The following are different shopping scenarios. You will be presented with a total of six different shopping scenarios. You need to choose between two types of chicken (OPTION A or OPTION B) or no chicken (NONE) based on your preferences. The chicken types presented vary in terms of the country of origin, product form, storage form, production claim, and price. To facilitate your choices, we provide some brief description of the attributes of the chicken considered:

i. Country-of-origin: this indicates whether the chicken was produced in Ghana or in another country (Foreign).

ii. Product form: this refers to whether the chicken is whole (dressed) or has been cut into parts.

iii. Storage form: this indicates whether the chicken has been stored frozen or fresh (under chilled conditions).

iv. Production claim: this refers to claims of whether the chicken was raised with the use of antibiotics/growth hormones (No claim) or without (antibiotic/hormone free).

Apart from the above-mentioned differences, any other characteristics you may think of the chicken are the same in all aspects (e.g., same weight, $1.3 \mathrm{~kg}$ ).

Please, remember that you have a limited amount of money available for food purchases. Therefore, try to make your purchase decision just as you would do in real life. 
Choice set 1

\begin{tabular}{|l|c|c|}
\hline & OPTION A & OPTION B \\
\hline Country of origin & Ghana & Ghana \\
\hline Product form & Cuts/Parts & Whole dressed \\
\hline Storage form & Frozen & Fresh \\
\hline Production claim & Antibiotic/Hormone free & No claim \\
\hline Price (GH $\varnothing$ per 1.3kg) & GH $\varnothing 50$ & GH $₫ 38$ \\
\hline
\end{tabular}

B-1. Given the information provided in choice set 1, which option do you prefer? (Please select one). $1=$ OPTION A $\square 2=$ OPTION B $\square \quad 3=$ I prefer NONE

Choice set 2

\begin{tabular}{|l|c|c|}
\hline \multicolumn{1}{|c|}{ OPTION A } & OPTION B \\
\hline Prountry of origin & Foreign & Ghana \\
\hline Storage form & Whole dressed & Cuts/Parts \\
\hline Production claim & Frozen & Fresh \\
\hline Price (GH $\varnothing$ per 1.3kg) & Antibiotic/Hormone free & No claim \\
\hline
\end{tabular}

B-2. Given the information provided in choice set 2, which option do you prefer? (Please select one). $1=$ OPTION A $\square 2=$ OPTION B $\square \quad 3=$ I prefer NONE

Choice set 3

\begin{tabular}{|l|c|c|}
\hline & OPTION A & OPTION B \\
\hline Country of origin & Ghana & Foreign \\
\hline Product form & Cuts/Parts & Whole dressed \\
\hline Storage form & Fresh & Frozen \\
\hline Production claim & Antibiotic/Hormone free & Antibiotic/Hormone free \\
\hline Price (GH per 1.3kg) & GH $₫ 38$ & GH $₫ 50$ \\
\hline
\end{tabular}

B-3. Given the information provided in choice set 3, which option do you prefer? (Please select one). $1=$ OPTION A $\square 2=$ OPTION B $\square \quad 3=$ I prefer NONE

Choice set 4

\begin{tabular}{|l|c|c|}
\hline & OPTION A & OPTION B \\
\hline Country of origin & Ghana & Ghana \\
\hline Product form & Cuts/Parts & Whole dressed \\
\hline Storage form & Frozen & Fresh \\
\hline Production claim & Antibiotic/Hormone free & No claim \\
\hline Price (GH $\phi$ per 1.3kg) & GH $\phi 26$ & GH $\varnothing 50$ \\
\hline
\end{tabular}

B-4. Given the information provided in choice set 4, which option do you prefer? (Please select one). $1=$ OPTION A $\square 2=$ OPTION B $\square \quad 3=$ I prefer NONE

Choice set 5

\begin{tabular}{|l|c|c|}
\hline & OPTION A & OPTION B \\
\hline Country of origin & Ghana & Ghana \\
\hline Product form & Cuts/Parts & Whole dressed \\
\hline Storage form & Frozen & Fresh \\
\hline Production claim & No claim & No claim \\
\hline Price (GHф per 1.3kg) & GH $₫ 38$ & GH $\phi 26$ \\
\hline
\end{tabular}

B-5. Given the information provided in choice set 5, which option do you prefer? (Please select one). $1=$ OPTION A $\square 2=$ OPTION B $\square \quad 3=$ I prefer NONE

Choice set 6

\begin{tabular}{|l|c|c|}
\hline & OPTION A & OPTION B \\
\hline Country of origin & Foreign & Ghana \\
\hline Product form & Whole dressed & Cuts/Parts \\
\hline Storage form & Frozen & Frozen \\
\hline Production claim & Antibiotic/Hormone free & No claim \\
\hline Price (GH per $1.3 \mathrm{~kg}$ ) & GH $ф 26$ & GH $₫ 38$ \\
\hline
\end{tabular}

B-6. Given the information provided in choice set 6, which option do you prefer? (Please select one). $1=$ OPTION A $\square 2=$ OPTION B $\square \quad 3=$ I prefer NONE 
Choice set 7

\begin{tabular}{|l|c|c|}
\hline & OPTION A & OPTION B \\
\hline Country of origin & Ghana & Foreign \\
\hline Product form & Whole dressed & Cuts/Parts \\
\hline Storage form & Frozen & Frozen \\
\hline Production claim & Antibiotic/Hormone free & No claim \\
\hline Price (GH per 1.3kg) & GH $\not 14$ & GH $₫ 38$ \\
\hline
\end{tabular}

B-7. Given the information provided in choice set 7, which option do you prefer? (Please select one). $1=$ OPTION A $\square 2=$ OPTION B $\square \quad 3=$ I prefer NONE

Choice set 8

\begin{tabular}{|l|c|c|}
\hline & OPTION A & OPTION B \\
\hline Country of origin & Foreign & Ghana \\
\hline Product form & Whole dressed & Cuts/Parts \\
\hline Storage form & Frozen & Frozen \\
\hline Production claim & No claim & Antibiotic/Hormone free \\
\hline Price (GH $\varnothing$ per 1.3kg) & GH $\varnothing 50$ & GH $\varnothing 14$ \\
\hline
\end{tabular}

B-8. Given the information provided in choice set 8, which option do you prefer? (Please select one). $1=$ OPTION A $\square 2=$ OPTION B $\square \quad 3=$ I prefer NONE

Choice set 9

\begin{tabular}{|l|c|c|}
\hline & OPTION A & OPTION B \\
\hline Country of origin & Ghana & Foreign \\
\hline Product form & Cuts/Parts & Whole dressed \\
\hline Storage form & Fresh & Frozen \\
\hline Production claim & No claim & Antibiotic/Hormone free \\
\hline Price (GH (Ger 1.3kg) & GH $₫ 38$ & GH $\varnothing 14$ \\
\hline
\end{tabular}

B-9. Given the information provided in choice set 9, which option do you prefer? (Please select one). $1=$ OPTION A $\square 2=$ OPTION B $\square \quad 3=$ I prefer NONE

Choice set 10

\begin{tabular}{|l|c|c|}
\hline & OPTION A & OPTION B \\
\hline Country of origin & Ghana & Foreign \\
\hline Product form & Whole dressed & Cuts/Parts \\
\hline Storage form & Fresh & Frozen \\
\hline Production claim & No claim & Antibiotic/Hormone free \\
\hline Price (GH $\phi$ per 1.3kg) & GH $\phi 14$ & GH $\phi 50$ \\
\hline
\end{tabular}

B-10. Given the information provided in choice set 10, which option do you prefer? (Please select one).

$$
1=\text { OPTION A } \square 2=\text { OPTION B } \square \quad 3=\text { I prefer NONE }
$$

Choice set 11

\begin{tabular}{|l|c|c|}
\hline & OPTION A & OPTION B \\
\hline Country of origin & Foreign & Ghana \\
\hline Product form & Cuts/Parts & Whole dressed \\
\hline Storage form & Frozen & Frozen \\
\hline Production claim & No claim & Antibiotic/Hormone free \\
\hline Price (GH per 1.3kg) & GH $\varnothing 50$ & GH $\varnothing 14$ \\
\hline
\end{tabular}

B-11. Given the information provided in choice set 11, which option do you prefer? (Please select one).

$$
1=\text { OPTION A } \square 2=\text { OPTION B } \square \quad 3=\text { I prefer NONE }
$$

Choice set 12

\begin{tabular}{|l|c|c|}
\hline & OPTION A & OPTION B \\
\hline Country of origin & Ghana & Ghana \\
\hline Product form & Whole dressed & Cuts/Parts \\
\hline Storage form & Fresh & Frozen \\
\hline Production claim & No claim & Antibiotic/Hormone free \\
\hline Price (GH per 1.3kg) & GH $\phi 38$ & GH $\phi 26$ \\
\hline
\end{tabular}

B-12. Given the information provided in choice set 12, which option do you prefer? (Please select one).

$$
1=\text { OPTION A } \square 2=\text { OPTION B } \square \quad 3=\text { I prefer NONE }
$$


B-13. If you chose the "I prefer NONE" option in any of the scenarios, what was the main reason?

$1=\mathrm{I}$ did not see a difference in the offered products

$2=\mathrm{I}$ cannot afford to pay for the associated prices

$3=$ It was the easiest to choose

$4=\mathrm{I}$ did not like the offered products

$5=$ Not applicable

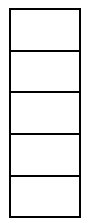

B-14. To what extent did you consider each attribute when making the choices? (Please rank each attribute in terms of consideration)

\begin{tabular}{|c|l|c|c|c|c|c|}
\hline & & Never & Rarely & Sometimes & Often & Always \\
\hline & & 1 & 2 & 3 & 4 & 5 \\
\hline 1 & Price & & & & & \\
\hline 2 & Country of origin & & & & & \\
\hline 3 & Production claim & & & & & \\
\hline 4 & Storage form & & & & & \\
\hline 5 & Product form & & & & & \\
\hline
\end{tabular}

SECTION C: PURCHASING AND CONSUMPTION PATTERNS

Thank you, now we would like to ask about your actual meat consumption.

C-1. How often do you cook or prepare food in your household?

$1=$ Once or twice a week

$2=3-4$ times a week

$3=5-6$ times a week

$4=$ Everyday

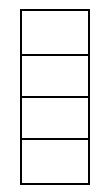

C-2. On average, how often do you eat the following meat types in your household?

\begin{tabular}{|l|l|c|c|c|c|c|c|c|}
\hline & Never & Occassionally & $\begin{array}{c}\text { Once a } \\
\text { month }\end{array}$ & $\begin{array}{c}2-3 \text { times } \\
\text { a month }\end{array}$ & $\begin{array}{c}\text { Once a } \\
\text { week }\end{array}$ & $\begin{array}{c}2-3 \text { times } \\
\text { a week }\end{array}$ & $\begin{array}{c}4 \text { times a } \\
\text { week or } \\
\text { more }\end{array}$ \\
\hline & & 1 & 2 & 3 & 4 & 5 & 6 & 7 \\
\hline 1 & Chicken & & & & & & & \\
\hline 2 & Beef & & & & & & & \\
\hline 3 & Lamb/Mutton & & & & & & & \\
\hline 4 & Chevon(Goat) & & & & & & & \\
\hline 5 & Pork & & & & & & & \\
\hline 6 & Tilapia & & & & & & & \\
\hline 7 & Other fish & & & & & & & \\
\hline
\end{tabular}

C-3. What are your main motivations/reasons for buying chicken? (Please select all that apply)
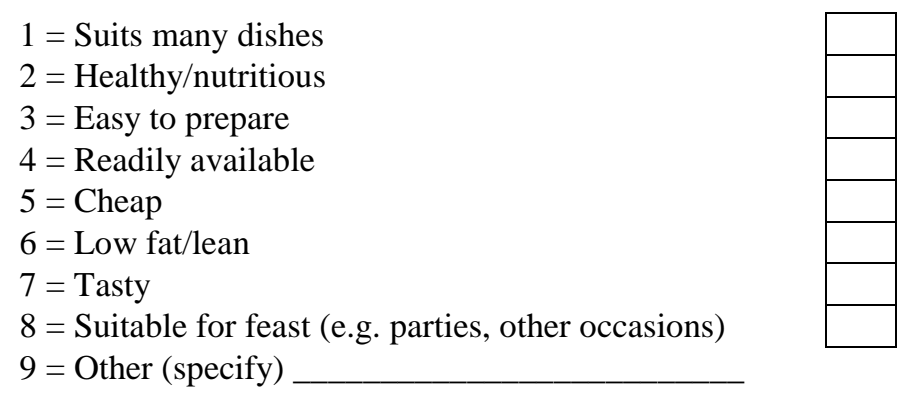
C-4. Where does the chicken, which you usually buy, come from? (Please select all that apply)

$1=$ Europe: Netherlands, Germany....

$2=$ Ghana

3 = Imported chicken, but don't know the exact country

$4=$ Brazil

$5=\mathrm{USA}$

$6=\mathrm{I}$ don't know

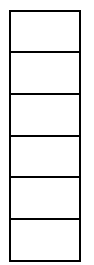

C-5. How do you know whether the chicken, which you usually buy, is produced in Ghana or in other countries? (Please select all that apply)

$$
\begin{aligned}
& 1=\text { Using label information } \\
& 2=\text { Asking seller/vendor } \\
& 3=\text { I don't know } \\
& 4=\text { Other (specify) }
\end{aligned}
$$

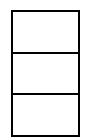

C-6. On average, how often do you eat chicken from the following origins in your household?

\begin{tabular}{|l|l|c|c|c|c|c|c|c|}
\hline & Never & Occassionally & $\begin{array}{c}\text { Once a } \\
\text { month }\end{array}$ & $\begin{array}{c}2-3 \text { times } \\
\text { a month }\end{array}$ & $\begin{array}{c}\text { Once a } \\
\text { week }\end{array}$ & $\begin{array}{c}2-3 \\
\text { times a } \\
\text { week }\end{array}$ & $\begin{array}{c}4 \text { times a } \\
\text { week or } \\
\text { more }\end{array}$ \\
\hline 1 & & 1 & 2 & 3 & 4 & 5 & 6 & 7 \\
\hline 2 & Ghana (Domestic) & & & & & & & \\
\hline
\end{tabular}

C-7. How important are the following factors when you buy chicken produced in Ghana? (Please rate each attribute in terms of importance) (Skip if question C-6.1 =1)

\begin{tabular}{|c|l|c|c|c|c|c|}
\hline & & $\begin{array}{c}\text { Not very } \\
\text { important }\end{array}$ & $\begin{array}{c}\text { Somewhat } \\
\text { important }\end{array}$ & $\begin{array}{c}\text { Moderately } \\
\text { important }\end{array}$ & Important & $\begin{array}{c}\text { Very } \\
\text { important }\end{array}$ \\
\hline 1 & Price & 1 & 2 & 3 & 4 & 5 \\
\hline 2 & Taste & & & & & \\
\hline 3 & Tenderness & & & & \\
\hline 4 & Freshness & & & & & \\
\hline 5 & Ease of preparation & & & & & \\
\hline 6 & Availability & & & & & \\
\hline 7 & Health and safety issues & & & & & \\
\hline 8 & General appearance/color & & & & & \\
\hline 9 & Nutritional value & & & & & \\
\hline 10 & Weight/size & & & & & \\
\hline
\end{tabular}

C-7b. Are there other criteria that are very important when you buy chicken produced in Ghana?

C-8. How important are the following factors when you buy imported chicken? (Please rate each attribute in terms of importance) (Skip if question C-6.2=1)

\begin{tabular}{|c|l|c|c|c|c|c|}
\hline & & $\begin{array}{c}\text { Not very } \\
\text { important }\end{array}$ & $\begin{array}{c}\text { Somewhat } \\
\text { important }\end{array}$ & $\begin{array}{c}\text { Moderately } \\
\text { important }\end{array}$ & Important & $\begin{array}{c}\text { Very } \\
\text { important }\end{array}$ \\
\hline & & 1 & 2 & 3 & 4 & 5 \\
\hline 1 & Price & & & & & \\
\hline 2 & Taste & & & & & \\
\hline 3 & Tenderness & & & & & \\
\hline 4 & Freshness & & & & & \\
\hline 5 & Ease of preparation & & & & & \\
\hline 6 & Availability & & & & & \\
\hline 7 & Health and safety issues & & & & & \\
\hline 8 & General appearance/color & & & & & \\
\hline
\end{tabular}




\begin{tabular}{|c|l|c|c|c|c|c|}
\hline & & $\begin{array}{c}\text { Not very } \\
\text { important }\end{array}$ & $\begin{array}{c}\text { Somewhat } \\
\text { important }\end{array}$ & $\begin{array}{c}\text { Moderately } \\
\text { important }\end{array}$ & Important & $\begin{array}{c}\text { Very } \\
\text { important }\end{array}$ \\
\hline 9 & Country of origin & & & & & \\
\hline 10 & Nutritional value & & & & & \\
\hline 11 & Label (e.g. HALAL) & & & & & \\
\hline
\end{tabular}

C-8b. Are there other criteria that are very important when you buy imported chicken?

C-9. How often do you buy chicken from the following markets?

\begin{tabular}{|l|l|c|c|c|c|c|}
\hline & & Never & Rarely & Sometimes & Often & Always \\
\hline & & 1 & 2 & 3 & 4 & 5 \\
\hline 1 & Traditional/local market & & & & & \\
\hline 2 & Cold store & & & & & \\
\hline 3 & Supermarket & & & & & \\
\hline 4 & Farm gate (poultry farm) & & & & & \\
\hline
\end{tabular}

C-10. If you indicated that you "often/always" buy from the traditional/local market, what are the reasons?

(Select all that apply) (Ask only if question C-9.1 = 4 or 5 )

$1=$ Lower price

$2=$ Availability of variety/choices

$3=$ Availability of fresh chicken

$4=$ Proximity/convenience of location

$5=$ Assured good quality

$6=$ Hygiene or cleanliness

$7=$ Possibility to bargain

$8=$ Trust in and relationship with seller

$9=$ Other (specify)

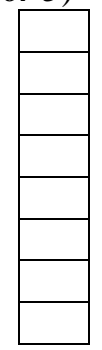

C-11. If you indicated that you "often/always" buy from the cold store, what are the reasons? (Select all that apply) (Ask only if question C-9.2 $=4$ or 5 )

$1=$ Lower price

$2=$ Availability of variety/choices

$3=$ Availability of fresh chicken

$4=$ Proximity/convenience of location

$5=$ Assured good quality

$6=$ Hygiene or cleanliness

$7=$ Possibility to bargain

$8=$ Trust in and relationship with seller

$9=$ Other (specify)

C-12. If you indicated that you "often/always" buy from the supermarket, what are the reasons? (Select all that apply) (Ask only if question C-9.3 = 4 or 5 )

$1=$ Lower price

$2=$ Availability of variety/choices

$3=$ Availability of fresh chicken

$4=$ Proximity/convenience of location

$5=$ Assured good quality

$6=$ Hygiene or cleanliness

$7=$ Possibility to bargain

$8=$ Trust in and relationship with seller

$9=$ Other (specify)

C-13. If you indicated that you "often/always" buy from the farm gate, what are the reasons? (Select all that apply) (Ask only if question C-9.4 = 4 or 5 )

$1=$ Lower price

$2=$ Availability of variety/choices
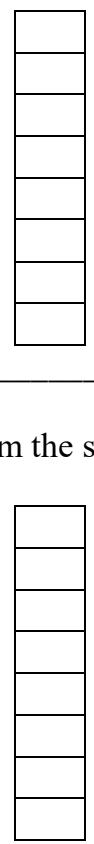
$3=$ Availability of fresh chicken

$4=$ Proximity/convenience of location

$5=$ Assured good quality

$6=$ Hygiene or cleanliness

$7=$ Possibility to bargain

$8=$ Trust in and relationship with seller

$9=$ Other (specify)

C-14. What type of chicken do you often buy from these markets? (Select one for each market)

\begin{tabular}{|l|l|c|c|c|c|c|}
\hline & Live & $\begin{array}{c}\text { Fresh } \\
\text { whole } \\
\text { dressed }\end{array}$ & $\begin{array}{c}\text { Frozen } \\
\text { whole } \\
\text { dressed }\end{array}$ & $\begin{array}{c}\text { Frozen } \\
\text { parts }\end{array}$ & $\begin{array}{c}\text { Not } \\
\text { applicable }\end{array}$ \\
\hline & & 1 & 2 & 3 & 4 & 5 \\
\hline 1 & Traditional/local market & & & & & \\
\hline 2 & Cold store & & & & & \\
\hline 3 & Supermarket & & & & & \\
\hline 4 & Farm gate (poultry farm) & & & & & \\
\hline
\end{tabular}

C-15. On average, how far do you travel (by vehicle) from home to the nearest market where you frequently purchase chicken? minutes

\section{SECTION D: PERCEPTIONS AND ATTITUDES TOWARDS CHICKEN MEAT}

We would like to know your views regarding chicken compared to other meat types and your opinions about chicken produced in Ghana versus imported chicken.

I am now going to read out several statements to you. Please indicate the response that best reflects your opinion. Choices range from 'strongly disagree' to 'strongly agree'.

D-1. What is your view on the following statements?

\begin{tabular}{|c|c|c|c|c|c|c|}
\hline & Statements & $\begin{array}{l}\text { Strongly } \\
\text { disagree }\end{array}$ & Disagree & $\begin{array}{l}\text { Neither } \\
\text { agree nor } \\
\text { disagree }\end{array}$ & Agree & $\begin{array}{l}\text { Strongly } \\
\text { agree }\end{array}$ \\
\hline & & 1 & 2 & 3 & 4 & 5 \\
\hline 1 & $\begin{array}{l}\text { I am very concerned about the use of } \\
\text { antibiotics and hormones in food }\end{array}$ & & & & & \\
\hline 2 & $\begin{array}{l}\text { I would pay a premium for antibiotic-free } \\
\text { and hormone-free chicken }\end{array}$ & & & & & \\
\hline 3 & The safety of meat concerns me a lot & & & & & \\
\hline 4 & $\begin{array}{l}\text { It is good that chicken is available because it } \\
\text { is low in fat }\end{array}$ & & & & & \\
\hline 5 & I reflect a lot about my health & & & & & \\
\hline 6 & $\begin{array}{l}\text { I take care of what I eat because of health } \\
\text { reasons }\end{array}$ & & & & & \\
\hline 7 & $\begin{array}{l}\text { It is important for me to have chicken } \\
\text { available throughout the year at } \\
\text { markets/stores close to where I live or work }\end{array}$ & & & & & \\
\hline 8 & $\begin{array}{l}\text { Chicken is easy to prepare compared to other } \\
\text { meats }\end{array}$ & & & & & \\
\hline 9 & $\begin{array}{l}\text { It is easier to obtain chicken than other meats } \\
\text { (excluding fish) }\end{array}$ & & & & & \\
\hline 10 & $\begin{array}{l}\text { Price is the most important factor for me } \\
\text { when I am shopping }\end{array}$ & & & & & \\
\hline 11 & $\begin{array}{l}\text { It is mainly the price that influences my } \\
\text { choice of chicken }\end{array}$ & & & & & \\
\hline 12 & $\begin{array}{l}\text { It is important to me to cook daily fresh food } \\
\text { for my family and me }\end{array}$ & & & & & \\
\hline
\end{tabular}




\begin{tabular}{|c|l|l|l|l|l|l|}
\hline & Statements & $\begin{array}{l}\text { Strongly } \\
\text { disagree }\end{array}$ & Disagree & $\begin{array}{c}\text { Neither } \\
\text { agree nor } \\
\text { disagree }\end{array}$ & Agree & $\begin{array}{c}\text { Strongly } \\
\text { agree }\end{array}$ \\
\hline 13 & $\begin{array}{l}\text { It is not possible to differentiate between the } \\
\text { taste of chicken produced in Ghana and } \\
\text { imported }\end{array}$ & & & & & \\
\hline 14 & $\begin{array}{l}\text { I do not care whether chicken is produced in } \\
\text { Ghana or in other countries }\end{array}$ & & & & & \\
\hline 15 & $\begin{array}{l}\text { It is important for me to know the country } \\
\text { where the chicken I eat comes from }\end{array}$ & & & & & \\
\hline 16 & $\begin{array}{l}\text { I reject all types of chicken during times of } \\
\text { bird flu disease outbreaks }\end{array}$ & & & & & \\
\hline 17 & I have much experience in buying chicken & & & & & \\
\hline 18 & $\begin{array}{l}\text { It is important that animals are free to move } \\
\text { in open spaces (free-range) and not confined }\end{array}$ & & & & & \\
\hline 19 & $\begin{array}{l}\text { It is important that animals are well fed, } \\
\text { raised, and healthy }\end{array}$ & & & & & \\
\hline 20 & $\begin{array}{l}\text { Government should monitor and ensure good } \\
\text { animal husbandry practices and standards in } \\
\text { the production and processing of meat }\end{array}$ & & & & & \\
\hline
\end{tabular}

D-2. Consider chicken produced in Ghana (DOMESTIC) and chicken from other countries (IMPORTED). To what extent do you agree or disagree with the following statements?

\begin{tabular}{|c|c|c|c|c|c|c|}
\hline & Statements & $\begin{array}{l}\text { Strongly } \\
\text { disagree }\end{array}$ & Disagree & $\begin{array}{l}\text { Neither } \\
\text { agree nor } \\
\text { disagree }\end{array}$ & Agree & $\begin{array}{l}\text { Strongly } \\
\text { agree }\end{array}$ \\
\hline & & 1 & 2 & 3 & 4 & 5 \\
\hline 1 & $\begin{array}{l}\text { Domestic chicken is completely safe to eat } \\
\text { compared to imported chicken }\end{array}$ & & & & & \\
\hline 2 & $\begin{array}{l}\text { Domestic chicken has no antibiotics, } \\
\text { hormones or additives }\end{array}$ & & & & & \\
\hline 3 & $\begin{array}{l}\text { Imported chicken has no antibiotics, } \\
\text { hormones or additives }\end{array}$ & & & & & \\
\hline 4 & $\begin{array}{l}\text { I consider imported chicken to be of less } \\
\text { quality than domestic chicken }\end{array}$ & & & & & \\
\hline 5 & $\begin{array}{l}\text { I consider domestic chicken to be healthier } \\
\text { than imported chicken }\end{array}$ & & & & & \\
\hline 6 & $\begin{array}{l}\text { Domestic chicken is more expensive than } \\
\text { imported chicken }\end{array}$ & & & & & \\
\hline 7 & $\begin{array}{l}\text { The price of domestic chicken is too high for } \\
\text { me }\end{array}$ & & & & & \\
\hline 8 & $\begin{array}{l}\text { Imported chicken is the cheapest meat you } \\
\text { can get }\end{array}$ & & & & & \\
\hline 9 & $\begin{array}{l}\text { I prefer domestic chicken because of its good } \\
\text { taste and freshness }\end{array}$ & & & & & \\
\hline 10 & For me, imported chicken is not tasty & & & & & \\
\hline 11 & $\begin{array}{l}\text { I prefer imported chicken because it is } \\
\text { available in parts, which makes it more } \\
\text { convenient }\end{array}$ & & & & & \\
\hline 12 & $\begin{array}{l}\text { Domestic chicken is easier to obtain than } \\
\text { imported chicken }\end{array}$ & & & & & \\
\hline 13 & $\begin{array}{l}\text { Imported chicken is easily available for me } \\
\text { because there are a lot of stores to buy from }\end{array}$ & & & & & \\
\hline 14 & $\begin{array}{l}\text { Domestic chicken is difficult to prepare and } \\
\text { time-consuming compared to imported } \\
\text { chicken }\end{array}$ & & & & & \\
\hline 15 & $\begin{array}{l}\text { For me, imported chicken is everyday food } \\
\text { but not for special occasions }\end{array}$ & & & & & \\
\hline 16 & $\begin{array}{l}\text { For special occasions, I would only buy } \\
\text { domestic chicken }\end{array}$ & & & & & \\
\hline
\end{tabular}




\begin{tabular}{|c|l|c|c|c|c|c|}
\hline & Statements & $\begin{array}{l}\text { Strongly } \\
\text { disagree }\end{array}$ & Disagree & $\begin{array}{c}\text { Neither } \\
\text { agree nor } \\
\text { disagree }\end{array}$ & Agree & $\begin{array}{c}\text { Strongly } \\
\text { agree }\end{array}$ \\
\hline 17 & $\begin{array}{l}\text { I would buy more domestic chicken if it } \\
\text { would be more expensive }\end{array}$ & & & & \\
\hline 18 & $\begin{array}{l}\text { I would pay extra for processed domestic } \\
\text { chicken }\end{array}$ & & & & & \\
\hline
\end{tabular}

D-3. Please indicate to what extent you agree or disagree with the following statements.

\begin{tabular}{|c|c|c|c|c|c|c|}
\hline & Statements & $\begin{array}{l}\text { Strongly } \\
\text { disagree }\end{array}$ & Disagree & $\begin{array}{l}\text { Neither } \\
\text { agree nor } \\
\text { disagree }\end{array}$ & Agree & $\begin{array}{c}\text { Strongly } \\
\text { agree }\end{array}$ \\
\hline & & 1 & 2 & 3 & 4 & 5 \\
\hline 1 & $\begin{array}{l}\text { Only those food products that are not } \\
\text { available in Ghana should be imported }\end{array}$ & & & & & \\
\hline 2 & $\begin{array}{l}\text { It is good to import foreign food products } \\
\text { so that we can get cheaper alternatives }\end{array}$ & & & & & \\
\hline 3 & $\begin{array}{l}\text { Ghanaians should not buy foreign food } \\
\text { products, because this hurts Ghanaian } \\
\text { business and causes unemployment }\end{array}$ & & & & & \\
\hline 4 & $\begin{array}{l}\text { Government should set up processing } \\
\text { plants to help process poultry }\end{array}$ & & & & & \\
\hline 5 & $\begin{array}{l}\text { Foreign food products should be imported } \\
\text { when domestic supply cannot meet the } \\
\text { demand }\end{array}$ & & & & & \\
\hline 6 & $\begin{array}{l}\text { Foreign products should be taxed heavily } \\
\text { to reduce their entry into Ghana }\end{array}$ & & & & & \\
\hline 7 & $\begin{array}{l}\text { Food products that our farmers cannot } \\
\text { produce cheaply should be imported so } \\
\text { that they can concentrate on producing } \\
\text { other things that make them competitive } \\
\text { and improve our food situation }\end{array}$ & & & & & \\
\hline 8 & $\begin{array}{l}\text { Farmers should consider integrating } \\
\text { processing into their poultry business }\end{array}$ & & & & & \\
\hline
\end{tabular}

\section{SECTION E: INFORMATION SOURCES AND USE}

Next, we would like to ask about the information you use in relation to your purchase and consumption of chicken and how you trust this information.

E-1. To what extent do you use the following information sources for your purchase and/or consumption of chicken?

\begin{tabular}{|l|l|c|c|c|c|c|}
\hline & Information sources & Never & Rarely & Sometimes & Often & Always \\
\hline & & 1 & 2 & 3 & 4 & 5 \\
\hline 1 & Television & & & & & \\
\hline 2 & Radio & & & & & \\
\hline 3 & Newspapers & & & & & \\
\hline 4 & $\begin{array}{l}\text { Health professional (e.g. medical } \\
\text { doctor, nurse, nutritionist, etc.) }\end{array}$ & & & & & \\
\hline 5 & Family, friends and colleagues & & & & & \\
\hline 6 & Sellers/Vendors & & & & & \\
\hline 7 & Government sources & & & & & \\
\hline 8 & Internet/Social media & & & & & \\
\hline 9 & Magazines, pamphlets and flyers & & & & & \\
\hline
\end{tabular}


E-2. What types of information do you usually search for on chicken from these sources? Please, indicate how often you search for these information cues.

\begin{tabular}{|l|l|c|c|c|c|c|}
\hline & Information cues & Never & Rarely & Sometimes & Often & Always \\
\hline & & 1 & 2 & 3 & 4 & 5 \\
\hline 1 & Price & & & & & \\
\hline 2 & Safety issues & & & & & \\
\hline 3 & Quality & & & & & \\
\hline 4 & Nutritional information & & & & & \\
\hline 5 & Health benefits & & & & \\
\hline 6 & Country of origin (i.e. imported) & & & & & \\
\hline 7 & Place of purchase & & & & \\
\hline 8 & $\begin{array}{l}\text { Method of preparation/Cooking } \\
\text { recommendations }\end{array}$ & & & & & \\
\hline
\end{tabular}

E-3. To what extent do you trust information about chicken from the following sources?

\begin{tabular}{|l|l|c|c|c|c|c|}
\hline & Information sources & $\begin{array}{c}\text { Completely } \\
\text { distrust }\end{array}$ & Distrust & $\begin{array}{c}\text { Neither } \\
\text { trust nor } \\
\text { distrust }\end{array}$ & Trust & $\begin{array}{c}\text { Completely } \\
\text { trust }\end{array}$ \\
\hline & & 1 & 2 & 3 & 4 & 5 \\
\hline 2 & Television & & & & & \\
\hline 3 & Radio & & & & & \\
\hline 4 & $\begin{array}{l}\text { Health professional (e.g. medical } \\
\text { doctor, nurse, nutritionist, etc.) }\end{array}$ & & & & & \\
\hline 5 & Family, friends and colleagues & & & & & \\
\hline 6 & Sellers/Vendors & & & & & \\
\hline 7 & Government sources & & & & & \\
\hline 8 & Internet/Social media & & & & & \\
\hline 9 & Magazines, pamphlets and flyers & & & & & \\
\hline
\end{tabular}

\section{SECTION F: SOCIO-ECONOMIC INFORMATION}

We would like to get some information about you and your household. This will help us to understand your responses.

F-1. Gender of the respondent? 1= Male $\square \quad 2=$ Female $\square$

F-2. What level of formal education did you complete?
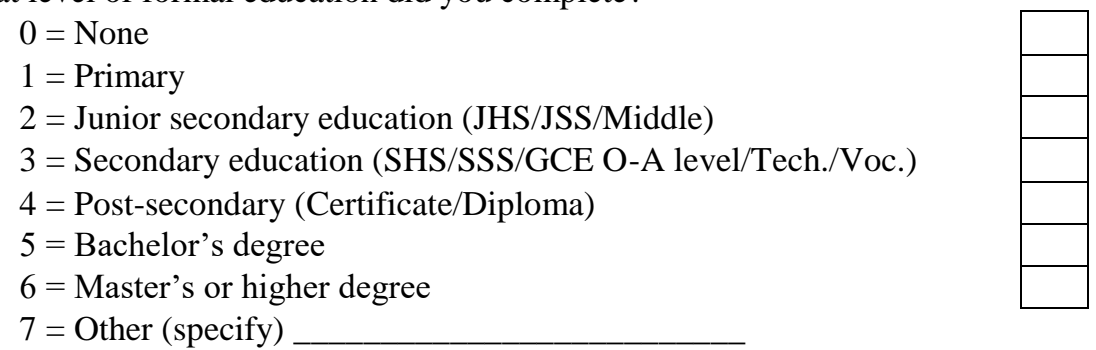

F-3. What is your religion?

$1=$ No religion

$2=$ Christianity

$3=$ Muslim

$4=$ Traditional

$5=$ Other $($ specify $)$ 
F-4. What is your family stand/status?

$$
\begin{aligned}
& 1=\text { Married } \\
& 2=\text { Single } \\
& 3=\text { Divorced/separated } \\
& 4=\text { Widowed } \\
& 5=\text { Living together/cohabiting }
\end{aligned}
$$

F-5. What is your employment status?

$$
\begin{aligned}
& 1=\text { Full-time employed } \\
& 2=\text { Part-time employed } \\
& 3=\text { Self-employed } \\
& 4=\text { Unemployed } \\
& 5=\text { Retired } \\
& 6=\text { Household duties (Homemaker) } \\
& 7=\text { Student } \\
& 8=\text { Other (specify) }
\end{aligned}
$$

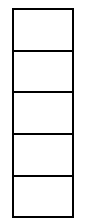

F-6. In which one of the following categories of income brackets does your monthly combined (includes your partner if any) net household income lie?

$$
\begin{aligned}
& 1=\mathrm{GH} \phi<200 \\
& 2=\mathrm{GH} \phi 200 \text { to }<600 \\
& 3=\mathrm{GH} \phi 600 \text { to }<1,000 \\
& 4=\mathrm{GH} \phi 1,000 \text { to }<1,400 \\
& 5=\mathrm{GH} \phi 1,400 \text { to }<1,800 \\
& 6=\mathrm{GH} \phi 1,800 \text { to }<2,200 \\
& 7=\mathrm{GH} \phi 2,200 \text { to }<2,600 \\
& 8=\mathrm{GH} \phi 2,600 \text { and above } \\
& 9=\mathrm{I} \text { prefer not to state my income }
\end{aligned}
$$

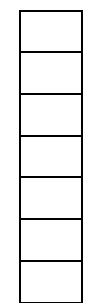

F-7. How many people live in your household (including you)?

F-8. Do you have children (below 18 years) living in your household?

$$
1=\text { Yes }
$$

$$
2=\text { No }
$$

F-9. If YES, how many children are there in your household?

F-10. Do you have any chickens in your backyard?

$$
1=\text { Yes }
$$

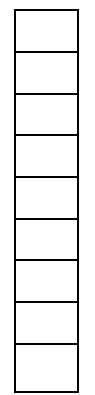

$$
2=\text { No }
$$

